NUREG/CR-6325

\title{
An Implicit Steady-State Initialization Package for the RELAP5 Computer Code
}

Manuscript Completed: July 1995

Date Published: August 1995

Prepared by

M. P. Paulsen, C. E. Peterson

F. Odar, NRC Project Manager

Computer Simulation and Analysis, Inc.

P.O. Box 51596

Idaho Falls, ID 83405

Prepared for

Division of Systems Technology

Office of Nuclear Regulatory Research

U.S. Nuclear Regulatory Commission

Washington, DC 20555-0001

NRC Job Code W6128

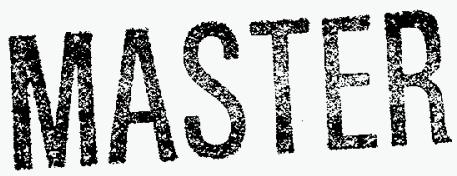




\section{DISCLAIMER}

This report was prepared as an account of work sponsored by an agency of the United States Government. Neither the United States Government nor any agency thereof, nor any of their employees, make any warranty, express or implied, or assumes any legal liability or responsibility for the accuracy, completeness, or usefulness of any information, apparatus, product, or process disclosed, or represents that its use would not infringe privately owned rights. Reference herein to any specific commercial product, process, or service by trade name, trademark, manufacturer, or otherwise does not necessarily constitute or imply its endorsement, recommendation, or favoring by the United States Government or any agency thereof. The views and opinions of authors expressed herein do not necessarily state or reflect those of the United States Government or any agency thereof. 


\section{DISCLAIMER}

Portions of this document may be illegible in electronic image products. Images are produced from the best available original document. 


\begin{abstract}
A direct steady-state initialization (DSSI) method has been developed and implemented in the RELAP5 hydrodynamic analysis program. It provides a means for users to specify a small set of initial conditions which are then propagated through the remainder of the system. The DSSI scheme utilizes the steadystate form of the RELAP5 balance equations for nonequilibrium two-phase flow. It also employs the RELAP5 component models and constitutive model packages for wall-to-phase and interphase momentum and heat exchange. A fully implicit solution of the linearized hydrodynamic equations is implemented. An implicit coupling scheme is used to augment the standard steady-state heat conduction solution for steam generator use. It solves the primary-side tube region energy equations, heat conduction equations, wall heat flux boundary conditions, and overall energy balance equation as a coupled system of equations and improves convergence. The DSSI method for initializing RELAP5 problems to steady-state conditions has been compared with the transient solution scheme using a suite of test problems including; adiabatic single-phase liquid and vapor flow through channels with and without heating and area changes; a heated two-phase test bundle representative of BWR core conditions; and a single-loop PWR model.
\end{abstract}




\section{ACKNOWLEDGEMENT}

The authors acknowledge the assistance of Mr. Ken Katsma who was instrumental in developing the testbed code for the Phase I effort and provided invaluable assistance during the initial development for the Phase 2 work.

We wish to thank Dr. Frank Odar of the U.S. Nuclear Regulatory Commission for his patience, support and suggestions during the completion of this work. We also express our gratitude to Pam Richardson for her assistance in preparing this document. 


\section{CONTENTS}

$\begin{array}{ll}\text { Section } & \text { Page }\end{array}$

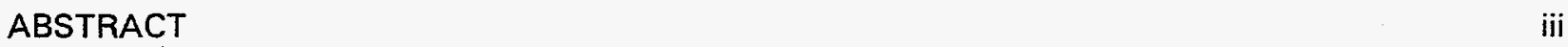

ACKNOWLEDGEMENT

LIST OF FIGURES viii

LIST OF TABLES $\quad$ ix

ABBREVIATIONS $\quad x$

1 SUMMARY 1

2 STEADY-STATE INITIALIZATION 3

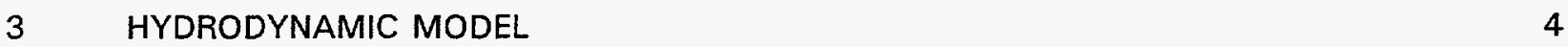

3.1 Steady-State Field Equations 4

3.2 Initial Condition Specification

3.2.1 Junction Flow Rates 8

3.2.2 Volume Pressure and Junction Loss Coefficients 8

3.2.3 Phasic Internal Energy 9

3.2.4 Vapor Void Fraction 9

3.2.5 Initial Volume State Properties With Noncondensables 9

3.2.6 Required User Input 9

3.3 Implicit Solution Method 10

$\begin{array}{lll}3.4 & \text { EOS Relationships } & 28\end{array}$

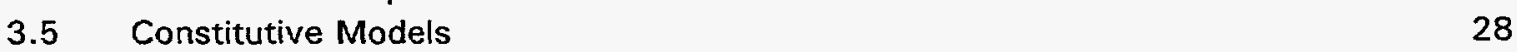

3.5.1 Flow Regime Maps $\quad 28$

$\begin{array}{ll}3.5 .2 \text { Interphase Friction } & 29\end{array}$

3.5.3 Coefficient of Virtual Mass 29

3.5.4 Wall Friction 29

3.5.5 Wall Heat Transfer 29

3.5.6 Interphase Heat Transfer. 30

3.6 Special Process Models 30

3.6.1 Choked Flow 30

3.6.2 Horizontal Stratification and Entrainment 30

3.6.3 Abrupt Area Change 30

3.6.4 Crossflow Junction 31

3.6.5 Water Packing Mitigation 31

3.6.6 Countercurrent Flow Limitation 31 


\section{CONTENTS (CONT'D)}

Section

Page

3.7 Component Models

3.7.1 Branch

3.7.2 Separator

3.7.3 Jet Mixer

3.7.4 Centrifugal Pump Model

3.7.5 Turbine Model

3.7.6 Valves

3.7.7 Accumulator

35

3.7.8 ECC Mixer Model

4.1 Steady-State Heat Conduction Equation and Solution 36

4.2 Implicit Convective Boundary Conditions 40

$\begin{array}{lll}4.3 & \text { Steady-State Procedure - } & 42\end{array}$

$5 \quad$ CONTROL AND TRIP SYSTEM MODELS 44

$\begin{array}{lll}5.1 & \text { Control Systems } & 44\end{array}$

5.2 Trip System $\quad 44$

$\begin{array}{lll}6 & \text { REACTOR KINETICS } & 45\end{array}$

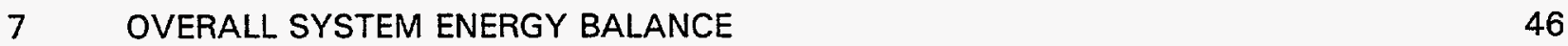

$\begin{array}{lll}7.1 & \text { Flow Network Identification } & 46\end{array}$

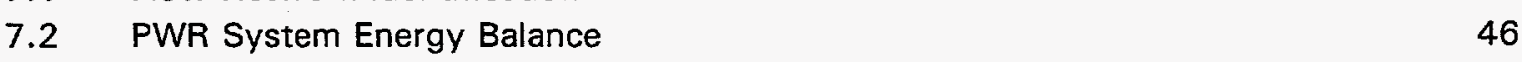

7.2.1 Environmental Heat Losses $\quad 48$

7.2.2 Steam Generators 51

7.2.3 Open System Energy Balance $\quad 61$

$\begin{array}{lll}7.3 & \text { BWR System Energy Balance } & 62\end{array}$

$8 \quad$ IMPLEMENTATION

8.1 Program Flow Overview $\quad 63$

$\begin{array}{lll}8.2 & \text { Input Data } & 65\end{array}$

$\begin{array}{lll}8.3 & \text { Initialization } & 65\end{array}$

$\begin{array}{ll}\text { 8.3.1 Flow Initial Conditions } & 68\end{array}$

8.3.2 Control Volume Initial Conditions 68

$\begin{array}{lll}8.4 & \text { DSSI Solution Scheme } & 69\end{array}$

9 DEMONSTRATION ANALYSIS $\quad 72$

$\begin{array}{lll}9.1 & \text { Test Problem } 1 & 73\end{array}$

9.2 Test Problems 2, 3, and $4 \quad 76$ 


\section{CONTENTS (CONT'D)}

Section

Page

$\begin{array}{lll}9.3 & \text { Test Problem } 5 & 76\end{array}$

9.4 Test Problem $6 \quad 85$

9.5 Test Problem $7 \quad 85$

9.6 FRIGG 36-Rod Heated Bundle 88

$\begin{array}{lll}\text { 9.7 PWR Test Problem } & 93\end{array}$

$\begin{array}{ll}10 & \text { REFERENCES } \\ \end{array}$

APPENDIX A - DIRECT STEADY-STATE INITIALIZATION INPUT REQUIREMENTS A-1 


\section{LIST OF FIGURES}

Figure

Page

3.1 Mass, energy, and momentum cell noding 13

$\begin{array}{lll}7.1 & \text { Typical PWR primary system schematic } & 48\end{array}$

7.2 Typical environmental loss heat structure 49

7.3 Typical once-through steam generator $\quad 52$

7.4 Typical U-tube steam generator $\quad 52$

8.1 Main program flow $\quad 64$

$\begin{array}{lll}8.2 & \text { Input processing overview } & 66\end{array}$

$\begin{array}{lll}\text { 8.3 New problem input processing } & 67\end{array}$

$\begin{array}{lll}8.4 & \text { DSSI solution scheme } & 70\end{array}$

$\begin{array}{lll}9.1 & \text { Noding diagram for test problem } 1 & 74\end{array}$

9.2 Schematic diagrams for test problems 2, 3, and $4 \quad 78$

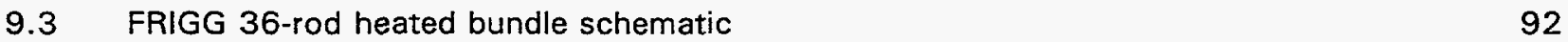

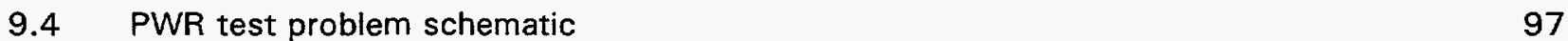

9.5 RELAP5 "stdy-st" option steam dome pressure 99

9.6 RELAP5 "stdy-st" option core inlet fluid temperature 99

9.7 RELAP5 "stdy-st" option core outlet fluid temperature 100

$\begin{array}{lll}9.8 & \text { RELAP5 "stdy-st" option pressurizer mass flow } & 100\end{array}$

9.9 RELAP5 "stdy-st" option steam generator primary mass flow 101

9.10 RELAP5 "stdy-st" option steam generator secondary mass flow 101

9.11 RELAP5 "stdy-st" option steam line mass flow $r$

9.12 RELAP5 "stdy-st" option separator fallback liquid velocity 102

9.13 RELAP5 "stdy-st" option bypass void fraction 103

9.14 RELAP5 "stdy-st" option core power 103

9.15 RELAP5 "stdy-st" option steam generator primary power 104

9.16 RELAP5 "stdy-st" option steam generator power 104

9.17 RELAP5 "stdy-st" option downcomer level 105 


\section{LIST OF TABLES}

Table

Page

8.1 DSSI input data card summary $\quad 65$

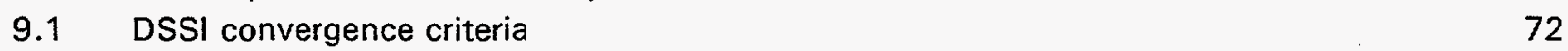

9.2 Test problem 1 pressure and loss coefficient convergence using DSSI

9.3 Test problem 1 transient solution $\quad 77$

$\begin{array}{lll}9.4 & \text { Data for test problems 2, 3, and } 4 & 79\end{array}$

9.5 Results for test problems 2, 3, and 4 using DSSI 80

9.6 Loss coefficient convergence for test problems 2, 3, and $4 \quad 80$

$\begin{array}{lll}9.7 & \text { Test problem } 2 \text { transient solution } & 81\end{array}$

$\begin{array}{lll}9.8 & \text { Test problem } 3 \text { transient solution } & 82\end{array}$

9.9 Test problem 4 transient solution $\quad 83$

9.10 Test problem 5 loss coefficient convergence $\quad 84$

9.11 Test problem 5 transient solution $\quad 86$

9.12 Test problem 6 loss coefficient convergence $\quad 87$

$\begin{array}{lll}9.13 & \text { Test problem } 6 \text { transient solution } & 87\end{array}$

9.14 Test problem 7 loss coefficient convergence $\quad 89$

9.15 Test problem 7 transient solution 9

$\begin{array}{lll}9.16 & \text { FRIGG } 413149 \text { solution using DSSI } & 94\end{array}$

9.17 FRIGG 413149 transient solution (nearly implicit) 95

9.18 FRIGG 413149 transient solution (semi-implicit) 96

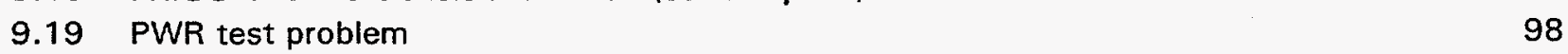

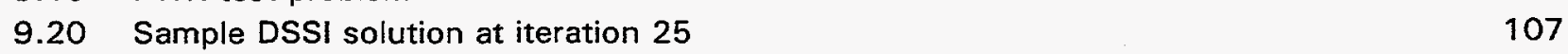

9.21 Sample DSSI solution at iteration 78 $\quad 114$

9.22 Comparison of the "stdy-st" and DSSI methods $\quad 121$ 


\section{ABBREVIATIONS}

$\begin{array}{ll}\text { BWR } & \text { Boiling Water Reactors } \\ \text { CHF } & \text { Critical Heat Flux } \\ \text { CPU } & \text { Central Processor Unit } \\ \text { DSSI } & \text { Direct Steady-State Initialization } \\ \text { ECC } & \text { Emergency Core Cooling } \\ \text { EOS } & \text { Equation of State } \\ \text { LOCA } & \text { Loss of Coolant Accident } \\ \text { LWR } & \text { Light Water Reactor } \\ \text { OTSG } & \text { Once-Through Steam Generator } \\ \text { PWR } & \text { Pressurized Water Reactor } \\ \text { RCS } & \text { Reactor Coolant System } \\ \text { SBIR } & \text { Small Business Innovative Research } \\ \text { USNRC } & \text { United States Nuclear Regulatory Commission }\end{array}$




\section{SUMMARY}

This report documents the research and development work that has been completed as a Phase II SBIR project funded by the USNRC. The work has focused on developing and implementing a fully implicit steady-state solution method for the RELAP5 MOD3.1 computer code (Ref. 1). The solution method is based on experience gained from the RELAP5 testbed code that was written as part of the Phase I SBIR development for RELAP5 (Ref. 2), and similar work for the RETRAN code (Refs. 3 , $4,: 51$.

Phase I of the SBIR demonstrated the feasibility of developing a steady-state initial condition solver for single-phase conditions. A nearly implicit approach to solving two-phase situations was proposed; however, initial attempts at implementing the nearly implicit scheme during the Phase II effort were not successful, and it was abandoned in favor of a fully implicit solution similar to the method used in RETRAN-03 (Refs. 4 and 5).

The usefulness of the fully implicit solution as a general purpose steady-state initialization tool has been demonstrated by using the Phase I test case suite and a single-phase vapor test case, an adiabatic two-phase flow case, a model of the FRIGG experimental facility (Ref. 7), and a demonstration PWR model. The Phase I test suite covers a range of single-phase conditions including adiabatic and diabatic flow, and abrupt expansions and contractions. The single-phase liquid cases demonstrate that the solution algorithms approach to the correct limit, i.e., the vapor continuity and energy equations are not solved. Similarly, the single-phase vapor test case demonstrates that the solution algorithms degenerate correctly, i.e., the vapor continuity and liquid energy equations are not solved. The adiabatic two-phase flow model verifies the full six-equation solution algorithms.

The FRIGG test case covers a range of conditions from subcooled liquid at the inlet to two phase at the exit, and is typical of BWR conditions. The PWR demonstration includes both single phase and two-phase conditions and a steam generator which utilizes a special heat transfer coupling scheme to ensure an overall system energy balance and accelerate convergence.

The results obtained from the test case suite demonstrate that steady-state initial conditions can be obtained rapidly. The steady-state solver has the potential of saving computer time, and more importantly, improving the productivity of RELAP5 analysts. It will allow users to initialize a model and perform a transient calculation in a single run rather than running a null transient to obtain initial conditions and then restarting the problem to supply transient-specific input.

The design for steady-state initialization is such that it is a separate module that has a minimum impact on the existing coding and input models. Many of the existing RELAP5 subroutines are used in the steady-state solution without modification. Those that required modification required only minor changes. The design presented here minimizes the impact of incorporating the steady-state coding in RELAP5 and also incorporates the steady-state solution as an option. Code users can run RELAP5 with existing input models and options and little additional input is required to use the steady-state initialization option. 
The work documented herein represents the completion of Phase II of a NRC SBIR project to examine improved steady-state initialization algorithms for computer codes. In particular, this work has focused on the RELAP5 code. The steady-state field equations and the solution method are presented. The constitutive, component and special process models are reviewed with respect to any special treatment required for steady-state initialization. Special consideration for other models such as control systems, trip systems, and reactor kinetics is also discussed. Finally, the implementation of the solution scheme and the results of the demonstration analyses are presented.

The DSSI solution scheme provides a sound basis for developing a commercial software product. However, a number of comparatively minor extensions and modifications will be required to produce a viable commercial product. This additional development will be performed as a Phase III commercialization effort using private funding sources. The extent of the additional development will be dictated by the market place. 


\section{STEADY-STATE INITIALIZATION}

The RELAP5 computer code has broad acceptance as a tool for analyzing the transient behavior of hydrodynamic systems, particularly for applications relating to the licensing of nuclear power plants. An important consideration for transient analysis is the initial state from which a transient is initiated. For most applications the initial state corresponds to a steady-state condition. While RELAP5 provides a means of specifying initial conditions, a steady-state solution consistent with the transient solution is not available.

Many LWR transient simulations are initiated from steady-state conditions by introducing small perturbations. It is important that these simulations begin from a true steady state so that initial deviations from a steady-state condition do not mask the true dynamic behavior. For severe transients like large break LOCAs, the inability to accurately specify a steady-state condition has less of an impact on the transient response, provided the initial mass and energy inventories are approximately correct.

The existing approach used to obtain steady-state initial conditions for RELAP5 analyses is to solve the transient fluid flow equations, simulating a transient until a steady-state solution is obtained (Ref. 1). This requires that long transients be run to obtain steady-state conditions and special userdefined control systems are required to drive the solution to the desired initial conditions. These control systems are complicated and may have complex interactions with the hydrodynamic solution. Once a steady condition is reached, the user must restart the problem, and these restarts may require revising the nodalization and eliminating the steady-state controllers. 


\section{HYDRODYNAMIC MODEL}

The steady-state balance equations, initial conditions, and the methods used to solve the equations are presented in this section. A review of the EOS, the constitutive models, the component models, and the special process models summarizing the modifications required to implement the DSSI solution are presented.

The RELAP5 hydrodynamic model is a transient, one-dimensional, two-fluid model for flow of some two-phase steam-water mixtures. Two-fluid equations of motion form the basis of the hydrodynamic model presented by Carlson, et al. (Ref. 1).

The RELAP5 hydrodynamic model is used as the basis of the steady-state initialization. Two different hydrodynamic models are given in Reference 1, one model for the semi-implicit solution method and another for the nearly implicit method. An artificial viscosity term is included in the semi-implicit model, but not in the model used for the nearly implicit method. The work presented herein uses the nearly implicit form of the model and does not include the artificial viscosity term. This form is consistent with the nearly implicit transient solution method and ensures consistency between the steady-state and nearly implicit transient solutions. A truly consistent approach will allow the transient equations to be advanced in time from the initial conditions without changing the initial conditions, provided no forcing functions are imposed on the system. This is referred to as a null transient and is the measure of a truly consistent steady-state solution.

The following sections present the steady-state field equations that are used in the DSSI solution, the initial condition specifications, and the fully implicit solution method.

\subsection{Steady-State Field Equations}

The steady-state field equations provide the basis for the DSSI solution. They are obtained from the time-dependent field equations by setting the time derivative components to zero. When noncondensable gases are considered, seven governing field equations are used; they are comprised of two phasic continuity equations, two phasic energy equations, two phasic momentum equations, and a noncondensable gas continuity equation. The primary dependent variables are the pressure $(P)$, the phasic specific internal energies $\left(u_{g}, u_{f}\right)$, vapor void fraction $\left(a_{g}\right)$, phasic velocities $\left(v_{g}, v_{f}\right)$, and the noncondensable quality $\left(x_{n}\right)$. The independent variable for the one-dimensional spacial coordinate is given by $z$. Incorporation of the noncondensable governing equation into the steadystate solution has been deferred until the Phase III effort.

The steady-state vapor continuity equation is

$\frac{1}{A} \frac{\partial}{\partial z}\left[\alpha_{g} \rho_{g} v_{g} A\right]=\Gamma_{g}+\Gamma_{n c}$ 
and the steady-state liquid continuity equation is

$\frac{1}{A} \frac{\partial}{\partial z}\left[\alpha_{f} \rho_{f} v_{f} A\right]=-\Gamma_{g}+\Gamma_{s}$

where
A $=$ flow area, $\mathrm{m}^{2}$
$\mathrm{z}=$ spatial coordinate, $\mathrm{m}$
$\alpha_{\mathrm{g}}=$ gas volume fraction (void)
$\rho_{\mathrm{g}}=$ gas density, $\mathrm{kg} / \mathrm{m}^{3}$
$\mathrm{v}_{\mathrm{g}} \cdot=$ gas velocity, $\mathrm{m} / \mathrm{s}$
$\alpha_{\mathrm{f}}=$ liquid volume fraction, $1-\alpha_{\mathrm{g}}$
$\rho_{\mathrm{f}}=\quad$ liquid density, $\mathrm{kg} / \mathrm{m}^{3}$
$v_{f}=$ liquid velocity, $\mathrm{m} / \mathrm{s}$
$r_{g}=$ vapor generation rate, $\mathrm{kg} / \mathrm{m}^{3}-\mathrm{s}$
$\Gamma_{\mathrm{nc}}^{\mathrm{g}}=$ noncondensable generation rate, $\mathrm{kg} / \mathrm{m}^{3}-\mathrm{s}$
$r_{\mathrm{s}}=$ solute generation rate, $\mathrm{kg} / \mathrm{m}^{3}-\mathrm{s}$

The vapor generation rate is

$$
r_{g}=-\frac{H_{i g}\left(T_{s}-T_{g}\right)+H_{i f}\left(T_{s}-T_{f}\right)}{h_{g}^{*}-h_{f}^{*}}+r_{w}
$$

The steady-state vapor energy equation is

$$
\begin{aligned}
\frac{1}{A} \frac{\partial}{\partial z}\left[\alpha_{g} \rho_{g} u_{g} v_{g} A\right] & +\frac{P}{A} \frac{\partial}{\partial z}\left[\alpha_{g} v_{g} A\right]=-\left[\frac{h_{f}^{*}}{h_{g}^{*}-h_{f}^{*}}\right] H_{i g}\left(\Gamma_{s}-T_{g}\right)-\left[\frac{h_{g}^{*}}{h_{g}^{*}-h_{f}^{*}}\right] H_{i f}\left(T_{s}-T_{f}\right) \\
& +\left[\left(\frac{1+\epsilon}{2}\right) h_{g s}+\left(\frac{1-\epsilon}{2}\right) h_{f s}\right] \Gamma_{w}+Q_{w g}+r_{g}+r_{n c} H_{n c}
\end{aligned}
$$

and the steady-state liquid energy equation is

$$
\begin{aligned}
\frac{1}{A} \frac{\partial}{\partial z}\left[\alpha_{f} \rho_{f} u_{f} v_{f} A\right] & +\frac{P}{A} \frac{\partial}{\partial z}\left[\alpha_{f} v_{f} A\right]=\left[\frac{h_{f}^{*}}{h_{g}^{*}-h_{f}^{*}}\right] H_{i g}\left(T_{s}-T_{g}\right)+\left[\frac{h_{g}^{*}}{h_{g}^{*}-h_{f}^{*}}\right] H_{i f}\left(T_{s}-T_{f}\right) \\
& -\left[\left(\frac{1+\epsilon}{2}\right) h_{g s}+\left(\frac{1-\epsilon}{2}\right) h_{f s}\right] \Gamma_{w}+Q_{w f}+T_{f}+\Gamma_{s} H_{s}
\end{aligned}
$$


where

$\mathrm{u}_{\mathrm{g}} \quad=\quad$ gas specific internal energy, $\mathrm{J} / \mathrm{kg}$

$\mathrm{P}=$ pressure, $\mathrm{kg} / \mathrm{m}-\mathrm{s}^{2}$

$h_{f}^{*}=$ phasic liquid enthalpy, $\mathrm{J} / \mathrm{kg}$

$\mathrm{h}_{\mathrm{g}^{*}}=$ phasic gas enthalpy, $\mathrm{J} / \mathrm{kg}$

$\mathrm{H}_{\mathrm{ig}}=$ gas interphase heat transfer coefficient, $w / \mathrm{m}^{3}-\mathrm{k}$

$\mathrm{T}_{\mathrm{s}}=$ saturation temperature, $\mathrm{k}$

$\mathrm{T}_{\mathrm{g}}=$ gas temperature, $\mathrm{k}$

$\mathrm{H}_{\mathrm{if}}=$ fluid interphase heat transfer coefficient, $\mathrm{w} / \mathrm{m}^{3}-\mathrm{k}$

$\mathrm{T}_{\mathrm{f}}=$ fluid temperature, $\mathrm{k}$

$\epsilon . \quad=\quad$ enthalpy weighing coefficient

$\mathrm{h}_{\mathrm{gs}}=$ gas enthalpy at saturation, $\mathrm{J} / \mathrm{kg}$

$\mathrm{h}_{\mathrm{fs}}=\quad$ liquid enthalpy at saturation, $\mathrm{J} / \mathrm{kg}$

$\Gamma_{\mathrm{w}}=$ vapor generation at wall, $\mathrm{kg} / \mathrm{m}^{3}-\mathrm{s}$

$\mathrm{Q}_{w g}=$ wall heat addition to gas, $w / \mathrm{m}^{3}$

$\tau_{\mathrm{g}}=$ wall dissipation to gas, $\mathrm{w} / \mathrm{m}^{3}$

$\mathrm{H}_{\mathrm{nc}}=$ enthalpy of noncondensables, $\mathrm{J} / \mathrm{kg}$

$u_{f} \quad=\quad$ liquid-specific internal energy, $\mathrm{J} / \mathrm{kg}$

$\mathrm{Q}_{\mathrm{wf}}=$ wall heat addition to liquid, $\mathrm{w} / \mathrm{m}^{3}$

$T_{\mathrm{f}}=$ wall dissipation to liquid, $w / \mathrm{m}^{3}$

$\mathrm{H}_{\mathrm{s}} \quad=\quad$ enthalpy of solute, $\mathrm{J} / \mathrm{kg}$

The enthalpy weighing coefficient is defined as follows

$\epsilon=1, \Gamma_{w}>0$

$\epsilon=-1, \Gamma_{w}<0$

and the vapor and liquid dissipation are respectively given by

$T_{g}=\alpha_{g} \rho_{g} f_{w g} v_{g}^{2}$

$T_{f}=\alpha_{f} \rho_{f} f_{w f} v_{f}^{2}$

where

$f_{w g}=$ gas wall friction factor, $s^{-1}$

$f_{w f}=\quad$ liquid wall friction factor, $s^{-1}$

The details associated with the mass and energy transfer source terms are given by Carlson, et al. (Ref.1). 
The form of the momentum equations used by RELAP5 depends on the transient solution option selected. An artificial viscosity term is included in the model used with the semi-implicit solution. It is included to improve the method's numerical stability. The nearly implicit solution method is used for the steady-state solution and the artificial viscosity terms are not included. This is consistent with the model used for the nearly implicit transient solution.

The steady-state vapor momentum equation is

$$
\begin{aligned}
\frac{1}{2} \alpha_{g} \rho_{g} A \frac{\partial v_{g}^{2}}{\partial z}= & -\alpha_{g} A \frac{\partial P}{\partial z}+\alpha_{g} \rho_{g} B_{x} A-\alpha_{g} \rho_{g} A f_{w g} v_{g}+\Gamma_{g} A\left(v_{i}-v_{g}\right) \\
& -\alpha_{g} \rho_{g} A f_{i g}\left(C_{f} v_{g}-C_{g} v_{f}\right)-\alpha_{g} \rho_{g} A H_{g g} v_{g} \\
& -r_{n c} v_{g} A+f_{x} \alpha_{f} \alpha_{g} \rho_{g} f_{w g} A v_{g}-f_{x} \alpha_{g} \alpha_{f} \rho_{f} f_{w f} A v_{f}
\end{aligned}
$$

and the steady-state liquid momentum equation is

$$
\begin{aligned}
\frac{1}{2} \alpha_{f} \rho_{f} A \frac{\partial v_{f}^{2}}{\partial z}= & -\alpha_{f} A \frac{\partial P}{\partial z}+\alpha_{f} \rho_{f} B A-\alpha_{f} \rho_{f} A f_{w f} v_{f}-r_{g} A\left(v_{i}-v_{f}\right) \\
& -\alpha_{f} \rho_{f} A f_{i f}\left(C_{o} v_{f}-C_{1} v_{g}\right)-\alpha_{f} \rho A H_{f f} v_{f}-r_{s} v_{f} A+f_{x} \alpha_{g} \alpha_{f} \rho_{f} f_{f f} A v_{f}-f_{x} \alpha_{f} \alpha_{g} \rho_{g} f_{w g} A v_{g}
\end{aligned}
$$

where

$\begin{array}{lll}B_{x} & = & \text { body forces, } \mathrm{m} / \mathrm{s}^{2} \\ v_{i} & = & \text { interfacial velocity, } \mathrm{m} / \mathrm{s} \\ f_{i g} & = & \text { interphase friction, } \mathrm{s}^{-1} \\ \mathrm{C}_{1} & = & \text { drift flux parameter } \\ \mathrm{C}_{o} & = & \text { drift flux profile parameter } \\ \mathrm{H}_{\ell g} & = & \text { gas loss coefficient, } \mathrm{s}^{-1} \\ \mathrm{f}_{\mathrm{x}} & = & \text { wall friction coefficient } \\ \mathrm{H}_{\ell f} & = & \text { liquid loss coefficient, } \mathrm{s}^{-1}\end{array}$

As defined below, the interphase velocity is defined to be equal to the appropriate phase velocity.

$$
\begin{aligned}
& v_{i}=v_{f} \text { for } r_{g}>0 \\
& v_{i}=v_{g} \text { for } r_{g}<0
\end{aligned}
$$

\subsection{Initial Condition Specification}

The steady-state field equations are solved, using appropriate initial conditions, to obtain the steady initial state. In order to achieve a steady-state balance, one dependent variable must be used to balance each of the steady-state field equations. Therefore, users cannot completely specify all the 
volume state properties and system flow distribution as currently required. In fact, in the large majority of instances, users do not know or would find it difficult to accurately specify all initial condition information. The DSSI method allows users to pick the type and location of thermalhydraulic input that will remain fixed during steady-state initialization. Users can then specify the information that is best known and let the DSSI module compute the remaining information.

For steady-state initialization, only a minimal set of thermodynamic input and flow rates is required when using the DSSI option. The remaining unknown values for volume pressure, phasic internal energies, and junction flow rates are obtained by solving the appropriate steady-state balance equations. The form of the governing balance equations that are solved and the required initial conditions are interrelated. In fact, the desired initial condition specification will influence the form of the balance equations that are used. Two approaches relative to the momentum equation solution are viable. One allows the mass flow rate (or phasic velocities) to be computed from a specified pressure drop. The other allows the mass flow rate values to be specified and the pressure drop to be balanced by adjusting form losses.

For most applications, the mass flow rate is the desired initial condition specification. Consequently the RETRAN computer codes (Ref. 3, 4 and 5) and the new RELAP5 DSSI package use flow initial conditions. It would be possible to also allow the flow to be computed from the pressure drop, but this feature was not part of the Phase II work scope. The mass flow initial condition gives rise to the use of the sum continuity equation rather than the liquid continuity equation.

\subsubsection{Junction Flow Rates}

The sum continuity equation is used to ensure that a mass flow balance exists in the system.

Currently RELAP5 users must input the mass flow rates throughout the system. This is also allowed in the DSSI scheme; however, the sum continuity equation is evaluated for each volume to detect any initial flow imbalances that may exist prior to continuing the steady-state solution. Optionally, users are able to specify a minimal number of mass flow rates and then allow the code to propagate those flow rates around the rest of the system. In this instance, only a single flow rate needs to be input in a pipe component and the sum continuity equation is used to propagate it through the rest of the pipe. The flow rates at all flow splits must be input. In all cases, if a flow imbalance is found, an error message is written and the run is terminated.

As a minimum, the sum continuity equation will be used to propagate unspecified junction flow rates and check the continuity balance in each fluid volume. The input requirement will be minimal in that only one junction flow rate is required for each simple pipe geometry and flow rates at branches must be defined (such as tees, manifolds or other complex geometries). Since the continuity equation is used only to propagate input flow values through the system, it can be solved separately from the other equations.

\subsubsection{Volume Pressure and Junction Loss Coefficients}

The steady-state sum momentum balance is obtained by summing Equations 3-8 and 3-9. It is satisfied by computing either the upstream or downstream volume pressure or the junction form 
loss coefficient. Users select the junctions where loss coefficients are computed, and the control volumes where pressures are supplied as initial conditions through input data. Based on this input, the steady-state logic will determine whether the sum momentum equation is used to solve a junction loss coefficient, or upstream or downstream volume pressure.

Logic is included in the initial condition processing routine to determine the unknown parameter associated with each sum momentum equation. The logic also insures that the initial condition specifications adequately specify a unique steady-state condition. Both the sum and difference momentum equations are written in general form that is valid for any of the three possible unknowns.

\subsubsection{Phasic Internal Energy}

The steady-state phasic energy equations are used to solve for the liquid and gas internal energy. Users specify the internal energy in any single-phase volume within a flow network and the phasic energy equations are used to compute the fluid internal energy distribution in the fluid volumes around the rest of the flow network. In some situations such as simple pipe flow, an inlet flow boundary conditions will determine the fluid energy initial condition.

\subsubsection{Vapor Void Fraction}

In two-phase volumes, the vapor void fraction is required to define the initial thermodynamic state. The phasic internal energies determine the extent of any temperature differences between the phases. All three parameters $\left(u_{f}, u_{g}\right.$ and $\left.\alpha_{g}\right)$ must be supplied where a user wants to define a two-phase initial state.

\subsubsection{Initial Volume State Properties With Noncondensables}

For normal LWR operating conditions, noncondensable gases should not be flowing through the system. Noncondensables will exist in isolated stagnant areas such as the accumulator or other volumes that will not be an integral part of the initialization process. Therefore, it is not necessary to consider noncondensable gases in the steady-state initialization process for most problems and they have not been considered in the Phase II work.

\subsubsection{Required User Input}

RELAP5 users must now input the thermodynamic conditions for all components along with the geometric description information input deck. These conditions are also required for the DSSI for three reasons. First, it is necessary that the steady-state initialization option use existing input models without major revisions. Second, the current input thermodynamic condition specifications provide initial estimates of the thermodynamic states that are used to start the steady-state iteration scheme. These initial guesses need not be very accurate and users can easily provide these initial estimates. Third, if the existing input requirements were revised, a significant effort to revise the input coding would be required. Given that the base RELAP5 input requirements remain unchanged, 
only a small amount of additional input data is required. This additional data is used to specify initial conditions for the DSSI option.

The pressure distribution around the system is determined from the steady-state solution of the sum momentum equation. Users have the choice of using a mix of volume pressure initial conditions. There is a unique number of initial conditions that must be specified since one unknown parameter must be available to balance each sum momentum equation. If insufficient initial conditions are specified, the system of equations is under specified and if too many initial conditions are supplied, the system is over specified. As an example of the type of input required, consider a RELAP5 model of a straight pipe made up of several consecutive volumes and junctions. At one extreme, a user can specify the pressure in all the fluid volumes and have the code compute the form loss coefficients for all junctions. At the other extreme, only one volume pressure is specified, all but one junction loss coefficient is fixed and the remaining volume pressures are computed. The user can specify a mix of volume pressures and loss coefficients as long as there is a fixed loss coefficient for each unknown pressure or vice versa. This simple example illustrates how the user can choose to specify the best known initial conditions and allow the DSSI module to compute the rest.

The system energy distribution is determined from the solution of the phasic energy equations. Users must specify the internal energy in a given volume within a flow network. The internal energies for the remainder of the fluid volumes are obtained from the solution of the energy equations. As an example, consider a RELAP5 model of a PWR. To initialize the primary side fluid volumes, the internal energy must be specified in a single volume such as a hot leg volume, a cold leg volume, lower plenum, or any primary volume. Since the primary and secondary sides are not connected by flow paths, the secondary cannot be initialized unless the internal energy in a single volume is also fixed. In addition, the internal energy must be supplied for any stagnant branches (no initial flow) off of the flowing networks. A typical PWR system model will require a volume internal energy specification on the primary loop, the secondary side and in any stagnant nodes.

\subsection{Implicit Solution Method}

Experience obtained while developing steady-state solution schemes for other transient thermalhydraulic analysis codes (Refs. 3, 4, and 5), indicates that implicit techniques have much better convergence characteristics than explicit techniques. This finding was also confirmed during the initial phase of this work. The companion Phase I work (Ref. 2) utilized a two-step procedure where the sum and difference momentum equations comprised a coupled system of equations written in terms of the node pressure and junction vapor velocities. The phasic energy and continuity equations were solved in a manner that was similar to the nearly implicit transient solution (Ref. 1). Each of the separate system equations for the continuity and energy equations were written in terms of the new iterate velocities. These velocities were obtained from the solution of the momentum equations and mixture continuity equation. These separate systems of equations were not coupled to each other, resulting in several smaller systems of equations to solve.

The two-step iteration scheme used in Phase I was patterned after the nearly implicit transient scheme. It made use of the simplifications that increase numerical efficiency and reduce 
computational effort. The nearly implicit solution method solves the sum and difference momentum equations as a coupled system of $2 n$ equations ( $n=$ number of junctions). However, the global system of equations initially contains $2 n+m$ unknowns ( $m=$ number of control volumes). A locally coupled set of continuity and energy equations was written for each control volume. The intermediate solution for these equation sets gives a relationship for the control volume pressure in terms of the associated phasic velocities. These relationships were substituted into the $2 n$ coupled equations to eliminate the pressure dependency. Once this was accomplished, the velocities were obtained by using a direct solution method.

The next step evaluated the pressures and the intermediate or "tilde" level values for the phasic energies and densities. They were then used to evaluate "tilde" level mass and energy transfer rate source terms that were used in the final evaluation of the mass and energy equations.

In the final step, the mass and energy equations for each phase were cast in separate, but similar, systems of equations. The coefficient matrices for the mass and energy equations were identical but the solution vectors and right-hand sides were different. Thus, only one matrix of order $m$ needed to be inverted for each phase. After the inverse was obtained, it was used to obtain the solution for both the mass and energy equations. This significantly reduced the CPU time since only two order $\mathrm{m}$ matrices were inverted rather than one order $5 \mathrm{~m}$ matrix.

The Phase I work was for single-phase conditions and the two-step method converged rapidly. However, as the method was applied to two-phase conditions during the early stage of the Phase II work, it was found to be nonconvergent. The problem was related to the lack of coupling between the vapor continuity equation and the other governing equations. To assure a successful outcome for the Phase II work, the nearly implicit method was abandoned in favor of a fully implicit solution scheme.

A fully implicit solution method accounts for the coupling that exists between the momentum, continuity and energy equations. As a result, the fully implicit solution utilizes a large coupled system of equations that are solved iteratively. The complete system of governing equations is comprised of $2 n+4 m$ coupled equations. It can be reduced to a system of $2 n+3 m$ equations by substituting the sum (or mixture) continuity equation into the other equations.

The steady-state solution employs an iterative procedure, where the iterative loop is analogous to the time advancement loop in the transient solution. The starting point (or zeroth iterate) for the iterative solution is given by the initial condition specifications that are supplied with the base RELAP5 model.

Each of the governing steady-state fluid flow equations is given below. The method used to solve the coupled system of equations is then presented. The sum momentum equation is obtained by adding Equations 3-8 and 3-9 and dividing by the area. The resulting equation is 


$$
\begin{aligned}
\frac{1}{2} \alpha_{g} \rho_{g} \frac{\partial v_{g}^{2}}{\partial z} & +\frac{1}{2} \alpha_{f} \rho_{f} \frac{\partial v_{f}^{2}}{\partial z}=-\alpha_{g} \frac{\partial P}{\partial z}-\alpha_{f} \frac{\partial P}{\partial z}+\alpha_{g} \rho_{g} B_{x}+\alpha_{f} \rho_{f} B_{x}-\alpha_{g} \rho_{g} f_{w g} v_{g} \\
& -\alpha_{f} \rho_{f} f_{w f} v_{f}-\Gamma_{g}\left(v_{g}-v_{f}\right)-\alpha_{g} \rho_{g} H_{2 g} v_{g}-\alpha_{f} \rho_{f} H_{l f} v_{f}-\Gamma_{n c} v_{g}-\Gamma_{g} v_{f}
\end{aligned}
$$

The difference momentum equation is obtained by subtracting Equation 3-9 from Equation 3-8 after dividing the vapor momentum Equation $3-8$ by $\alpha_{g} \rho_{g}$, and the fluid momentum Equation 3-9 by $\alpha_{f} \rho_{f}$. The resulting equation is

$$
\begin{aligned}
\frac{1}{2}\left(\frac{\alpha_{g} \rho_{g}}{\alpha_{g} \rho_{g}}\right) \frac{\partial v_{g}^{2}}{\partial z} & -\frac{1}{2}\left(\frac{\alpha_{f} \rho_{f}}{\alpha_{f} \rho_{f}}\right) \frac{\partial v_{f}^{2}}{\partial z}=-\left(\frac{1}{\rho_{g}}-\frac{1}{\rho_{f}}\right) \frac{\partial P}{\partial z}-\left[\left(1-f_{x}\right)+\alpha_{g} f_{x}\left(1-\rho_{g} / \rho_{f}\right)\right] f_{w g} v_{g} \\
& +\left[\left(1-f_{x}\right)+\alpha_{f} f_{x}\left(1-\rho_{f} \rho_{g}\right)\right] f_{w f} v_{f}-\rho_{j} F_{1}\left(C_{1} v_{g}-C_{o} v_{f}\right)+\frac{\rho_{j} \Gamma_{g}\left(v_{g}-v_{f}\right)}{\alpha_{g} \rho_{g} \alpha_{f} \rho_{f}} \\
& -\left(\frac{\alpha_{g} \rho_{g}}{\alpha_{g} \rho_{g}}\right) H_{g g} v_{g}+\left(\frac{\alpha_{f} \rho_{f}}{\alpha_{f} \rho_{f}}\right) H_{f f} v_{f}-\frac{\Gamma_{n c} v_{g}}{\alpha_{g} \rho_{g}}+\frac{\Gamma_{s} v_{f}}{\alpha_{f} \rho_{f}}
\end{aligned}
$$

where the relationships

$-\alpha_{g} \rho_{g} f_{i g}=\alpha_{f} \rho_{f} f_{i f}$

and

$$
f_{\text {ig }}=f_{i f}=F_{i}
$$

have been substituted.

The spatial noding and integration of the field equations are discussed by Carlson, et al. (Ref. 1). They note that the equations are developed for slowly changing areas (stream tube approach). However, special models are included to compensate for the effects of abrupt area changes, choking, and special flow patterns. The mass and energy equations are integrated from $z_{j}$ to $z_{j+1}$, defining volume boundaries. The momentum equations are integrated from volume (node) center to volume center. Figure 3-1 illustrates the spatial noding and integration regions for the balance equations. 


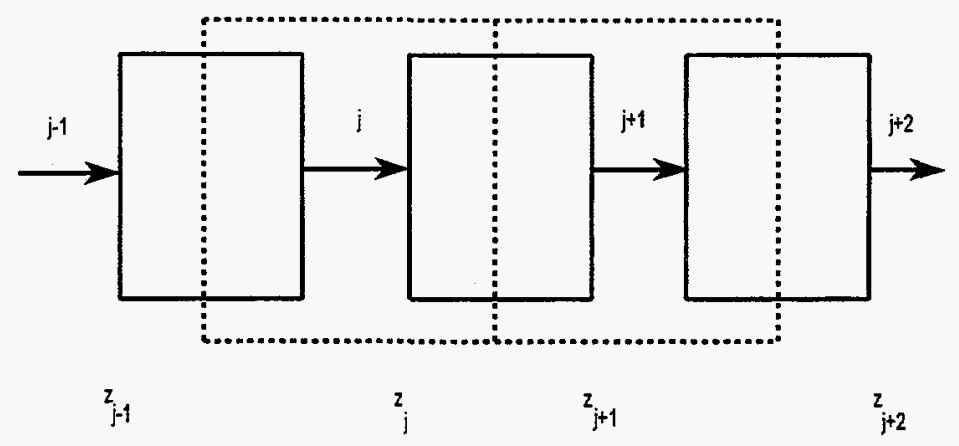

Solid lines denote mass and energy nodes. Dashed lines denote momentum nodes.

Figure 3.1 Mass, energy, and momentum cell noding

The same spatial integration is used to obtain the steady-state balance equations. The gradient of the phasic velocity squared terms is integrated from the center of the upstream node to the center of the downstream node. The general form is

$\frac{1}{2} \int_{z_{k}}^{z_{L}} \frac{\partial v_{a}^{2}}{\partial z} d z=\frac{1}{2}\left[v_{a, L}^{2}-v_{a, K}^{2}\right]$

where the a subscript can be replaced with the vapor and liquid designations $g$ and $f$, respectively. The $K$ and $L$ subscripts indicate that the velocities are volume average quantities located at the volume node centers, or momentum node boundaries.

The integral form for the steady-state sum momentum equation is

$$
\begin{aligned}
F_{s m} & =\left[\left(\alpha_{g} \rho_{g}\right)_{j} f_{w g, j} \Delta x_{j}+\left(\alpha_{g} \rho_{g}\right)_{j} H_{g g, j}+\Gamma_{g} \Delta x_{j}+\Gamma_{n c} \Delta x_{j}\right] v_{g, j}+\frac{1}{2}\left(\alpha_{g} \rho_{g}\right)_{j}\left[v_{g, L}^{2}-v_{g, K}^{2}\right] \\
& +\left[\left(\alpha_{f} \rho_{f}\right)_{j} f_{w f, j} \Delta x_{j}+\left(\alpha_{f} \rho_{f}\right)_{j} H_{f f, j}-\Gamma_{g} \Delta x_{j}+\Gamma_{s} \Delta x_{j}\right] v_{f, j} \\
& +\frac{1}{2}\left(\alpha_{f} \rho_{f}\right)_{j}\left[v_{f, L}^{2}-v_{f, K}^{2}\right]-\left(P_{k}-P_{L}\right)+\rho_{j} B_{x} \Delta x_{j}=0
\end{aligned}
$$


The integral form for the difference momentum equation is

$$
\begin{aligned}
F_{d m} & =\left[\left[\left(1-f_{x}\right)+\alpha_{f, j} f_{x}\left(1-\rho_{f} \rho_{g}\right)_{j}\right] f_{w f j} \Delta x_{j}+\left(\frac{\alpha_{f} \rho_{f}}{\alpha_{f} \rho_{f}}\right)_{j} H_{f, j}+\rho_{j} F_{i, j} C_{o} \Delta x_{j}+\frac{\rho_{j} \Gamma_{g} \Delta x_{j}}{\left(\alpha_{g} \rho_{g} \alpha_{f} \rho_{f}\right)_{j}}+\frac{\Gamma_{g} \Delta x_{j}}{\left(\alpha_{f} \rho_{f}\right)_{j}}\right] v_{f, j} \\
& +\frac{1}{2}\left(\frac{\alpha_{f} \rho_{f}}{\alpha_{f} \rho_{f}}\right)\left[v_{f, L}^{2}-v_{f, K}^{2}\right]-\left[\left[\left(1-f_{x}\right)+\alpha_{g, j} f_{x}\left(1-\rho_{g} / \rho_{f}\right)_{j}\right] f_{w g, j} \Delta x_{j}+\left(\frac{\alpha_{g} \rho_{g}}{\alpha_{g} \rho_{g}}\right)_{j} H_{g g j}\right. \\
& \left.+\rho_{j} F_{i, j} c_{1} \Delta x_{j}+\frac{\rho_{j} \Gamma_{g} \Delta x_{j}}{\left(\alpha_{g} \rho_{g} \alpha_{f} \rho_{f}\right)_{j}}+\frac{\Gamma_{n c} \Delta x_{j}}{\left(\alpha_{g} \rho_{g}\right)_{j}}\right] v_{g, j}-\frac{1}{2}\left(\frac{\alpha_{g} \rho_{g}}{\alpha_{g} \rho_{g}}\right)_{j}\left[v_{g, L}^{2}-v_{g, K}^{2}\right]+\left(\frac{\rho_{g}-\rho_{f}}{\rho_{g} \rho_{f}}\right)_{j}\left(P_{L}-P_{K}\right)=0
\end{aligned}
$$

where

$f_{x}=$ a weighing constant, $0 \leq f_{x} \leq 1$

which is determined by the form of the friction model. The over dot indicates volume donor values for junction properties as opposed to average values.

The integral form for the sum continuity equation is

$$
F_{s c}=\sum_{j \in i-0}\left[\left(\alpha_{g} \rho_{g} v_{g} A\right)_{j}+\left(\alpha_{f} \rho_{f} v_{f} A\right)_{j}\right]=0
$$

It is used to propagate flow initial conditions and to ensure that an overall continuity balance exists as described in Section 8.3.

The integral forms for the vapor continuity and energy balance equations are

$$
F_{v c}=\sum_{j \in i-0}\left(\alpha_{g} \rho_{g} v_{g} A\right)_{j}+\Gamma_{g, L} v_{L}=0
$$

and

$$
F_{v e}=\sum_{j e i-0}\left\{\left[\alpha_{g}\left(\rho_{g} \dot{u}_{g}+\dot{P}\right)\right]_{j} v_{g . j} A_{j}\right\}+v_{L}\left[Q_{w g}+Q_{i g}+\Gamma_{i g} h_{g}^{*}+\Gamma_{w} h_{g}^{s}+T_{g}\right]=0
$$

where the summation indicates a summation over the junctions flowing into volume $L$ less those flowing out of volume L. Similarly, the integral liquid energy equation is

$$
F_{l e}=\sum_{j \in i-0}\left\{\left[\alpha_{f}\left(\rho_{f} u_{f}+\dot{P}\right)\right]_{j} v_{f j} A_{j}\right\}+V_{L}\left[Q_{w f}+Q_{i f}+\Gamma_{i f} h_{f}^{*}-\Gamma_{w} h_{f}^{s}+\tau_{f}\right]=0
$$


The interphase heat transfer source terms shown in the above equations are defined as

$$
Q_{i g}=H_{i g}\left(T_{s}-T_{g}\right)-\left(\frac{1-\varepsilon}{2}\right) \Gamma_{w}\left(h_{g}^{s}-h_{f}^{s}\right)
$$

and

$$
Q_{\text {if }}=H_{\text {if }}\left(T_{s}-T_{f}\right)-\left(\frac{1+\epsilon}{2}\right) \Gamma_{w}\left(h_{g}^{s}-h_{f}^{s}\right)
$$

where

$$
\begin{aligned}
& \epsilon= \begin{cases}1 & \text { if } \Gamma_{w} \geq 0 \\
-1 & \text { if } \Gamma_{w}<0\end{cases} \\
& \Gamma_{i g}=-\frac{H_{i g}\left(T_{s}-T_{g}\right)+H_{i f}\left(T_{s}-T_{f}\right)}{h_{g}^{*}-h_{f}^{*}}
\end{aligned}
$$

and

$$
\Gamma_{\text {if }}=-\Gamma_{\text {ig }}
$$

If $\Gamma_{\text {ig }} \geq 0$

$h_{f}^{*}=u_{f}+\frac{P}{\rho_{f}}$

and

$h_{g}^{*}=h_{f}^{s}$

while if $\Gamma_{\text {ig }}<0$

$h_{f}^{*}=h_{f}^{s}$

and

$h_{g}^{*}=u_{g}+\frac{P}{\rho_{g}}$ 
The following equation, obtained from the definition of the mass flow rate, is used to eliminate the liquid velocity from Equations 3-15 through 3-20. The junction liquid velocity is given by

$$
v_{f, j}=\frac{w_{j}-\left(\alpha_{g} \rho_{g} v_{g} A\right)_{J}}{\left(\alpha_{f} \rho A\right)_{j}}
$$

which uses the mass flow rate initial condition $w_{j}$.

The revised balance equations, with the liquid velocity eliminated, follow. The sum momentum equation is

$$
\begin{aligned}
F_{s m} & =\left\{\left[\left(\alpha_{g} \rho_{g}\right)_{j} f_{w g, j} \Delta x_{j}+\left(\alpha_{g} \rho_{g}\right)_{j} H_{g g, j}+r_{g} \Delta x_{j}+\Gamma_{n c} \Delta x_{j}\right]\right. \\
& \left.-\left[\left(\alpha_{f} \rho_{f}\right)_{j} f_{w f, j} \Delta x_{j}+\left(\alpha_{f} \rho_{f}\right)_{j} H_{l f, j}-r_{g} \Delta x_{j}+\Gamma_{s} \Delta x_{j}\right]\left(\frac{\alpha_{g} \rho_{g}}{\alpha_{f} \rho_{f}}\right)_{j}\right] v_{g, j} \\
& \left.+\frac{1}{2}\left(\alpha_{g} \rho_{g}\right)_{j}\left[v_{g, L}^{2}-v_{g, K}^{2}\right]+\frac{1}{2}\left(\alpha_{f} \rho_{f}\right)_{j}\left[v_{f, L}^{2}-v_{f, K}^{2}\right]-P_{K}-P_{L}\right)+\rho_{j} B_{x} \Delta x_{j} \\
& +\left[\left(\alpha_{f} \rho_{f}\right)_{j} f_{w f, j} \Delta x_{j}+\left(\alpha_{f} \rho_{f}\right) H_{l f, j}-\Gamma_{g} \Delta x_{j}+\Gamma_{s} \Delta x_{j}\right] \frac{w_{j}}{\left(\alpha_{f} \rho_{f} A\right)_{j}}=0
\end{aligned}
$$


Similarly, the difference momentum equation with the liquid velocity eliminated is

$$
\begin{aligned}
& F_{d m}=-\left\{\left[\left[\left(1-f_{x}\right)+\alpha_{g j} f_{x}\left(1-\frac{\rho_{g}}{\rho_{f}}\right)\right]_{j}\right] f_{w g, j} \Delta x_{j}+\left(\frac{\alpha_{g} \rho_{g}}{\alpha_{g} \rho_{g}}\right) H_{g, j}\right. \\
& \left.+\rho_{j} F_{i, j} C_{1} \Delta x_{j}+\frac{\rho_{j} \Gamma_{g} \Delta x_{j}}{\left(\alpha_{g} \rho_{g} \alpha_{f} \rho_{f}\right)_{j}}+\frac{\Gamma_{n c} \Delta x_{j}}{\left(\alpha_{g} \rho_{g}\right)_{j}}\right] \\
& +\left[\left[\left(1-f_{x}\right)+\alpha_{f, j} f_{x}\left(1-\frac{\rho_{f}}{\rho_{g}}\right)_{j}\right] f_{w f j} \Delta x_{j}+\left(\frac{\alpha_{f} \rho_{f}}{\alpha_{f} \rho_{f}}\right) H_{f f, j}\right. \\
& \left.\left.+\rho_{j} F_{i, j} C_{0} \Delta x_{j}+\frac{\rho_{f} \Gamma_{g} \Delta x_{j}}{\left(\alpha_{g} \rho_{g} \alpha_{f} \rho_{f}\right)}+\frac{\Gamma_{s} \Delta x_{j}}{\left(\alpha_{f} \rho_{f}\right)_{j}}\right]\left(\frac{\alpha_{g} \rho_{g}}{\alpha_{f} \rho_{f}}\right)_{j}\right\} v_{g, j} \\
& +\frac{1}{2}\left(\frac{\alpha_{f} \rho_{f}}{\alpha_{f} \rho_{f}}\right)\left[v_{f, L}^{2}-v_{f, K}^{2}\right]-\frac{1}{2}\left(\frac{\alpha_{g} \rho_{g}}{\alpha_{f} \rho_{f}}\right)\left[v_{g, L}^{2}-v_{g, K}^{2}\right] \\
& +\left(\frac{\rho_{g}-\rho_{f}}{\rho_{g} \rho_{f}}\right)_{j}\left(P_{L}-P_{K}\right)+\left[\left[\left(1-f_{x}\right)+\alpha_{f, j} f_{x}\left(1-\frac{\rho_{f}}{\rho_{g}}\right)_{j}\right] f_{w f, \Delta x_{j}}+\left(\frac{\alpha_{f} \rho_{f}}{\alpha_{f} \rho_{f}}\right) H_{e f j}\right. \\
& \left.+\rho_{j} F_{i, j} C_{0} \Delta x_{j}+\frac{\rho_{j} \Gamma_{g} \Delta x_{j}}{\left(\alpha_{g} \rho_{g} \alpha_{f} \rho_{f}\right)}+\frac{\Gamma_{s} \Delta x_{j}}{\left(\alpha_{f} \rho_{f}\right)_{j}}\right] \frac{w_{j}}{\left(\alpha_{f} \rho_{f} A\right)}=0
\end{aligned}
$$

The liquid energy equation written in terms of the mass flow rate and vapor velocity is

$$
\begin{aligned}
F_{l e} & =\sum_{j \in i-0}\left[\alpha_{f}\left(\rho_{f} \dot{u}_{f}+\dot{P}\right)\right]_{j} \frac{w_{j}}{\left(\alpha_{f} \rho_{f}\right)_{j}}-\sum_{j \in i-0}\left[\alpha_{f}\left(\rho_{f} u_{f}+\dot{P}\right)\right]_{j}\left(\frac{\alpha_{g} \rho_{g}}{\alpha_{f} \rho_{f}}\right)_{j} v_{g, j} \\
& +V_{L}\left[Q_{w f}+Q_{i f}+\Gamma_{i f} h_{f}^{*}+\Gamma_{w} h_{f}^{s}+T_{f}\right]=0
\end{aligned}
$$

Equations $3-18,3-19,3-25,3-26$, and $3-27$ provide a set of $2 n+3 m$ balance equations where the mixture momentum equations are used to obtain the volume pressures. The vapor velocities are obtained from the difference momentum equations. The vapor void fractions, vapor internal energies, and liquid internal energies are computed from the vapor continuity and energy equations and the liquid energy equations, respectively. Generally there will be more junctions than control volumes. Since there will be one momentum equation for each junction and one pressure for each control volume, there will be fewer unknown pressures than equations. Another complication is that some of the volume pressures will be supplied as initial conditions.

The unknown pressures are supplemented by form loss terms, which are also unknown, at key locations. These additional unknowns balance the pressure drops, and the number of unknowns 
with the number of independent equations. The form loss equations are used to obtain a sum momentum equation where the form loss coefficient is the principal unknown.

To accomplish this, first examine the liquid and vapor losses given below.

$$
H_{f f, j}=\frac{1}{2}\left(\frac{\alpha_{f} \rho_{f}}{\alpha_{f} \rho_{f}}\right)\left[F_{f, j}+F_{\text {lossf }}+F_{j e t}\right]\left|v_{f}\right|
$$

and

$$
H_{\mathrm{gg}, \mathrm{j}}=\frac{1}{2}\left(\frac{\alpha_{g} \rho_{g}}{\alpha_{g} \rho_{g}}\right)\left[F_{g, j}+F_{\text {lossg }}+F_{\text {jet }}\right]\left|v_{g}\right|
$$

The form loss terms are

$$
F_{\text {lossf }}=F_{\text {lossg }}=\left\{\begin{array}{l}
F_{\text {junf }} \text { for } v_{g^{\prime}} v_{f}>0 \\
F_{\text {junr }} \text { for } v_{g^{\prime}}, v_{f}<0
\end{array}\right.
$$

Now defining the coefficients

$$
\begin{aligned}
& C_{f s}=\frac{1}{2}\left(\frac{\alpha_{f} \rho_{f}}{\alpha_{f} \rho_{f}}\right) \operatorname{sgn}\left(v_{f}\right) \\
& C_{g s}=\frac{1}{2}\left(\frac{\alpha_{g} \rho_{g}}{\alpha_{g} \rho_{g}}\right) \operatorname{sgn}\left(v_{g}\right)
\end{aligned}
$$

where the sign function assigns the sign of the argument.

The loss terms are rewritten as

$$
\begin{aligned}
& H_{d, j}=C_{f s}\left(F_{\text {ormf }}+F_{\text {lossf }}+F_{j e t}\right) v_{f} \\
& H_{g g, j}=C_{g s}\left(F_{\text {ormg }}+F_{\text {lossg }}+F_{\text {jet }}\right) v_{g}
\end{aligned}
$$

A first order Taylor series expansion of the integral form of the balance equations is used to obtain a coupled system of linear equations. These equations are then solved iteratively according to

$$
F^{k+1}=F^{k}+\left(\frac{\partial F^{k}}{\partial Y}\right) \Delta Y^{k+1}=0
$$


where $\mathrm{F}$ is comprised of the $\mathrm{n}$ sum momentum equations, $\mathrm{n}$ difference momentum equations, and $\mathrm{m}$ vapor continuity, vapor energy and liquid energy equations.

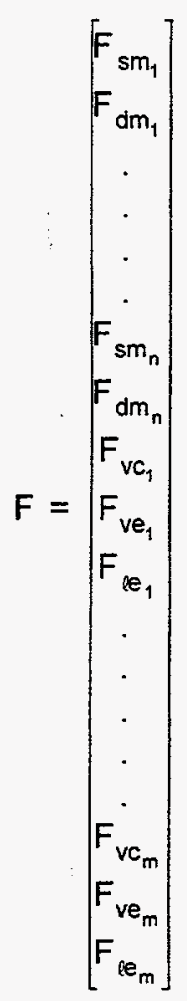

and

$\left.Y=P_{1}, v_{g_{1}}, \ldots P_{n}, v_{g_{n}}, \alpha_{g_{1}}, u_{g_{1}}, u_{f_{1}}, \ldots \alpha_{g_{m}}, u_{g_{m}}, u_{f_{m}}\right]^{\top}$

The partial derivatives that comprise the Jacobian matrix are

$$
\begin{array}{ll}
\frac{\partial F_{s m}}{\partial P_{K}}=1 & \text { if } P_{K} \text { is an unknown } \\
\frac{\partial F_{S m}}{\partial P_{L}}=-1 & \text { if } P_{L} \text { is an unknown }
\end{array}
$$


and

$\frac{\partial F_{s m}}{\partial F_{j u n f}}=2\left[\left(\alpha_{g} \rho_{g}\right)_{j} C_{g s} v_{g, j}+\left(\alpha_{f} \rho_{f}\right) C_{f s} v_{f, j}\right] \quad$ if $F_{j u n f}$ is an unknown

If the particular parameter is input as an initial condition (not an unknown), the corresponding derivative is zero. The phasic densities are dependent on the system pressure, but the dependency is weak and can be neglected for the current work. For very low pressure situations this assumption may need to be reconsidered.

The partial derivatives of the sum momentum equation with respect to the vapor velocity are

$$
\begin{aligned}
\frac{\partial F_{s m}}{\partial v_{g}} & =\left[\left(\alpha_{g} \rho_{g}\right)_{j} f_{w g j} \Delta x_{j}+\left(\alpha_{g} \rho_{g}\right)_{j} H_{g g, j}+r_{g} \Delta x_{j}+r_{n c} \Delta x_{j}\right] \\
& \left.-\left(\alpha_{f} \rho_{f}\right)_{j} f_{w f j} \Delta x_{j}+\left(\alpha_{f} \rho_{f}\right)_{j} H_{2 f, j}-r_{g} \Delta x_{j}+r_{s} \Delta x_{j}\right]\left(\frac{\alpha_{g} \rho_{g}}{\alpha_{f} \rho_{f}}\right)
\end{aligned}
$$

These derivatives will contribute to the off diagonal elements. Additional derivatives with respect to the junction vapor velocity arise from the momentum convection terms and also contribute to the off diagonal terms. They are

$$
\frac{\partial F_{s m}}{\partial v_{g}}=\left(\alpha_{g} \rho_{g}\right)_{j}\left[v_{g, L} \frac{\partial v_{g, L}}{\partial v_{g}}-v_{g, K} \frac{\partial v_{g, K}}{\partial v_{g}}\right]+\left(\alpha_{f} \rho_{f}\right)_{j}\left[v_{f, L} \frac{\partial v_{f, L}}{\partial v_{g}}-v_{f, K} \frac{\partial v_{f, K}}{\partial v_{g}}\right]
$$

where the volume average velocities are given by

$$
\begin{aligned}
& v_{g, m}=\frac{1}{R_{g}}\left[\sum_{j \in i}\left(\alpha_{g} \rho_{g} A v_{g}\right)_{j} \cdot \sum_{j \in i} A_{j}+\sum_{j \in 0}\left(\alpha_{g} \rho_{g} A v_{g}\right)_{j} \cdot \sum_{j \in 0} A_{j}\right] \\
& v_{f, m}=\frac{1}{R_{f}}\left[\sum_{j \in i}\left(\alpha_{f} \rho_{f} A v_{f}\right)_{j} \cdot \sum_{j \in i} A_{j}+\sum_{j \in 0}\left(\alpha_{f} \rho_{f} A v_{f}\right)_{j} \cdot \sum_{j \in 0} A_{j}\right]
\end{aligned}
$$

and

$$
R_{a}=A_{m} \sum_{j \in i, 0}\left(\alpha_{a} \rho_{a} A\right)_{j}
$$


The subscript " $\mathrm{m}$ " indicates either the "from " volume $\mathrm{K}$ or the "to" volume $\mathrm{L}$, and the "a" subscript indicates the vapor or liquid phases " $g$ " or " $f$ ", respectively. Equation 3-24 is used to eliminate the liquid velocity from Equation 3-34b, giving

$v_{f, m}=\frac{1}{R_{f}}\left\{\left[\sum_{j \in i} w_{j}-\sum_{j \in i}\left(\alpha_{g} \rho_{g} A v_{g}\right)_{j}\right] \cdot \sum_{j \in i} A_{j}+\left[\sum_{j \in 0} w_{j}-\sum_{j \in 0}\left(\alpha_{g} \rho_{g} A v_{g}\right)_{j}\right] \cdot \sum_{j \in 0} A_{j}\right\}$

The partial derivatives of the volume average vapor velocities with respect to the junction vapor velocities are

$$
\frac{\partial v_{g, m}}{\partial v_{g}}=\frac{1}{R_{g}}\left(\alpha_{g} \rho_{g} A\right)_{n} \sum_{j \in i} A_{j}
$$

and

$$
\frac{\partial v_{g, m}}{\partial v_{g}}=\frac{1}{R_{g}}\left(\alpha_{g} \rho_{g} A\right)_{n} \sum_{j \in 0} A_{j}
$$

for junctions $\mathrm{n}$ which are respectively inlets or outlets to volume $\mathrm{m}$. Similarly, the derivatives of the volume average liquid velocities are

$$
\frac{\partial v_{f, m}}{\partial v_{g}}=\frac{-1}{R_{f}}\left(\alpha_{g} \rho_{g} A\right)_{n} \sum_{j \in i} A_{j}
$$

and

$$
\frac{\partial v_{f, m}}{\partial v_{g}}=\frac{-1}{R_{f}}\left(\alpha_{g} \rho_{g} A\right)_{n} \sum_{j \in 0} A_{j}
$$

All wall friction, form loss, interphase friction, and momentum convection terms are functions of the phasic void fractions. The transient solution scheme neglects this dependence and it is also neglected here. The interphase friction can be a relatively strong function of the void fraction and is treated implicitly in the RETRAN-03 computer code solution scheme (Ref. 4). Rather than including the detailed coding that would be required to linearize the model, a relaxation scheme will be used. Only the body force term is linearized in terms of the void fraction and is

$$
\frac{\partial F_{s m}}{\partial \alpha_{g}}=\left(\rho_{g}-\rho_{f}\right) B_{x} \Delta x_{j}
$$


The phasic densities are functions of the corresponding phasic internal energies. These dependencies are also neglected. The interphase vapor generation rate is linearized in terms of the pressure and phasic internal energies for the transient solution scheme. Pressure dependencies have been neglected, while the internal energy dependencies have been retained in the steady-state solution. They are

$$
\frac{\partial F_{s m}}{\partial u_{g}}=\left[\left(1-\frac{\alpha_{g} \rho_{g}}{\alpha_{f} \rho_{f}}\right) v_{g, j}-\frac{w_{j}}{\left(\alpha_{f} \rho_{f} A\right)_{j}}\right] \Delta x_{j} \frac{\partial \Gamma_{g}}{\partial u_{g}}
$$

and

$$
\frac{\partial F_{s m}}{\partial u_{f}}=\left[\left(1-\frac{\alpha_{g} \rho_{g}}{\alpha_{f} \rho_{f}}\right) v_{g, j}-\frac{w_{j}}{\left(\alpha_{f} \rho_{f} A\right)_{j}}\right] \Delta x_{j} \frac{\partial \Gamma_{g}}{\partial u_{f}}
$$

Using Equation 3-3, the partial derivatives of the interphase mass transfer are obtained from

$$
\frac{\partial \Gamma_{g}}{\partial u_{g}}=\frac{H_{i g}}{h_{g}^{*}-h_{f}^{*}} \frac{\partial T_{g}}{\partial u_{g}}
$$

and

$$
\frac{\partial \Gamma_{g}}{\partial u_{f}}=\frac{H_{i f}}{h_{g}^{*}-h_{f}^{*}} \frac{\partial T_{f}}{\partial u_{f}}
$$

Again, the dependence on pressure has been neglected. The wall vapor generation rate has also been assumed to be independent of the dependent variables for the steady-state hydrodynamic balance equations, consistent with the transient solution.

Applying the same assumptions and simplifications as used with the sum momentum equation, the necessary partial derivatives for the difference momentum equations are obtained.

$$
\begin{array}{ll}
\frac{\partial F_{d m}}{\partial P_{k}}=-\left(\frac{\rho_{g}-\rho_{f}}{\rho_{g} \rho_{f}}\right) & \text { if } P_{k} \text { is unknown } \\
\frac{\partial F_{d m}}{\partial P_{L}}=\left(\frac{\rho_{g}-\rho_{f}}{\rho_{g} \rho_{f}}\right) & \text { if } P_{L} \text { is unknown }
\end{array}
$$


and

$\frac{\partial F_{d m}}{\partial F_{j u n f}}=2\left[-\left(\frac{\alpha_{g} \rho_{g}}{\alpha_{g} \rho_{g}}\right) C_{g s} v_{g, j}+\left(\frac{\alpha_{f} \rho_{f}}{\alpha_{f} \rho_{f}}\right) C_{f s} v_{f, j}\right] \quad$ if $F_{\text {junf }}$ is unknown

The principal component of the Jacobian diagonal element for the difference momentum equation is

$$
\begin{aligned}
\frac{\partial F_{d m}}{\partial v_{g, j}} & =-\left\{\int\left[\left(1-f_{x}\right)+\alpha_{g, j} f_{x}\left(1-\frac{\rho_{g}}{\rho_{f}}\right)_{j}\right] f_{w g} \Delta x_{j}+\left(\frac{\alpha_{g} \rho_{g}}{\alpha_{g} \rho_{g}}\right) H_{l g, j}\right. \\
& \left.+\rho_{j} F_{i, j} c_{j} \Delta x_{j}+\frac{\rho_{j} \Gamma_{g} \Delta x_{j}}{\left(\alpha_{g} \rho_{g} \alpha_{f} \rho_{f}\right)_{j}}+\frac{\Gamma_{n c} \Delta x_{i}}{\left(\alpha_{g} \rho_{g}\right)_{j}}\right] \\
& +\left[\left[\left(1-f_{x}\right)+\alpha_{f j} f_{x}\left(1-\frac{\rho_{f}}{\rho_{g}}\right)_{j}\right]_{w f j} \Delta x_{j}+\left(\frac{\alpha_{f} \rho_{f}}{\alpha_{f} \rho_{f}}\right) H_{f f, j}\right. \\
& \left.\left.+\rho_{j} F_{i, j} c_{o} \Delta x_{j}+\frac{\rho_{f} r_{g} \Delta x_{j}}{\left(\alpha_{g} \rho_{g} \alpha_{f} \rho_{f}\right)}+\frac{\Gamma_{s} \Delta x_{j}}{\left(\alpha_{f} \rho_{f}\right)_{j}}\right]\left(\frac{\alpha_{g} \rho_{g}}{\alpha_{f} \rho_{f}}\right)_{j}\right\}
\end{aligned}
$$

with additional terms arising from momentum convection are

$$
\begin{aligned}
\frac{\partial F_{d m}}{\partial v_{g}} & =\left(\frac{\alpha_{f} \rho_{f}}{\alpha_{f} \rho_{f}}\right)\left[v_{f, L} \frac{\partial v_{f, L}}{\partial v_{g}}-v_{f, K} \frac{\partial v_{f, K}}{\partial v_{g}}\right] \\
& -\left(\frac{\alpha_{g} \rho_{g}}{\alpha_{g} \rho_{g}}\right)\left[v_{g, L} \frac{\partial v_{g, L}}{\partial v_{g}}-v_{f, K} \frac{\partial v_{f, K}}{\partial v_{g}}\right]
\end{aligned}
$$

where the derivatives of the volume average velocities are as defined by Equations 3-34 and 3-35. Equation 3-24 is used to eliminate the fluid velocity in Equation 3-26. Examination of Equation 3-24 leads to the conclusion that the liquid velocity is dependent on the vapor void fraction. This dependence leads to the following partial derivative of the difference momentum equation with respect to the donor volume void fraction

$$
\begin{aligned}
\frac{\partial F_{d m}}{\partial \alpha_{g}} & =\left[\left[\left(1-f_{x}\right)+\alpha_{f, j} f_{x}\left(1-\frac{\rho_{f}}{\rho_{g}}\right)_{j}\right] f_{w f, j} \Delta x_{j}+\left(\frac{\alpha_{f} \rho_{f}}{\alpha_{f} \rho_{f}}\right) H_{f f, j}\right. \\
& \left.+\rho_{j} F_{i, j} C_{o} \Delta x_{j}+\frac{\rho_{j} \Gamma_{g} \Delta x_{j}}{\left(\alpha_{g} \rho_{g} \alpha_{f} \rho_{f}\right)}+\frac{\Gamma_{s} \Delta x_{j}}{\left(\alpha_{f} \rho_{f}\right)_{j}}\right] \frac{\partial v_{f, j}}{\partial \alpha_{g}}
\end{aligned}
$$


where the necessary partial derivative of the fluid velocity is obtained from Equation 3-24 as

$$
\frac{\partial v_{f, j}}{\partial \alpha_{g}}=\left(\frac{1}{\alpha_{f}^{2} p_{f}}\right)_{j}\left(\frac{W}{A}-\rho_{g} v_{g}\right)_{j}
$$

Finally, the partial derivatives of the difference momentum equations with respect to the phasic energies are given by

$$
\frac{\partial F_{d m}}{\partial u_{g}}=\frac{-\rho_{j} \Delta x_{j}}{\left(\alpha_{g} \rho_{g} \alpha_{f} \rho_{f}\right)_{j}}\left(v_{g}-v_{f}\right) \frac{\partial \Gamma_{g}}{\partial u_{g}}
$$

and

$$
\frac{\partial F_{d m}}{\partial u_{f}}=\frac{-\rho_{j} \Delta x_{j}}{\left(\alpha_{g} \rho_{g} \alpha_{f} \rho_{f}\right)_{j}}\left(v_{g}-v_{f}\right) \frac{\partial r_{g}}{\partial u_{f}}
$$

The components of the Jacobian matrix for the vapor continuity equation convective terms are given below. The vapor velocity derivatives are

$$
\frac{\partial F_{v c}}{\partial v_{g}}= \begin{cases}\left(\alpha_{g} \rho_{g} A\right)_{j} & \text { for inlet junctions } \\ -\left(\alpha_{g} \rho_{g} A\right)_{j} & \text { for outlet junctions }\end{cases}
$$

and the derivatives with respect to the junction donor volume void fractions are

$$
\frac{\partial F_{v c}}{\partial \alpha_{g}}=\left(\rho_{g} A v_{g}\right)_{j}
$$

Below are the derivatives of the vapor continuity equation source term or generation rate with respect to the phasic internal energies

$$
\frac{\partial F_{v c}}{\partial u_{g}}=V_{L} \frac{\partial \Gamma_{g, L}}{\partial u_{g}}
$$

and

$$
\frac{\partial F_{v c}}{\partial u_{f}}=V_{L} \frac{\partial \Gamma_{g, L}}{\partial u_{f}}
$$


The vapor energy equation partial derivatives are presented below. For the convective terms

$$
\begin{aligned}
& \frac{\partial F_{v e}}{\partial v_{g}}=\left\{\begin{array}{cc}
\alpha_{g}\left(\rho_{g} \dot{u}_{g}+\dot{P}\right)_{j} A_{j} & \text { for inlet junctions } \\
-\alpha_{g}\left(\rho_{g} \dot{u}_{g}+\dot{P}\right)_{j} A_{j} & \text { for outlet junctions }
\end{array}\right. \\
& \frac{\partial F_{v e}}{\partial \alpha_{g}}= \begin{cases}\left(\rho_{g} \dot{u}_{g}+\dot{P}\right)_{j} v_{g j} A_{j} & \text { for inlet junctions } \\
-\left(\rho_{g} \dot{u}_{g}+\dot{P}\right)_{j} v_{g j} A_{j} & \text { for outlet junctions }\end{cases}
\end{aligned}
$$

and

$$
\frac{\partial F_{v e}}{\partial u_{g}}=\left\{\begin{array}{cc}
\alpha_{g} \rho_{g} v_{g, j} A_{j} & \text { for inlet junctions } \\
-\alpha_{g} \rho_{g} v_{g j} A_{j} & \text { for outlet junctions }
\end{array}\right.
$$

Additional terms arise due to the functional dependencies of the source terms. As before, the wall related heat and mass transfer terms are treated as constants, but the interphase terms are linearized. The dissipation terms are also assumed constant. Jacobian terms related to the interphase mass and energy exchange are

$$
\begin{aligned}
& \frac{\partial F_{v e}}{\partial u_{g}}=V_{L}\left[\frac{\partial Q_{i g}}{\partial u_{g}}+h_{g}^{*} \frac{\partial \Gamma_{i g}}{\partial u_{g}}+\Gamma_{i g} \frac{\partial h_{g}^{*}}{\partial u_{g}}\right] \\
& \frac{\partial F_{v e}}{\partial u_{f}}=V_{L} h_{g}^{*} \frac{\partial \Gamma_{i g}}{\partial u_{f}}
\end{aligned}
$$

where

$$
\begin{aligned}
& \frac{\partial Q_{i g}}{\partial u_{g}}=-H_{i g} \frac{\partial T_{g}}{\partial u_{g}} \\
& \frac{\partial \Gamma_{i g}}{\partial u_{g}}=\left(\frac{1}{h_{g}^{*}-h_{f}^{*}}\right)\left[H_{i g} \frac{\partial T_{g}}{\partial u_{g}}+\Gamma_{i g} \frac{\partial h_{g}^{*}}{\partial u_{g}}\right]
\end{aligned}
$$


and

$$
\frac{\partial \Gamma_{i g}}{\partial u_{f}}=\left(\frac{1}{h_{g}^{*}-h_{f}^{*}}\right)\left[H_{i f} \frac{\partial T_{f}}{\partial u_{f}}+\Gamma_{i g} \frac{\partial h_{f}^{*}}{\partial u_{f}}\right]
$$

are obtained directly by differentiating Equations $3-21$ and 3-22. Equations 3-23 are differentiated to obtain

$$
\frac{\partial h_{g}^{*}}{\partial u_{g}}= \begin{cases}1 & \text { if } \Gamma_{\text {ig }}<0 \\ 0 & \text { if } \Gamma_{\text {ig }} \geq 0\end{cases}
$$

and

$$
\frac{\partial h_{f}^{*}}{\partial u_{f}}= \begin{cases}1 & \text { if } \Gamma_{\text {ig }} \geq 0 \\ 0 & \text { if } \Gamma_{\text {ig }}<0\end{cases}
$$

The elements of the Jacobian matrix arising from the liquid energy equation are similar in form to those for the vapor energy. Again, Equation 3-24 is used to eliminate the liquid velocity when the derivatives are evaluated. The pertinent derivatives are

$$
\begin{aligned}
& \frac{\partial F_{l e}}{\partial v_{g}}=\left\{\begin{array}{cc}
-\alpha_{f}\left(\rho_{f} \dot{u}_{f}+\dot{P}\right)_{j} A_{j}\left(\frac{\alpha_{g} \rho_{g}}{\alpha_{f} \rho_{f}}\right) & \text { for inlet junctions } \\
\alpha_{f}\left(\rho_{f} \dot{u}_{f}+\dot{P}\right)_{j} A_{j}\left(\frac{\alpha_{g} \rho_{g}}{\alpha_{f} \rho_{f}}\right) & \text { for outlet junctions }
\end{array}\right. \\
& \frac{\partial F_{l e}}{\partial \alpha_{g}}=\left\{\begin{array}{cc}
-\left(\rho_{f} \dot{u}_{f}+\dot{P}\right)_{j} A_{j} v_{f j} A_{j} & \text { for inlet junctions } \\
\left(\rho_{f} u_{f}+\dot{P}\right)_{j} A_{j} v_{f j} A_{j} & \text { for outlet junctions }
\end{array}\right.
\end{aligned}
$$

and

$$
\frac{\partial F_{l e}}{\partial u_{f}}=\left\{\begin{aligned}
\alpha_{f} \rho_{f} v_{f, j} A_{j} & \text { for inlet junctions } \\
-\alpha_{f} \rho_{f} v_{f, j} A_{j} & \text { for outlet junction }
\end{aligned}\right.
$$

Finally, the derivatives due to the source terms are

$$
\frac{\partial F_{l e}}{\partial u_{g}}=-V_{L} h_{f}^{*} \frac{\partial \Gamma_{i g}}{\partial u_{g}}
$$




$$
\frac{\partial F_{\ell e}}{\partial u_{f}}=V_{L}\left[\frac{\partial Q_{i f}}{\partial u_{f}}-h_{f}^{*} \frac{\partial \Gamma_{i g}}{\partial u_{f}}-\Gamma_{i g} \frac{\partial h_{f}^{*}}{\partial u_{f}}\right]
$$

where

$\frac{\partial Q_{i f}}{\partial u_{f}}=-H_{i f} \frac{\partial T_{f}}{\partial u_{f}}$

This completes development of the terms that are currently included in the Jacobian matrix.

Examining Equation 3-32a, it is apparent that both the function values and elements of the Jacobian matrix are evaluated at the previous iteration values. Rearranging Equation 3-32a, the changes in the dependent variables needed to drive the system of equations to zero are obtained as

$$
\Delta Y^{k+1}=\left[\frac{\partial F^{k}}{\partial Y}\right]^{-1}\left(-F^{k}\right)
$$

This system of coupled algebraic equations is then solved using the sparse matrix solution developed by Curtis and Reid (Ref. 7). The sparse matrix solver is also used in the RELAP5 transient scheme, but for a smaller system of equations.

Once the solution vector is obtained, the dependent variables are updated using

$$
\begin{aligned}
& P^{k+1}=P^{k}+\Delta P^{k+1} \\
& F_{j u n f}^{k+1}=F_{j u n f}^{k}+\Delta F_{j u n f}^{k+1} \\
& v_{g}^{k+1}=v_{g}^{k}+\Delta v_{g}^{k+1} \\
& \alpha_{g}^{k+1}=\alpha_{g}^{k}+\Delta \alpha_{g}^{k+1} \\
& u_{g}^{k+1}=u_{g}^{k}+\Delta u_{g}^{k+1}
\end{aligned}
$$

and

$$
u_{f}^{k+1}=u_{f}^{k}+\Delta u_{f}^{k+1}
$$

The state properties are evaluated for each control volume using the new pressures and phasic interval energies with the transient solution EOS where 


$$
\begin{aligned}
& \rho_{g}^{k+1}=\rho_{g}\left(P^{k+1}, u_{g}^{k+1}\right) \\
& \rho_{f}^{k+1}=\rho_{f}\left(P^{k+1}, u_{f}^{k+1}\right) \\
& T_{g}^{k+1}=T_{g}\left(P^{k+1}, u_{g}^{k+1}\right)
\end{aligned}
$$

and

$$
T_{f}^{k+1}=T_{f}\left(P^{k+1}, u_{f}^{k+1}\right)
$$

After the volume state properties are updated, the junction properties are computed using the transient junction property subroutine. The liquid velocities are then updated using Equation 3-24 which gives

$$
v_{f}^{k+1}=\frac{w_{j}}{\left(\alpha_{f} \rho_{f}\right)_{j}^{k+1} A_{j}}-\left(\frac{\alpha_{g} \rho_{g}}{\alpha_{f} \rho_{f}}\right)_{j}^{k+1} v_{g, j}^{k+1}
$$

This completes the implicit steady-state solution scheme.

\subsection{EOS Relationships}

The EOS relationship used in the RELAP5 code utilizes the dependent variables $\left(P, u_{g}, u_{f}, \alpha_{g}\right)$, which are obtained from the solution of the hydrodynamic balance equations. Details of the EOS are given in Reference 1 and will not be repeated here. The steady-state solver uses the transient solution scheme EOS unchanged.

\subsection{Constitutive Models}

Constitutive models are required for closure of the momentum and energy equations. These include flow regime maps and models for interphase friction, wall friction, wall heat transfer and interphase mass transfer. A discussion of each of these constitutive models and any special treatment required for steady-state initialization is presented.

\subsubsection{Flow Regime Maps}

Four flow regime maps are used in RELAP5, a vertical flow regime map, a horizontal flow regime map, a high mixing volume flow regime map and an ECC mixer map. The vertical flow regime map is the most detailed with nine distinct flow regimes and several transition regimes modeled. The horizontal flow regime map has pre-CHF regimes plus a stratified flow regime. The criteria for selecting and defining transition between flow regimes in the vertical and horizontal flow maps are based on several empirical correlations. Flow regime selection in the high mixing flow regime map 
is based simply on void fraction. The existing flow regime selection logic for the vertical, horizontal and high mixing flow regime maps was not modified for the steady-state initialization package.

The ECC mixer volume flow regime map is used in the interfacial heat transfer calculation for condensation. The flow regime selection logic used for this map should be valid for steady-state initialization; however, there should not be any situations in which this map is required for initial conditions in a LWR and no special treatment was implemented.

\subsubsection{Interphase Friction}

The RELAP5 interphase drag models utilize either drift flux relationships or correlations for interphase area and friction factors. In both of these approaches, the relationships are algebraic and no special treatment was required for steady-state initialization.

Smoothing is used in the RELAP5 solution to minimize the effects of discontinuous changes in the drag models during flow regime transitions. This smoothing takes the form of time-dependent exponential smoothing in many cases. In these instances, the time smoothing was replaced with a relaxation scheme.

\subsubsection{Coefficient of Virtual Mass}

The coefficient of virtual mass is based on the junction flow regime and is smoothed via junction void fraction between flow regimes. Since this term is associated with the velocity time derivative which is zero for steady state, this model was not modified for steady-state initialization.

\subsubsection{Wall Friction}

The wall friction calculation requires that the wall surface area wetted by each phase and the appropriate friction factor be determined. The wall surface area wetted by each phase is determined for the particular flow regime selected from the flow regime map. As with the interphase drag term, there are no specific wall area and friction factor models for the transition flow regimes. In these instances, a time-dependent exponential smoothing is used between the end flow regimes. The time-dependent smoothing is replaced with a relaxation scheme for steady-state initialization.

\subsubsection{Wall Heat Transfer}

A large number of heat transfer coefficient correlations are available for use in RELAP5. The logic to select these correlations is based on several factors such as pressure, wall temperature, presence of noncondensable gas, vapor void fraction and CHF. The heat transfer coefficient selection logic does not require modification for steady-state initialization. Also, the energy partitioning logic used to determine the heat source terms for the phasic energy equations was not modified for the steady-state initialization. A steady-state form of the conduction solution is used to obtain the initial conductor temperature distribution and wall heat flux and is described in Section 4. 


\subsubsection{Interphase Heat Transfer}

The expressions used for interfacial area and heat transfer coefficients are selected based on the fluid volume flow regime. As with the interphase drag term, time smoothing is utilized between correlations in the transition flow regimes. The time smoothing was replaced with a relaxation method for steady-state initialization.

\subsection{Special Process Models}

Several special process models are present in RELAP5 to simulate processes that cannot be simulated directly by the balance equations and default constitutive models. In many cases, the phenomena modeled by these special purpose models are encountered only in transient situations and need not be considered during steady-state initialization. These models are summarized below.

\subsubsection{Choked Flow}

The choked flow model serves as a junction flow boundary condition at the point the flow becomes independent of the downstream conditions. Choked flow would be expected to occur at breaks in the system or at open safety or relief valves. When choked flow is predicted during a transient simulation, an additional equation is solved in conjunction with the upstream momentum equation, therefore, the matrix solution is modified.

If choking is allowed during the steady-state iterations, logic would have to be added to detect choking and modify the coefficient matrix accordingly. However, since choked flow should not exist in any LWR during normal steady-state operation (excluding turbines), choking is not considered in the steady-state solution. Additionally, choked flow is not consistent with the flow initial conditions that are used in the DSSI implementation.

\subsubsection{Horizontal Stratification and Entrainment}

When horizontal stratification occurs, the junction void fraction may be different than that of the donor volume depending on the junction elevation relative to the stratified level. The horizontal stratification and entrainment model simulates the effects of stratification and vapor or liquid pull through on junction void fraction. As with the choked flow model, the conditions for which this model is activated would not be expected during steady-state operation. Therefore, the horizontal stratification and entrainment model is not considered in the steady-state solution.

\subsubsection{Abrupt Area Change}

Momentum effects of abrupt area changes, from contractions, expansions or orifices are not modeled explicitly by the momentum equations. Therefore, an abrupt area change model is formulated to include these effects. This model did not require any modifications for steady-state initialization and is included directly in the solution scheme. 


\subsubsection{Crossflow Junction}

Since the momentum equations are based on one-dimensional flow, special process models are used to approximate an improved physical response to a multi-dimensional situation. The momentum flux terms are specially formulated and wall friction is modified for crossflow junctions. The special treatment of these junctions does not require modification for steady-state initialization and is included as part of the normal steady-state iteration process.

\subsubsection{Water Packing Mitigation}

This special model is required only for the transient solution and the logic for this model is bypassed in steady-state initialization.

\subsubsection{Countercurrent Flow Limitation}

This phenomena will not be encountered during normal steady-state operation, therefore, the logic dealing with this model is bypassed in steady-state solution.

\subsection{Component Models}

Several subsystem models are required for complete modeling of LWRs. These include branches, separators, jet mixers, pumps, turbines, valves, and accumulators. This section contains a brief summary of the component models in the steady-state initialization logic.

\subsubsection{Branch}

The branch component is merely a user convenience to input a series of single volume and junction components. Once past the input processing, the volumes and junctions in a branch are treated in the same manner as other volumes and junctions in the system model. The branch component does not require any modification for steady-state solution.

\subsubsection{Separator}

The separator model allows the outlet junction void fractions to be a function of the separator void fraction rather than the default model that simply donors the volume void to the junction. The relationships specifying how the outlet junction void fractions vary with the volume void fraction, are supplied by the user. One junction void fraction function is required for each of the two outlet junctions, but they need not be related in any manner. Both the steam outlet junction vapor void fraction and the liquid fall back junction liquid void fractions are in general approximately equal to unity.

Even though the junction void fractions are defined from the model, the junction phasic velocities are computed in the standard manner from the phasic momentum equations. Therefore, no modifications to the momentum equation solutions are required. 
The separator model was modified to ensure a steady-state vapor mass balance for the separator volume. During steady-state conditions, the vapor convection rate into a volume must equal the convection rate out of the volume. Since in the current formulation, the void fraction of the two outlet junctions are based on user supplied functions, the vapor mass balance can be violated unless appropriate adjustments are made.

In order to ensure that the separator volume steady-state vapor continuity equations are balanced, the steady-state initialization process was modified to adjust one of the outlet junction void fractions. An arbitrary decision was made to adjust the void fraction of the liquid fall back junction. The user-supplied void fraction function for the vapor outlet junction is unchanged and the separator fall back function is adjusted to achieve the liquid fall back junction void fraction required to satisfy the vapor continuity equation.

The steam separator model requires the use of three junctions. One is the inlet where two-phase fluid flows into the separator. Another is the steam flow path that is primarily steam, and the other is the liquid fall back (or recirculation) junction which is primarily liquid. The vapor continuity equation for the separator can then be written as

$$
F_{v c k e p}=\left(\alpha_{g} \rho_{g} v_{g} A\right)_{\text {in }}-\left(\alpha_{g} \rho_{g} v_{g} A\right)_{r}-\left(\alpha_{g} \rho_{g} v_{g} A\right)_{s t}+r_{g}=0
$$

Note that the recirculation and steam flow path void fractions do not have the over dot, indicating that they are not strictly donor values (under normal flow pattern). Rather, they are obtained from a model where

$$
\alpha_{g_{s t}}= \begin{cases}\frac{\alpha_{g}}{v_{\text {over }}} & \text { if } \alpha_{g}<v_{\text {over }} \\ \alpha_{g} & \text { if } \alpha_{g} \geq v_{\text {over }}\end{cases}
$$

and

$\alpha_{g_{r}}= \begin{cases}\alpha_{f} & \text { if } \alpha_{f} \geq v_{\text {under }} \\ \frac{\alpha_{f}}{v_{\text {under }}} & \text { if } \alpha_{f}<v_{\text {under }}\end{cases}$

where $v_{\text {over }}$ and $v_{\text {under }}$ are user-supplied model parameters. Assuming that $\alpha_{g}$ and $v_{\text {over }}$ are specified as initial conditions, it is possible to satisfy the vapor continuity equation by computing $\alpha_{g_{r}}$ (or $v_{\text {under }}$ ). This is accomplished by using Equation 3-59 and the following partial derivatives in place of the normal formulation given above. The derivatives for the inlet are unchanged. Those for the steam and recirculation flow paths are

$$
\frac{\left.\partial F_{v c}\right)_{\text {sep }}}{\partial \alpha_{g_{r}}}=\left(-\rho_{g} v_{g} A\right)_{r}
$$




$$
\begin{aligned}
& \frac{\left.\partial F_{v c}\right)_{\text {sep }}}{\partial v_{g_{r}}}=\left(\alpha_{g} \rho_{g} A\right)_{r} \\
& \frac{\left.\partial F_{v c}\right)_{\text {sep }}}{\partial \alpha_{g_{s t}}}=0 \\
& \text { and } \\
& \frac{\left.\partial F_{v c}\right)_{\text {sep }}}{\partial v_{g_{s t}}}=\left(\alpha_{g_{s t}} \rho A\right)_{s t}
\end{aligned}
$$

Based upon the above derivatives, the volume downstream of the steam flow junction is not coupled to Equation 3-59, but the volume downstream of the liquid fall back junction is.

The source term derivatives are as defined previously. Using this formulation, the unknown void fraction is the recirculation path vapor void fraction rather than the separator volume void fraction. However, the volume void fraction is temporarily updated (to simplify logic) and the recirculation path vapor void fraction is then

$$
\alpha_{g_{r}}^{k+1}=\alpha_{g_{r}}^{k}+\left(\alpha_{g}^{k+1}-\alpha_{g}^{k}\right)
$$

After the above is evaluated, the volume void fraction is reset to the input value and the recirculation path model parameter is evaluated using

$$
v_{\text {under }}=\frac{\left(1-\alpha_{g}\right)}{\left(1-\alpha_{g_{r}}\right)^{k+1}}
$$

The model is limited to vapor void fractions in the range $0 \leq \alpha_{g_{r}} \leq 1$. This model ensures a vapor mass balance in separator volumes.

\subsubsection{Jet Mixer}

Momentum exchange between two fluid streams entering a control volume at different velocities is not modeled by the standard RELAP5 momentum equations. Fluid stream momentum exchange is required to model BWR jet pumps and may be needed at ECC injection points. The jet mixer model simulates stream mixing by computing another differential pressure term for the momentum equations of the mixing streams (junctions).

The logic for this optionally activated model is already part of the momentum equation formulation and does not require modification for steady-state initialization. 


\subsubsection{Centrifugal Pump Model}

The pump model is a component model requiring a single hydraulic volume and two junctions. The pump model provides a head term that is equally distributed between the inlet and outlet junction momentum equations and a dissipation term that is included as a source term in the energy equations for pump volumes. The pump head and energy dissipation terms are functions of pump speed, pump volume volumetric flow and volume density.

The energy dissipation term is included in the steady-state initialization scheme through the phasic energy equations and in the overall energy balance. The two parameters that could require special consideration during steady-state initialization are the pump head and initial pump speed.

The pump head is included in the inlet and outlet junction momentum equations as part of the existing RELAP5 solution. The developed pump head must balance the pressure losses around the system. There are two optional methods that could be implemented to ensure the head balance. The first option is to have steady-state initialization adjust the pump speed to balance the system pressure drop. The second option is to have the initialization process adjust a junction loss coefficient in the loop (preferably at the pump outlet) to make up for the pressure imbalance. This option has been used for over 15 years in the RETRAN-02 code (Ref. 3) and has been found to be satisfactory by users. Consequently, a similar approach is used in the RELAP5 steady-state initialization package. An option to adjust the pump speed or rated head can be added during the Phase III effort if interest warrants.

The rated pump motor torque is adjusted to balance the net hydraulic and frictional torque. This ensures a torque imbalance will not lead to a change in the pump speed when the transient solution is advanced.

\subsubsection{Turbine Model}

The turbine model modifies the form of the momentum equations and energy equations. This model is currently neglected. If the model is included in steady-state initialization, a normalization procedure to ensure the turbine removes the correct amount of initial energy will be required.

\subsubsection{Valves}

Several valve model options are available for use; however, they all serve the same purpose to define the junction flow area. The valve model can define flow areas for opening and closing using tables, instantaneous open and close trips and from the control system. As far as steady-state initialization is concerned, the junction flow area is assumed to be fixed during the iteration process and the area used in the steady-state initialization calculation must be consistent with that defined by the control system or area tables.

The initial junction area used for steady-state initialization must be obtained from the valve models rather than relying on the area input on the junction data cards. Therefore, the valve models are 
evaluated prior to any steady-state iteration to ensure the junction area used will be consistent with that used when the transition to the transient module is made.

\subsubsection{Accumulator}

The accumulator is isolated from the rest of the system during normal operation. It is only during transient conditions that the accumulator influences the system response. Therefore, it is assumed that users will provide all necessary initial conditions and no special treatment for the accumulator is required during steady-state initialization.

\subsubsection{ECC Mixer Model}

The ECC mixer model generally becomes active during a transient, once ECCs injection begins. Since no ECC injection would be expected during normal steady-state operation, this model is neglected for the steady-state initialization logic. 


\section{HEAT STRUCTURES}

Heat is transferred from solids such as fuel rods, steam generator tubes, piping, vessel walls, and internal structures to hydrodynamic volumes via heat structures. The location of heat structures and the material composition of heat structures is specified by the user. The structures can have an internal heat source (core conductors) and can transfer energy to or between volumes. A steadystate solution of the one-dimensional heat conduction is a requirement for the steady-state initialization feature. It provides the initial temperature distribution and surface heat flux.

There are several heat structure configurations that can be modeled and, therefore, must be considered for proper heat structure initialization. For all configurations, the internal node temperature must be adjusted to achieve the desired initial conditions. These configurations and the pertinent considerations are

- for all powered heat structures, the internal heat generation rate must equal the heat transfer rate through the conductor surface(s),

- for passive (nonpowered) heat structures that have a fluid volume on one side and are insulated on the other side, the initial heat transfer rate must be zero, and

- for passive heat structures with fluid volumes on both sides or a fluid volume on one side and a boundary condition on the other side, the initial heat transfer rate in one side of the conductor must equal the heat transfer rate out the other side

A subroutine in RELAP5 provides the initial heat structure node temperatures by solving the steadystate conduction equations and satisfying the above constraints. In the base RELAP5 code, this subroutine is called only during initialization to provide an initial guess for conductor temperatures. After the initial call, the transient conduction equations are solved while running a transient to obtain steady-state conditions.

The steady-state heat conduction subroutine, "ht1sst", is used in the steady-state solution scheme to provide conductor temperature distributions and wall heat fluxes. These steady-state heat fluxes define source terms for the energy equation.

\subsection{Steady-State Heat Conduction Equation and Solution}

The heat conduction equation, its finite differencing, and transient and steady-state solution methods are discussed in Reference 1 . The equations are briefly reviewed in order to relate them to the steady-state solution. The RELAP5 code solves the one-dimensional heat conduction equation in integral form given by

$$
\int_{V} c_{v}(T, x) \frac{\partial T(x, t)}{\partial t} d V=\int_{S} k(T, x) \nabla T(x, t) \cdot d S+\int_{V} S(x, t) d V
$$


where

$\begin{array}{lll}c_{\mathrm{v}} & = & \text { volumetric heat capacity, } \mathrm{J} / \mathrm{m}^{3}-\mathrm{K} \\ \mathrm{T} & = & \text { temperature, } \mathrm{K} \\ \mathrm{V} & = & \text { conductor volume, } \mathrm{m}^{3} \\ \mathrm{k} & = & \text { thermal conductivity, } \mathrm{w} / \mathrm{m}-\mathrm{K} \\ \mathrm{s} & = & \text { conductor surface area, } \mathrm{m}^{2} \\ \mathrm{~S}(\mathrm{x}, \mathrm{t}) & = & \text { volumetric heat source, } \mathrm{w} / \mathrm{m}^{3}\end{array}$

with boundary conditions given by the expression

$A(T) T(t)+B(T) \frac{\partial T(t)}{\partial n}=D(T)$

or

$-\frac{\partial T(t)}{\partial n}=\frac{A(T) T(t)-D(T)}{B(T)}$

where

$A(T)=$ heat transfer coefficient, $w / m^{2}-K$

$\mathrm{B}(\mathrm{T})=$ conductivity, $\mathrm{w} / \mathrm{m}-\mathrm{K}$

$\mathrm{D}(\mathrm{T})=$ heat flux boundary condition, $w / \mathrm{m}^{2}$

The steady-state form of Equation 4-1 is obtained by setting the left-hand side (time derivative) to zero.

The treatment of material boundaries, spacial nodalization, material properties, and various onedimensional geometries is given in detail in Reference 1. Equation 4-3 gives the difference equation for the $\mathrm{m}$-th interval node.

$a_{m} T_{m-1}^{n+1}+b_{m} T_{m}^{n+1}+c_{m} T_{m+1}^{n+1}=d_{m}$

where

$a_{m}=k_{l_{m}}^{n} \delta_{l_{m}}^{s}$

$b_{m}=-a_{m}^{n}-c_{m}^{n}$

$c_{m}=-k_{r_{m}}^{n} \delta_{r_{m}}^{s}$ 
and

$$
d_{m}=P_{f} P^{n+1}\left(Q_{l_{m}} \delta_{l_{m}}^{v}+Q_{r_{m}} \delta_{r_{m}}^{v}\right)
$$

where

$P_{f} \quad=\quad$ power fraction

P. $\quad=$ power, $\mathrm{w}$

The subscripts on the thermal conductivity, geometry surface weights, $\delta^{s}$, volume weights, $\delta^{v}$, and spacial power fraction, $Q$, indicate the location where the quantities are evaluated.

For the left boundary $(m=1)$, the difference equation is

$b_{1} T_{1}^{n+1}+c_{1} T_{2}^{n+1}=d_{1}$

where

$b_{1}=k_{r_{1}} \delta_{r_{1}}^{b} \frac{A}{B_{1}}-c_{1}$

$c_{1}=-k_{r_{1}} \delta_{r_{1}}^{s}$

and

$d_{1}=k_{r_{1}} \delta_{r_{1}}^{b} \frac{A_{1}}{B_{1}} T_{1}^{n}-k_{r_{1}} \delta_{r_{1}}^{b}\left[\frac{A_{1} T_{1}^{n}-D_{1}}{B_{1}}\right]+P_{f} P^{n+1} Q_{r_{1}} \delta_{r_{1}}^{v}$

The difference equation for the right boundary node $(m=M)$ is

$$
a_{M} T_{M-1}^{n+1}+b_{M} T_{M}^{n+1}=d_{m}
$$

where

$$
\begin{aligned}
& a_{M}=-k_{l_{M}} \delta_{l_{M}}^{s} \\
& b_{M}=k_{l_{M}} \delta_{l_{M}}^{s} \frac{A_{M}}{B_{M}}-a_{M}
\end{aligned}
$$


and

$d_{M}=k_{\ell_{M}} \delta_{\ell_{M}}^{b} \frac{A_{M}}{B_{M}} T_{M}^{n}-k_{\ell_{M}} \delta_{\ell_{M}}^{b}\left[\frac{A_{M} T_{M}^{n}-D_{M}}{B_{M}}\right]+P P^{n+1} Q_{\ell_{M}} \delta_{l_{M}}^{v}$

For a given geometry with $m$ mesh points ( $M-1$ regions), an $M \times M$ tridiagonal matrix in the coefficients $a_{m}, b_{m}, c_{m}$ is generated as well as a vector in $d_{m}$. The solution of the equations is then obtained by Gaussian elimination, giving the following equations for the temperature distribution.

$E_{1}=\frac{c_{1}}{b_{1}}$

$F_{1}=\frac{d_{1}}{b_{1}}$

$E_{J}=\frac{c_{j}}{b_{j}-a_{j} E_{j-1}}$

$F_{j}=\frac{d_{j}-a_{j} F_{j-1}}{b_{j}-a_{j} E_{j-1}}$

for $j=2,3, \ldots, M-1$

$T_{M}^{n+1}=\frac{d_{M}-a_{M} F_{M-1}}{b_{M}-a_{M} E_{M-1}}$

and

$T_{j}^{n+1}=-E_{j} T_{j-1}^{n+1}+F_{j} \quad$ for $j=M-1, M-2, \ldots, 2,1$

Convective boundary conditions can be used on either the left or right surfaces, or both. In RELAP5, the convective boundary conditions in Equations $4-6 c$ and $4-8 c$ are explicit since they are evaluated at the old iterate values for the surface temperatures $\left(T_{1}^{n}\right.$ and $\left.T_{M}^{n}\right)$ and the boundary fluid volume temperatures. This explicit treatment is adequate for most applications, but a more implicit treatment is necessary for steam generators where adjacent fluid volume energy equations are coupled through heat structures used to model the tube bundle. An implicit treatment of the flux boundary conditions for steam generator tubes is developed in the next section. 


\subsection{Implicit Convective Boundary Conditions}

It has been demonstrated that an explicit treatment of the convective boundary conditions for steam generator tubes, leads to poorly or nonconvergenced steady-state solutions (Ref. 5). In order to ensure a convergent steady-state solution scheme for PWR applications, an implicit heat conduction solution is necessary for the steam generator tubes, where the boundary fluid volume and conductor temperatures, both surface and internal, are obtained simultaneously and for the new iterate level.

The explicit convective boundary conditions used in Equations 4-6c and 4-8c are replaced by implicit convective boundary conditions by setting

$$
\begin{aligned}
& A_{1}=A_{M}=0 \\
& B_{1}=k_{r_{1}} \\
& B_{M}=k_{l_{M}} \\
& D_{1}=q_{l}^{n+1} \\
& D_{2}=q_{r}^{n+1}
\end{aligned}
$$

These changes yield

$$
d_{1}=\delta_{1}^{b} q_{l}^{n+1}
$$

and

$$
d_{M}=\delta_{M}^{b} q_{r}^{n+1}
$$

Equations $4-10 a$ and $4-10 b$ are simplified by also making the assumption that there is no internal heat generation in steam generator tube walls.

The left-hand side of the resulting set of coupled equations is unchanged. On the right-hand side the $d_{j}$ terms are zero, resulting in the $F_{j} s$ in Equation 4-9d also being zero. New terms appear for the two flux boundary conditions. They appear as a coefficient matrix of surface area weights times a vector containing the unknown flux boundary conditions. Only two nonzero elements appear in the surface area weight coefficient matrix, the first diagonal element which contains the left surface value and the last diagonal element containing the right area weight. Similarly, the wall heat flux vector is comprised of the left wall heat flux in the first element, the right wall heat flux in the last, and all others are zero. 
Gaussian elimination is also used to solve this new system of coupled equations. The new terms that appear as the result of the unknown flux boundary condition are

$$
G_{1}=\frac{\delta_{1}^{b}}{b_{1}}
$$

and

$G_{j}=\frac{-a_{j} G_{j-1}}{b_{j}-a_{j} E_{j=1}} \quad$ for $j=2.3 \ldots M$

The temperature for any node in the heat structure is then

$$
T_{j}^{n+1}=Y q_{l_{w}}^{n+1}+Z_{j} q_{r_{w}}^{n+1}
$$

where

$$
Y_{M}=G_{M}
$$

$z_{M}=\frac{\delta_{M}^{b}}{b_{M}-a_{M} E_{M-1}}$

$Y_{j}=G_{j}-E_{j} Y_{j+1}$

$Z_{j}=-E_{j+1}$

for $h=1,2, \ldots, M$

An equation is obtained for the left wall heat flux in terms of the left and right surface temperatures $(j=1$ and $j=M$ ) by writing Equation $4-12 a$ for $j=M$ and then solving it for the right wall heat flux. The resulting equation is substituted into Equation $4-12 a$ written for $j=1$. After rearranging, the left wall heat flux is

$$
q_{l_{w}}^{n+1}=\alpha_{1} T_{1}^{n+1}+\alpha_{2} T_{M}^{n+1}
$$

where

$$
\alpha_{1}=\frac{Z_{M}}{Y_{1} Z_{M}-Y_{M} Z_{1}}
$$


and

$$
\alpha_{2}=\frac{-Z_{1}}{Y_{1} Z_{M}-Y_{M} Z_{1}}
$$

A similar procedure can be used to obtain an expression for the right wall heat flux. It is

$$
q_{r_{w}}^{n+1}=\beta_{1} T_{1}^{n+1}+\beta_{2} T_{M}^{n+1}
$$

where

$$
\beta_{1}=\frac{-Y_{M}}{Y_{1} Z_{M}-Y_{M} Z_{1}}
$$

and

$$
\beta_{2}=\frac{Y_{1}}{Y_{1} Z_{M}-Y_{M} Z_{1}}
$$

The implicit form of the convective boundary conditions for the left and right wall heat flux are

$q_{\ell}^{n+1}=h_{\ell}\left(T_{1}^{n+1}-T_{B_{\ell}}^{n+1}\right)$

and

$$
q_{r_{w}}^{n+1}=h_{r}\left(R_{M}^{n+1}-T_{B_{r}}^{n+1}\right)
$$

Equations 4-13a. 4-14a, 4-15a, and 4-15b give four independent equations in terms of the four unknowns, $q_{e_{w}}, q_{r_{w}}, T_{\gamma}$, and $T_{M}$. These equations are used in the implicit steam generator solution that is developed in Section 8.

\subsection{Steady-State Procedure}

From necessity, the procedure for the solution of the steady-state conduction equation, when using convective fluid dependent flux boundary conditions is very similar to the transient solution.

However, for steady state, the field equations must be brought into balance without advancing time and with temporal derivatives equal to zero. The conduction equations at steady state are much simpler than the transient form, free of time constants, and should converge much more quickly. 
For the steady-state solution, the RELAP5 subroutine "ht1sst" is used with out modification. For calls to "ht1sst", the initial values of the source term ( $\int_{v} S d V$ of Equation 4-1) are available as initial conditions. For situations where the source integrals are nonzero, e.g., electrical heaters or nuclear cores, flux boundary conditions are used. However, for convective boundary conditions, the surface flux is a variant in terms of the fluid conditions and the conduction solution becomes an iterative procedure with the hydrodynamics and fluid state equations. 


\section{CONTROL AND TRIP SYSTEM MODELS}

The control system models in RELAP5 allow users to simulate typical plant control systems such as feedwater control and turbine valve modulation in models used to simulated transients. The control system models can also be used to evaluate any arbitrary algorithm using RELAP5 computed quantities as inputs. The output of these control systems can be monitored by trips, edited, or used to define characteristics of components within the system such as valve area, pump speed, or junction flow.

The trip model is used to monitor signal or parameter values and set a logical flag if a threshold value is reached. Trips are used to initiate actions once a desired condition has been satisfied. Typical uses include opening and/or closing valves on high or low pressure, turning pumps on or off, and scramming a reactor.

\subsection{Control Systems}

The control system models currently available in RELAP5 have two type of uses. The first is the "standard" use, in which the user constructs a control system by interconnecting the control blocks in a logical manner to define some plant controller or to perform an auxiliary calculation. The second use is through a generic set of controllers, called "self-initialization" controllers, used to force the transient solution to maintain the input value of a few parameters (such as cold leg temperature, loop flow, pump speed and secondary flow or pressure). The self-initialization controllers are not used or required for the DSSI method. The DSSI method solves the steady-state hydrodynamic balance equations. In doing so, the control system parameters are treated as fixed initial conditions. The control system can be included in the steady-state solution during Phase III.

\subsection{Trip System}

Only elapsed time trip signals (those that trip at time zero with no delay) are allowed during the steady-state solution. This is done to prevent nonconvergent oscillations that may be introduced by pressure and temperature trips being activated by early and possibly poor initial estimates of the trip signal parameters. 


\section{REACTOR KINETICS}

A point kinetics model is available as an option in RELAP5 to define the normalized reactor power. The power distribution is defined by the user initially and remains constant throughout the transient. Reactivity feedback can be modeled through a series of tables of reactivity versus moderator density and/or fuel temperature. In addition, reactivity can be contributed by any arbitrary function through the control system. A scram table can also be supplied to model control rod movement.

By definition, during steady-state operation, the net reactivity must be zero and the power should be time invariant. Currently, RELAP5 is run with null reactivity feedback quantities to maintain constant initial power in order to achieve steady-state conditions. Once the desired steady-state results are obtained by running the transient solution, the user must restart and supply the actual reactivity feedback tables along with the change cards to initiate the transient.

The initial power must also remain constant during the DSSI solution. The power shape and amplitude are provided as initial conditions and the point kinetics equations are not evaluated during the iteration process. However, after a converged set of steady-state initial thermal-hydraulic conditions are obtained, the initial reactivity is evaluated. This initial reactivity (both from feedback terms and explicit reactivity) is used to bias the reactivity at each time step in the transient so the net reactivity is measured as a change from time zero. In order to evaluate the initial bias reactivity, the reactivity initialization subroutine is called from the steady-state initialization driver after the thermal-hydraulic conditions have converged, thus, ensuring consistency between the steady-state thermal-hydraulic conditions and the reference feedback reactivities. Section 8 discusses the reactivity initialization procedure, relative to the DSSI solution scheme. 


\section{OVERALL SYSTEM ENERGY BALANCE}

Various models are available in the RELAP5 code to model energy addition or removal from control volumes. The typical sources of energy are nuclear or electrically heated cores. They are modeled by use of heat structures with internal power generation. Centrifugal pumps are also sources of energy addition through dissipation. In addition, local source terms in the volume energy equations due to friction are computed. In PWRs, the energy removed from the primary system via steam generators is modeled using heat conductors for the tubes with primary system fluid volumes on one side and secondary-side volumes on the other side. In BWRs, the energy is removed by an open flow system that consists of boundary conditions for feedwater inlet and steam outlet flows. Small amounts of energy can also be removed by the makeup and letdown systems or from environmental heat losses. On a local basis, the steady-state energy equations are solved for each volume. However, for a consistent set of steady-state conditions, the energy removal and addition rates must be equal for each flowing network, or hydrodynamic system. In order to ensure this, special balancing techniques have been implemented. They are discussed in this section.

\subsection{Flow Network Identification}

For steady-state conditions within a closed flowing network, or system in RELAP5 terminology, the energy addition and removal rates must be equal. A flowing network is defined as a set of volumes that are interconnected by active flow paths. As an example, a PWR primary side is a closed flowing network. Any branches off of the primary that are connected by a closed valve are considered part of the system since they may become active if the value is opened. Steam generator primary and secondary sides are generally separate hydrodynamic systems connected via heat structures but not flow paths. Therefore, the steam generator secondary side and associated steam line volumes are generally considered to be a separate flow network. Each flow network must be identified to ensure that the energy sources and sinks are equal for that network. In most instances, some adjustments are required to obtain an energy balance.

The RELAP5 user has a great deal of flexibility related to nodalization, component numbering, and placement of heat sources and sinks. Logic has been incorporated into the code to identify the energy sources and sinks that belong to each network. This information is used by the steady-state initialization logic to sum all the flow network sources and sinks and make the appropriate adjustments for an overall energy balance. The specific adjustments are described in the following subsections.

\subsection{PWR System Energy Balance}

Typical PWR models contain at least two active flow networks, the RCS and the steam generator secondary side. The RCS is made up of the reactor core, the vessel, the cold and hot legs, and steam generator tubes. The RCS energy sources generally include the reactor core and the coolant pumps. The initial core power is considered constant for steady-state initialization with the coolant heating rate from the core conductors equal to the initial power. The energy added by the pumps is a function of the initial pump speed, the flow through the pump, and the fluid density. Also, the effects of friction are included in the volume energy equations via dissipation source terms. 
The majority of the energy added to reactor coolant is removed by the steam generator. A smaller amount of energy may also be removed from the system by environmental heat loss or through letdown and makeup systems. The net system heat rate or power is given by

$$
Q_{\text {sys }}=\sum Q_{\text {core }}+\sum Q_{\text {htr }}+\sum Q_{\text {pmp }}+\sum Q_{\text {env }}+\sum w_{m u} h_{m u}-\sum w_{\ell d} h_{l d}+\sum Q_{\text {dis }}
$$

where the summations indicate that all related source terms within the system are included in the net heat rate.

The individual terms are defined below.

$\mathrm{Q}_{\text {core }}=$ nuclear heat generation, $\mathrm{J} / \mathrm{s}$

$\mathrm{Q}_{\mathrm{htr}}=$ electrical or specified heating (cooling), J/s

$Q_{p m p}=$ pump dissipation, $\mathrm{J} / \mathrm{s}$

$\mathrm{Q}_{\mathrm{env}}=$ environmental heat losses, $\mathrm{J} / \mathrm{s}$

$\mathrm{Q}_{\text {dis }}=$ viscous dissipation, $\mathrm{J} / \mathrm{s}$

$\mathrm{w}_{\text {mu }}=$ makeup flow rate, $\mathrm{kg} / \mathrm{s}$

$\mathrm{h}_{\mathrm{mu}}=$ makeup enthalpy, $\mathrm{J} / \mathrm{kg}$

$\mathrm{w}_{\ell \mathrm{d}}=$ letdown flow rate, $\mathrm{kg} / \mathrm{s}$

$\mathrm{h}_{\ell \mathrm{d}}=$ letdown enthalpy, $\mathrm{J} / \mathrm{kg}$

At steady-state conditions, the steam generator(s) must remove the net system power. Thus,

$Q_{\text {sys }}=\sum^{s g} \sum^{\text {hs }} Q_{s g}$

and

$\mathrm{Q}_{\mathrm{sg}}=\quad$ system generator heat transfer rate, $\mathrm{J} / \mathrm{s}$

where the outer summation is over all steam generators and the inner summation is over all heat structures within a given steam generator.

A typical PWR system is shown in Figure 7.1 with the various contributions to the net system power. The core and heater components are known initial conditions at steady state. Both the pump and viscous dissipation terms are relatively small compared with the nominal core power. Although they are dependent on the fluid conditions and mass flow rate, their overall effect on the net system power is small enough that they can be evaluated using previous iterate values without degrading the convergence characteristics of the overall energy balance.

Steady-state heat losses to the environment may be significant and are not constant. They are dependent on the temperature gradient between the system and environment, as well as the 


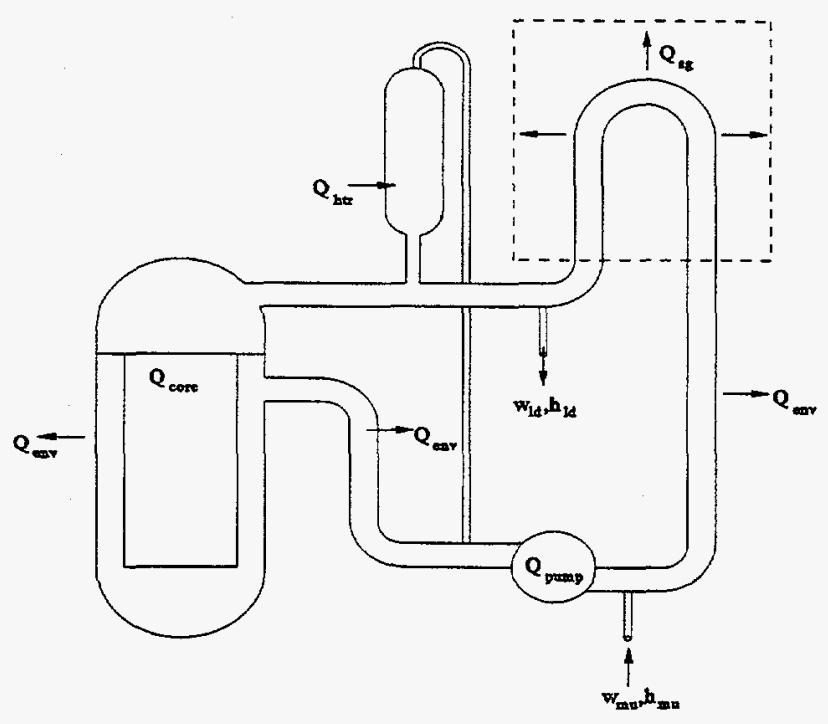

Figure 7.1 Typical PWR primary system schematic

primary flow conditions. Due to the coupling between the heat loss and system temperature, this temperature dependence needs to be accounted for in the overall energy balance. An implicit scheme consistent with the solution of the system governing balance equations is presented below.

\subsubsection{Environmental Heat Losses}

Heat losses from a thermal hydraulic system to the environment are simulated using the heat structure model. Using this approach, one of the bounding temperatures is specified as a constant or time-dependent temperature history (the environment), while the bounding temperature for the other surface is determined by the thermodynamic conditions within a hydrodynamic system. These losses are referred to as environmental heat losses and can include heat losses from the vessel and piping (if modeled).

A simplified illustration of a heat structure, modeling environmental heat losses, is shown in Figure 7.2. The hydraulic system is shown on the left surface, and the environment is on the right. The magnitude of the heat loss is determined by the temperature gradient between the system and environment. While the environmental boundary temperature is fixed at steady state, the corresponding system temperature can change, depending on the modeling detail, initial conditions, and variations from one iteration to the next. 


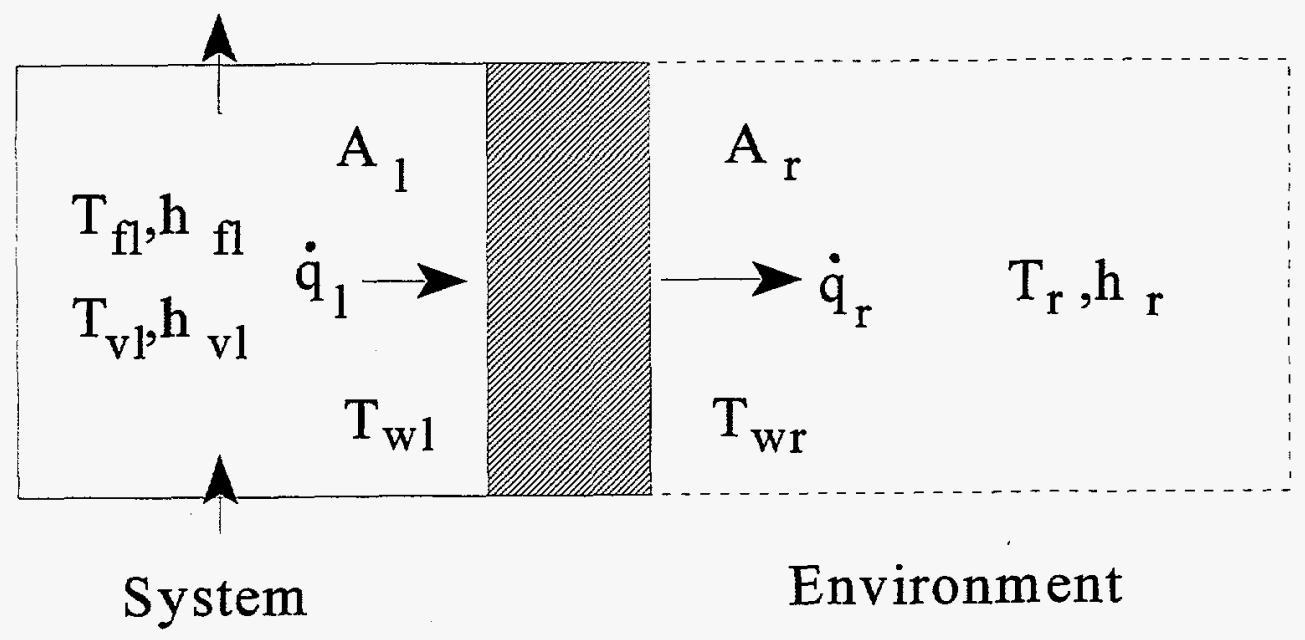

Figure 7.2 Typical environmental loss heat structure

The environmental losses can be written as

$q_{l}=h_{f_{p}}\left(T_{w_{p}}-T_{f_{f}}\right)+h_{v_{p}}\left(T_{w_{f}}-T_{v_{f}}\right)$

which defines the wall heat flux on the left surface. The corresponding wall heat flux on the right surface is

$q_{r}=h_{r}\left(T_{w_{s}}-T_{r}\right)$

The environmental heat losses can be written as

$Q_{\text {env }}=A_{t} q_{q}=A_{i}\left[h_{8} T_{w_{0}}-\left(h_{t} T_{f_{g}}+h_{v_{g}} T_{v_{0}}\right)\right]$

where

$h_{\ell}=h_{f_{g}}+h_{v_{\ell}}$

These losses are written at the new steady-state iteration level by using a first-order Taylor series expansion in terms of the dependent variables as follows: 


$$
\begin{aligned}
Q_{e n v}^{k+1} & =Q_{e n v}^{k}+A_{\ell}\left\{\left[h_{\ell}\right) \frac{\partial T_{w_{f}}}{\partial P}-h_{f_{f}} \frac{\partial T_{f_{g}}}{\partial P}-h_{v_{f}} \frac{\partial T_{v_{f}}}{\partial P}\right] \Delta P^{k+1} \\
& \left.+\left[h_{\ell} \frac{\partial T_{w_{f}}}{\partial u_{v}}-h_{v_{l}} \frac{\partial T_{v_{f}}}{\partial u_{v}}\right] \Delta u_{v}^{k-1}+\left[h_{\ell} \frac{\partial T_{w_{f}}}{\partial u_{f}}-h_{f_{f}} \frac{\partial T_{f_{f}}}{\partial u_{f}}\right] \Delta u_{f}^{k+1}\right\}
\end{aligned}
$$

where the partial derivatives of the phasic temperatures with respect to pressure and phasic energy are obtained from the EOS. The wall temperature derivatives are developed below.

General expressions for the left and right wall heat fluxes were developed for the 1-D conductor solution in Section 4. The left wall heat flux is given by

$$
q_{l}=\alpha_{1} T_{w_{p}}+\alpha_{2} T_{w_{r}}+\alpha_{3}
$$

where $\alpha_{1}$ and $\alpha_{2}$ are functions of the geometry and conductivity and $\alpha_{3}$ is due to internal heat generation (generally zero). They are defined by Equations 4-13a and 4-13b.

The right wall heat flux is given by

$$
q_{r}=\beta_{1} T_{w_{6}}+\beta_{2} T_{w_{r}}+\beta_{3}
$$

where $\beta_{1}$ and $\beta_{2}$ are also functions of geometry and conductivity and $\beta_{3}$ is due to internal heat generation. They are defined by Equations 4-14b and 4-14c.

Equation 7-7 is substituted into Equation 7-3 and then rearranged to give an expression for the left wall surface temperature as a function of the right wall surface temperature and the left boundary temperature. A similar combination of Equations 7-8 and 7-4 produces an expression for the right wall surface temperature as a function of the left wall temperature and right boundary temperatures. These equations are then combined and rearranged to give expressions for the left wall surface temperature as functions of the boundary volume fluid temperatures. The left temperature is given by

$$
\left.T_{w_{\ell}}=\delta_{l}\left[h_{f_{p}} T_{f_{l}}+h_{v_{p}} T_{v_{p}}\right)-V_{\ell} h_{t} T_{r}\right]
$$

where

$$
\delta_{l}=\frac{-\left(\beta_{2}-h_{r}\right)}{\left(\alpha_{1}-h_{l}\right)\left(\beta_{2}-h_{r}\right)-\alpha_{2} \beta_{1}}
$$


and

$V_{l}=\frac{\alpha_{2}}{\left(\beta_{2}-h_{r}\right)}$

This allows the left wall surface temperature to be evaluated from the liquid and vapor temperatures for the left boundary volume, since the temperature and heat transfer coefficient for the environment are known from user specifications. Assuming that approximate values of the wall to liquid and vapor heat transfer coefficients are known, the partial derivatives of the left wall surface temperature with respect to the pressure and phasic internal energies are obtained from Equation 79a. The necessary derivatives are given by

$$
\begin{aligned}
& \frac{\partial T_{w_{p}}}{\partial P}=\delta_{\ell}\left(h_{f_{f}} \frac{\partial T_{f_{f}}}{\partial P}+h_{v_{s}} \frac{\partial T_{v_{f}}}{\partial P}\right) \\
& \frac{\partial T_{w_{p}}}{\partial U_{f}}=\delta_{\ell} h_{f_{p}} \frac{\partial T_{f_{f}}}{\partial u_{f}}
\end{aligned}
$$

and

$$
\frac{\partial T_{w_{p}}}{\partial u_{g}}=\delta_{l} h_{v_{\rho}} \frac{\partial T_{v_{\rho}}}{\partial u_{v}}
$$

Given Equations 7-6 and 7-10, the environmental heat loss terms can be treated implicitly in the evaluation of the net system heating rate. They have not been included in the Phase II work, but will be considered during Phase III.

\subsubsection{Steam Generators}

Steam generators are used to transfer energy from the RCS to a secondary system where steam is produced for the turbine generator. A steam generator is modeled in RELAP5 by using two surface heat conductors between adjacent hydrodynamic systems, e.g., the RCS and secondary sides. Generally, a number of two-surface heat conductors and associated fluid volumes comprise a RELAP5 steam generator model. As a result of the flexibility that this modeling approach provides, both $U$-tube and once-through steam generators can be modeled. Figures 7.3 and 7.4 are simple schematics of $U$-tube and once-through steam generators as they might be modeled with RELAP5. It is also possible to model multiple steam generators.

The net system heat rate given by Equation 7-1 must be removed by the steam generators included in a model, whether there is one or four. For a given steam generator, the required heat removal rate is then 


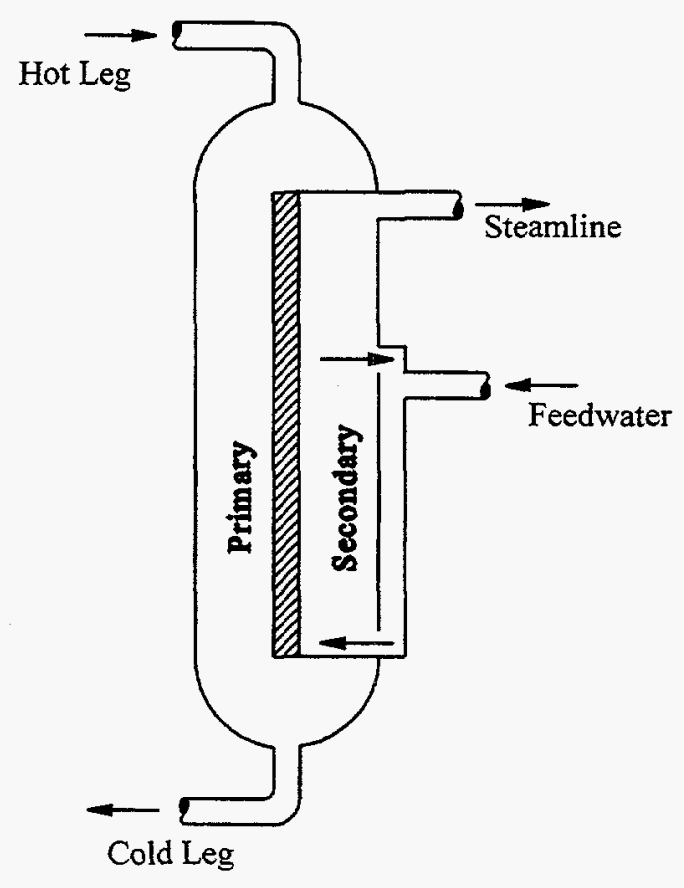

Figure 7.3 Typical once-through steam generator

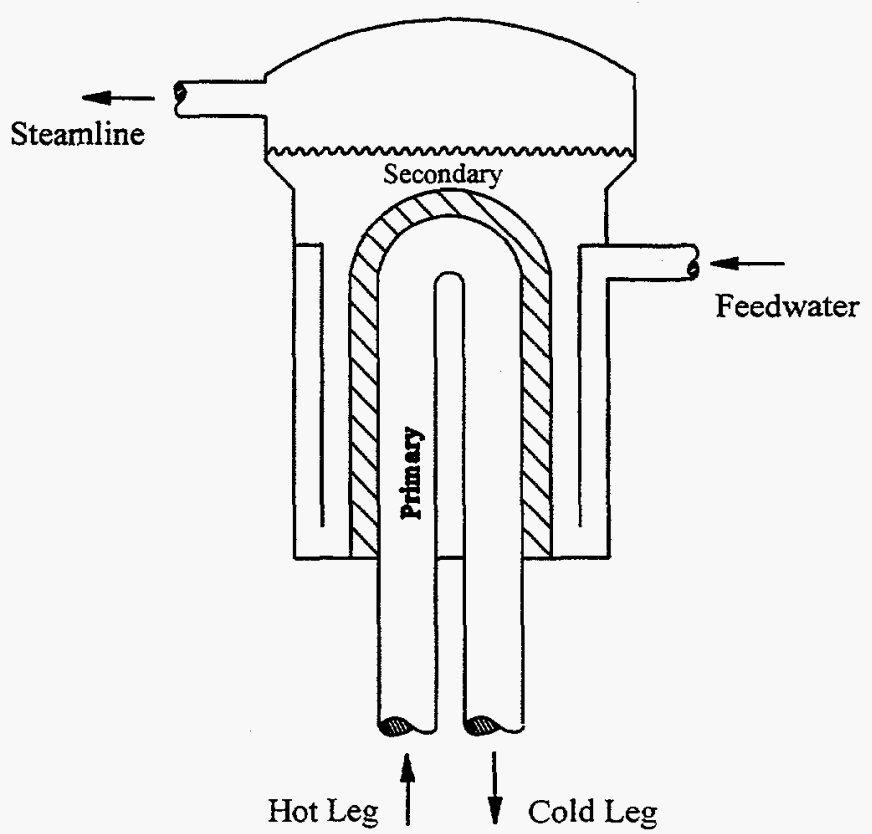

Figure 7.4 Typical U-tube steam generator 
$Q_{s g}=P_{f} Q_{s y s}$

where

$\sum P_{f}=1$

Four governing equations define the heat transfer and conduction through a two-surface conductor. By limiting the primary side to single-phase liquid flow, the first equation is given by the convective heat transfer on the left surface

$q_{l}=h_{l}\left(T_{w_{0}}-T_{f_{l}}\right)$

For the right surface, the convective boundary condition is written as

$\left.q_{r}=h_{r} T_{w_{r}}-h_{f_{r}} T_{f_{r}}+h_{v_{r}} T_{v_{r}}\right)$

When subcooled boiling is predicted, the liquid portion of Equation 7-13 is actually comprised of a macroscopic heat transfer component times the liquid temperature and a microscopic component times the saturation temperature. The heat conduction and energy balance equations, Equations $7-7$ and 7-8, provide the necessary information to close the equation set, assuming that the temperatures in the bounding fluid volumes are known. In reality, the temperatures are not known and they are dependent on the heat transfer in neighboring nodes within a steam generator.

The base steady-state (and transient) hydrodynamic solution schemes assume that the primary and secondary systems are independent. This is used to reduce the computer time and storage requirements needed to solve a complete system model by solving several smaller problems. Upon examination of the energy equations, Equations 3-18 and 3-19, it is apparent that the two systems should be coupled through the wall heat flux values that appear in the energy equation source terms.

The transient solution scheme treats the wall heat flux explicitly by evaluating it using old time level values. This is acceptable for the transient solution since the temperatures do not change rapidly in most transients of interest. It has been demonstrated that this coupling is very important in steadystate initialization schemes (Ref. 5). A steam generator initialization scheme has been implemented in the RETRAN-03 computer code that couples the thermal-hydraulic balance equations for the primary and secondary system through implicit wall heat flux boundary conditions, the heat conduction equation, and an energy balance equations. If a similar scheme were implemented for RELAP5, there would be 16 coupled equations to solve for each heat conductor if each conductor was connected to a unique volume on both the primary and secondary sides, such as a oncethrough steam generator. The number of equations is reduced somewhat for $U$-tube steam generators since a single secondary volume can be connected to several conductors. By assuming that the primary is single-phase liquid only, the number of equations per conductor is reduced to 13 . A solution based on this full system of coupled equations would provide the most versatile and 
robust scheme, but it is beyond the scope of the current work. Consequently, a simplified scheme has been developed that still accounts for the coupling between the primary and secondary.

The heat removal from the steam generator is specified by Equation 7-11. A simple energy balance gives the enthalpy at the outlet of the primary side as

$\left(u_{f}\right)_{\text {out }}=\frac{\left(u_{f}+P / \rho_{f}\right)_{\text {in }}\left(\rho_{f} v_{f} A\right)_{\text {in }}+P Q_{f} Q_{\text {sys }}}{\left(\rho_{f} v_{f} A\right)_{\text {out }}}$

Given this, the primary system can be initialized, except for the nodes within the steam generator. Without some additional information, there is not a unique solution for the steam generator temperature (or energy) distribution.

This additional information is provided by coupling the heat transfer and conduction governing equations with the fluid flow equations. A scheme that provides some limited coupling between the primary and secondary systems is used as an intermediate or coupling step. Estimates of the fluid and wall temperatures, and resulting heat flux values obtained from the coupling step are used in the explicit evaluation of the flux boundary conditions for the separate uncoupled solutions.

The primary side of a steam generator is assumed to be single-phase liquid at steady state. For these conditions, the vapor continuity and energy equations, and the difference momentum equations are omitted. The sum continuity equation is satisfied through the flow specification. Pressure changes due to temperature fluctuations will be negligible. Consequently, the sum momentum equation can be neglected on the primary side. The liquid energy equation is the only balance equation that is necessary. Equation 3-19 gives the steady-state form of the liquid energy equation. For the coupling scheme, the liquid energy equation is written in terms of the liquid temperature by substituting $c_{p_{\ell}} T_{f_{\ell}}$ for $\left(u_{\ell}+P / \rho_{\ell}\right)$, substituting unity for the liquid void fraction, and dropping the mass transfer terms to give

$$
\sum_{\text {in-out }} w c_{p_{f}} T_{f_{l}}+A_{l} q_{l}=0
$$

This provides one liquid energy equation for each primary-side node that resides in the steam generator. The resulting set of coupled liquid energy equations provides the basis for determining the liquid temperature for each node, where Equation 7-12 defines the wall heat flux in terms of the left wall surface temperature and liquid temperature.

Equation 7-9 was developed for heat conductors that are used to model environmental heat losses where the boundary temperature is known. A similar equation can be developed for two-sided conductors were both boundary temperatures are unknown. The main difference is due to a different, although equivalent, way of writing the wall heat flux. This is accomplished by using Equations 7-12 and 7-13 rather than Equations $7-3$ and 7-4. The result is simplified for use in the coupling scheme, since the primary system is limited to single-phase liquid flow. This allows the vapor terms to be dropped, giving the following equation for the left wall surface temperature 
$T_{w_{l}}=\delta_{l}\left[h_{\ell} T_{f_{l}}-Y_{l} h_{R} T_{R}\right]$

Substituting Equation 7-16 into Equation 7-12 gives an equation for the left wall heat flux as a function of the left surface boundary node liquid temperature and the secondary side temperature $T_{R}$. Note that a single secondary-side heat transfer coefficient $h_{R}$ is used. The rational used to determine their values is discussed below. The left wall heat flux is

$q_{l}=h_{l}\left[\left(h_{l} \delta_{l}-1\right) T_{f_{l}}-\delta_{l} Y_{l} h_{R} T_{R}\right]$

The secondary side of a steam generator will in general be two phase. A rigorous solution scheme would utilize the full six-equation set of balance equations and compute the void, pressure, vapor velocity, and liquid and vapor temperatures in addition to the primary temperatures for each node.

A less rigorous solution has been implemented. In fact, the fluid flow balance equations are not used in the coupling step. An assumption is made that a single reference temperature can be used for the secondary side. The following discussion justifies this argument.

The six-equation solution provides both liquid and vapor temperatures that drive the wall and interfacial heat transfer processes. Although the separate liquid and vapor temperatures will not be in complete thermal equilibrium, the interfacial heat transfer process drives both temperatures toward the saturation temperature. As a result, the saturation temperature should provide, a reasonable reference temperature for two-phase situations that will be encountered for U-tube steam generators.

The saturation temperature will not be a reasonable reference temperature for OTSGs where the inlet to the secondary side is subcooled, the exit is superheated, and only the middle region is two phase. A single-phase temperature, say the inlet liquid temperature, will be a better reference temperature. The secondary-side reference temperature and its use is discussed in more detail latter, but the overall system energy balance must be discussed first.

An overall balance equation for the steam generator heat removal rate is written by summing the right surface wall heat transfer rates and recognizing that the sum must equal the designated steam generator power. This is written as

$\sum^{s g} A_{r} Q_{r}-P_{f} Q_{s y s}=0$

An equation for the right wall temperature in terms of the primary-side liquid and secondary-side reference temperatures is obtained by using a procedure similar to the one used to obtain Equation 7-16. It is

$$
T_{w_{r}}=\delta_{r}\left(\gamma_{r} h_{l} T_{f_{i}}-h_{R} T_{R}\right)
$$


where

$$
\delta_{r}=\frac{\left(\alpha_{1}-h_{l}\right)}{\left(\alpha_{1}-h_{l}\right)\left(\beta_{2}-h_{r}\right)-\alpha_{2} \beta_{1}}
$$

and

$Y_{r}=\frac{\beta_{1}}{\left(\alpha_{1}-h_{\ell}\right)}$

Substituting Equations 7-19a into Equation 7-13a gives an equation for the right surface wall heat flux as a function of left surface boundary volume temperature and the secondary temperature. It is

$q_{r}=h_{r} \delta_{r} Y_{r} h_{\ell} T_{f_{p}}-h_{R}\left(h_{r} \delta_{r}+1\right) T_{R}$

It is necessary to define the reference heat transfer coefficient, $h_{R}$, and reference temperature, $T_{R}$. The wall heat flux is defined by Equation 7-13. For the steady-state steam generator coupling scheme, this flux component is written as

$q_{r}=h_{R}\left(T_{w}-T_{R}\right)$

The reference heat transfer coefficient, $h_{R}$ is then

$h_{R}=\frac{q_{r}}{T_{w}-T_{R}}$

if the pressure is adjusted as a means of satisfying the overall energy balance.

For the option where the inlet liquid internal energy is adjusted as a means of satisfying the overall energy balance, the assumption is made that a uniform change in the energy convection occurs through out the flow path. This model is recommended for use with OTSG models. The change in inlet enthalpy will affect the temperatures in the single-phase (liquid and vapor) volumes. It is assumed that the two-phase volumes are at the saturation temperature which is not dependent on the inlet enthalpy.

Changing the inlet enthalpy may cause the boundaries between single-phase and two-phase regions to move, but this effect will only be accounted for through the explicit solution where the heat transfer coefficients are updated.

The reference heat transfer coefficients for the subcooled liquid and superheated regions are given by 
$h_{R}=\frac{q_{r}}{T_{w_{r}}-T_{f_{r}}}$

and

$h_{R}=\frac{q_{r}}{T_{w_{r}}-T_{v_{r}}}$

respectively. In all cases $h_{R}$ is obtained from the explicit heat transfer evaluation.

The reference temperature, $T_{R}$, used in Equation 7-21 will be either the local saturation temperature or the single-phase liquid or vapor temperatures as specified by user input.

As the wall heat fluxes are defined, they are functions of the local reference boundary volume temperature on the right side. This means that there is effectively one unknown temperature for each secondary volume, but there is only one balance equation, Equation 7-18. This disparity between the number of equations and unknowns is eliminated by assuming that the new value of the reference temperature can be obtained by using a first-order Taylor series expansion in terms of the reference temperature and then applying the change in the reference temperature to obtain an overall energy balance, e.g., pressure or inlet enthalpy. Any change in the reference pressure will be observed nearly uniformly by all volumes. Similarly, a change in the liquid enthalpy will be propagated through all volumes as a uniform change to the internal energy flow product. This assumption reduces the number of unknowns to a single value of either pressure or internal energy change.

Equations $7-15,7-17,7-18$, and $7-20$ represent $3 n+1$ equations in terms of $n$ unknown left boundary volume liquid temperatures, $n$ left and right surface heat fluxes, and one reference temperature change. These simplified balance equations provide the basis for the semi-implicit coupling scheme. Direct substitution of the appropriate wall heat flux equations into Equations 7-15 and $7-18$ reduces the number of unknowns and equations to $n+1$.

If $F$ is considered the system of $n+1$ equations, a new iterate or coupling step estimate of the primary-side liquid temperatures and reference parameter change are determined from a first-order Taylor series expansion

$F^{k+1}=F^{k}+\frac{\partial F}{\partial Y} \Delta Y$

where $F$ is comprised of the $n$ primary liquid temperature equations and the single overall energy balance equation 


$$
F=\left[\begin{array}{c}
F_{T_{1}} \\
\cdot \\
F_{T_{n}} \\
F_{B}
\end{array}\right]
$$

The vector of dependent variables, $Y$, is

$$
Y=\left[T_{f_{f_{1}}}, T_{f_{f_{2}}, \ldots} \ldots T_{f_{f_{n}}}, R\right]^{T}
$$

and contains the $n$ primary liquid temperatures and the single reference balance parameter $\mathrm{R}$.

The individual primary liquid temperature equations and overall balance equation in functional form are

$$
F_{T}=\left(w c_{p_{\ell}}\right)_{j-1} T_{\ell_{i-1}}-\left(w c_{p_{\ell}}\right)_{j} T_{\ell_{i}}+A_{\ell} q_{\ell}=0
$$

and

$$
F_{B}=\sum^{s g} A_{r} q_{r}-P_{f} Q_{\text {sys }}=0
$$

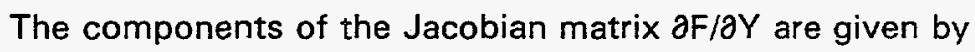

$$
\begin{aligned}
& \frac{\partial F_{T}}{\partial T_{f_{f}}}=\left(w c_{p_{\ell} f_{-1}}\right. \\
& \frac{\partial F_{T}}{\partial T_{f_{\ell}}}=-\left(w c_{\left.p_{\ell}\right)_{j}}+A_{\ell} \frac{\partial q_{\ell}}{\partial T_{f_{\ell}}}\right. \\
& \frac{\partial F_{T}}{\partial R}=A_{l} \frac{\partial q_{\ell}}{\partial T_{R}} \frac{\partial T_{R}}{\partial R} \\
& \frac{\partial F_{B}}{\partial T_{f_{l}}}=A_{r} \frac{\partial q_{r}}{\partial T_{f_{f}}}
\end{aligned}
$$


and

$$
\frac{\partial F_{B}}{\partial R}=A_{r} \frac{\partial q_{r}}{\partial T_{R}} \frac{\partial T_{R}}{\partial R}
$$

Equation $7-17$ is used to obtain the necessary partial derivatives of the left wall heat flux. They are

$$
\frac{\partial q_{\ell}}{\partial T_{f_{\ell}}}=h_{\ell}\left(h_{\ell} \delta_{\ell}-1\right)
$$

and

$\frac{\partial \hat{q}_{\ell}}{\partial T_{R}}=-h_{\ell} \delta_{\ell} Y_{\ell} h_{R}$

The necessary partial derivatives of the right wall heat flux are obtained, as follows, from Equation 7-22

$$
\frac{\partial q_{r}}{\partial T_{f_{\ell}}}=h_{r} \delta_{r} y_{r} h_{\ell}
$$

and

$$
\frac{\partial q_{r}}{\partial T_{R}}=-h_{R}\left(h_{r} \delta_{r}+1\right)
$$

The partial derivative of $T_{R}$ with respect to the reference balance parameter $R$ depends on the balance scheme specified through user input. For the pressure adjustment scheme where $R=P$ and $T_{R}$ is the local saturation temperature, thus

$$
\frac{\partial T_{R}}{\partial R}=\frac{\partial T_{\text {sat }}(P)}{\partial P}
$$

If the inlet liquid enthalpy is adjusted, $R=\left(h_{f}\right)_{i n}$. The assumption regarding the uniform enthalpy convection implies

$$
w \Delta h=w_{\text {in }}\left(\Delta h_{f}\right)_{h n}
$$


which gives

$\Delta h=\frac{w_{\text {in }}}{w} \Delta h_{f}$

The "in" subscript was dropped for simplification. The necessary partial derivative of the reference temperature with respect to the inlet enthalpy is then

$$
\begin{array}{ll}
\frac{\partial T_{R}}{\partial R}=\frac{\partial T_{f}}{\partial h_{f}} \frac{w_{\text {in }}}{w} & \text { if } a_{g}=0 \\
\frac{\partial T_{R}}{\partial R}=0 & \text { if } 0<a_{g}<1
\end{array}
$$

and

$$
\left.\frac{\partial T_{R}}{\partial R}=\frac{\partial T_{v}}{\partial h_{v}} \frac{w_{\text {in }}}{w} \quad \text { if } a_{g}=1\right)
$$

The temperature derivatives shown in Equations 7-29 and 7-31 are obtained from the EOS.

A Gaussian elimination scheme is used to solve the system of equations for primary-side liquid temperatures and the reference parameter change. The reference temperatures are then obtained from the following

$$
\tilde{T}_{R}^{k+1}=T_{R}^{k}+\frac{\partial T_{f}}{\partial R} \Delta R^{k+1}
$$

If the pressure adjustment is used, the secondary phasic temperatures are estimated as

$$
\tilde{\mathrm{T}}_{v_{r}}^{k+1}=\tilde{T}_{\text {sat }}^{k+1}+\left(T_{v_{r}}^{k}-T_{\text {sat }}^{k}\right)
$$

and

$$
\tilde{\mathrm{T}}_{f_{r}}^{k+1}=\tilde{\mathrm{T}}_{\text {sat }}^{k+1}+\left(T_{f_{r}}^{k}-T_{\text {sat }}^{k}\right)
$$


For the case where the inlet liquid enthalpy is adjusted, the liquid phasic temperatures are given by

$$
\tilde{T}_{f_{r}}^{k+1}=T_{f_{f}}^{k}+\frac{\partial T_{f}}{\partial h_{f}} \frac{w_{\text {in }}}{w} \Delta h_{f}^{k+1}
$$

The temperatures in the two-phase region are unchanged, and the vapor temperatures are obtained from

$$
\tilde{T}_{v_{r}}^{k+1}=T_{v_{r}}{ }^{k}+\frac{\partial T_{v}}{\partial h_{v}} \frac{w_{\text {in }}}{w} \Delta h_{f}{ }^{k+1}
$$

The updated temperatures then provide estimates of the boundary temperatures for the explicit heat conduction solution. As the steam generator overall energy balance is approached, changes to the boundary temperatures approach zero.

\subsubsection{Open System Energy Balance}

The energy transferred from the RCS to the secondary must also be removed from the secondary. For most LWR system analyses, it is not practical to model the complete balance of plant. Consequently, secondary energy removal is generally modeled with an open flow system consisting of flow boundary conditions. The feedwater is typically modeled with a time-dependent junction downstream of a time-dependent volume where the fluid conditions are specified. The steam line is generally terminated at a pressure boundary defined by a time-dependent volume.

The overall energy balance scheme described in the previous section ensures that the net heat generated in a system is transferred to the secondary side of a steam generator (or steam generators). It does not guarantee that the heat transferred to the secondary side is removed. This balance is the topic of the following.

A steady-state energy balance for an open flow system is obtained when

$$
\begin{aligned}
P_{f} Q_{s y s} & \left.+\sum Q_{h t r}+\sum Q_{p m p}+\sum Q_{e n v}+w_{f w} h_{f w}+\Delta h_{f w}\right) \\
& +\sum w_{m u} h_{m u}-w_{s l} h_{s l}-\sum w_{l d} h_{l d}+\sum Q_{d i s}=0
\end{aligned}
$$

If the inlet liquid enthalpy adjustment (OTSGs) discussed in the previous section is used, the outlet enthalpy will vary and Equation 7-36 will be satisfied. For a U-tube steam generator, the outlet enthalpy is fixed at, or very near, the enthalpy of saturated steam by the separator component model. With the exit enthalpy constant, Equation 7-36 may not be satisfied. In order to guarantee an energy balance, the inlet enthalpy will require adjustment. The inlet enthalpy change is obtained by rearranging Equation 7-36 to give 


$$
\begin{aligned}
\Delta h_{\mathrm{fw}} & =\frac{-1}{w_{f w}}\left[P_{f} Q_{s y s}+\sum Q_{h t r}+\sum Q_{p m p}+\sum Q_{e n v}+w_{f w} h_{f w}\right. \\
& \left.+\sum w_{m u} h_{m u}-w_{s !} h_{s l}-\sum w_{l d} h_{l d}+\sum Q_{d i s s}\right]
\end{aligned}
$$

The enthalpy change is then used to update the enthalpy in the time-dependent volume associated with the feedwater junction.

\subsection{BWR System Energy Balance}

Typical BWR models are comprised of an open flow system model of the primary system. For this configuration the energy balance requirements are similar to the secondary side of a U-tube steam generator model using a separator component. By using the separator component, the exit enthalpy is limited to saturated vapor (or nearly so). With the exit enthalpy fixed, the feedwater enthalpy must be adjusted to satisfy the overall energy balance, and ensure that the net system power is removed. This is true if

$$
w_{f w}\left(h_{f w}+\Delta h_{f w}\right)-w_{f_{s l}} h_{s l}+w_{v_{s l}} h_{s l}+Q_{s y s}=0
$$

The feedwater is assumed to be single-phase liquid, but the steam line can be two phase. The net system power is determined from Equation 7-1 and the steam line enthalpies are known approximately from the separator model. This establishes the required feedwater enthalpy change as

$$
\Delta h_{f w}=\frac{w_{f_{s l}} h_{s l}+w_{v_{s l}} h_{s l}-Q_{s y s}-w_{f w} h_{f w}}{w_{f w}}
$$

The time-dependent volume enthalpy is adjusted by the value determined using Equation 7-39. 


\section{IMPLEMENTATION}

This section describes the methods used to implement the DSSI solution scheme into the RELAP5 computer code. Three functional areas comprise the necessary source code modifications. They include a subroutine to read the new input data, others that use the input data to initialize the required variables, and finally those that perform the steady-state solution and test for convergence.

One development goal, in addition to developing a robust steady-state initialization option, was to implement the DSSI scheme while requiring no changes to existing input models and only minimal changes to the base RELAP5 source code. This goal has been achieved. A small set of input data is used to supplement a base RELAP5 input deck and specify the desired steady-state initial conditions. Most of the code modifications required for the DSSI module are contained in new standalone subroutines. In a few instances, existing RELAP5 subroutines required modification. These were generally necessary to by-pass transient solution specific coding such as time weighted smoothing of constitutive models. In general, changes to the base RELAP5 source code were kept to a minimum.

New subroutines used to read the supplemental steady-state input data and to initialize dynamic storage arrays and variables were written. A new driver subroutine for the DSSI scheme was written which parallels the transient solution subroutine "tran". This driver utilizes a combination of existing RELAP5 subroutines and new subroutines that iteratively solve the steady-state form of the governing balance equations. Each steady-state iteration is analogous to a transient time-step advancement.

The following sections provide an overview of the implementation of the DSSI program option. A discussion is given for the top level logic used to direct the program flow for the input processing, data initialization, and the DSSI solution. It precedes individual sections for each of the three functional areas.

\subsection{Program Flow Overview}

The main program "RELAP5" provides overall flow control for the program. Because of the modular design of the RELAP5 code, only minor modifications were required to implement the DSSI program option. These modifications consist of adding a call to the DSSI module "ssadvc" as shown in Figure 8-1. The flow control variable "iroute" is used to direct the program flow. It is initialized according to the problem type and option data that are processed by subroutine "inputd". A value of 6 is used to designate the DSSI option. Note that the new DSSI module "ssadvc" is outlined with a double line, while RELAP5 modules have a single line.

Additional source code modifications were made to subroutine "inputd". They are discussed in the following section. 

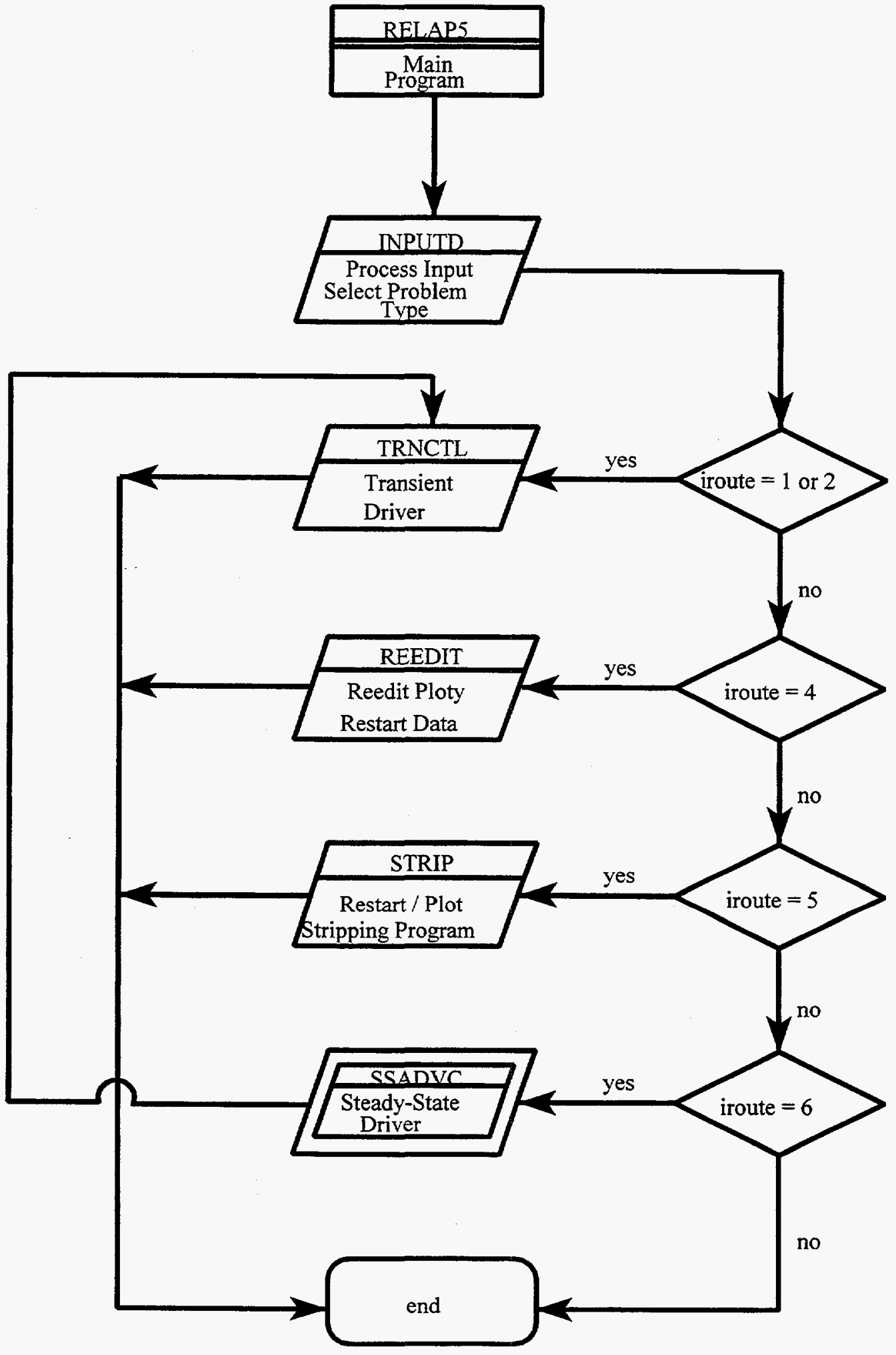

Figure 8.1 Main program flow 


\subsection{Input Data}

A partial overview of subroutine "inputd" is illustrated in Figure 8-2. It provides the flow control for reading input data and initializing arrays and variables. Appendix $A$ gives specific details regarding the input data and associated card numbers for the DSSI option.

One of the first tasks performed when RELAP5 is executed is to process the free form input data. This is accomplished by subroutine "rcards". After subroutine "rcards" has completed its task, various problem control data cards are processed. Card 100 is read to determine the type of problem that will be run and the associated options. The code was modified to allow a new problem option so users can request the DSSI solution. Word 2 on Card 100 defines the problem option that will be used. When it is supplied as "state", variable "iroute" is set to 6 . It is then used to direct the program flow to the DSSI routines.

The input data required for the new program option is then processed by subroutine "rnewp". Figure 8-3 gives a partial overview of subroutine "rnewp", which also shows calls to DSSI subroutines "isstat" and "rsstat". The base RELAP5 input deck is read by subroutines "rtsc" through "rconvr" and the input data for the DSSI option is read by subroutine "rsstat". With the exception of Card 100, all of the data cards given in Appendix A are read in subroutine "rsstat". The DSSI data cards and their use are summarized in Table 8-1.

Table 8.1 DSSI input data card summary

Card Numbers

Description

100

148

150-169

170-189

190-199
Problem Type and Options (Revised)

Steady-State Convergence Criteria

Volume Initial Conditions

Junction Initial Conditions

Steam Generator and Feedwater System

Descriptions

After reading the DSSI input cards, processing continues with the data initialization routines. The DSSI initialization routine is summarized in the following section.

\subsection{Initialization}

As shown in Figure 8-3, initialization subroutines "impen1" through "iusvrv" are used to initialize base models. Subroutine "isstat" performs the initialization necessary for the DSSI option. The 


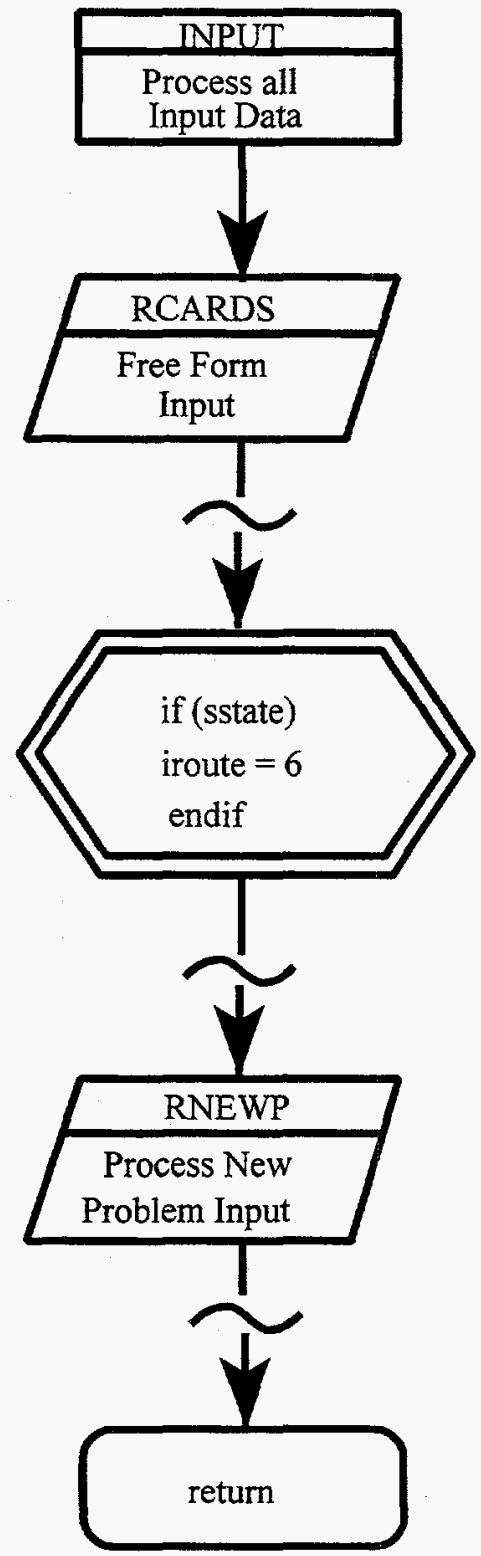

Figure 8.2 Input processing overview 


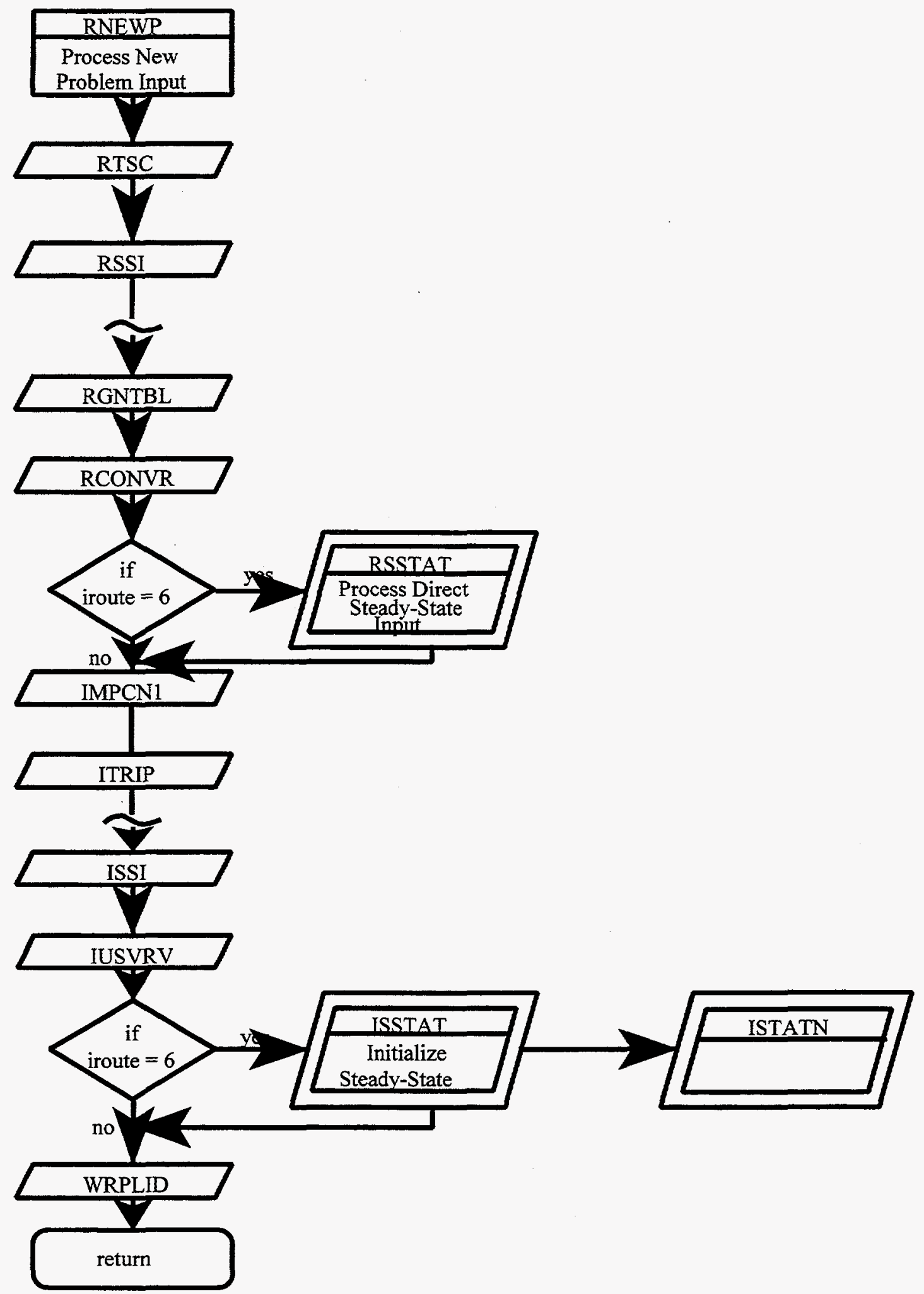

Figure 8.3 New problem input processing 
DSSI initialization includes evaluation of the initial conditions to ensure that they are adequate to uniquely define the initial state of the system.

Section 3 summarizes the governing steady-state balance equations that are used to implement the DSSI solution. The sum continuity equation, Equation 3-17, is used to propagate input mass flow rates and to further insure that the mixture continuity equations are satisfied for all control volumes (except time-dependent volumes). The details regarding the use of the mixture continuity equation in the DSSI solution are given below.

Pressures that are not supplied as initial conditions are obtained from the solution of the sum momentum equations. Depending on the location of the pressure initial conditions, a given sum momentum equation can be used to determine either an upstream or downstream pressure. The method used to associate unknown pressures with sum momentum equations is given in Section 8.3.2.

\subsubsection{Flow Initial Conditions}

The sum continuity equation, Equation $3-17$, is applied during the initialization process. It can be used to propagate flows through pipe components or branches, or if all flows are given it may be used to ensure that they satisfy the sum continuity equations. For pipe components, the flow must be equal in all junctions to satisfy the mixture continuity equations. If a single flow is known, either through input specification or by propagation from another component, all junction flows for the component can be determined. Only one flow into or out of a given control volume can be propagated. Therefore, branch components, or other components that allow for more than a single junction in and a single junction out, require an additional mass flow rate initial condition to be provided.

A reactor core provides an example of the flow propagation process where there are multiple flow paths into or out of a volume. For instance, flow from the lower plenum can pass through bypass channels, hot channels, and average core channels. In order to propagate the flow rates, flow initial conditions must be specified for each parallel channel connecting to the lower plenum, or alternatively for all but one of the parallel channels and the total flow into the plenum.

The mixture continuity equation must be satisfied during the initialization process. If it is not, the problem is terminated with an informative error message. Once the initialization process is successfully completed, the mixture continuity equation does not have to be included directly in the set of coupled steady-state balance equations that are solved.

\subsubsection{Control Volume Initial Conditions}

Initial conditions are required for each hydrodynamic system. At least one energy specification must be provided. It can be a single-phase internal energy, or for two-phase conditions, both phasic internal energies and the void fraction must be supplied. Additionally, at least one pressure must be supplied. More than one pressure can be supplied, but a general rule is that for every additional pressure that is specified, another loss coefficient must be computed. 
Using the specified internal energy as a reference, the energy equations and vapor continuity equations are used to compute the remaining phasic internal energies and volume fractions. The sum momentum equations are used to determine the unknown pressures, and in some situations form loss coefficients. Where there is a one-for-one correspondence between energy equation and internal energies and vapor continuity equations and volume fractions, each sum momentum equation is associated with two volume pressures. As a result, special logic is used to determine which pressure, upstream or downstream, is computed for a given sum momentum equation. This logic must ensure that all unknown pressures are solved and that the number of sum momentum equations matches the number of unknowns. In most instances there will be more momentum equations than unknown pressures. As a result, another parameter must be treated as an unknown that can be computed to obtain a momentum balance. This parameter is the junction form loss coefficient.

A marching scheme is used to associate unknowns with the sum momentum equations. When an upstream pressure is known, it can be propagated downstream using the sum momentum equation. Likewise, a downstream pressure can be propagated upstream. The propagation approach is not used to do the actual pressure calculation, but rather to associate unknowns with sum momentum equations.

Starting in volumes where pressures are input to remain constant, sum momentum equations for junctions exiting the volume are associated with the downstream volume pressure. Once a pressure is effectively advanced or propagated downstream, junctions leaving this volume are considered and the propagation process repeated. Any given pressure can only be determined from one momentum equation. A similar marching scheme is applied upstream. Junctions where the loss coefficient is to be computed, rather than an upstream or downstream pressure, must be flagged. This is accomplished with the junction initial condition data. During the marching scheme, pressure propagation stops at junctions where the loss coefficient is to be computed and the unknown loss coefficient is associated with the junction. When no more pressures can be propagated, the number of assigned unknowns must match the number of sum momentum equations or an informative error message is written and the problem terminated.

\subsection{DSSI Solution Scheme}

The DSSI solution is analogous to the transient solution. Figure 8-4 is a flow diagram of the steadystate program module "ssadvc". Many of the subroutines shown are RELAP5 routines that are used without madification. Where the transient solution scheme contains an outer loop to advance the time, the steady-state scheme has an outer loop to advance to the next iteration.

In order to start the DSSI solution, initial estimates of the volume states must be available. For the RETRAN codes (Ref. 3 and 4) a subroutine was written to obtain the starting values since state information is not supplied for control volumes, except where initial conditions are specified. For RELAP5, the starting values are obtained from the volume state information that is required input data for components. Each iteration then updates the volume states consistent with the user supplied initial conditions and the solution of the governing balance equations. 


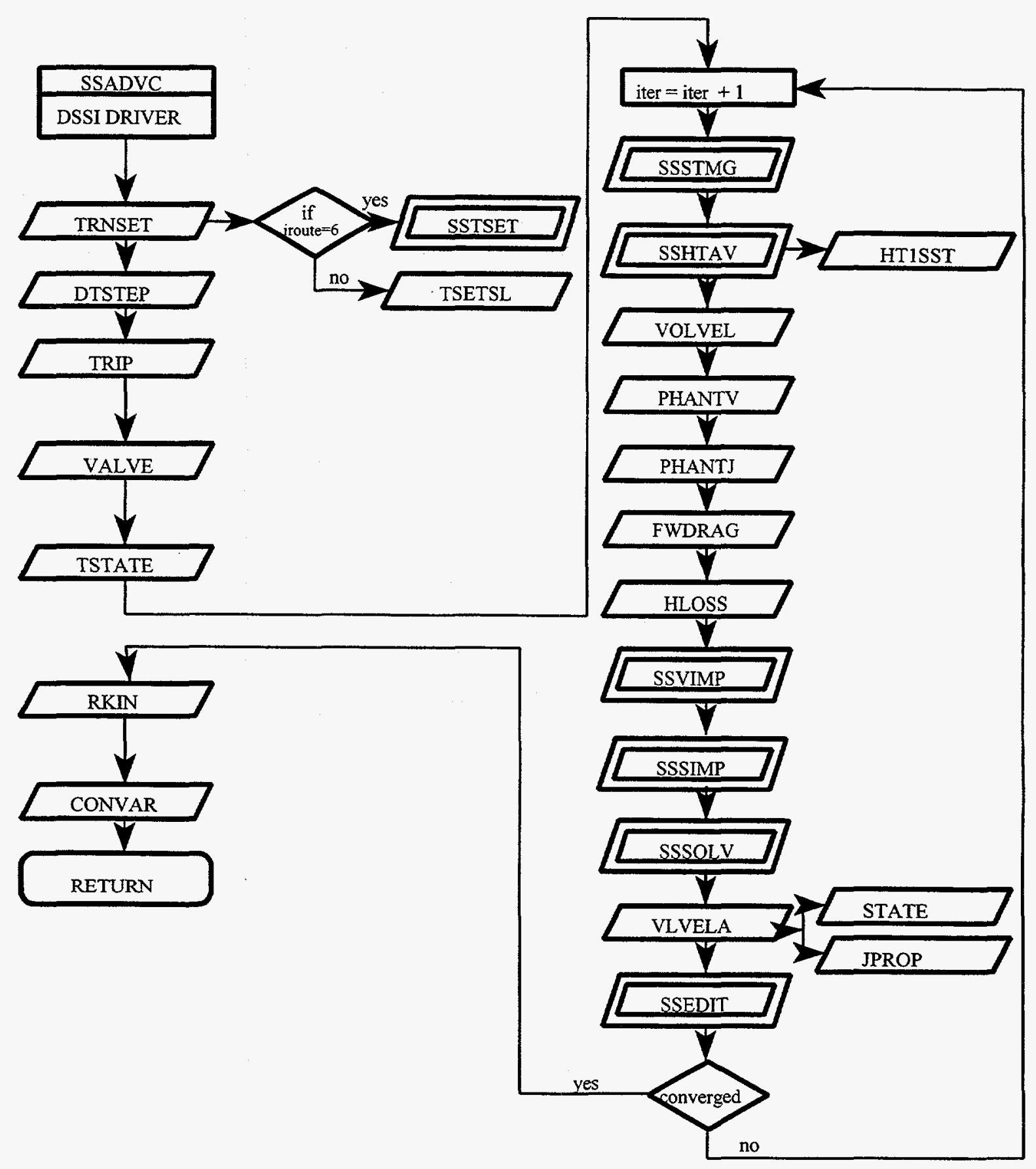

Figure 8.4 DSSI solution scheme 
For the most part, the RELAP5 constitutive models are used without change. The only exception is the constitutive models for wall and interfacial friction, interfacial heat transfer, and wall heat transfer. The time weighted smoothing that is used in the RELAP5 solution scheme is eliminated so the instantaneous values are available. Relaxation appropriate for the DSSI solution is then applied.

Subroutine "trnset" is a RELAP5 routine that is used to set up and initialize storage arrays used by the solution scheme. One of the subroutines it calls is "tsetsl" which initializes the connection arrays used to set up the coupled system of balance equations. It also reserves and initializes the scratch arrays used by the matrix solver. Since the DSSI scheme uses a fully implicit set of equations which is larger than the set(s) used for the transient solution, a new subroutine was written for steady-state. It is named "sstset".

Several new subroutines were written to generate and solve the matrix for the DSSI equation set. The equations that are implemented are summarized in Section 3. Subroutine "ssvimp" sets up the sum and difference momentum equations, or the upper portion of the full matrix. The bottom portion of the matrix corresponds to the phasic energy and vapor continuity equations and they are set up by subroutine "sssimp". The system of equations is then solved by subroutine "sssolv".

Two new subroutines are associated with heat structures. Subroutine "sshtav" is used to obtain a steady-state solution for the heat conduction equations. It utilizes the RELAP5 heat conduction routine "ht1sst". The overall system energy balance and implicit steam generator coupling scheme, developed in Section 8, are implemented in DSSI subroutine "ssstmg".

Results from each steady-state iteration are written to the output file by subroutine "ssedit" which is the steady-state counterpart of RELAP5 subroutine "majout".

The steady-state iteration is terminated once the convergence criteria are satisfied. At this point, the point reactor kinetics and control systems are initialized. The next step is to delete the DSSI matrix connection arrays and scratch space and then obtain the corresponding arrays for the transient solution by calling subroutine "trnset" after flow control variable "iroute" is set to 2 . Subroutine "ssadvc" returns to the main program shown in Figure 8-1 with "iroute" equal to 2 , where the transient solution is then executed. 


\section{DEMONSTRATION ANALYSIS}

Nine demonstration analyses have been performed using the DSSI program option as implemented in RELAP5/MOD3.1. The first five analyses were the demonstration cases used with the steadystate testbed code (Ref. 2). They were limited to single-phase liquid conditions and have been repeated using the DSSI solution method. The last four demonstration analyses use single-phase vapor and two-phase conditions. The demonstration problems are

(1) Single-Phase Liquid - No Heat Addition

(2) Single Contraction

(3) Single Expansion

(4) Several Expansions and Contractions

(5) Problem 1 Model with Heat Addition

(6) Problem 1 Model with Single-Phase Vapor

(7) Problem 1 Model with Two-Phase Inlet

(8) FRIGG 36-Rod Heated Bundle

(9) PWR System Test Problem

The steady-state results obtained for Demonstration Problems 1 through 5 are essentially identical to those given in Reference 2. One significant difference is that the convergence criteria are more stringent and the rate of convergence is quicker for the current work. The improved rate of convergence is due to the implicit numerics of the DSSI scheme.

The demonstration problems were run using the DSSI solver and then rerun using the nearly implicit RELAP5 transient solution to achieve steady-state conditions. A direct measure of convergence of the transient solution to a steady-state is not made for the demonstration problems. That is, the time derivatives which should approach zero values, were not available. When the changes in computed quantities were no longer observable because of the limited precision of the output edits, the solution was considered converged. In all instances the DSSI problems converged two to three orders of magnitude better than the corresponding traditional RELAP5 solution. All problems used the default convergence criteria given in Table 9.1, unless explicitly noted in the problem discussion.

Table 9.1 DSSI convergence criteria

\begin{tabular}{lcc}
\hline \multicolumn{1}{c}{ Equations } & Criteria & Limit \\
\hline & $\mid\left[\sum_{j \mathrm{i}-0} \mathrm{w}_{\mathrm{j}} \mid\left\langle\mathrm{w}_{\mathrm{k}}\right|\right.$ & $5.0 \times 10^{-7}$ \\
Sum Continuity & $|\Delta \mathrm{P} / \mathrm{P}|$ & $5.0 \times 10^{-8}$ \\
Sum Momentum & $\left|\Delta \mathrm{v}_{\mathrm{g}} / \mathrm{v}_{\mathrm{g}}\right|$ & $5.0 \times 10^{-5}$ \\
Difference Momentum & $\left|\Delta \alpha_{\mathrm{g}}\right|$ & $5.0 \times 10^{-5}$ \\
Vapor Continuity & $\left|\Delta \mathrm{u}_{\mathrm{g}} / \mathrm{u}_{\mathrm{g}}\right|$ & $5.0 \times 10^{-7}$ \\
Vapor Energy & $\left|\Delta \mathrm{u}_{\mathrm{f}} / \mathrm{u}_{\mathrm{f}}\right|$ & $5.0 \times 10^{-7}$ \\
\hline Fluid Energy & &
\end{tabular}


For Demonstration Problems 1 through 7, the pressures at both ends of the pipe were input using time-dependent volumes, the flow was input, and all loss coefficients were input except for the exit junction (99). Steady-state initialization was used to compute the volume pressure distribution within the channel and the unknown loss coefficient. To verify that the steady-state initialization was performing properly, the same cases were run with standard RELAP5 using the transient solution. For the transient RELAP5 runs, the same pressure boundaries were used, the unknown loss coefficient computed from the steady-state run was input for the exit junction, and the flow through the channel and pressure distribution were computed. The pressure distribution, phasic velocities and mass flow rates matched for the two methods in all cases, indicating that the steadystate code was functioning correctly.

The nodalization for the first seven problems was based on the FRIGG 36-rod heated bundle model of Problem 8. While Problems 1 through 7 used pressure boundary conditions at the inlet and exit, Problem 8 used a time-dependent junction at the inlet. With this boundary condition option, it is not necessary to compute a form loss coefficient at the exit. The Demonstration Problem 8 was run using a procedure similar to that used for the single-phase cases. First the steady-state initialization option was run, then the transient solution was used to run the problem to steady state.

The PWR demonstration case was treated differently, in that it used the standard RELAP5 steadystate option. This option used the special control system options to drive the transient solution to a desired steady-state condition. While the transient approached a steady-state condition, the rate of convergence was poor. On the other hand, the DSSI solution converged rapidly.

\subsection{Test Problem 1}

A schematic for the Test Problem 1 model is shown in Figure 9.1. As shown, time-dependent volumes are used to provide pressure boundary conditions to a ten-cell pipe component. For this demonstration analysis, all the normal volume pressures were input as $182.75 \mathrm{psia}$ and an initial mass flow rate of $9.48 \mathrm{lb} / \mathrm{sec}$ was specified. The volume pressure distribution was supplied as a flat pressure profile, since all that is required is a starting guess at the steady-state value. The boundary volumes were initialized using the conditions shown in Figure 9.1. A pressure differential of 6.45 psi was applied using the time-dependent pressure boundaries. The specified mass flow rate was propagated through the pipe and the loss coefficient in junction 99 was adjusted to balance the total pressure drop defined by the two boundary pressures. In this example, the internal pressure distribution was obtained from the DSSI solution.

The steady-state pressure distribution converged to $0.01 \mathrm{psi}$ (limit of output edit precision) on the first steady-state iteration and the exit loss coefficient converged to less than $10^{-7}$ on the fourth iteration. Each of the steady-state iterations is computationally equivalent to a single time-step advancement in the transient solution scheme. Table 9.2 shows the pressure distribution and junction 99 loss coefficient for the four iterations taken. The exit junction loss coefficient is the only parameter in Table 9.2 that changes appreciably after the first iteration. 


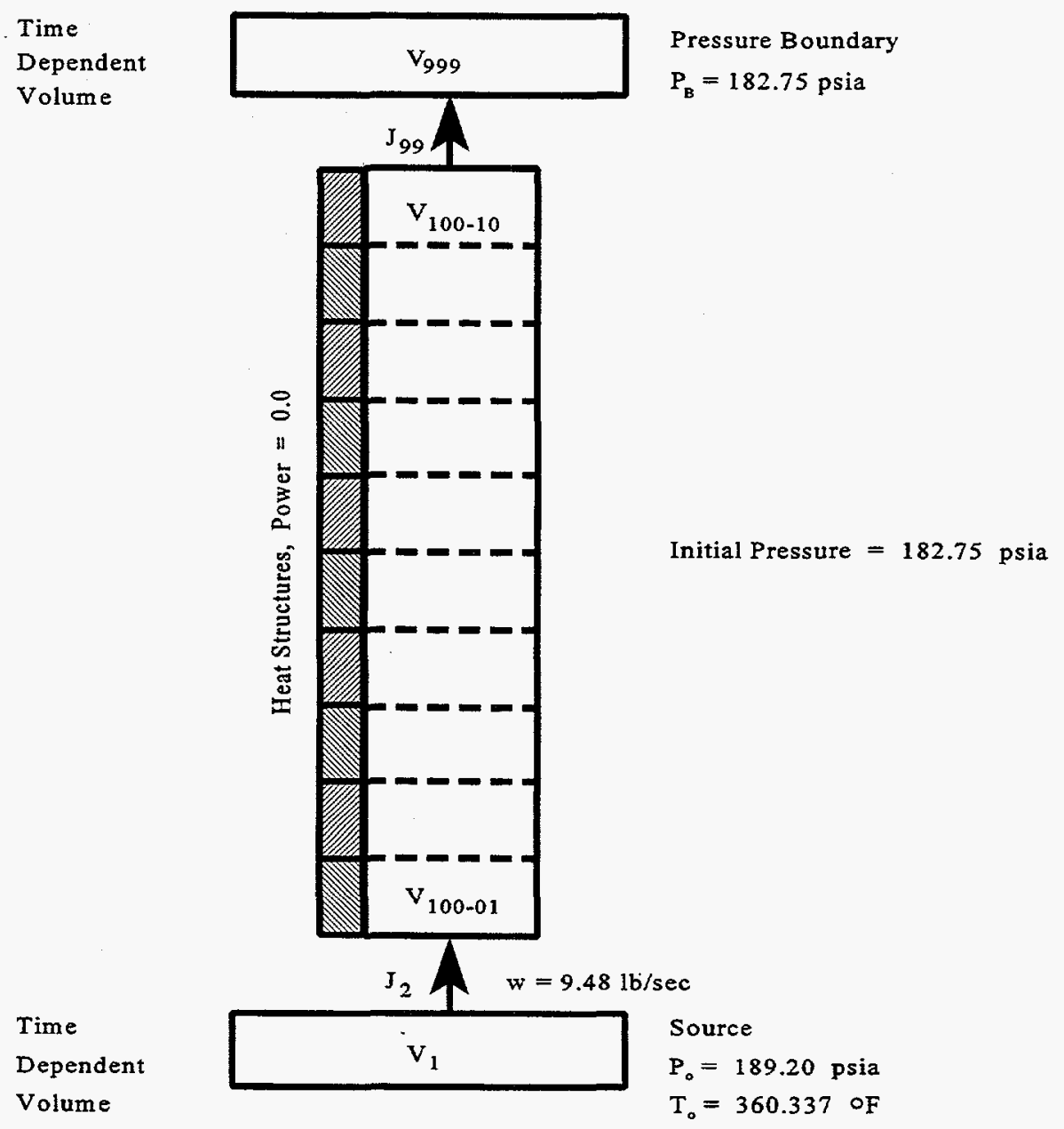

Figure 9.1 Noding diagram for test problem 1 
Table 9.2 Test problem 1 pressure and loss coefficient convergence using DSSI

\begin{tabular}{|c|c|c|c|c|c|}
\hline \multirow[b]{2}{*}{ Node } & \multicolumn{5}{|c|}{ Pressure at Iteration (psia) } \\
\hline & 0 & 1 & 2 & 3 & 4 \\
\hline $\begin{array}{l}1 \\
\vdots\end{array}$ & 189.20 & 189.20 & 189.20 & 189.20 & 189.20 \\
\hline $100-01$ & 182.75 & 188.73 & 188.73 & 188.73 & 188.73 \\
\hline $100-02$ & 182.75 & 188.12 & 188.12 & 188.12 & 188.12 \\
\hline $100-03$ & 182.75 & 187.48 & 187.48 & 187.48 & 187.48 \\
\hline $100-04$ & 182.75 & 186.87 & 186.87 & 186.87 & 186.87 \\
\hline $100-05$ & 182.75 & 186.23 & 186.23 & 186.23 & 186.23 \\
\hline $100-06$ & 182.75 & 185.62 & 185.62 & 185.62 & 185.62 \\
\hline $100-07$ & 182.75 & 184.98 & 184.98 & 184.98 & 184.98 \\
\hline $100-08$ & 182.75 & 184.37 & 184.37 & 184.37 & 184.37 \\
\hline $100-09$ & 182.75 & 183.72 & 183.72 & 183.72 & 183.72 \\
\hline $100-10$ & 182.75 & 183.11 & 183.11 & 183.11 & 183.11 \\
\hline 999 & 182.75 & 182.75 & 182.75 & 182.75 & 182.75 \\
\hline \multicolumn{6}{|c|}{ Jun $100-05 \mathrm{Vel} .(\mathrm{ft} / \mathrm{s}) 5.2318$} \\
\hline Jun 99 Vel. (ft/s) & 5.2319 & & & & \\
\hline Loss coefficient & 0.421 & 0.378359 & 0.747020 & 0.747059 & 0.747062 \\
\hline
\end{tabular}


The RELAP5 transient solution was then used to obtain the steady-state solution for the same problem. The initial condition specifications were identical to those used with the DSSI option, except that the junctions were initialized to the phasic velocities computed by the steady-state code and the loss coefficient computed at junction 99 was input with six-digit accuracy. Fixed 0.1second time steps were used.

A steady-state solution identical to the one obtained with the steady-state code was obtained after two seconds (20 time steps) of transient simulation. As shown in Table 9.3, the pressure reached the steady-state values after the first time-step advancement and the flows and velocities were converged at two seconds.

\subsection{Test Problems 2, 3, and 4}

To more completely verify the steady-state code modifications, three additional problems were executed. The problems were run primarily to test momentum flux terms and further verify the loss coefficient computation. Problems 2 and 3 tested a single contraction and expansion, respectively, and Problem 4 tested a combination of expansions and contractions as shown in Figure 9.2. For each problem, the DSSI solver was executed first. The computed loss coefficient was then input to the RELAP5 transient code which was run to a steady state. For all three problems, identical steady states were obtained using the two methods. Initial conditions and converged steady-state values are tabulated in Tables 9.4 and 9.5 , respectively.

Table 9.6 shows the convergence of the exit loss coefficient for the three momentum flux test problems for the five iterations required to obtain convergence. Note that the loss coefficients converge rapidly and the change from one iteration to the next translates to a pressure change much smaller than the 0.01 psia value used to establish convergence for the transient solution method.

Tables 9.7, 9.8, and 9.9 contain the transient solutions for Test Problems 2, 3, and 4, respectively. All three problems converge to steady-state solutions within the first three or four seconds of transient simulation. These solutions were identical to the corresponding solutions obtained using the DSSI method.

\subsection{Test Problem 5}

Test Problem 5 used the same configuration as Test Problem 1 except that heat was added by using a powered heat structure. For thermal equilibrium conditions, $0.15 \mathrm{MW}$ would heat the inlet fluid to the saturation temperature at the exit. This power level was reduced to $0.1 \mathrm{MW}$ to insure that there would be no subcooled boiling in the heated section. The DSSI solution utilized the steady-state heat conduction solution described in Section 4. The steady-state conduction solution converged each iteration of the hydraulic solution using only one or two conduction solution iterations. The problem hydraulically and thermally converged to a steady-state solution in four iterations.

After the first steady-state iteration, the pressures converged to 0.01 psia (output edit precision limit). After four iterations, the pressure was converged to $10^{-5} \mathrm{psia}$. The exit loss coefficient convergence is shown in Table 9.10. 
Table 9.3 Test problem 1 transient solution

\begin{tabular}{|c|c|c|c|c|c|c|}
\hline \multirow[b]{2}{*}{ Times(s) } & \multicolumn{2}{|c|}{ Pressure (psia) } & \multicolumn{2}{|c|}{ Velocity $(\mathrm{ft} / \mathrm{s})$} & \multicolumn{2}{|c|}{ Mass flow (lb/s) } \\
\hline & Node $100-05$ & Node $100-10$ & Jun 100-05 & Jun 99 & Jun $100-05$ & Jun 99 \\
\hline 0.0 & 182.75 & 182.75 & 5.2300 & 5.2300 & 9.4765 & 9.4765 \\
\hline 0.1 & 186.23 & 183.11 & 5.2303 & 5.2298 & 9.4772 & 9.4762 \\
\hline 0.2 & 186.23 & 183.11 & 5.2306 & 5.2307 & 9.4778 & 9.4778 \\
\hline 0.3 & 186.23 & 183.11 & 5.2308 & 5.2309 & 9.4781 & 9.4781 \\
\hline 0.4 & 186.23 & 183.11 & 5.2309 & 5.2310 & 9.4783 & 9.4783 \\
\hline 0.5 & 186.23 & 183.11 & 5.2310 & 5.2311 & 9.4785 & 9.4785 \\
\hline 0.6 & 186.23 & 183.11 & 5.2311 & 5.2312 & 9.4787 & 9.4787 \\
\hline 0.7 & 186.23 & 183.11 & 5.2312 & 5.2313 & 9.4788 & 9.4788 \\
\hline 0.8 & 186.23 & 183.11 & 5.2313 & 5.2313 & 9.4790 & 9.4790 \\
\hline 0.9 & 186.23 & 183.11 & 5.2313 & 5.2314 & 9.4791 & 9.4791 \\
\hline 1.0 & 186.23 & 183.11 & 5.2314 & 5.2315 & 9.4792 & $9: 4792$ \\
\hline 1.1 & 186.23 & 183.11 & 5.2315 & 5.2315 & 9.4793 & 9.4793 \\
\hline 1.2 & 186.23 & 183.11 & 5.2315 & 5.2316 & 9.4794 & 9.4794 \\
\hline 1.3 & 186.23 & 183.11 & 5.2316 & 5.2316 & 9.4795 & 9.4795 \\
\hline 1.4 & 186.23 & 183.11 & 5.2316 & 5.2317 & 9.4796 & 9.4796 \\
\hline 1.5 & 186.23 & 183.11 & 5.2316 & 5.2317 & 9.4796 & 9.4796 \\
\hline 1.6 & 186.23 & 183.11 & 5.2317 & 5.2317 & 9.4797 & 9.4797 \\
\hline 1.7 & 186.23 & 183.11 & 5.2317 & 5.2317 & 9.4797 & 9.4797 \\
\hline 1.8 & 186.23 & 183.11 & 5.2317 & 5.2318 & 9.4798 & 9.4797 \\
\hline 1.9 & 186.23 & 183.11 & 5.2317 & 5.2318 & 9.4798 & 9.4798 \\
\hline 2.0 & 186.23 & 183.11 & 5.2317 & 5.2318 & 9.4798 & 9.4798 \\
\hline 2.1 & 186.23 & 183.11 & 5.2317 & 5.2318 & 9.4798 & 9.4798 \\
\hline 2.2 & 186.23 & 183.11 & 5.2317 & 5.2318 & 9.4798 & 9.4798 \\
\hline 2.3 & 186.23 & 183.11 & 5.2317 & 5.2318 & 9.4798 & 9.4798 \\
\hline 2.4 & 186.23 & 183.11 & 5.2317 & 5.2318 & 9.4798 & 9.4798 \\
\hline 2.5 & 186.23 & 183.11 & 5.2317 & 5.2318 & 9.4798 & 9.4798 \\
\hline 2.6 & 186.23 & 183.11 & 5.2317 & 5.2318 & 9.4799 & 9.4798 \\
\hline 2.7 & 186.23 & 183.11 & 5.2317 & 5.2318 & 9.4799 & 9.4798 \\
\hline 2.8 & 186.23 & 183.11 & 5.2317 & 5.2318 & 9.4799 & 9.4798 \\
\hline 2.9 & 186.23 & 183.11 & 5.2317 & 5.2318 & 9.4799 & 9.4798 \\
\hline 3.0 & 186.23 & 183.11 & 5.2317 & 5.2318 & 9.4799 & 9.4798 \\
\hline 3.1 & 186.23 & 183.11 & 5.2317 & 5.2318 & 9.4799 & 9.4798 \\
\hline 3.2 & 186.23 & 183.11 & 5.2317 & 5.2318 & 9.4799 & 9.4799 \\
\hline 3.3 & 186.23 & 183.11 & 5.2317 & 5.2318 & 9.4799 & 9.4799 \\
\hline 3.4 & 186.23 & 183.11 & 5.2317 & 5.2318 & 9.4799 & 9.4799 \\
\hline 3.5 & 186.23 & 183.11 & 5.2317 & 5.2318 & 9.4799 & 9.4799 \\
\hline 3.6 & 186.23 & 183.11 & 5.2317 & 5.2318 & 9.4799 & 9.4799 \\
\hline 3.7 & 186.23 & 183.11 & 5.2317 & 5.2318 & 9.4799 & 9.4799 \\
\hline 3.8 & 186.23 & 183.11 & 5.2317 & 5.2318 & 9.4799 & 9.4799 \\
\hline 3.9 & 186.23 & 183.11 & 5.2317 & 5.2318 & 9.4799 & 9.4799 \\
\hline 4.0 & 186.23 & 183.11 & 5.2317 & 5.2318 & 9.4799 & 9.4799 \\
\hline
\end{tabular}




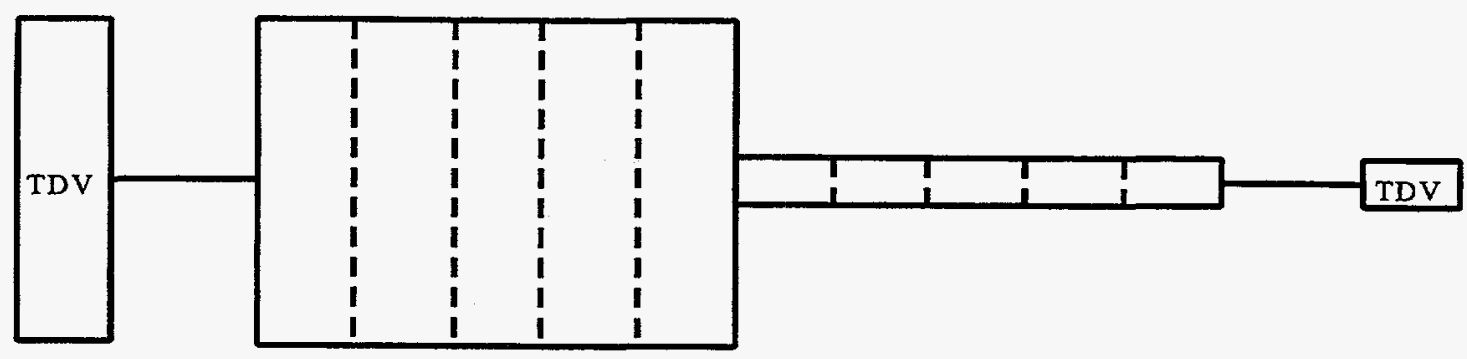

Problem 2 - Contraction

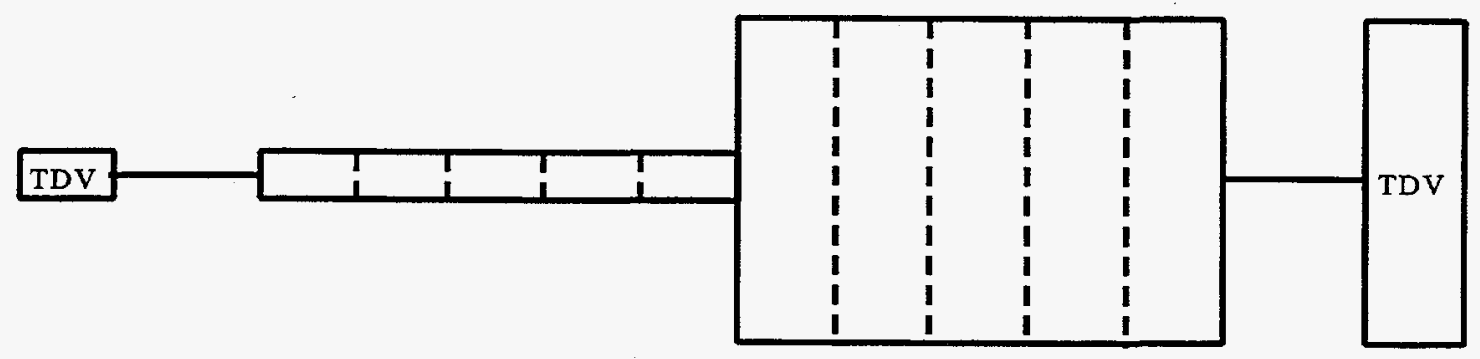

Problem 3 - Expansion

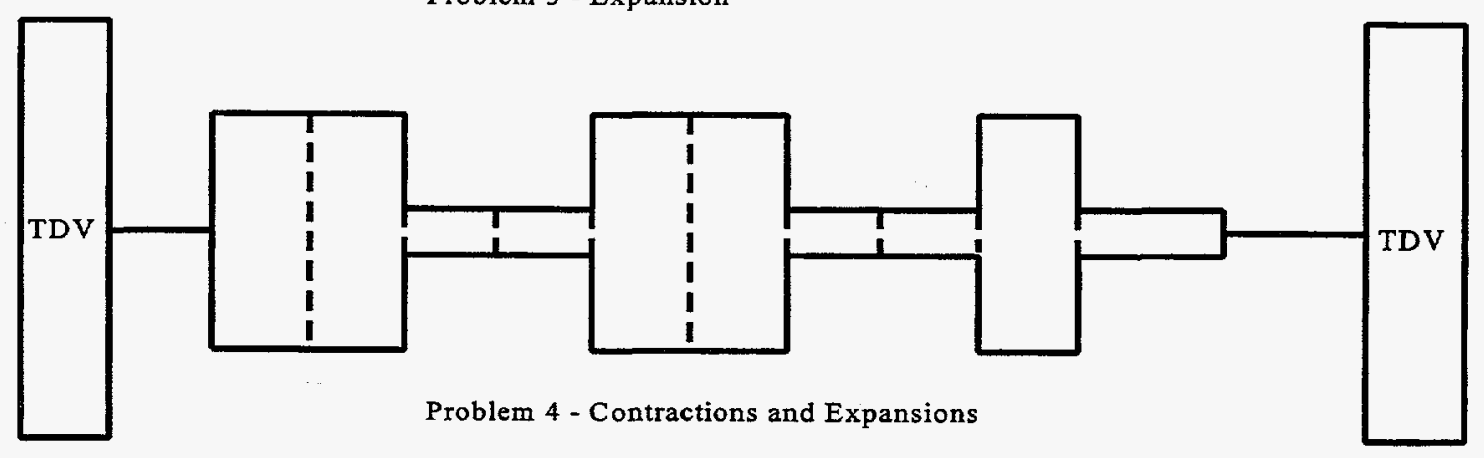

Figure 9.2 Schematic diagrams for test problems 2, 3, and 4 
Table 9.4 Data for test problems 2, 3, and 4

\begin{tabular}{llll}
\hline & Problem 2 & Problem 3 & Problem 4 \\
\hline Inlet to Volume Pressure (psia) & 195.00 & 195.00 & 193.00 \\
Annulus Initial Pressure (psia) & 182.75 & 182.75 & 182.75 \\
Outlet TD Volume Pressure (psia) & 182.75 & 182.75 & 182.75 \\
Inlet TD Volume Flow Area $\left(\mathrm{ft}^{2}{ }^{2}\right.$ & 0.032816 & 0.0100 & 100.00 \\
Restricted Annulus Flow Area $\left(\mathrm{ft}^{2}\right)$ & 0.0100 & 0.0100 & 0.0100 \\
Expanded Annulus Flow Area $\left(\mathrm{ft}^{2}\right.$ ) & 0.032816 & 0.032816 & 0.032816 \\
Outlet TD Volume Flow Area $\left(\mathrm{ft}^{2}{ }^{2}\right)$ & 0.0100 & 0.032816 & 0.041424 \\
Annulus Node Length (ft) & 1.45013 & 1.45013 & 1.45013 \\
Number of Nodes & 10 & 10 & 10 \\
Orientation & Horizontal & Horizontal & Vertical \\
Input Flow Rate (lbm/s) & 9.480 & 9.480 & 9.480 \\
\hline
\end{tabular}


Table 9.5 Results for test problems 2, 3, and 4 using DSSI

\begin{tabular}{lccc}
\hline & Problem 2 & Problem 3 & Problem 4 \\
& & & \\
\hline & & & \\
Computed Loss Coefficient & 4.09207 & 63.2933 & 0.298537 \\
$\vdots$ & & & \\
Mass Flow Rate (lbm/s) & 9.480 & 9.480 & 9.480 \\
& & & \\
Velocity in Contraction (ft/s) & 17.168 & 17.168 & 17.169 \\
Velocity in Expansion (ft/s) & & & \\
& 5.2316 & 5.2316 & \\
Annulus Pressure (psia) & & & \\
V100-01 & & & 192.53 \\
V100-02 & 194.97 & 194.75 & 191.92 \\
V100-03 & 194.92 & 194.26 & 189.17 \\
V100-04 & 194.83 & 193.44 & 188.12 \\
V100-05 & 194.78 & 192.95 & 188.55 \\
V100-06 & 194.69 & 192.12 & 185.94 \\
V100-07 & 192.83 & 193.44 & 184.13 \\
V100-08 & 192.00 & 193.36 & 184.56 \\
V100-09 & 191.51 & 193.30 & 182.14 \\
V100-10 & 190.69 & 193.22 & \\
& 190.19 & 193.16 & \\
\hline
\end{tabular}

Table 9.6 Loss coefficient convergence for test problems 2, 3, and 4

\begin{tabular}{cccc}
\hline & \multicolumn{3}{c}{ Loss Coefficient } \\
\cline { 2 - 4 } Iteration & Problem 2 & Problem 3 & Problem 4 \\
\hline 1 & 4.57446 & 63.2885 & 0.356733 \\
2 & 4.09199 & 63.2915 & 0.298556 \\
3 & 4.09208 & 63.2933 & 0.298533 \\
4 & 4.09207 & 63.2933 & 0.298537 \\
5 & 4.09207 & 63.2933 & 0.298537 \\
\hline
\end{tabular}


Table 9.7 Test problem 2 transient solution

\begin{tabular}{|c|c|c|c|c|c|c|}
\hline \multirow[b]{2}{*}{ Time(s) } & \multicolumn{2}{|c|}{ Pressure (psia) } & \multicolumn{2}{|c|}{ Velocity (ft/s) } & \multicolumn{2}{|c|}{ Mass flow $\mid(b / s)$} \\
\hline & Node $100-05$ & Node $100-10$ & Jun 100-05 & Jun 99 & Jun 100-05 & Jun 99 \\
\hline 0.0 & 182.75 & 182.75 & 5.230 & 5.230 & 2.8878 & 2.8878 \\
\hline 0.1 & 487.14 & 242.43 & 273.50 & 273.46 & 151.13 & 151.10 \\
\hline 0.2 & 203.44 & 220.10 & 31.174 & 31.200 & 17.195 & 17.219 \\
\hline 0.3 & 196.89 & 197.87 & 20.526 & 20.455 & 11.321 & 11.310 \\
\hline 0.4 & 195.20 & 191.87 & 18.063 & 18.064 & 9.9628 & 9.9678 \\
\hline 0.5 & 194.82 & 190.60 & 17.435 & 17.372 & 9.6171 & 9.6026 \\
\hline 0.6 & 194.73 & 190.31 & 17.252 & 17.251 & 9.5169 & 9.5196 \\
\hline 0.7 & 194.70 & 190.21 & 17.215 & 17.154 & 9.4972 & 9.4817 \\
\hline 0.8 & 194.70 & 190.20 & 17.191 & 17.190 & 9.4855 & 9.4867 \\
\hline 0.9 & 194.69 & 190.18 & 17.196 & 17.141 & 9.4888 & 9.4738 \\
\hline 1.0 & 194.69 & 190.19 & 17.185 & 17.184 & 9.4838 & 9.4841 \\
\hline 1.2 & 194.69 & 190.19 & 17.181 & 17.180 & 9.4834 & 9.4831 \\
\hline 1.4 & 194.69 & 190.19 & 17.177 & 17.176 & 9.4824 & 9.4820 \\
\hline 1.6 & 194.69 & 190.19 & 17.174 & 17.173 & 9.4813 & 9.4810 \\
\hline 1.8 & 194.69 & 190.19 & 17.171 & 17.171 & 9.4804 & 9.4802 \\
\hline 2.0 & 194.69 & 190.19 & 17.170 & 17.170 & 9.4799 & 9.4798 \\
\hline 2.2 & 194.69 & 190.19 & 17.169 & 17.169 & 9.4796 & 9.4796 \\
\hline 2.4 & 194.69 & 190.19 & 17.168 & 17.168 & 9.4795 & 9.4795 \\
\hline 2.6 & 194.69 & 190.19 & 17.168 & 17.168 & 9.4795 & 9.4795 \\
\hline 2.8 & 194.69 & 190.19 & 17.168 & 17.168 & 9.4795 & 9.4795 \\
\hline 3.0 & 194.69 & 190.19 & 17.168 & 17.168 & 9.4796 & 9.4795 \\
\hline 3.2 & 194.69 & 190.19 & 17.168 & 17.168 & 9.4796 & 9.4796 \\
\hline 3.4 & 194.69 & 190.19 & 17.168 & 17.168 & 9.4796 & 9.4796 \\
\hline 3.6 & 194.69 & 190.19 & 17.168 & 17.168 & 9.4797 & 9.4796 \\
\hline 3.8 & 194.69 & 190.19 & 17.168 & 17.168 & 9.4797 & 9.4797 \\
\hline 4.0 & 194.69 & 190.19 & 17.168 & 17.168 & 9.4798 & 9.4798 \\
\hline 4.2 & 194.69 & 190.19 & 17.168 & 17.168 & 9.4798 & 9.4798 \\
\hline 4.4 & 194.69 & 190.19 & 17.168 & 17.168 & 9.4799 & 9.4799 \\
\hline 4.6 & 194.69 & 190.19 & 17.168 & 17.168 & 9.4800 & 9.4800 \\
\hline 4.8 & 194.69 & 190.19 & 17.168 & 17.168 & 9.4800 & 9.4800 \\
\hline 5.0 & 194.69 & 190.19 & 17.168 & 17.168 & 9.4800 & 9.4800 \\
\hline
\end{tabular}


Table 9.8 Test problem 3 transient solution

\begin{tabular}{|c|c|c|c|c|c|c|}
\hline \multirow[b]{2}{*}{ Time(s) } & \multicolumn{2}{|c|}{ Pressure (psia) } & \multicolumn{2}{|c|}{ Velocity (ft/s) } & \multicolumn{2}{|c|}{ Mass flow $)|\mathrm{b} / \mathrm{s}|$} \\
\hline & Node $100-05$ & Node $100-10$ & Node 100-05 & Node 99 & Node 100-05 & Node 99 \\
\hline 0.0 & 182.75 & 182.75 & 5.230 & 5.230 & 2.8878 & 9.4765 \\
\hline 0.1 & 257.56 & 236.04 & 85.002 & 25.884 & 46.945 & 6.912 \\
\hline 0.2 & 204.48 & 212.76 & 24.332 & 7.4313 & 13.432 & 13.467 \\
\hline 0.3 & 195.53 & 198.30 & 18.263 & 5.5687 & 10.081 & 10.091 \\
\hline 0.4 & 192.61 & 193.94 & 17.370 & 5.2942 & 9.5894 & 9.5933 \\
\hline 0.5 & 192.21 & 193.30 & 17.206 & 5.2430 & 9.4990 & 9.5004 \\
\hline 0.6 & 192.14 & 193.19 & 17.175 & 5.2331 & 9.4825 & 9.4825 \\
\hline 0.7 & 192.12 & 193.17 & 17.169 & 5.2318 & 9.4797 & 9.4800 \\
\hline 0.8 & 192.12 & 193.16 & 17.169 & 5.2308 & 9.4797 & 9.4785 \\
\hline 0.9 & 192.12 & 193.16 & 17.169 & 5.2316 & 9.4798 & 9.4797 \\
\hline 1.0 & 192.12 & 193.16 & 17.168 & 5.2311 & 9.4799 & 9.4788 \\
\hline 1.2 & 192.12 & 193.16 & 17.169 & 5.2310 & 9.4802 & 9.4787 \\
\hline 1.4 & 192.12 & 193.16 & 17.169 & 5.2311 & 9.4803 & 9.4789 \\
\hline 1.6 & 192.12 & 193.16 & 17.169 & 5.2312 & 9.4803 & 9.4791 \\
\hline 1.8 & 192.12 & 193.16 & 17.169 & 5.2313 & 9.4802 & 9.4793 \\
\hline 2.0 & 192.12 & 193.16 & 17.169 & 5.2314 & 9.4802 & 9.4794 \\
\hline 2.2 & 192.12 & 193.16 & 17.169 & 5.2314 & 9.4801 & 9.4796 \\
\hline 2.4 & 192.12 & 193.16 & 17.168 & 5.2315 & 9.4800 & 9.4797 \\
\hline 2.6 & 192.12 & 193.16 & 17.168 & 5.2316 & 9.4800 & 9.4798 \\
\hline 2.8 & 192.12 & 193.16 & 17.168 & 5.2316 & 9.4800 & 9.4798 \\
\hline 3.0 & 192.12 & 193.16 & 17.168 & 5.2316 & 9.4800 & 9.4798 \\
\hline 3.2 & 192.12 & 193.16 & 17.168 & 5.2316 & 9.4799 & 9.4799 \\
\hline 3.4 & 192.12 & 193.16 & 17.168 & 5.2316 & 9.4800 & 9.4799 \\
\hline 3.6 & 192.12 & 193.16 & 17.168 & 5.2316 & 9.4800 & 9.4799 \\
\hline 3.8 & 192.12 & 193.16 & 17.168 & 5.2316 & 9.4800 & 9.4799 \\
\hline 4.0 & 192.12 & 193.16 & 17.168 & 5.2317 & 9.4800 & 9.4800 \\
\hline 4.2 & 192.12 & 193.16 & 17.168 & 5.2317 & 9.4800 & 9.4800 \\
\hline 4.4 & 192.12 & 193.16 & 17.168 & 5.2317 & 9.4800 & 9.4800 \\
\hline 4.6 & 192.12 & 193.16 & 17.168 & 5.2317 & 9.4800 & 9.4800 \\
\hline 4.8 & 192.12 & 193.16 & 17.168 & 5.2317 & 9.4800 & 9.4800 \\
\hline 5.0 & 192.12 & 193.16 & 17.168 & 5.2317 & 9.4800 & 9.4800 \\
\hline
\end{tabular}


Table 9.9 Test problem 4 transient solution

\begin{tabular}{|c|c|c|c|c|c|c|}
\hline \multirow[b]{2}{*}{ Time(s) } & \multicolumn{2}{|c|}{ Pressure (psia) } & \multicolumn{2}{|c|}{ Velocity (ft/s) } & \multicolumn{2}{|c|}{ Mass flow (lb/s) } \\
\hline & Node 100-05 & Node $100-10$ & Node $100-05$ & Node 99 & Node $100-05$ & Node 99 \\
\hline 0.0 & 182.75 & 182.75 & 0.0000 & 0.0000 & 0.0000 & 0.0000 \\
\hline 0.1 & 189.05 & 183.46 & 1.5200 & 4.9860 & 2.7542 & 2.7530 \\
\hline 0.2 & 188.51 & 183.11 & 2.5831 & 8.4771 & 4.6805 & 4.6807 \\
\hline 0.3 & 188.51 & 182.86 & 3.4147 & 11.206 & 6.1874 & 6.1874 \\
\hline 0.4 & 188.52 & 182.64 & 4.0213 & 13.197 & 7.2865 & 7.2865 \\
\hline 0.5 & 188.53 & 182.47 & 4.4418 & 14.577 & 8.0486 & 8.0486 \\
\hline 0.6 & 188.53 & 182.36 & 4.7235 & 15.501 & 8.5589 & 8.5589 \\
\hline 0.7 & 188.54 & 182.28 & 4.9077 & 16.106 & 8.8927 & 8.8927 \\
\hline 0.8 & 188.54 & 182.23 & 5.0264 & 16.495 & 9.1078 & 9.1078 \\
\hline 0.9 & 188.54 & 182.20 & 5.1021 & 16.744 & 9.2450 & 9.2450 \\
\hline 1.0 & 188.55 & 182.18 & 5.1501 & 16.901 & 9.3320 & 9.3320 \\
\hline 1.2 & 188.55 & 182.16 & 5.1995 & 17.063 & 9.4215 & 9.4215 \\
\hline 1.4 & 188.55 & 182.15 & 5.2191 & 17.127 & 9.4570 & 9.4569 \\
\hline 1.6 & 188.55 & 182.14 & 5.2268 & 17.153 & 9.4709 & 9.4709 \\
\hline 1.8 & 188.55 & 182.14 & 5.2298 & 17.163 & 9.4764 & 9.4764 \\
\hline 2.0 & 188.55 & 182.14 & 5.2310 & 17.167 & 9.4786 & 9.4786 \\
\hline 2.2 & 188.55 & 182.14 & 5.2315 & 17.168 & 9.4794 & 9.4794 \\
\hline 2.4 & 188.55 & 182.14 & 5.2316 & 17.169 & 9.4798 & 9.4798 \\
\hline 2.6 & 188.55 & 182.14 & 5.2317 & 17.169 & 9.4799 & 9.4799 \\
\hline 2.8 & 188.55 & 182.14 & 5.2317 & 17.169 & 9.4800 & 9.4799 \\
\hline 3.0 & 188.55 & 182.14 & 5.2318 & 17.169 & 9.4800 & 9.4800 \\
\hline 3.2 & 188.55 & 182.14 & 5.2318 & 17.169 & 9.4800 & 9.4800 \\
\hline 3.4 & 188.55 & 182.14 & 5.2318 & 17.169 & 9.4800 & 9.4800 \\
\hline 3.6 & 188.55 & 182.14 & 5.2318 & 17.169 & 9.4800 & 9.4800 \\
\hline 3.8 & 188.55 & 182.14 & 5.2318 & 17.169 & 9.4800 & 9.4800 \\
\hline 4.0 & 188.55 & 182.14 & 5.2318 & 17.169 & 9.4800 & 9.4800 \\
\hline 4.2 & 188.55 & 182.14 & 5.2318 & 17.169 & 9.4800 & 9.4800 \\
\hline 4.4 & 188.55 & 182.14 & 5.2318 & 17.169 & 9.4800 & 9.4800 \\
\hline 4.6 & 188.55 & 182.14 & 5.2318 & 17.169 & 9.4800 & 9.4800 \\
\hline 4.8 & 188.55 & 182.14 & 5.2318 & 17.169 & 9.4800 & 9.4800 \\
\hline 5.0 & 188.55 & 182.14 & 5.2318 & 17.169 & 9.4800 & 9.4800 \\
\hline
\end{tabular}


Table 9.10 Test problem 5 loss coefficient convergence

\begin{tabular}{cc}
\hline Iteration & Loss Coefficient \\
\hline 1 & 0.747562 \\
2 & 0.850261 \\
3 & 0.850025 \\
4 & 0.850025 \\
\hline
\end{tabular}


A RELAP5 transient was executed using the converged loss coefficient shown in Table 9.10. Table 9.11 summarizes the solution for a few of the key parameters. This problem converges much slower than Test Problem 1 which converged in two seconds compared with 20 seconds. The final steady-state solution is essentially the same as that obtained using the DSSI method. The fluid temperatures are the slowest to converge. This is likely due to the thermal time constants associated with the heat conduction solution, since the starting heat conductor temperature distribution was initially in error (due to the estimation for the fluid boundary temperature). Thermal time constants restrict the rate at which the correct temperature distribution can be achieved. No effort was made to determine the exact cause of the slower convergence since it has no effect on the DSSI method which is the focus of this work.

\subsection{Test Problem 6}

Test Problem 6 is another variation of Problem 1. For Problem 6, the inlet fluid conditions were modified to be representative of single-phase vapor at $376.654 \mathrm{~F}$ and 188 psia. The exit pressure was set at 187.8 psia and the channel was initialized at 187.9 psia. The mass flow rate was input as $0.25663 \mathrm{lbm} / \mathrm{sec}$.

The DSSI method converged to a steady-state solution in three iterations. Table 9.12 contains the computed exit loss coefficient for each iteration. As with the single-phase liquid cases, this case converges rapidly.

The converged loss coefficient shown in Table 9.12 was then used in the exit junction and the RELAP5 transient calculation which was run to a steady-state condition. This steady condition was essentially identical to the solution obtained using the DSSI method. Table 9.13 presents a summary of the transient approach to steady state.

An observation regarding the transient solution scheme was made while performing this problem. Since there was no wall or interphase energy exchange, the exit convective energy should differ from the inlet value by the sum of the viscous dissipation terms. This was true for the DSSI solution but not for the RELAP5 transient solution. Another indication of the problem was evident in the node temperature values. They increased slightly from the inlet to exit for the DSSI case due to the viscous heating. However, the temperatures decreased for the transient solution. This may be the cause of the transient solution converging to a mass flow of $0.25660 \mathrm{lbm} / \mathrm{sec}$, rather than the value of 0.25663 used as a boundary condition for the DSSI method. No attempt was made to identify the cause of this apparent error in the transient. solution since it was beyond the scope of the current work.

\subsection{Test Problem 7}

Test Problem 7 was based on the geometric model description of Test Problem 1, but the inlet boundary conditions were revised to specify two-phase flow. The inlet fluid conditions were specified as a saturated two-phase mixture at 188.5 psia and a void fraction of 0.013044 . The sink pressure was set at 182.0 psia and the flow initial condition was specified to be $11.000 \mathrm{lbm} / \mathrm{sec}$. 


\begin{tabular}{|c|c|c|c|c|c|c|c|c|}
\hline 0.0 & 182.75 & 182.75 & 5.2300 & 5.2300 & 9.4765 & 9.47 .65 & 360.33 & 360.33 \\
\hline 0.5 & 186.24 & 183.13 & 5.2035 & 5.2196 & 9.4181 & 9.4469 & 361.96 & 362.00 \\
\hline 2.0 & 186.23 & 183.13 & 5.2228 & 5.2383 & 9.4364 & 9.4523 & 364.53 & 366.33 \\
\hline 3.0 & 186.23 & 183.13 & 5.2366 & 5.2525 & 9.4591 & 9.4660 & 364.86 & 368.12 \\
\hline 4.0 & 186.23 & 183.13 & 5.2432 & 5.2594 & 9.4703 & 9.4729 & 364.96 & 368.96 \\
\hline 5.0 & 186.23 & 183.13 & 5.2458 & 5.2624 & 9.4748 & 9.4760 & 365.00 & 369.31 \\
\hline 6.0 & 186.23 & 183.13 & 5.2470 & 5.2638 & 9.4767 & 9.4774 & 365.02 & 369.48 \\
\hline 7.0 & 186.23 & 183.13 & 5.2476 & 5.2646 & 9.4777 & 9.4782 & 365.04 & 369.58 \\
\hline 8.0 & 186.23 & 183.13 & 5.2480 & 5.2651 & 9.4783 & 9.4786 & 365.06 & 369.64 \\
\hline 9.0 & 186.23 & 183.13 & 5.2482 & 5.2655 & 9.4787 & 9.4790 & 365.07 & 369.69 \\
\hline 10.0 & 186.23 & 183.13 & 5.2484 & 5.2658 & 9.4790 & 9.4792 & 365.07 & 369.73 \\
\hline 11.0 & 186.23 & 183.13 & 5.2486 & 5.2660 & 9.4792 & 9.4794 & 365.08 & 369.76 \\
\hline 12.0 & 186.23 & 183.13 & 5.2487 & 5.2662 & 9.4795 & 9.4796 & 365.09 & 369.79 \\
\hline 13.0 & 186.23 & 183.13 & 5.2488 & 5.2662 & 9.4795 & 9.4796 & 365.09 & 369.79 \\
\hline 14.0 & 186.23 & 183.13 & 5.2488 & 5.2663 & 9.4796 & 9.4797 & 365.09 & 369.80 \\
\hline 15.0 & 186.23 & 183.13 & 5.2488 & 5.2664 & 9.4797 & 9.4797 & 365.09 & 369.81 \\
\hline 16.0 & 186.23 & 183.13 & 5.2664 & 5.2664 & 9.4797 & 9.4798 & 365.09 & 369.82 \\
\hline 17.0 & 186.23 & 183.13 & 5.2489 & 5.2664 & 9.4798 & 9.4798 & 365.09 & 369.82 \\
\hline 18.0 & 186.23 & 183.13 & 5.2489 & 5.2665 & 9.4798 & 9.4798 & 365.09 & 369.82 \\
\hline 19.0 & 186.23 & 183.13 & 5.2489 & 5.2665 & 9.4798 & 9.4798 & 365.09 & 369.82 \\
\hline 20.0 & 186.23 & 183.13 & 5.2489 & 5.2665 & 9.4798 & 9.4798 & 365.09 & 369.83 \\
\hline 21.0 & 186.23 & 183.13 & 5.2489 & 5.2665 & 9.4798 & 9.4798 & 365.09 & 369.83 \\
\hline 22.0 & 186.23 & 183.13 & 5.2489 & 5.2665 & 9.4798 & 9.4798 & 365.09 & 369.83 \\
\hline 23.0 & 186.23 & 183.13 & 5.2490 & 5.2665 & 9.4798 & 9.4798 & 365.09 & 369.83 \\
\hline 24.0 & 186.23 & 183.13 & 5.2490 & 5.2665 & 9.4798 & 9.4798 & 365.09 & 369.83 \\
\hline 25.0 & 186.23 & 183.13 & 5.2490 & 5.2665 & 9.4798 & 9.4798 & 365.09 & 369.83 \\
\hline
\end{tabular}


Table 9.12 Test problem 6 loss coefficient convergence

\begin{tabular}{lcc}
\hline Iteration & Loss Coefficient \\
\hline 1 & 4.26122 \\
2 & 4.32537 \\
3 & 4.32540 \\
\hline
\end{tabular}

Table 9.13 Test problem 6 transient solution

\begin{tabular}{|c|c|c|c|c|c|c|}
\hline \multirow[b]{2}{*}{ Time(s) } & \multicolumn{2}{|c|}{ Pressure (psia) } & \multicolumn{2}{|c|}{ Velocity (ft/s) } & \multicolumn{2}{|c|}{ Mass flow $(\mathrm{lb} / \mathrm{s})$} \\
\hline & Node 100-05 & Node $100-10$ & Jun $100-05$ & Jun 99 & Jun 100-05 & Jun 99 \\
\hline 0.0 & 187.90 & 187.90 & 22.000 & 22.000 & 0.24817 & 0.24817 \\
\hline 0.1 & 187.95 & 187.89 & 22.591 & 22.589 & 0.25489 & 0.25481 \\
\hline 0.2 & 187.95 & 187.89 & 22.711 & 22.717 & 0.25624 & 0.25623 \\
\hline 0.3 & 187.95 & 187.89 & 22.735 & 22.742 & 0.25652 & 0.25651 \\
\hline 0.4 & 187.95 & 187.89 & 22.741 & 22.747 & 0.25659 & 0.25657 \\
\hline 0.5 & 187.95 & 187.89 & 22.742 & 22.748 & 0.25660 & 0.25659 \\
\hline 0.6 & 187.95 & 187.89 & 22.742 & 22.749 & 0.25661 & 0.25660 \\
\hline 0.7 & 187.95 & 187.89 & 22.742 & 22.748 & 0.25661 & 0.25660 \\
\hline 0.8 & 187.95 & 187.89 & 22.742 & 22.748 & 0.25661 & 0.25660 \\
\hline 0.9 & 187.95 & 187.89 & 22.742 & 22.748 & 0.25661 & 0.25660 \\
\hline 1.0 & 187.95 & 187.89 & 22.742 & 22.748 & 0.25660 & 0.25660 \\
\hline 1.1 & 187.95 & 187.89 & 22.741 & 22.748 & 0.25660 & 0.25660 \\
\hline 1.2 & 187.95 & 187.89 & 22.741 & 22.748 & 0.25660 & 0.25660 \\
\hline 1.3 & 187.95 & 187.89 & 22.741 & 22.748 & 0.25660 & 0.25660 \\
\hline 1.4 & 187.95 & 187.89 & 22.741 & 22.748 & 0.25660 & 0.25660 \\
\hline 1.5 & 187.95 & 187.89 & 22.741 & 22.748 & 0.25660 & 0.25660 \\
\hline 1.6 & 187.95 & 187.89 & 22.741 & 22.748 & 0.25660 & 0.25660 \\
\hline 1.7 & 187.95 & 187.89 & 22.741 & 22.748 & 0.25660 & 0.25660 \\
\hline 1.8 & 187.95 & 187.89 & 22.741 & 22.748 & 0.25660 & 0.25660 \\
\hline 1.9 & 187.95 & 187.89 & 22.741 & 22.748 & 0.25660 & 0.25660 \\
\hline 2.0 & 187.95 & 187.89 & 22.741 & 22.748 & 0.25660 & 0.25660 \\
\hline
\end{tabular}


Pressure and void fraction distributions approximating the steady-state solution were provided with the component data. These distributions provided the starting point for both DSSI and transient methods. The detailed distributions were not necessary for either the DSSI or transient solution methods, but did reduce the simulation time required to reach a steady-state for the transient and may have reduced the number of iterations for the DSSI method.

The DSSI solver converged to a steady condition in 32 iterations. Table 9.14 gives a history of the computed exit loss coefficient. During iterations 2 through 5 , negative loss coefficients were computed. They were reset to zero and the calculation continued. The final loss coefficient satisfied the pressure convergence criteria which is equivalent to $10^{-5} \mathrm{psia}$.

As, with previous test problems, the transient solution was used to solve for a steady-state condition given the boundary conditions and the converged exit loss coefficient obtained from the steady-state solution. Table 9.15 contains the results for a few key parameters which converged in 4.5 seconds. The DSSI method converged to essentially the same solution that the transient scheme converged (45 time steps) to.

The transient solution displays a problem similar to the one discussed in the previous section regarding the vapor temperature. For this simple two-phase flow problem, the liquid becomes superheated and flashes as it moves up the channel and the pressure drops. The resulting vapor appears at the local saturation temperature. In the final steady-state solution obtained using the transient solution, the vapor temperatures are consistently lower than the local saturation temperature.

Again this slight discrepancy in the vapor phase temperature may cause the difference between the transient mass flow rate of $10.996 \mathrm{lbm} / \mathrm{sec}$ and the DSSI initial condition of 11.000 .

\subsection{FRIGG 36-Rod Heated Bundle}

A series of experiments were performed in the $8 \mathrm{MW}$ FRIGG loop with electrically heated rod bundles, simulating conditions in the Marviken boiling heavy water reactor. Test 413149 was for a 36-rod bundle configuration (Ref. 7). The RELAP5 model treats the heated length as an annulus with 10 volumes. A time-dependent junction was used to specify the inlet flow boundary condition and an associated time-dependent volume specifies the fluid conditions. Another time-dependent volume at the exit provides a pressure boundary condition. With this configuration of boundary conditions, the pressures are back propagated from the exit boundary to the inlet and it is not necessary to compute a loss coefficient as was done in the previous test cases. The specified power is distributed uniformly between the 10 heat structures attached to the annulus volumes. Loss coefficients specified for the grid spacers have been incorporated into the model. Figure 9.3 shows a schematic of the model. It also includes the boundary conditions that were used for the test configuration.

The subcooled inlet coolant is heated and subcooled boiling begins in the first heated node. As a result of the heating, the vapor void fraction increases up the test assembly. An error in MOD3.1 
Table 9.14 Test problem 7 loss coefficient convergence

\begin{tabular}{|c|c|}
\hline Iteration & Loss Coefficient \\
\hline 1 & 1.34676 \\
\hline 2 & 0.000000 \\
\hline 3 & 0.000000 \\
\hline 4 & 0.000000 \\
\hline 5 & 0.000000 \\
\hline 6 & 0.205658 \\
\hline 7 & 0.220995 \\
\hline 8 & 0.112464 \\
\hline 9 & 0.103030 \\
\hline 10 & 0.918932 \\
\hline 15 & 0.969390 \\
\hline 20 & 0.971452 \\
\hline 25 & 0.972212 \\
\hline 26 & 0.972284 \\
\hline 27 & 0.972340 \\
\hline 28 & 0.972386 \\
\hline 29 & 0.972422 \\
\hline 30 & 0.972450 \\
\hline 31 & 0.972473 \\
\hline 32 & 0.972491 \\
\hline
\end{tabular}


Table 9.15 Test problem 7 transient solution

\begin{tabular}{|c|c|c|c|c|c|c|c|c|c|c|}
\hline \multirow[b]{2}{*}{ Time(s) } & \multicolumn{2}{|c|}{ Pressure (psia) } & \multicolumn{2}{|c|}{ Liquid Vel. (ft/s) } & \multicolumn{2}{|c|}{ Vapor Vel. $(\mathrm{ft} / \mathrm{s})$} & \multicolumn{2}{|c|}{ Mass Flow Rate $(1 \mathrm{bm} / \mathrm{s})$} & \multicolumn{2}{|c|}{ Void Fraction } \\
\hline & Node $100-05$ & Node $100 \cdot 10$ & Jun. 100.05 & Jun. 99 & Jun. 100.05 & Jun. 99 & Jun. 100.05 & Jun. 99 & Jun. 100.05 & Jun. 99 \\
\hline 0.0 & 185.66 & 182.71 & 8.0981 & 9.3136 & 9.9482 & 12.039 & 12.637 & 12.637 & 0.13055 & 0.24605 \\
\hline 0.1 & 185.41 & 182.65 & 7.7320 & 9.1647 & 9.4816 & 11.796 & 12.026 & 12.400 & 0.13347 & 0.24817 \\
\hline 0.2 & 185.39 & 182.62 & 7.5352 & 8.9358 & 9.3079 & 11.560 & 11.674 & 12.061 & 0.13688 & 0.25003 \\
\hline 0.3 & 185.37 & 182.60 & 7.4091 & 8.7340 & 9.1340 & 11.272 & 11.438 & 11.760 & 0.13997 & 0.25187 \\
\hline 0.4 & 185.34 & 182.59 & 7.3274 & 8.5598 & 9.0711 & 11.089 & 11.282 & 11.508 & 0.14231 & 0.25307 \\
\hline 0.5 & 185.33 & 182.58 & 7.2782 & 8.4362 & 8.9965 & 10.909 & 11.186 & 11.327 & 0.14387 & 0.25408 \\
\hline 0.6 & 185.33 & 182.57 & 7.2466 & 8.3440 & 8.9758 & 10.817 & 11.126 & 11.196 & 0.14478 & 0.25456 \\
\hline 0.7 & 185.33 & 182.56 & 7.2272 & 8.2880 & 8.9421 & 10.729 & 11.091 & 11.115 & 0.14523 & 0.25492 \\
\hline 0.8 & 185.33 & 182.56 & 7.2137 & 8.2485 & 8.9339 & 10.695 & 11.068 & 11.062 & 0.14539 & 0.25495 \\
\hline 0.9 & 185.33 & 182.56 & 7.2045 & 8.2278 & 8.9162 & 10.656 & 11.054 & 11.034 & 0.14537 & 0.25496 \\
\hline 1.0 & 185.33 & 182.56 & 7.1971 & 8.2125 & 8.9112 & 10.646 & 11.044 & 11.016 & 0.14526 & 0.25480 \\
\hline 1.1 & 185.33 & 182.56 & 7.1913 & 8.2056 & 8.9005 & 10.629 & 11.037 & 11.009 & 0.14513 & 0.25466 \\
\hline 1.2 & 185.33 & 182.56 & 7.1864 & 8.1993 & 8.8965 & 10.627 & 11.031 & 11.003 & 0.14499 & 0.25445 \\
\hline 1.3 & 185.33 & 182.56 & 7.1822 & 8.1967 & 8.8894 & 10.617 & 11.026 & 11.002 & 0.14486 & 0.25428 \\
\hline 1.4 & 185.33 & 182.56 & 7.1785 & 8.1933 & 8.8861 & 10.617 & 11.022 & 11.001 & 0.14475 & 0.25408 \\
\hline 1.5 & 185.33 & 182.56 & 7.1754 & 8.1918 & 8.8812 & 10.611 & 11.019 & 11.001 & 0.14465 & 0.25393 \\
\hline 1.6 & 185.33 & 182.56 & 7.1727 & 8.1895 & 8.8786 & 10.610 & 11.015 & 11.000 & 0.14457 & 0.25377 \\
\hline 1.7 & 185.33 & 182.56 & 7.1704 & 8.1883 & 8.8752 & 10.606 & 11.013 & 11.000 & 0.14451 & 0.25366 \\
\hline 1.8 & 185.33 & 182.56 & 7.1684 & 8.1865 & 8.8731 & 10.605 & 11.010 & 10.999 & 0.14445 & 0.25354 \\
\hline 1.9 & 185.33 & 182.56 & 7.1667 & 8.1855 & 8.8707 & 10.602 & 11.008 & 10.999 & 0.14441 & 0.25345 \\
\hline 2.0 & 185.33 & 182.56 & 7.1652 & 8.1841 & 8.8691 & 10.601 & 11.006 & 10.999 & 0.14437 & 0.25336 \\
\hline 2.1 & 185.33 & 182.56 & 7.1639 & 8.1833 & 8.8674 & 10.599 & 11.005 & 10.999 & 0.14434 & 0.25330 \\
\hline 2.2 & 185.33 & 182.56 & 7.1628 & 8.1823 & 8.8662 & 10.598 & 11.003 & 10.998 & 0.14432 & 0.25324 \\
\hline 2.3 & 185.33 & 182.56 & 7.1619 & 8.1817 & 8.8650 & 10.597 & 11.002 & 10.998 & 0.14430 & 0.25319 \\
\hline 2.4 & 185.33 & 182.56 & 7.1612 & 8.1809 & 8.8642 & 10.596 & 11.001 & 10.998 & 0.14429 & 0.25315 \\
\hline 2.5 & 185.33 & 182.56 & 7.1605 & 8.1805 & 8.8633 & 10.595 & 11.000 & 10.997 & 0.14428 & 0.25311 \\
\hline 2.6 & 185.33 & 182.56 & 7.1600 & 8.1800 & 8.8627 & 10.595 & 11.000 & 10.997 & 0.14427 & 0.25308 \\
\hline 2.7 & 185.34 & 182.56 & 7.1595 & 8.1797 & 8.8621 & 10.594 & 10.999 & 10.997 & 0.14426 & 0.25306 \\
\hline 2.8 & 185.34 & 182.56 & 7.1591 & 8.1793 & 8.8617 & 10.594 & 10.998 & 10.997 & 0.14426 & 0.25304 \\
\hline 2.9 & 185.34 & 182.56 & 7.1588 & 8.1791 & 8.8613 & 10.593 & 10.998 & 10.997 & 0.14426 & 0.25303 \\
\hline 3.0 & 185.34 & 182.56 & 7.1585 & 8.1788 & 8.8610 & 10.593 & 10.998 & 10.997 & 0.14425 & 0.25301 \\
\hline 3.1 & 185.34 & 182.56 & 7.1583 & 8.1787 & 8.8607 & 10.593 & 10.997 & 10.997 & 0.14425 & 0.25300 \\
\hline 3.2 & 185.34 & 182.56 & 7.1581 & 8.1785 & 8.8605 & 10.592 & 10.997 & 10.996 & 0.14425 & 0.25300 \\
\hline 3.3 & 185.34 & 182.56 & 7.1580 & 8.1784 & 8.8604 & 10.592 & 10.997 & 10.996 & 0.14425 & 0.25299 \\
\hline 3.4 & 185.34 & 182.56 & 7.1579 & 8.1783 & 8.8602 & 10.592 & 10.997 & 10.996 & 0.14425 & 0.25298 \\
\hline 3.5 & 185.34 & 182.56 & 7.1578 & 8.1782 & 8.8601 & 10.592 & 10.997 & 10.996 & 0.14425 & 0.25298 \\
\hline
\end{tabular}


Table 9.15 (Cont'd)

\begin{tabular}{|c|c|c|c|c|c|c|c|c|c|c|}
\hline \multirow[b]{2}{*}{ Time(s) } & \multicolumn{2}{|c|}{ Pressure (psia) } & \multicolumn{2}{|c|}{ Liquid Vel. $(\mathrm{ft} / \mathrm{s})$} & \multicolumn{2}{|c|}{ Vapor Vel. $(\mathrm{ft} / \mathrm{s})$} & \multicolumn{2}{|c|}{ Mass Flow Rate $(1 \mathrm{bm} / \mathrm{s})$} & \multicolumn{2}{|c|}{ Void Fraction } \\
\hline & Node 100.05 & Node $100-10$ & Jun. 100.05 & Jun. 99 & Jun. 100.05 & Jun. 99 & Jun. 100.05 & Jun. 99 & Jun. 100.05 & Jun. 99 \\
\hline $\begin{array}{l}3.6 \\
3.7 \\
3.8 \\
3.9 \\
4.0 \\
4.1 \\
4.2 \\
4.3 \\
4.4 \\
4.5\end{array}$ & $\begin{array}{l}185.34 \\
185.34 \\
185.34 \\
185.34 \\
185.34 \\
185.34 \\
185.34 \\
185.34 \\
185.34 \\
185.34\end{array}$ & $\begin{array}{l}182.56 \\
182.56 \\
182.56 \\
182.56 \\
182.56 \\
182.56 \\
182.56 \\
182.56 \\
182.56 \\
182.56\end{array}$ & $\begin{array}{l}7.1577 \\
7.1576 \\
7.1576 \\
7.1576 \\
7.1575 \\
7.1575 \\
7.1575 \\
7.1575 \\
7.1575 \\
7.1575\end{array}$ & $\begin{array}{l}8.1781 \\
8.1781 \\
8.1780 \\
8.1780 \\
8.1780 \\
8.1780 \\
8.1779 \\
8.1779 \\
8.1779 \\
8.1779\end{array}$ & $\begin{array}{l}8.8600 \\
8.8600 \\
8.8599 \\
8.8599 \\
8.8598 \\
8.8598 \\
8.8598 \\
8.8598 \\
8.8598 \\
8.8598\end{array}$ & $\begin{array}{l}10.592 \\
10.592 \\
10.592 \\
10.592 \\
10.592 \\
10.592 \\
10.592 \\
10.592 \\
10.592 \\
10.592\end{array}$ & $\begin{array}{l}10.996 \\
10.996 \\
10.996 \\
10.996 \\
10.996 \\
10.996 \\
10.996 \\
10.996 \\
10.996 \\
10.996\end{array}$ & $\begin{array}{l}10.996 \\
10.996 \\
10.996 \\
10.996 \\
10.996 \\
10.996 \\
10.996 \\
10.996 \\
10.996 \\
10.996\end{array}$ & $\begin{array}{l}0.14425 \\
0.14425 \\
0.14425 \\
0.14425 \\
0.14425 \\
0.14425 \\
0.14425 \\
0.14425 \\
0.14425 \\
0.14425\end{array}$ & $\begin{array}{l}0.25298 \\
0.25298 \\
0.25297 \\
0.25297 \\
0.25297 \\
0.25297 \\
0.25297 \\
0.25297 \\
0.25297 \\
0.25297\end{array}$ \\
\hline
\end{tabular}




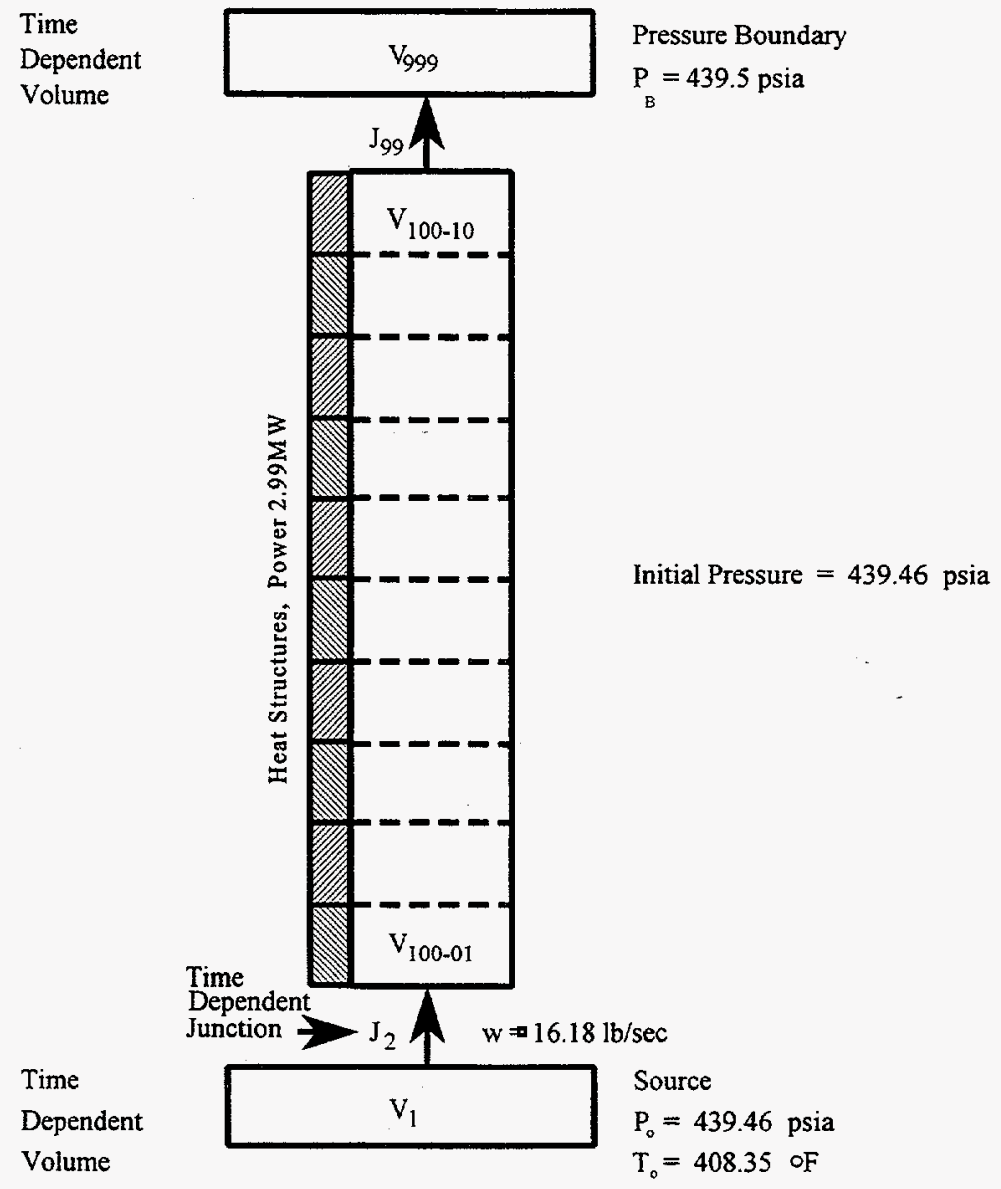

Figure 9.3 FRIGG 36-rod heated bundle schematic 
gives rise to an unrealistic void distribution. ${ }^{1}$ The void fraction increases up the heated section until the liquid subcooling nears zero. At this point the void fraction unexpectedly decreases for several nodes. It then begins to increase toward the exit. A steady-state solution is not reached for the transient solution method, and the void fraction and mass flow rate near the exit oscillate with no observable tendency of approaching a steady solution. Miller ${ }^{2}$ reports that the cause of the error has not been specifically identified, but that it has been corrected in the subsequent code version.

To: avoid the problem described above for the current work, modifications were made to subroutines "phantj" and "fidisj" to force the EPRI drift flux correlation to be used when evaluating the interfacial friction. This eliminated the problem for both the DSSI and transient solution methods. The DSSI method converged in 35 iterations and the resulting pressure, void fraction, temperature, and phasic velocity distributions are shown in Table 9.16.

A transient solution was also used to obtain a steady state using the boundary conditions shown on Figure 9.3. The transient solution is shown in Table 9.17. A steady condition was not obtained at 100.0 seconds (1000 time steps) of transient simulation and there is no indication that it will be reached. This indicates a potential error in MOD3.1 (nearly implicit method). The transient was rerun using the semi-implicit solution method and a steady condition was achieved at 40.0 seconds (400 time steps). The solution given in Table 9.18 agrees well with the DSSI solution. Several of the node pressures differ in the last significant figures $(0.01 \mathrm{psia})$, but this difference could be due to the artificial viscosity terms that are included in the semi-implicit solution. As discussed in Section 3 , these terms are not included in the steady-state momentum equation currently used with the DSSI method.

\subsection{PWR Test Problem}

The first five test problems demonstrate the ability of the DSSI method for single-phase liquid problems with and without heating and Problem 6 demonstrates single-phase vapor. Test Problems 7 and 8 demonstrate the method for two-phase conditions without and with heating. Problem 8 is representative of typical BWR core conditions. All eight of these test problems utilized similar geometries with inlet and exit boundary conditions specified. The final test problem is representative of a single-loop PWR system model which is comprised of a single-phase primary system and a twophase secondary system. Heat transfer through the heat structures representing the steam generator tubes couples the two hydrodynamic systems. A schematic of the model is shown in Figure 9.4 .

The primary system model is comprised of a three-node electrically heated core, a five-node pressurizer model, a three-node steam generator, a single recirculation pump, and a number of other piping volumes. Three nodes are modeled in the bundle region of the steam generator, which supplies a single separator volume. A separate steam bypass volume is connected to the upper plenum and upper downcomer volumes. A two-node lower downcomer connects to the bundle

1 C. S. Miller, EG\&G Idaho, Inc., RELAP5 Trouble Report - Personal Communication, August 1994.

2 C. S. Miller, EG\&G Idaho, Inc., Personal Communcation, October 1994. 
Table 9.16 FRIGG 413149 solution using DSSI

\begin{tabular}{|c|c|c|c|c|c|}
\hline $\begin{array}{l}\text { Volume } \\
\text { Number }\end{array}$ & $\begin{array}{l}\text { Pressure } \\
\text { (psia) }\end{array}$ & $\begin{array}{c}\text { Void } \\
\text { Fraction }\end{array}$ & $\begin{array}{l}\text { Liquid } \\
\text { Temp. (F) }\end{array}$ & $\begin{array}{l}\text { Vapor } \\
\text { Temp. (F) }\end{array}$ & $\begin{array}{l}\text { Saturation } \\
\text { Temp. (F) }\end{array}$ \\
\hline 1-01 & 439.46 & 0.0000 & 408.350 & 453.907 & 453.907 \\
\hline $100-01$ & 442.78 & 0.0471 & 423.568 & 454.661 & 454.661 \\
\hline $100-02$ & 442.10 & 0.1708 & 436.736 & 454.507 & 454.507 \\
\hline $100-03$ & 441.69 & 0.3670 & 446.016 & 454.413 & 454.413 \\
\hline $100-04$ & 441.35 & 0.5352 & 451.034 & 454.337 & 454.337 \\
\hline $100-05$ & 441.05 & 0.6453 & 453.253 & 454.268 & 454.268 \\
\hline $100-06$ & 440.76 & 0.7157 & 454.076 & 454.204 & 454.203 \\
\hline $100-07$ & 440.48 & 0.7651 & 454.133 & 454.140 & 454.140 \\
\hline $100-08$ & 440.24 & 0.7991 & 454.088 & 454.084 & 454.083 \\
\hline $100-09$ & 439.97 & 0.8237 & 454.029 & 454.024 & 454.024 \\
\hline $100-10$ & 439.67 & 0.8442 & 453.960 & 453.954 & 453.954 \\
\hline 999-01 & 439.50 & 0.9128 & 453.916 & 453.916 & 453.916 \\
\hline $\begin{array}{l}\text { Junction } \\
\text { Number }\end{array}$ & $\begin{array}{l}\text { Liquid Vel. } \\
\text { (ft/sec) }\end{array}$ & $\begin{array}{c}\text { Vapor Vel. } \\
\text { (ft/sec) }\end{array}$ & $\begin{array}{c}\text { Mass Flow } \\
\text { (lb/sec) }\end{array}$ & & \\
\hline $2-00$ & 1.9721 & 1.9721 & 16.180 & & \\
\hline $100-01$ & 2.0935 & 2.4415 & 16.180 & & \\
\hline $100-02$ & 2.4240 & 3.2178 & 16.180 & & \\
\hline $100-03$ & 3.1727 & 4.3079 & 16.180 & & \\
\hline $100-04$ & 4.2729 & 6.1602 & 16.180 & & \\
\hline $100-05$ & 5.4974 & 8.4778 & 16.180 & & \\
\hline $100-06$ & 6.7090 & 10.996 & 16.180 & & \\
\hline $100-07$ & 7.9224 & 13.581 & 16.180 & & \\
\hline $100-08$ & 9.0293 & 16.180 & 16.180 & & \\
\hline $100-09$ & 10.023 & 18.784 & 16.180 & & \\
\hline $990-00$ & 11.037 & 21.349 & 16.180 & & \\
\hline
\end{tabular}


Table 9.17 FRIGG 413149 transient solution (nearly implicit)

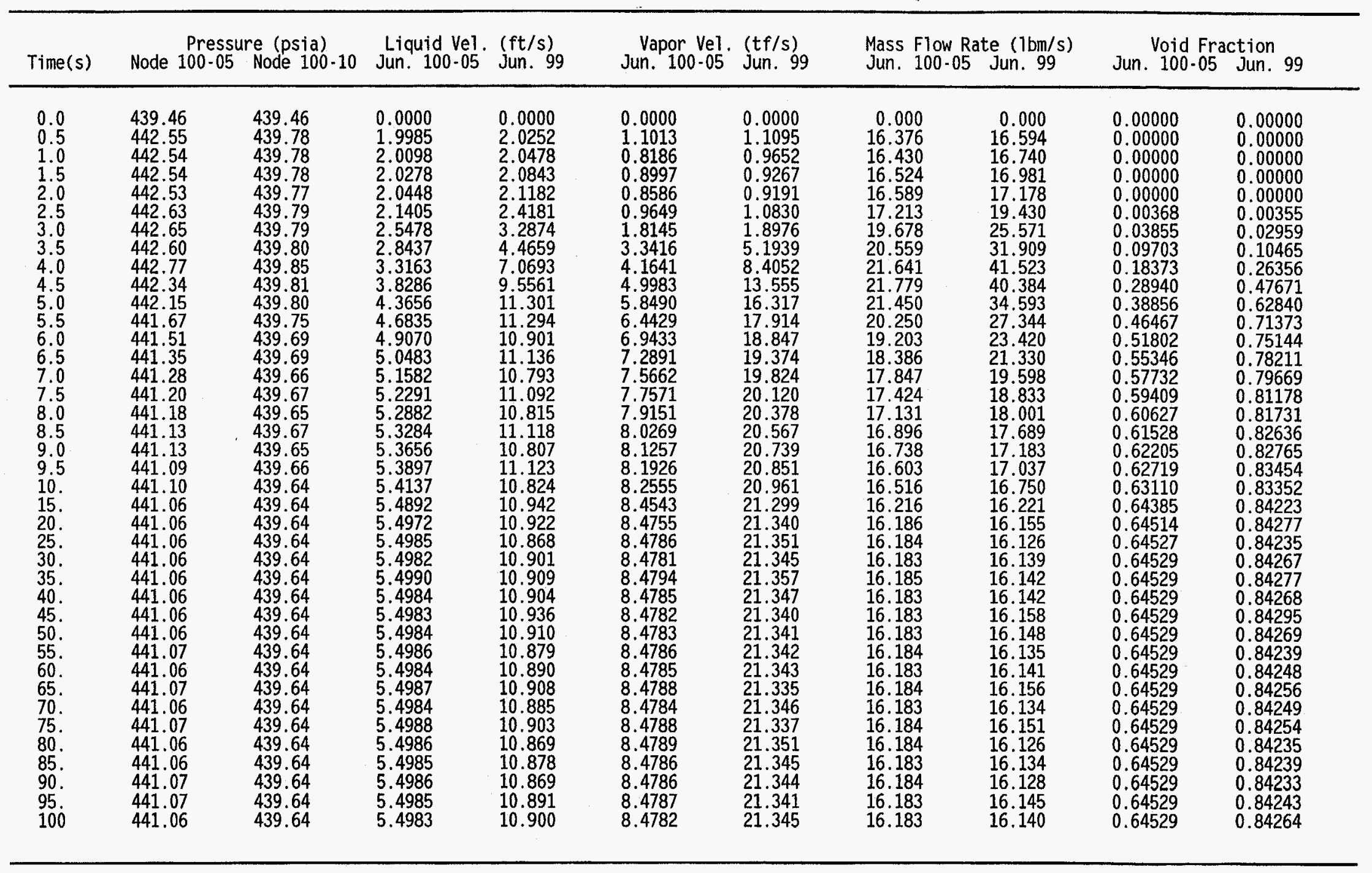


Table 9.18 FRIGG 413149 transient solution (semi-implicit)

\begin{tabular}{|c|c|c|c|c|c|c|c|c|c|c|}
\hline Time(s) & \multicolumn{2}{|c|}{$\begin{array}{l}\text { Pressure (psia) } \\
\text { Node } 100-05 \text { Node } 100-10\end{array}$} & $\begin{array}{l}\text { Liquid Vel } \\
\text { Jun. } 100.05\end{array}$ & $\begin{array}{l}\text { (ft/s) } \\
\text { Jun. } 99\end{array}$ & $\begin{array}{c}\text { Vapor Vel. } \\
\text { Jun. } 100-05\end{array}$ & $\begin{array}{l}(t f / s) \\
\text { Jun. } 99\end{array}$ & \multicolumn{2}{|c|}{$\begin{array}{l}\text { Mass Flow Rate }(1 \mathrm{bm} / \mathrm{s}) \\
\text { Jun. } 100-05 \text { Jun. } 99\end{array}$} & \multicolumn{2}{|c|}{$\begin{array}{l}\text { Void Fraction } \\
\text { Jun. } 100.05 \text { Jun. } 99\end{array}$} \\
\hline $\begin{array}{l} \\
0.0 \\
0.5 \\
1.0 \\
1.5 \\
2.0 \\
2.5 \\
3.0 \\
3.5 \\
4.0 \\
4.5 \\
5.0 \\
5.5 \\
\end{array}$ & $\begin{array}{l}439.46 \\
442.55 \\
442.54 \\
442.54 \\
442.53 \\
442.63 \\
442.64 \\
442.59 \\
442.82 \\
442.19 \\
441.94 \\
441.55 \\
441.40 \\
441.29 \\
441.22 \\
441.18 \\
441.15 \\
441.12 \\
441.11 \\
441.09 \\
441.08 \\
441.06 \\
441.05 \\
441.05 \\
441.05 \\
441.05 \\
441.05 \\
441.05 \\
441.05 \\
441.05 \\
441.05 \\
441.05 \\
441.05 \\
441.05 \\
441.05 \\
441.05 \\
441.05 \\
441.05 \\
441.05\end{array}$ & $\begin{array}{l}439.46 \\
439.78 \\
439.78 \\
439.78 \\
439.77 \\
439.79 \\
439.80 \\
439.81 \\
439.88 \\
439.81 \\
439.76 \\
439.71 \\
439.70 \\
439.68 \\
439.67 \\
439.67 \\
439.67 \\
439.66 \\
439.66 \\
439.66 \\
439.66 \\
439.66 \\
439.66 \\
439.66 \\
439.66 \\
439.66 \\
439.66 \\
439.66 \\
439.66 \\
439.66 \\
439.66 \\
439.66 \\
439.66 \\
439.66 \\
439.66 \\
439.66 \\
439.66 \\
439.66 \\
439.66\end{array}$ & $\begin{array}{l}0.0000 \\
1.9985 \\
2.0098 \\
2.0278 \\
2.0448 \\
2.1544 \\
2.5638 \\
2.8599 \\
3.3996 \\
3.9273 \\
4.4392 \\
4.7172 \\
4.9245 \\
5.0606 \\
5.1596 \\
5.2323 \\
5.2872 \\
5.3305 \\
5.3644 \\
5.3913 \\
5.4127 \\
5.4890 \\
5.4971 \\
5.4980 \\
5.4981 \\
5.4981 \\
5.4981 \\
5.4981 \\
5.4981 \\
5.4981 \\
5.4981 \\
5.4981 \\
5.4981 \\
5.4981 \\
5.4981 \\
5.4981 \\
5.4981 \\
5.4981 \\
5.4981\end{array}$ & $\begin{array}{l}0.0000 \\
2.0252 \\
2.0477 \\
2.0843 \\
2.1183 \\
2.4165 \\
3.2906 \\
4.5105 \\
7.4245 \\
9.8322 \\
10.797 \\
10.814 \\
10.883 \\
10.852 \\
10.854 \\
10.874 \\
10.897 \\
10.919 \\
10.938 \\
10.955 \\
10.969 \\
11.030 \\
11.037 \\
11.038 \\
11.038 \\
11.038 \\
11.038 \\
11.038 \\
11.038 \\
11.038 \\
11.038 \\
11.038 \\
11.038 \\
11.038 \\
11.038 \\
11.038 \\
11.038 \\
11.038 \\
11.038\end{array}$ & $\begin{array}{l}1.0000 \\
1.1013 \\
0.8187 \\
0.8998 \\
0.8586 \\
0.9832 \\
1.8812 \\
3.4509 \\
4.2698 \\
5.1759 \\
6.0044 \\
6.5678 \\
7.0346 \\
7.3600 \\
7.6036 \\
7.7884 \\
7.9310 \\
8.0436 \\
8.1321 \\
8.2020 \\
8.2574 \\
8.4524 \\
8.4731 \\
8.4754 \\
8.4756 \\
8.4756 \\
8.4756 \\
8.4756 \\
8.4756 \\
8.4756 \\
8.4756 \\
8.4756 \\
8.4756 \\
8.4756 \\
8.4756 \\
8.4756 \\
8.4756 \\
8.4756 \\
8.4756\end{array}$ & $\begin{array}{l}1.0000 \\
1.1095 \\
0.9651 \\
0.9267 \\
0.9191 \\
1.0812 \\
1.8503 \\
5.3155 \\
8.9933 \\
14.342 \\
16.832 \\
17.973 \\
18.883 \\
19.430 \\
19.834 \\
20.145 \\
20.389 \\
20.583 \\
20.737 \\
20.859 \\
20.956 \\
21.303 \\
21.340 \\
21.344 \\
21.344 \\
21.344 \\
21.344 \\
21.344 \\
21.344 \\
21.344 \\
21.344 \\
21.344 \\
21.344 \\
21.344 \\
21.344 \\
21.344 \\
21.344 \\
21.344 \\
21.344\end{array}$ & $\begin{array}{r}0.000 \\
16.381 \\
16.438 \\
16.536 \\
16.603 \\
17.380 \\
19.956 \\
20.838 \\
22.254 \\
22.080 \\
21.371 \\
19.975 \\
18.806 \\
18.119 \\
17.646 \\
17.295 \\
17.030 \\
16.832 \\
16.683 \\
16.571 \\
16.486 \\
16.211 \\
16.183 \\
16.180 \\
16.180 \\
16.180 \\
16.180 \\
16.180 \\
16.180 \\
16.180 \\
16.180 \\
16.180 \\
16.180 \\
16.180 \\
16.180 \\
16.180 \\
16.180 \\
16.180 \\
16.180\end{array}$ & $\begin{array}{r}0.000 \\
16.600 \\
16.748 \\
16.995 \\
17.196 \\
19.484 \\
25.868 \\
33.044 \\
44.593 \\
41.220 \\
31.815 \\
24.704 \\
22.411 \\
20.396 \\
19.157 \\
18.363 \\
17.815 \\
17.420 \\
17.127 \\
16.909 \\
16.745 \\
16.236 \\
16.186 \\
16.181 \\
16.180 \\
16.180 \\
16.180 \\
16.180 \\
16.180 \\
16.180 \\
16.180 \\
16.180 \\
16.180 \\
16.180 \\
16.180 \\
16.180 \\
16.180 \\
16.180 \\
16.180\end{array}$ & $\begin{array}{l}0.00000 \\
0.00000 \\
0.00000 \\
0.00000 \\
0.00000 \\
0.00425 \\
0.04142 \\
0.10510 \\
0.20406 \\
0.32014 \\
0.41884 \\
0.48826 \\
0.53419 \\
0.56404 \\
0.58432 \\
0.59889 \\
0.60965 \\
0.61773 \\
0.62385 \\
0.62851 \\
0.63209 \\
0.64397 \\
0.64519 \\
0.64532 \\
0.64533 \\
0.64533 \\
0.64533 \\
0.64533 \\
0.64533 \\
0.64533 \\
0.64533 \\
0.64533 \\
0.64533 \\
0.64533 \\
0.64533 \\
0.64533 \\
0.64533 \\
0.64533 \\
0.64533\end{array}$ & $\begin{array}{l}0.00000 \\
0.00000 \\
0.00000 \\
0.00000 \\
0.00000 \\
0.00326 \\
0.02803 \\
0.10520 \\
0.28926 \\
0.52616 \\
0.66534 \\
0.73062 \\
0.76615 \\
0.78950 \\
0.80442 \\
0.81445 \\
0.82158 \\
0.82683 \\
0.83077 \\
0.83375 \\
0.83602 \\
0.84336 \\
0.84409 \\
0.84417 \\
0.84418 \\
0.84418 \\
0.84418 \\
0.84418 \\
0.84418 \\
0.84418 \\
0.84418 \\
0.84418 \\
0.84418 \\
0.84418 \\
0.84418 \\
0.84418 \\
0.84418 \\
0.84418 \\
0.84418\end{array}$ \\
\hline
\end{tabular}




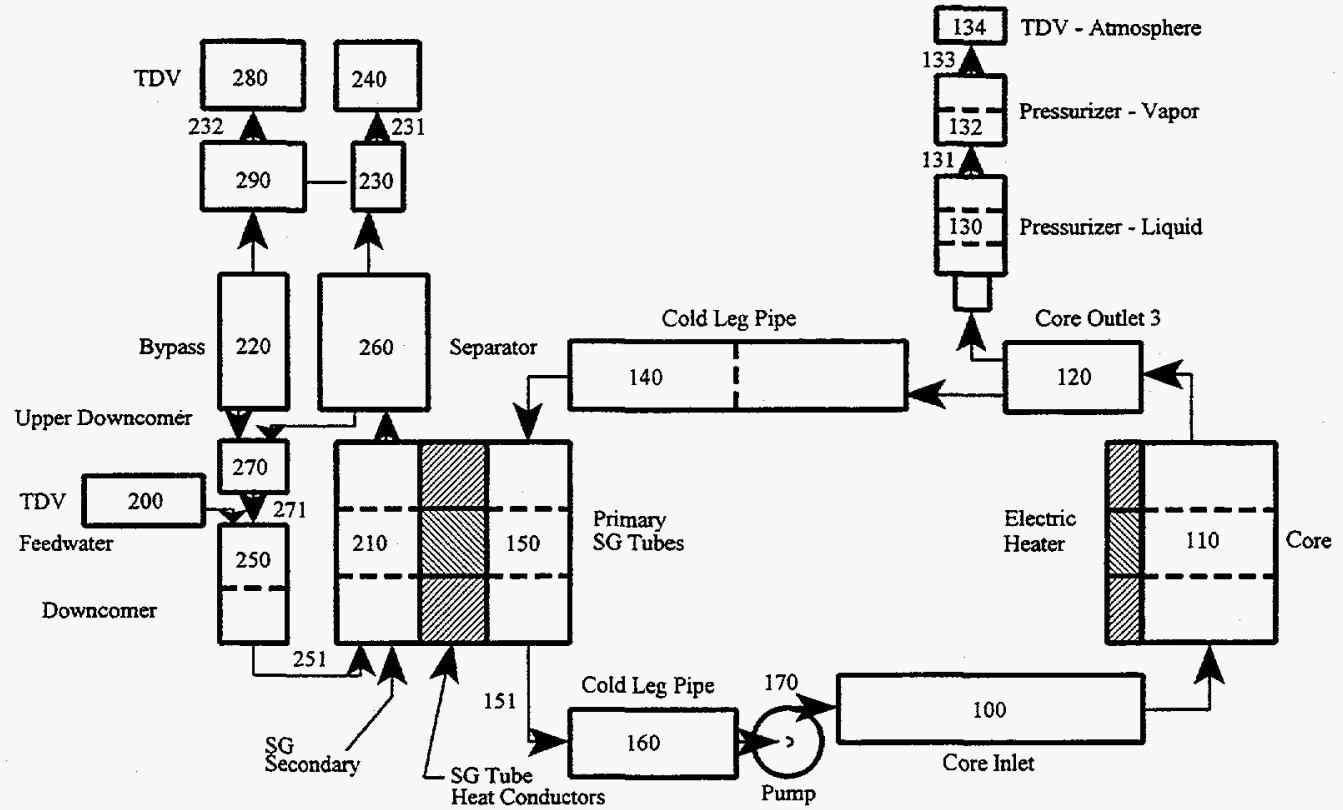

Figure 9.4 PWR test problem schematic

region. A full PWR system model will contain significantly more nodes in both the primary and secondary systems, and multiple steam generator loops may be modeled. However, the general configuration and component selection will be similar to the example problem.

The example PWR problem differs from all previous test problems which were essentially straight pipe problems with specified boundary conditions. Neither the primary nor secondary systems can be initialized to a steady-state condition using only boundary conditions. Initial conditions must be supplied for the primary system pressure and liquid internal energy. While the feedwater flow on the secondary side of the steam generator provides a boundary condition, it is not adequate to uniquely specify the initial state. Initial conditions must also be provided for the pressure and internal energy.

The base model for the PWR demonstration was originally used as a workshop problem to assess the system modeling capability (Ref. 8 ) and to demonstrate the control system features for obtaining a steady-state solution using the RELAP5 "stdy-st" solution scheme. Table 9.19 lists the initial conditions that were given in Reference 8. Some of these initial conditions defined the starting point for the transient solution rather than the desired steady-state initial conditions and are listed in the first column. The second column lists the desired initial conditions as deduced from the steady-state control models. In the original problem, special controller models were included to adjust the feedwater flow to obtain the desired level in the downcomer, another to adjust the steam flow, and another to adjust the pump speed to obtain the desired primary loop flow. A time-dependent volume was used to fix the pressurizer pressure. 
Table 9.19 PWR test problem

\begin{tabular}{lcc}
\hline \multicolumn{1}{c}{ Parameter } & Starting Values & Desired IC \\
\hline Primary System & & \\
Pressurizer Pressure (MPa) & 15.0 & 15.0 \\
Inlet Temperature (K) & 550.0 & 555.5 \\
Mass Flow Rate (kg/s) & 131.0 & 275.0 \\
Core Power (MW) & 50.0 & 50.0 \\
Pump Speed (RPM) & 275.0 & 369.0 \\
Pressurizer Level (M) & 4.5 & 4.5 \\
Secondary System & & \\
Pressure (MPs) & 2.0 & 2.6 \\
Feedwater Mass Flow (kg/s) & 15.0 & 26.5 \\
Feedwater Temperature (K) & 478.0 & 6.5 \\
Downcomer Level (M) & 6.19 & \\
\hline
\end{tabular}

After a steady-state condition was reached using the "stdy-st" option, the problem would have to be renodalized to replace the time-dependent volume representation of the pressurizer with normal volume nodalization. It is unlikely that the pressure specification for the renodalized pressurizer would yield the same pressure gradient as the time-dependent volume. This could lead to an unwanted forcing function at the beginning of a simulation. Additionally, the special steady-state controllers would have to be deactivated or eliminated during the renodalization procedure. These additional model modifications complicate the use of the code and increase the potential for errors. It should also be noted that the steady-state detection logic in the RELAP5 scheme is relatively loose by comparison with the DSSI option.

Figures 9.5 through 9.17 illustrate the approach to a steady-state solution for the base workshop problem. Although not shown, the pump speed controller increased the pump speed from the initial value to $369 \mathrm{rpm}$ to obtain the desired loop flow rate. The higher frequency oscillations shown on some curves are not physical and are possibly related to the code errors discussed above.

The workshop problem was modified to use the DSSI solution option. The desired initial conditions shown in column two of Table 9.19 were specified as input to the new option. Loss coefficients were calculated at the pump exit for the primary system and at the steam dome exit, separator liquid fallback, and bundle inlet junctions for the secondary side. A converged steady-state solution was obtained in 78 iterations. The feedwater liquid internal energy was adjusted by $3.96 \times 10^{4} \mathrm{~J} / \mathrm{kg}$ $\left(8.8^{\circ} \mathrm{K}\right)$ and the separator faliback void fraction was adjusted to be 0.02907 by recomputing the $v_{\text {under }}$ normalization parameter for the separator model. In order to obtain an overall energy balance, the secondary-side reference temperature (saturation) was adjusted by $1.08 \mathrm{~K}$, which corresponds to a pressure change of $0.052 \mathrm{MPa}$. The results obtained using the DSSI solution option are shown as dashed horizontal lines on Figures 9.5 through 9.17. If the high frequency oscillations are ignored, it is evident that the steady-state conditions obtained using the steady-state initialization, are in agreement with the transient solution. 


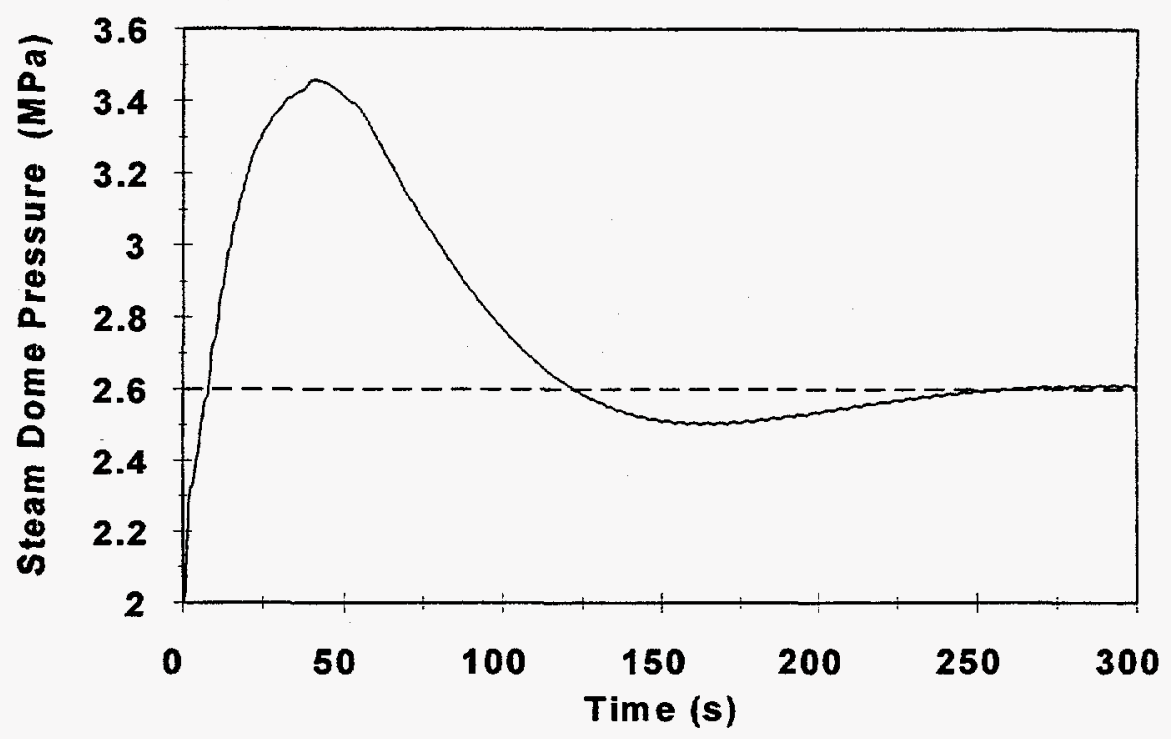

Figure 9.5 RELAP5 "stdy-st" option steam dome pressure

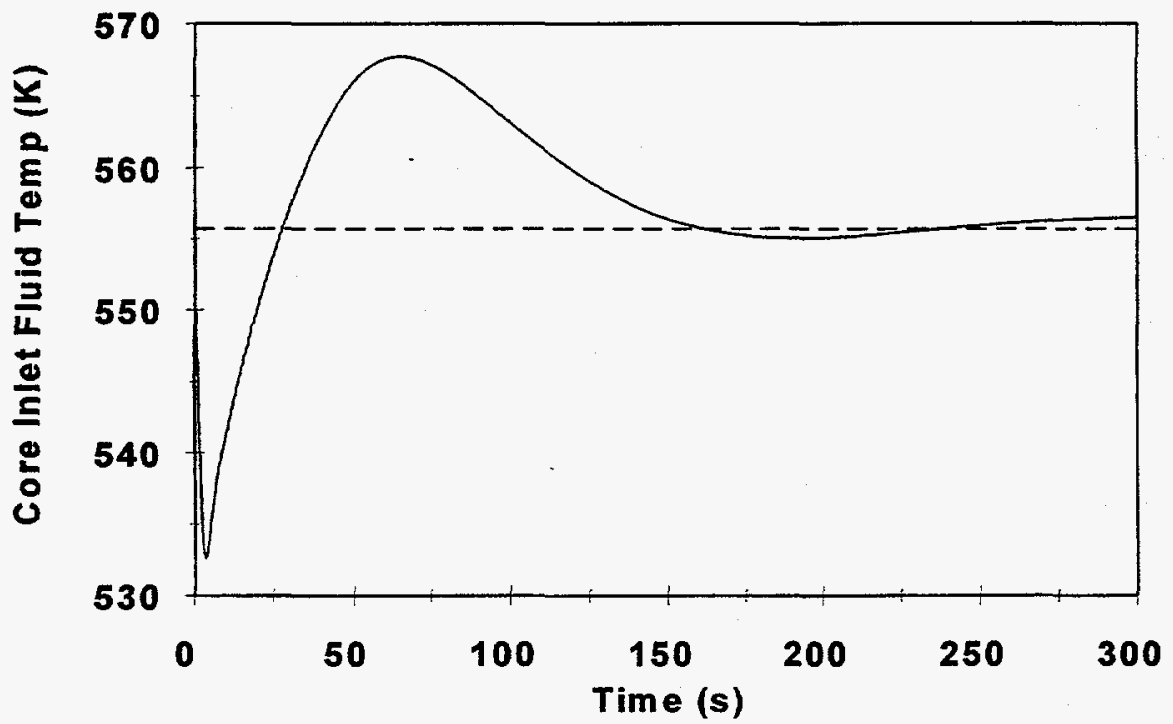

Figure 9.6 RELAP5 "stdy-st" option core inlet fluid temperature 


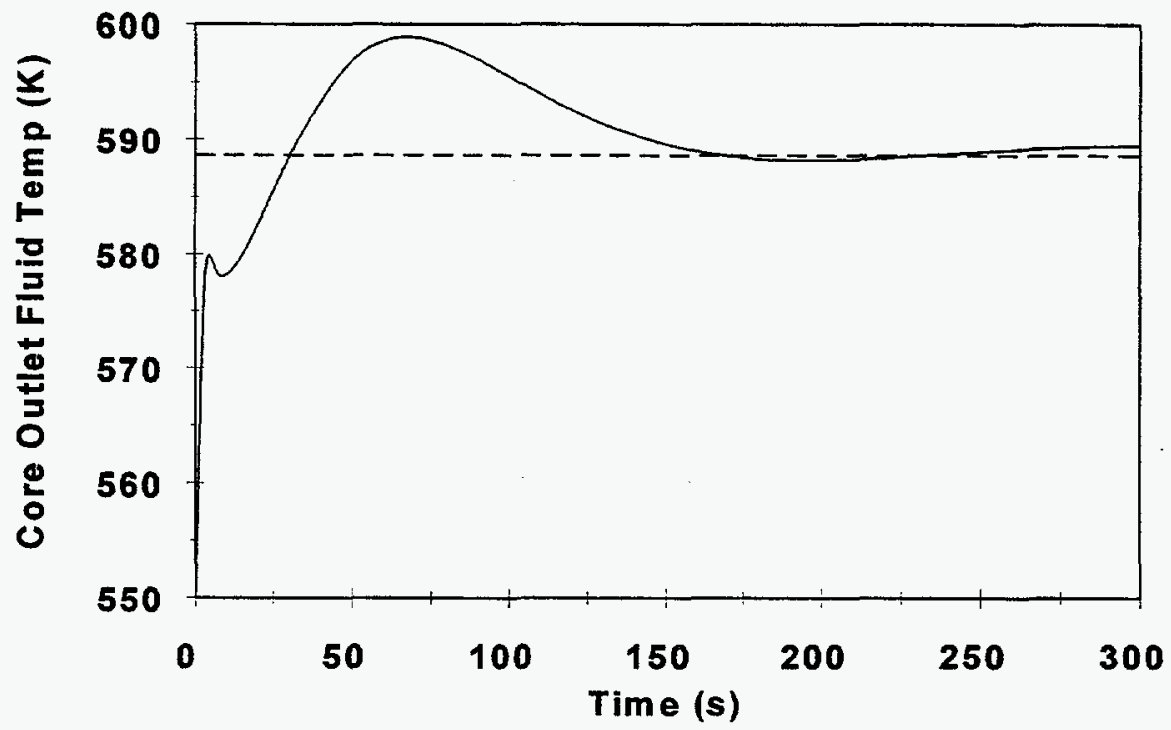

Figure 9.7 RELAP5 "stdy-st" option core outlet fluid temperature

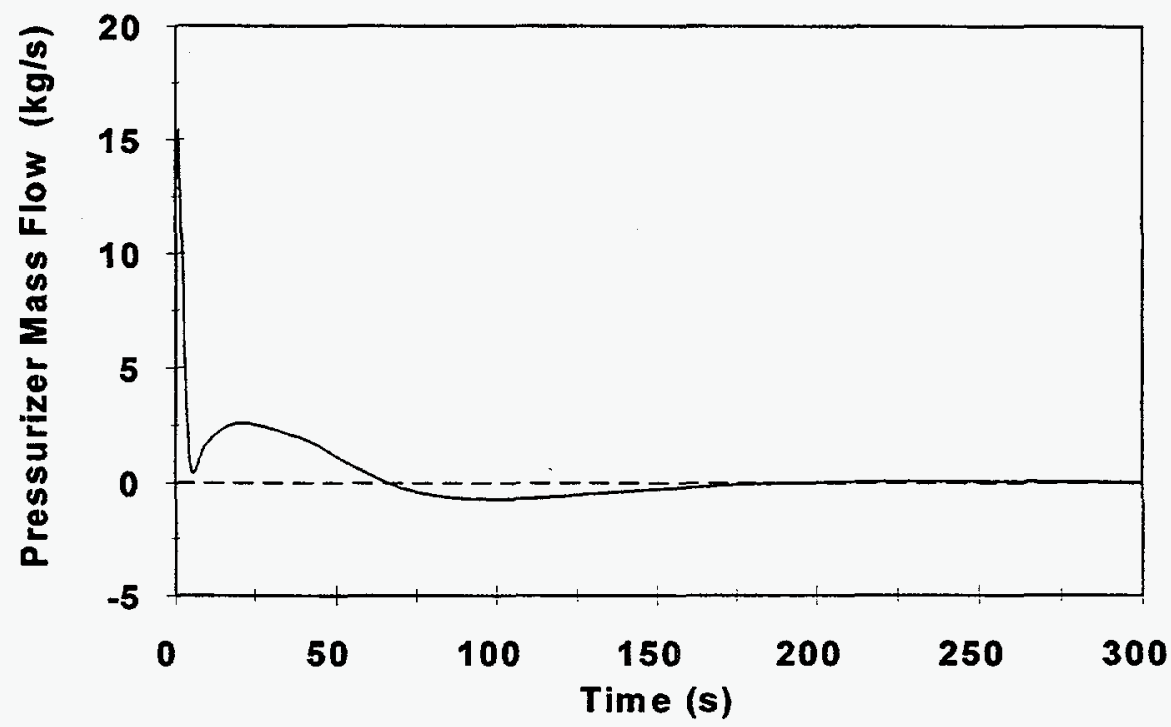

Figure 9.8 RELAP5 "stdy-st" option pressurizer mass flow 


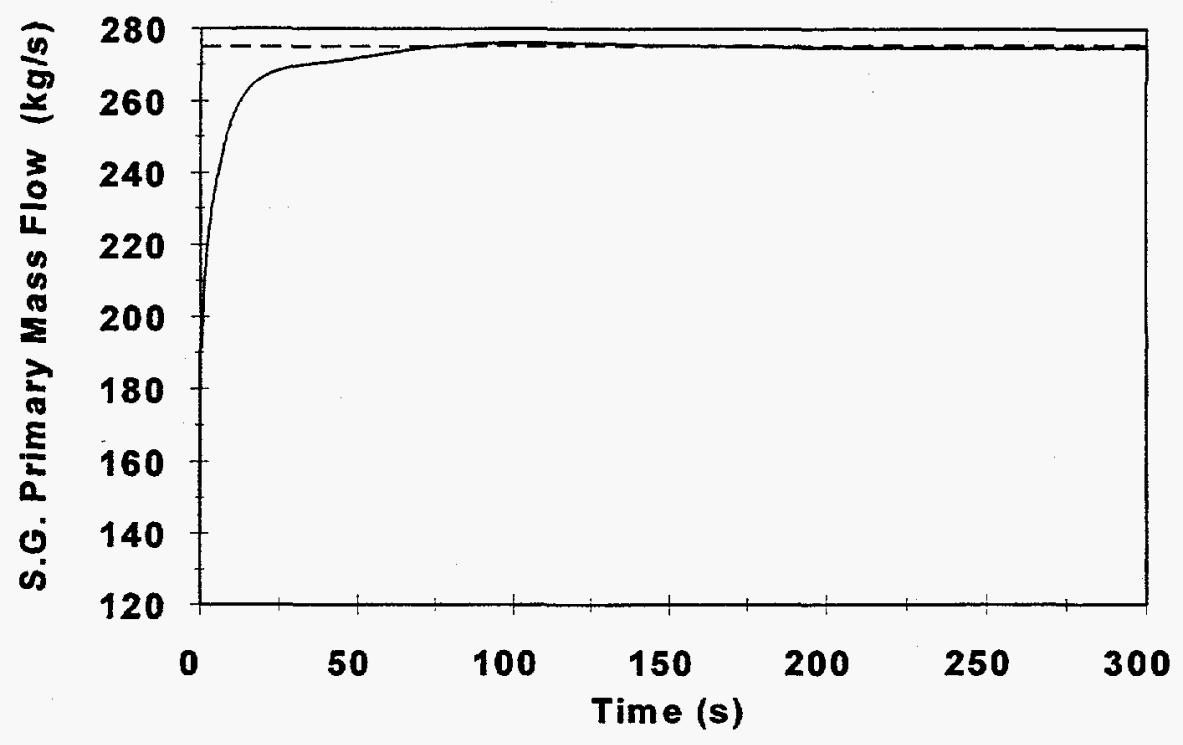

Figure 9.9 RELAP5 "stdy-st" option steam generator primary mass flow

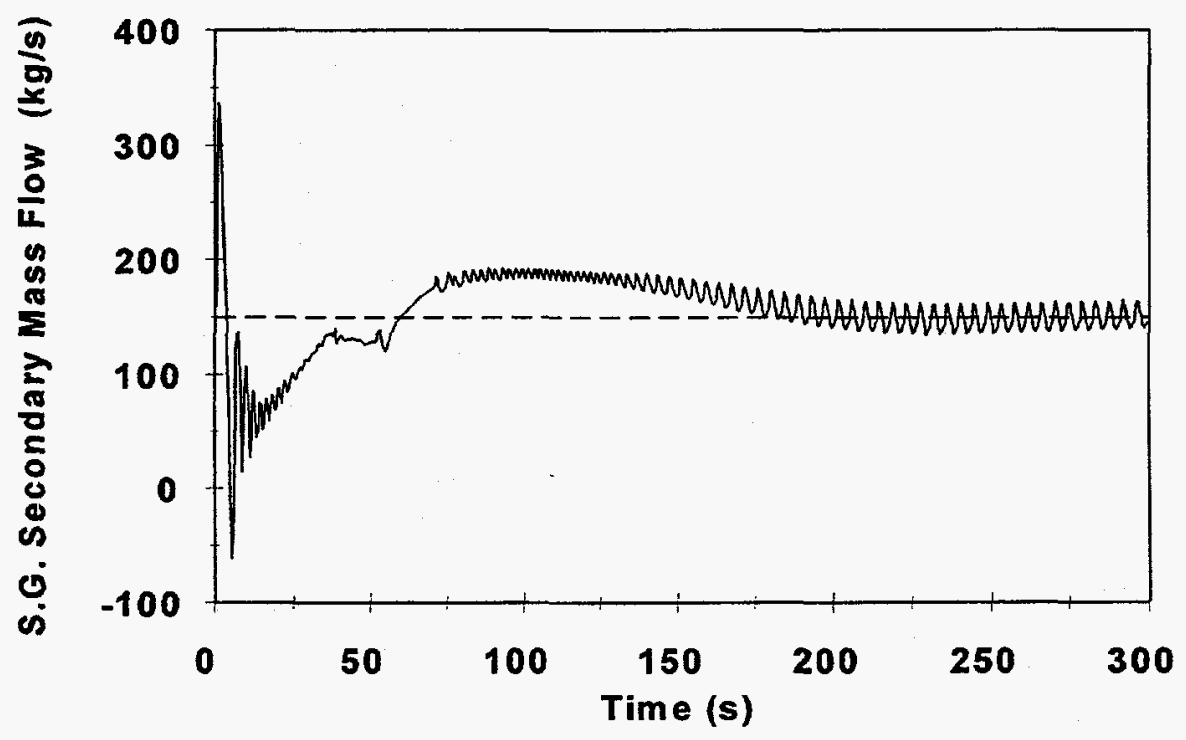

Figure 9.10 RELAP5 "stdy-st" option steam generator secondary mass flow 


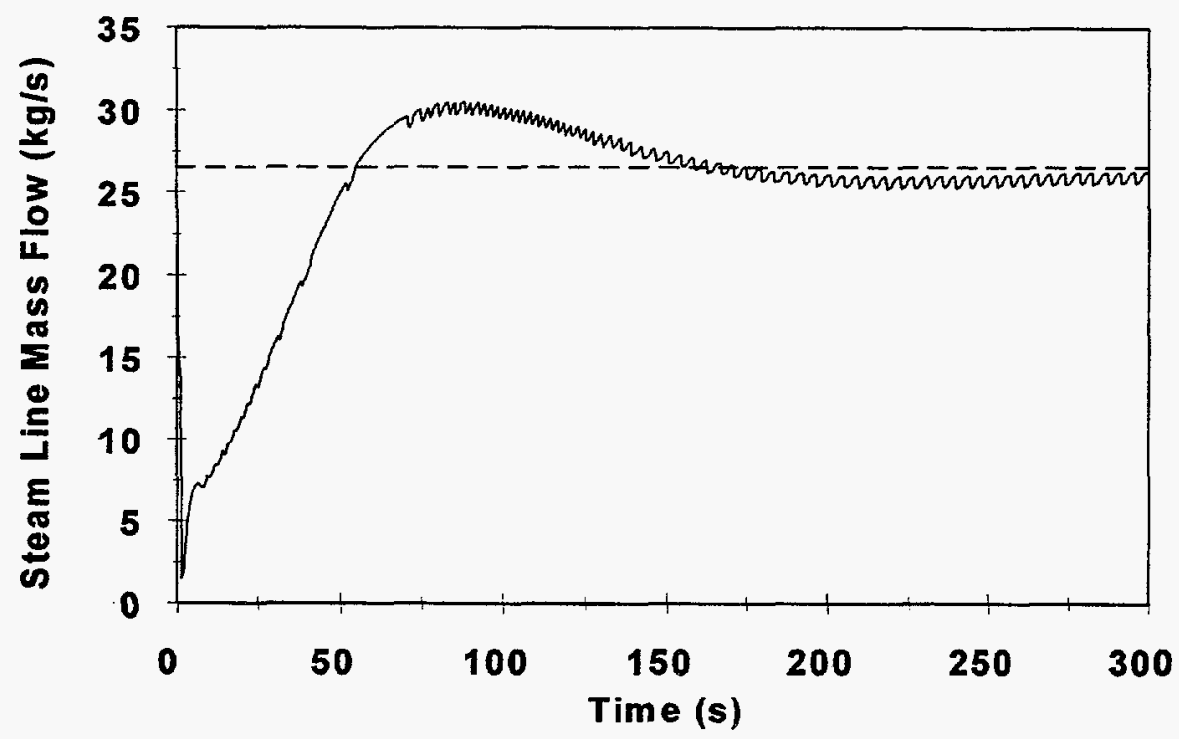

Figure 9.11 RELAP5 "stdy-st" option steam line mass flow

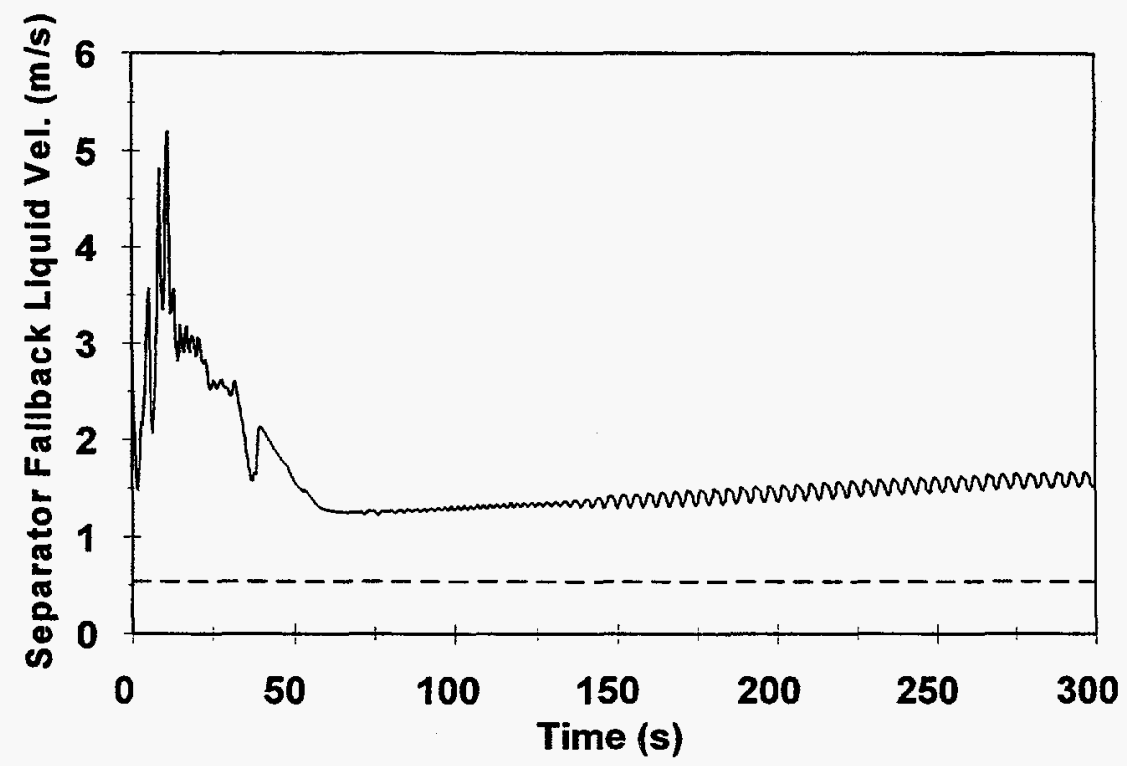

Figure 9.12 RELAP5 "stdy-st" option separator fallback liquid velocity 


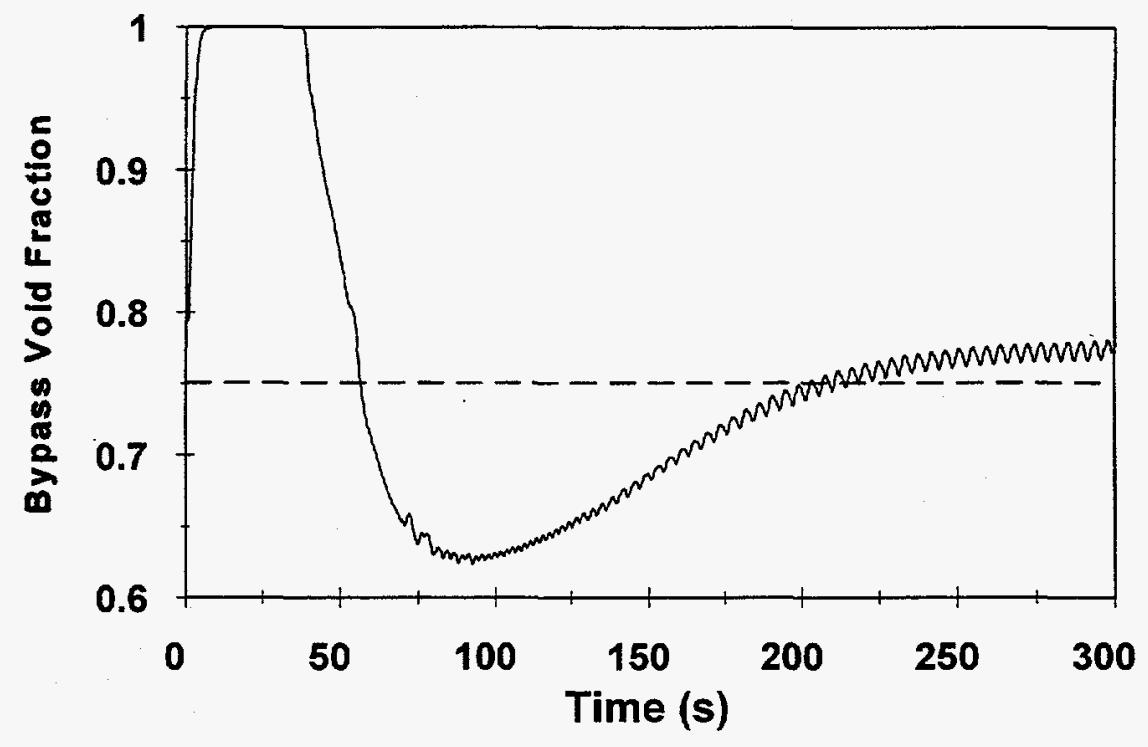

Figure 9.13 RELAP5 "stdy-st" option bypass void fraction

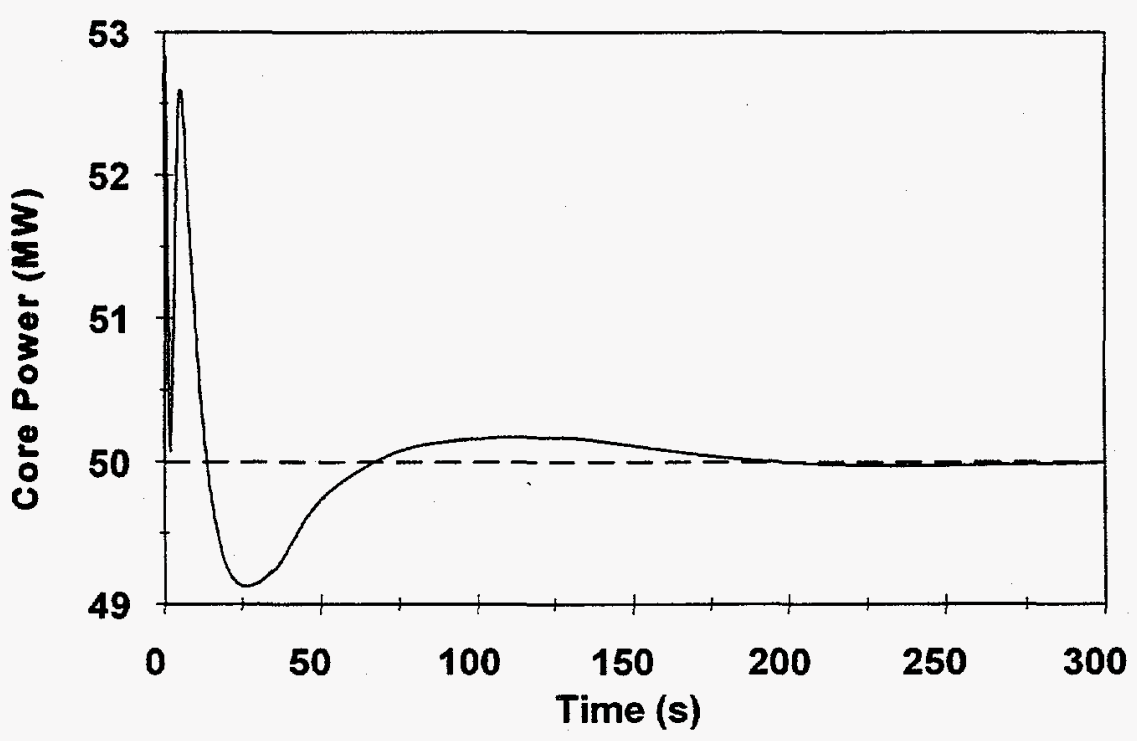

Figure 9.14 RELAP5 "stdy-st" option core power 


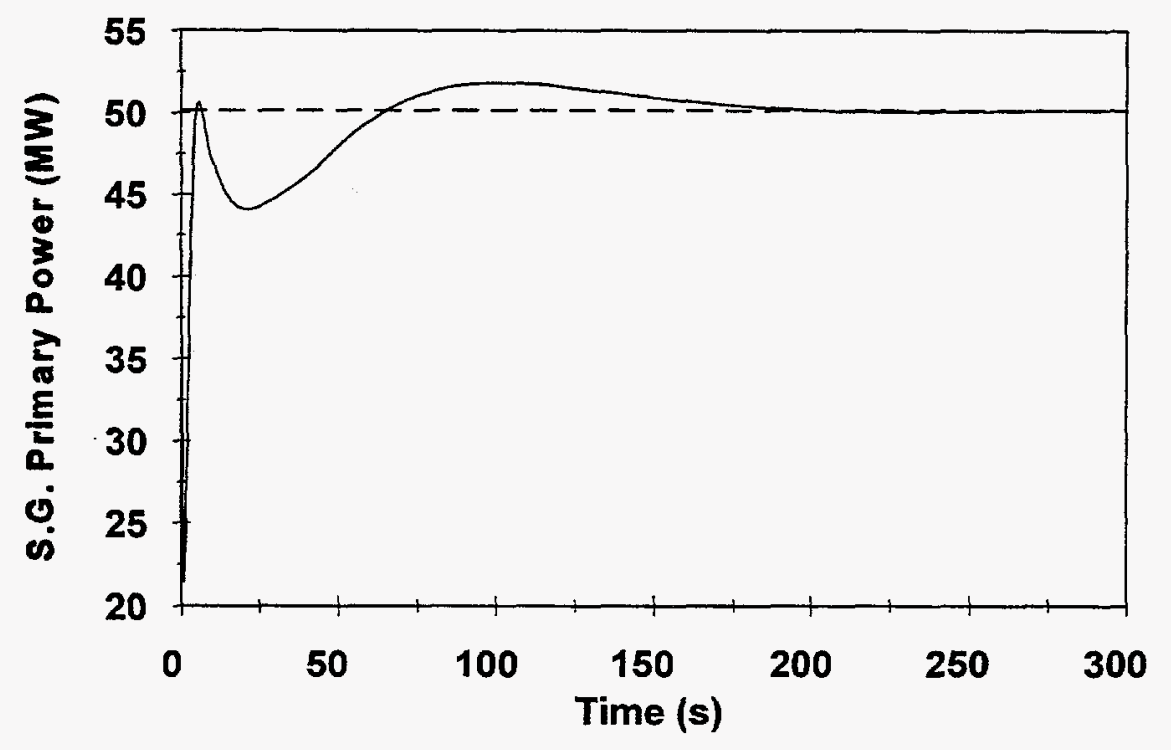

Figure 9.15 RELAP5 "stdy-st" option steam generator primary power

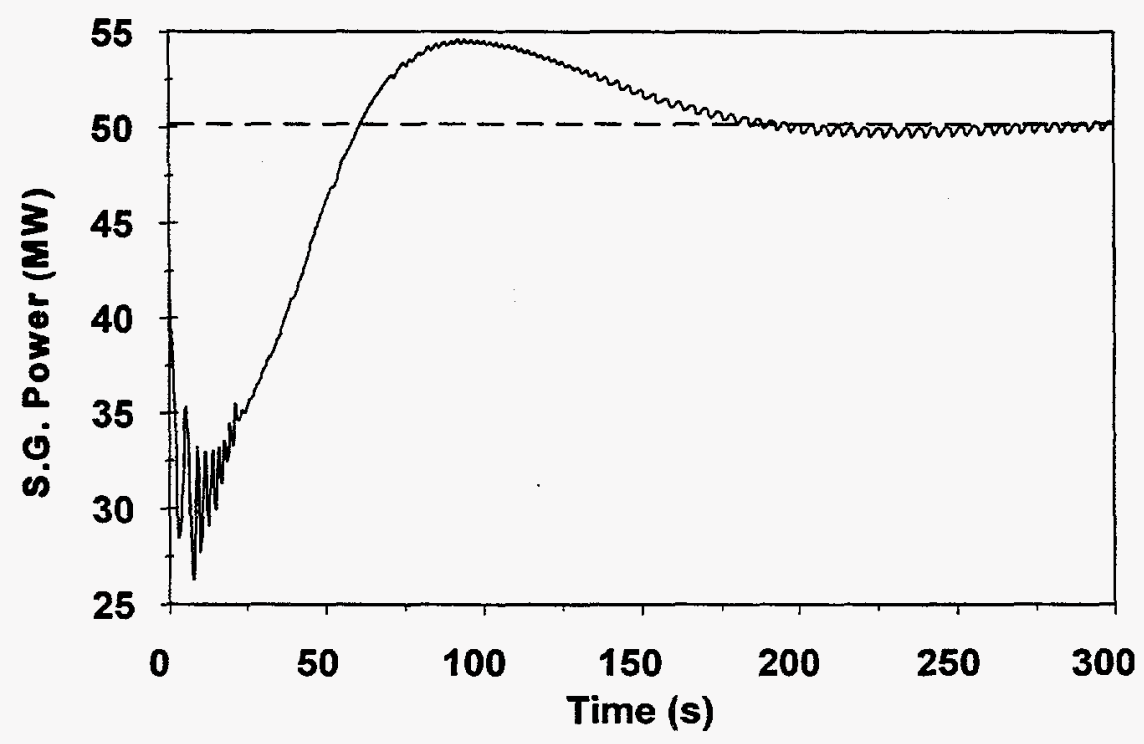

Figure 9.16 RELAP5 "stdy-st" option steam generator power 


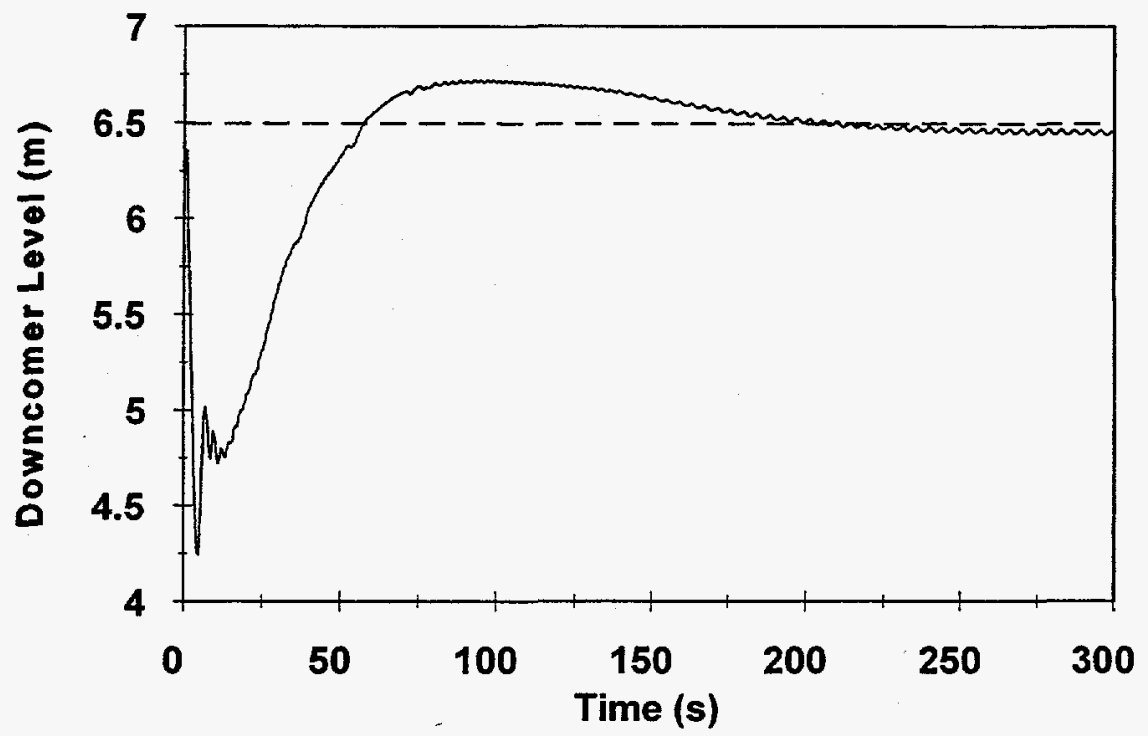

Figure 9.17 RELAP5 "stdy-st" option downcomer level

Tables 9.20 and 9.21 give the DSSI output for the 25th and 78th iterations, respectively. In addition to the component conditions, the current convergence is also given for the various balance equations. Note that the convergence at iteration 25 is better then the transient solution at 300 seconds ( 3000 time steps).

A comparison of the transient solution results at 300 seconds with the converged DSSI results will provide some useful insight into the accuracy of the two methods. In general, the primary-side solutions for both methods converged quickly since they are single-phase liquid. The pump speed controller and core and steam generator heat transfer time constants limit the rate of convergence for the "stdy-st" method. A loop flow rate of $274.95 \mathrm{~kg} / \mathrm{sec}$ was reached at 300 seconds (target value is $275 \mathrm{~kg} / \mathrm{sec}$.

The secondary side is more difficult to converge due to the two-phase conditions that are present. Test Problems 7 and 8 illustrated this fact via the increase in the number of steady-state iterations required to obtain a converged solution with the DSSI method and the number of time advancements for the transient method. Table 9.22 lists a few parameters for the secondary side that indicate the accuracy of the steady-state solutions.

Figure 9.14 demonstrates that the core power (actually convective heat transfer from the electric heaters) peaks at $52.5 \mathrm{Mw}$ but approaches a steady value of $50.0 \mathrm{Mw}$ at 300 seconds. The pump and viscous dissipation for the primary side are not available from the transient solution edits. They 
should be approximately equal to the values for the DSSI solution. The net heat rate for the primary system is then $50.265 \mathrm{MW}$. Figures 9.15 and 9.16 show the heat removal rates for the primary and secondary sides of the steam generator tubes. While they are quite different during the early portions of the transient, they are approaching the correct values at 300 seconds as can be seen in Table 9.22. The differences between the primary-and secondary-side values are due to the thermal time constants associated with the transient heat conduction solution.

For the DSSI method, the primary- and secondary-side heat removal rates are always equal in magnitude as a direct result of the steady-state conduction solution that is employed. The implicit coupling step incorporated in the DSSI scheme ensures that the steam generator heat removal rate matches the core power plus the primary-side dissipation.

The steam generator downcomer level shown in Figure 9.17 drops below $4.5 \mathrm{~m}$ early in the transient simulation, but recovers toward the target $6.5 \mathrm{~m}$ value at 300 seconds. Table 9.22 shows the value to be $6.465 \mathrm{~m}$. The feedwater and steamline flows are related to the level since an imbalance between the two is the mechanism used to change the level. The "stdy-st" controller is attempting to hit the target mixture level. Once this level is reached, the feedwater and steamline flow rates must be equal to satisfy the continuity equation. While the flows are nearly equal, they satisfy the continuity balance within $4 \times 10^{-3}(\triangle W / W)$ were the DSSI convergence is better than $5 \times 10^{-7}$.

The steam generator bundle mass flow rates are also shown in Table 9.22. There is a significant variation, up to six percent, in the flows from the inlet to the exit for the "stdy-st" method. This difference is related to the flow oscillations shown in Figure 9.10.

The DSSI solution converges rapidly and to a much tighter criteria than the transient approach. Also, the DSSI method allows users to specify desired initial conditions rather than requiring controllers to indirectly force the desired conditions on the transient solution. In general, this will allow less experienced code users to obtain better steady-state solutions and in a shorter time period. 
Table 9.20 Sample DSSI solution at iteration 25

RELAP5/3.1 Reactor Loss of Coolant Analysis Program

RELAP5 Direct Steady-State Initialization : Ver. 1.0 - 30/06/95 - Copyright 1995 by Computer Simulation \& Analysis, Inc. PWR DSSI Test Case (based on workshop sample problem no. 2) Iteration $=25$

Trip number, trip time (sec)

$\begin{array}{llll}501 & -1.000000 & 502 & .1 .000000\end{array}$

$\begin{array}{llll}501 & -1.000000 & 502 & -1.000000 \\ 601 & .0000000 \mathrm{E}+00 & 602 & -1.000000\end{array}$

$503.0000000 E+00$

$603-1.000000$

$02: 28: 32$

System 1 *none* mass $=3186.2 \mathrm{~kg}$

Vol.no. pressure voidg tempf
pump-out snglvol

$100 \cdot 010000 \quad 1.50801 E+07$

$110-010000$ pipe $1.51163 \mathrm{E}+07$

$110-020000 \quad 1.51010 \mathrm{E}+07$

$110-030000$ 1.50861E+07

coreout branch

$120-010000$ 1.49666E+07

prsszr pipe

$130-0100001.50524 E+07$

$130-020000 \quad 1.50243 \mathrm{E}+07$

$\begin{array}{ll}130-030000 & 1.50154 \mathrm{E}+07 \\ 130-040000 & 1.50066 \mathrm{E}+07\end{array}$

$130-040000 \quad 1.50066 \mathrm{E}+07$

prssztop pipe $132.0100001 .50014 \mathrm{E}+07$

$132.020000 \quad 1.50000 \mathrm{E}+07$

0000E $+00 \quad 555.494$

tempg

O000E+00 565.954

$0000 E+00 \quad 579.273$

$0000 \mathrm{E}+00 \quad 588.634$

615.708

615.900

615.818

615.739

$.0000 \mathrm{E}+00 \quad 588.600$

0000E+00 615.324

$0000 \mathrm{E}+00 \quad 615.300$

$\begin{array}{ll}000 \mathrm{E}+00 & 615.293 \\ 0000 \mathrm{E}+00 & 615.286\end{array}$

615.102

615.560

615.410

615.363

615.316

$1.000 \quad 615.288$

615.292

przbndry tmdpvo

$1.000 \quad 615.281$

615.281

$134.010000 \quad 1.00000 \mathrm{E}+05$

1.000

372.782

600.000

stgen - in pipe

$140.010000 \quad 1.50091 \mathrm{E}+07$

$140-0200001.50079 \mathrm{E}+07$

$0000 \mathrm{E}+00 \quad 588.612$

$0000 \mathrm{E}+00 \quad 588.612$

615.330

stgen pipe

$150.0100001 .49433 \mathrm{E}+07$

$150.020000 \quad 1.48865 \mathrm{E}+07$

588.612

615.330

$0000 \mathrm{E}+00 \quad 576.156$

$\begin{array}{ll}.0000 E+00 & 565.212 \\ .0000 E+00 & 555.352\end{array}$

614.978

1.48305E+07

614.673

614.372

$160-010000 \quad 1.48306 E+07 \quad .0000 E+00 \quad 555.352$

614.372

pump $=\operatorname{pump}_{369.00}(\mathrm{rad} / \mathrm{sec}) \quad$ head $=2.56795 \mathrm{E}+05(\mathrm{pa})$

$170-010000 \quad 1.50335 \mathrm{E}+07 \quad .0000 \mathrm{E}+00 \quad 555.492 \quad 615.459$

$504-1.000000$

sat. temp.
$(\mathrm{k})$
615.708
615.900
615.818
615.739
615.102
615.560
615.410
615.363
615.316
615.288
615.281
372.782
615.330
615.323
614.978
614.673
614.372
614.372

$604-1.000000$

$506-1.000000$

$605-1.000000$

\begin{tabular}{|c|c|c|}
\hline fvc/voidg & $\begin{array}{l}\text { - Convergence } \\
\text { dug/ug }\end{array}$ & duf/uf \\
\hline $.00000 \mathrm{E}+00$ & $.00000 E+00$ & $.00000 E+00$ \\
\hline $\begin{array}{l}.00000 E+00 \\
1.51622 E-21 \\
. .30808 E-21\end{array}$ & $\begin{array}{r}.00000 \mathrm{E}+00 \\
.9 .02151 \mathrm{E}-23 \\
.00000 \mathrm{E}+00\end{array}$ & $\begin{array}{l}6.31523 \mathrm{E}-10 \\
5.97119 \mathrm{E} \cdot 10 \\
5.73422 \mathrm{E}-10\end{array}$ \\
\hline $.00000 E+00$ & $.00000 E+00$ & $5.73274 \mathrm{E}-10$ \\
\hline $\begin{array}{l}.00000 \mathrm{E}+00 \\
.00000 \mathrm{E}+00 \\
.00000 \mathrm{E}+00 \\
.00000 \mathrm{E}+00\end{array}$ & $\begin{array}{l}.00000 E+00 \\
.00000 E+00 \\
.00000 E+00 \\
.00000 E+00\end{array}$ & $\begin{array}{l}.00000 \mathrm{E}+00 \\
.00000 \mathrm{E}+00 \\
.00000 \mathrm{E}+00 \\
.00000 \mathrm{E}+00\end{array}$ \\
\hline $\begin{array}{l}.00000 \mathrm{E}+00 \\
.00000 \mathrm{E}+00\end{array}$ & $\begin{array}{l}.00000 E+00 \\
.00000 E+00\end{array}$ & $\begin{array}{l}.00000 \mathrm{E}+00 \\
.00000 \mathrm{E}+00\end{array}$ \\
\hline $.00000 E+00$ & $.00000 E+00$ & $.00000 E+00$ \\
\hline $\begin{array}{l}.32373 \mathrm{E}-21 \\
.00000 \mathrm{E}+00\end{array}$ & $\begin{array}{l}.00000 \mathrm{E}+00 \\
.00000 \mathrm{E}+00\end{array}$ & $\begin{array}{l}5.73329 \mathrm{E}-10 \\
5.73324 \mathrm{E}-10\end{array}$ \\
\hline $\begin{array}{l}.00000 E+00 \\
.00000 E+00 \\
5.77626 E-21\end{array}$ & $\begin{array}{r}3.60872 \mathrm{E}-22 \\
.00000 \mathrm{E}+00 \\
.00000 \mathrm{E}+00\end{array}$ & $\begin{array}{l}-3.84598 E-06 \\
-5.63838 E-06 \\
-6.49130 E-06\end{array}$ \\
\hline $.00000 E+00$ & $3.60525 E-22$ & $-6.49157 \mathrm{E}-06$ \\
\hline
\end{tabular}

torque $=.724 .00 \quad(n-m)$

mtr torque $=724.00 \quad(n-m)$

$\begin{array}{llll}615.459 & .00000 E+00 & .00000 E+00 & -6.48717 E-06\end{array}$ 
Table 9.20 (Cont'd)

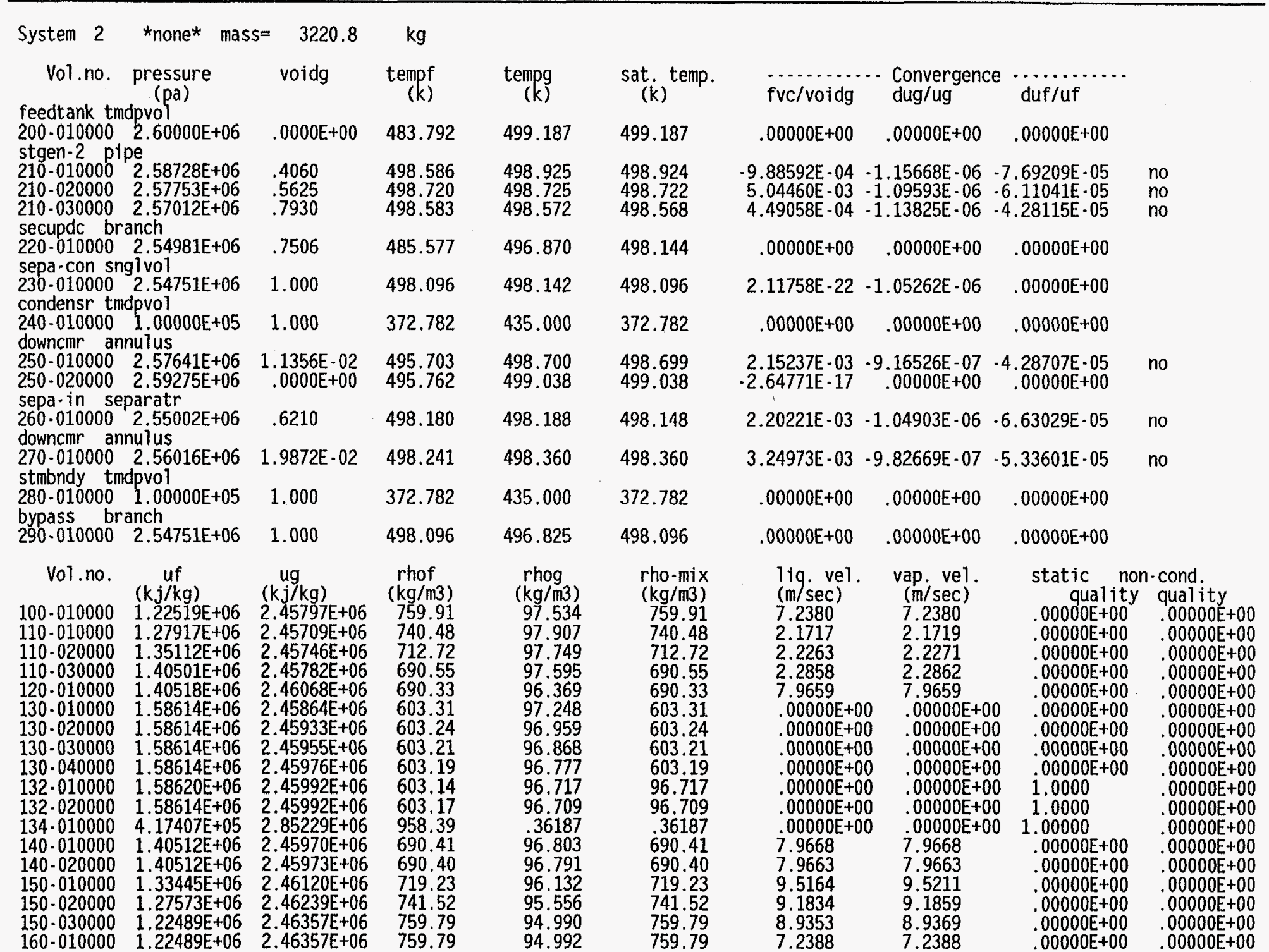


Table 9.20 (Cont'd)

\begin{tabular}{|c|c|c|c|c|c|c|c|c|c|c|}
\hline $\begin{array}{l}170-010000 \\
200-010000\end{array}$ & $\begin{array}{l}1.22526 E+06 \\
8.97880 E+05\end{array}$ & $\begin{array}{l}2.45911 \mathrm{E}+06 \\
2.60153 \mathrm{E}+06\end{array}$ & $\begin{array}{l}759.84 \\
863.30\end{array}$ & $\begin{array}{l}97.053 \\
13.011\end{array}$ & $\begin{array}{l}759.84 \\
863.30\end{array}$ & $\begin{array}{c}5.1704 \\
1.02813 \mathrm{E}-03\end{array}$ & $\begin{array}{c}5.1704 \\
1.02813 \mathrm{E}-03\end{array}$ & $\begin{array}{l}.00000 E+00 \\
.00000 E+00\end{array}$ & $\begin{array}{l}.00000 \mathrm{E}+0 \\
.00000 \mathrm{E}+0\end{array}$ & \\
\hline $\begin{array}{r}\text { Vol.no. } \\
210-010000 \\
210-020000 \\
210-030000 \\
220-010000 \\
230-010000 \\
240-010000 \\
250-010000 \\
250-020000 \\
260-010000 \\
270-010000 \\
280-010000 \\
290-010000\end{array}$ & $\begin{array}{c}u f \\
(\mathrm{kj} / \mathrm{kg}) \\
9.65841 \mathrm{E}+05 \\
9.66453 \mathrm{E}+05 \\
9.65823 \mathrm{E}+05 \\
9.06236 \mathrm{E}+05 \\
9.63582 \mathrm{E}+05 \\
4.17407 \mathrm{E}+05 \\
9.52625 \mathrm{E}+05 \\
9.52900 \mathrm{E}+05 \\
9.63972 \mathrm{E}+05 \\
9.64250 \mathrm{E}+05 \\
4.17407 \mathrm{E}+05 \\
9.63582 \mathrm{E}+05\end{array}$ & $\begin{array}{c}u g \\
(\mathrm{kj/kg}) \\
2.60149 \mathrm{E}+06 \\
2.60146 \mathrm{E}+06 \\
2.60144 \mathrm{E}+06 \\
2.59815 \mathrm{E}+06 \\
2.60146 \mathrm{E}+06 \\
2.60058 \mathrm{E}+06 \\
2.60145 \mathrm{E}+06 \\
2.60151 \mathrm{E}+06 \\
2.60145 \mathrm{E}+06 \\
2.60139 \mathrm{E}+06 \\
2.60058 \mathrm{E}+06 \\
2.59815 \mathrm{E}+06\end{array}$ & $\begin{array}{l}\begin{array}{c}r h o f \\
(\mathrm{~kg} / \mathrm{m} 3)\end{array} \\
833.37 \\
833.18 \\
833.36 \\
850.30 \\
833.99 \\
958.39 \\
837.23 \\
837.16 \\
833.88 \\
833.81 \\
958.39 \\
833.99\end{array}$ & $\begin{array}{l}\text { rhog } \\
(\mathrm{kg} / \mathrm{m} 3) \\
12.948 \\
12.900 \\
12.863 \\
12.821 \\
12.748 \\
.50187 \\
12.894 \\
12.975 \\
12.761 \\
12.813 \\
50187 \\
12.810\end{array}$ & $\begin{array}{c}\mathrm{rho} \cdot \mathrm{mix} \\
(\mathrm{kg} / \mathrm{m} 3) \\
500.27 \\
371.78 \\
182.74 \\
221.71 \\
12.748 \\
50187 \\
827.86 \\
837.16 \\
323.97 \\
817.49 \\
50187 \\
12.810\end{array}$ & $\begin{array}{l}\text { lig. vel. } \\
\text { (m/sec) } \\
.39830 \\
.53861 \\
.67602 \\
.00000 \mathrm{E}+00 \\
20.727 \\
2.0748 \\
.60547 \\
.60058 \\
9.03898 \mathrm{E}-04 \\
.50519 \\
.00000 \mathrm{E}+00 \\
.00000 \mathrm{E}+00\end{array}$ & $\begin{array}{l}\text { vap. vel. } \\
\text { (m/sec) } \\
2.1140 \\
2.9604 \\
3.7649 \\
.00000 \mathrm{E}+00 \\
20.727 \\
2.0748 \\
.60833 \\
.67187 \\
12.283 \\
.50066 \\
.00000 \mathrm{E}+00 \\
.00000 \mathrm{E}+00\end{array}$ & $\begin{array}{c}\text { static no } \\
\text { qual it } \\
1.05085 \mathrm{E}-02 \\
1.95167 \mathrm{E}-02 \\
5.58148 \mathrm{E}-02 \\
4.34054 \mathrm{E}-02 \\
1.0000 \\
1.0000 \\
1.76864 \mathrm{E}-04 \\
.00000 \mathrm{E}+00 \\
2.44605 \mathrm{E}-02 \\
3.11472 \mathrm{E}-04 \\
1.0000 \\
1.0000\end{array}$ & $\begin{array}{l}\text { on-cond. } \\
y \quad \text { qual ity } \\
.00000 \mathrm{E}+0 \\
.00000 \mathrm{E}+0 \\
.00000 \mathrm{E}+0 \\
.00000 \mathrm{E}+0 \\
.00000 \mathrm{E}+0 \\
.00000 \mathrm{E}+0 \\
.00000 \mathrm{E}+0 \\
.00000 \mathrm{E}+0 \\
.00000 \mathrm{E}+0 \\
.00000 \mathrm{E}+0 \\
.00000 \mathrm{E}+0 \\
.00000 \mathrm{E}+0\end{array}$ & \\
\hline $\begin{array}{l}\text { Vol.no. } \\
100 \cdot 010000 \\
110 \cdot 010000 \\
110-020000 \\
110 \cdot 030000 \\
120 \cdot 010000 \\
130-010000 \\
130-020000 \\
130-030000 \\
130 \cdot 040000 \\
132 \cdot 010000 \\
132-020000 \\
134-010000 \\
140-010000 \\
140-020000 \\
150-010000 \\
150-020000 \\
150-030000 \\
160-010000 \\
170-010000 \\
200-010000 \\
210-010000 \\
210 \cdot 020000 \\
210-030000 \\
220 \cdot 010000 \\
230-010000 \\
240-010000 \\
250-010000 \\
250-020000\end{array}$ & $\begin{array}{r}\text { tot.ht.jnp } \\
(\text { watts) } \\
.00000 \mathrm{E}+00 \\
1.50000 \mathrm{E}+07 \\
2.00000 \mathrm{E}+07 \\
1.50000 \mathrm{E}+07 \\
.00000 \mathrm{E}+00 \\
.00000 \mathrm{E}+00 \\
.00000 \mathrm{E}+00 \\
.00000 \mathrm{E}+00 \\
.00000 \mathrm{E}+00 \\
.00000 \mathrm{E}+00 \\
.00000 \mathrm{E}+00 \\
.00000 \mathrm{E}+00 \\
.00000 \mathrm{E}+00 \\
.00000 \mathrm{E}+00 \\
-1.97304 \mathrm{E}+07 \\
.1 .63712 \mathrm{E}+07 \\
.1 .41603 \mathrm{E}+07 \\
.00000 \mathrm{E}+00 \\
.00000 \mathrm{E}+00 \\
.00000 \mathrm{E}+00 \\
1.41603 \mathrm{E}+07 \\
1.63712 \mathrm{E}+07 \\
1.97304 \mathrm{E}+07 \\
.00000 \mathrm{E}+00 \\
.00000 \mathrm{E}+00 \\
.00000 \mathrm{E}+00 \\
.00000 \mathrm{E}+00 \\
.00000 \mathrm{E}+00\end{array}$ & $\begin{array}{c}\text { vap.ht. inp } \\
\text { (watts) } \\
.00000 \mathrm{E}+00 \\
.00000 \mathrm{E}+00 \\
.00000 \mathrm{E}+00 \\
.00000 \mathrm{E}+00 \\
.00000 \mathrm{E}+00 \\
.00000 \mathrm{E}+00 \\
.00000 \mathrm{E}+00 \\
.00000 \mathrm{E}+00 \\
.00000 \mathrm{E}+00 \\
.00000 \mathrm{E}+00 \\
.00000 \mathrm{E}+00 \\
.00000 \mathrm{E}+00 \\
.00000 \mathrm{E}+00 \\
.00000 \mathrm{E}+00 \\
.00000 \mathrm{E}+00 \\
.00000 \mathrm{E}+00 \\
.00000 \mathrm{E}+00 \\
.00000 \mathrm{E}+00 \\
.00000 \mathrm{E}+00 \\
.00000 \mathrm{E}+00 \\
.00000 \mathrm{E}+00 \\
.00000 \mathrm{E}+00 \\
.00000 \mathrm{E}+00 \\
.00000 \mathrm{E}+00 \\
.00000 \mathrm{E}+00 \\
.00000 \mathrm{E}+00 \\
.00000 \mathrm{E}+00 \\
.00000 \mathrm{E}+00\end{array}$ & $\begin{array}{c}\text { vapor-gen. } \\
(\mathrm{kg} / \mathrm{sec} \cdot \mathrm{m} 3) \\
.00000 \mathrm{E}+00 \\
.00000 \mathrm{E}+00 \\
.00000 \mathrm{E}+00 \\
.00000 \mathrm{E}+00 \\
.00000 \mathrm{E}+00 \\
.00000 \mathrm{E}+00 \\
.00000 \mathrm{E}+00 \\
.00000 \mathrm{E}+00 \\
.00000 \mathrm{E}+00 \\
.00000 \mathrm{E}+00 \\
.00000 \mathrm{E}+00 \\
.00000 \mathrm{E}+00 \\
.00000 \mathrm{E}+00 \\
.00000 \mathrm{E}+00 \\
.00000 \mathrm{E}+00 \\
.00000 \mathrm{E}+00 \\
.00000 \mathrm{E}+00 \\
.00000 \mathrm{E}+00 \\
.00000 \mathrm{E}+00 \\
.00000 \mathrm{E}+00 \\
5.5824 \\
7.4694 \\
9.0687 \\
-5.8168 \\
.00000 \mathrm{E}+00 \\
.00000 \mathrm{E}+00 \\
-1.29351 \mathrm{E}-02 \\
.00000 \mathrm{E}+00\end{array}$ & $\begin{array}{c}\text { wall flashing } \\
(\mathrm{kg} / \mathrm{sec}-\mathrm{m} 3) \\
.00000 \mathrm{E}+00 \\
.00000 \mathrm{E}+00 \\
.00000 \mathrm{E}+00 \\
.00000 \mathrm{E}+00 \\
.00000 \mathrm{E}+00 \\
.00000 \mathrm{E}+00 \\
.00000 \mathrm{E}+00 \\
.00000 \mathrm{E}+00 \\
.00000 \mathrm{E}+00 \\
.00000 \mathrm{E}+00 \\
.00000 \mathrm{E}+00 \\
.00000 \mathrm{E}+00 \\
.00000 \mathrm{E}+00 \\
.00000 \mathrm{E}+00 \\
.00000 \mathrm{E}+00 \\
.00000 \mathrm{E}+00 \\
.00000 \mathrm{E}+00 \\
.00000 \mathrm{E}+00 \\
.00000 \mathrm{E}+00 \\
.00000 \mathrm{E}+00 \\
6.0923 \\
7.4190 \\
8.9395 \\
.00000 \mathrm{E}+00 \\
.00000 \mathrm{E}+00 \\
.00000 \mathrm{E}+00 \\
.00000 \mathrm{E}+00 \\
.00000 \mathrm{E}+00\end{array}$ & $\begin{array}{c}1 \text { liq.int.htc } \\
(w a t t s / m 3-k) \\
.00000 \mathrm{E}+00 \\
.00000 \mathrm{E}+00 \\
.00000 \mathrm{E}+00 \\
.00000 \mathrm{E}+00 \\
.00000 \mathrm{E}+00 \\
.00000 \mathrm{E}+00 \\
.00000 \mathrm{E}+00 \\
.00000 \mathrm{E}+00 \\
.00000 \mathrm{E}+00 \\
1.01053 \mathrm{E}+11 \\
1.01058 \mathrm{E}+11 \\
1.00000 \mathrm{E}+12 \\
.00000 \mathrm{E}+00 \\
.00000 \mathrm{E}+00 \\
.00000 \mathrm{E}+00 \\
.00000 \mathrm{E}+00 \\
.00000 \mathrm{E}+00 \\
.00000 \mathrm{E}+00 \\
.00000 \mathrm{E}+00 \\
.00000 \mathrm{E}+00 \\
2.91578 \mathrm{E}+06 \\
8.68148 \mathrm{E}+06 \\
1.14927 \mathrm{E}+07 \\
139.54 \\
1.05031 \mathrm{E}+08 \\
1.00000 \mathrm{E}+12 \\
8098.8 \\
.00000 \mathrm{E}+00\end{array}$ & $\begin{array}{l}\text { vap.int.htc } \\
\text { (watts/m3-k) } \\
3.10820 \mathrm{E}+07 \\
3.10820 \mathrm{E}+07 \\
3.10820 \mathrm{E}+07 \\
3.10820 \mathrm{E}+07 \\
3.10820 \mathrm{E}+07 \\
3.10820 \mathrm{E}+07 \\
3.10820 \mathrm{E}+07 \\
3.10820 \mathrm{E}+07 \\
3.10820 \mathrm{E}+07 \\
.00000 \mathrm{E}+00 \\
.00000 \mathrm{E}+00 \\
.00000 \mathrm{E}+00 \\
3.10820 \mathrm{E}+07 \\
3.10820 \mathrm{E}+07 \\
3.10820 \mathrm{E}+07 \\
3.10820 \mathrm{E}+07 \\
3.10820 \mathrm{E}+07 \\
3.10820 \mathrm{E}+07 \\
3.10820 \mathrm{E}+07 \\
1.00000 \mathrm{E}+12 \\
2.95946 \mathrm{E}+05 \\
1.14235 \mathrm{E}+05 \\
1.46701 \mathrm{E}+05 \\
8.34972 \mathrm{E}+06 \\
.00000 \mathrm{E}+00 \\
.00000 \mathrm{E}+00 \\
6.19106 \mathrm{E}+05 \\
3.10820 \mathrm{E}+07\end{array}$ & $\begin{array}{l}\text { mass-flux } \\
(\mathrm{kg} / \mathrm{sec}-\mathrm{m} 2) \\
5500.0 \\
1617.6 \\
1617.6 \\
1617.6 \\
5500.0 \\
.00000 \mathrm{E}+00 \\
.00000 \mathrm{E}+00 \\
.00000 \mathrm{E}+00 \\
.00000 \mathrm{E}+00 \\
.00000 \mathrm{E}+00 \\
.00000 \mathrm{E}+00 \\
.00000 \mathrm{E}+00 \\
5500.0 \\
5500.0 \\
6707.3 \\
6707.3 \\
6707.3 \\
5500.0 \\
3928.6 \\
44379 \\
250.00 \\
250.00 \\
250.00 \\
.00000 \mathrm{E}+00 \\
264.50 \\
13.225 \\
500.00 \\
500.00\end{array}$ & $\begin{array}{l}\text { Reynolds } \\
7 \text { iquidd } \\
1.42452 \mathrm{E}+07 \\
8.77638 \mathrm{E}+05 \\
9.22543 \mathrm{E}+05 \\
9.60156 \mathrm{E}+05 \\
1.61546 \mathrm{E}+07 \\
.00000 \mathrm{E}+00 \\
.00000 \mathrm{E}+00 \\
.00000 \mathrm{E}+00 \\
.00000 \mathrm{E}+00 \\
.00000 \mathrm{E}+00 \\
.00000 \mathrm{E}+00 \\
.00000 \mathrm{E}+00 \\
1.61532 \mathrm{E}+07 \\
1.61533 \mathrm{E}+07 \\
7.56130 \mathrm{E}+05 \\
7.27135 \mathrm{E}+05 \\
7.03079 \mathrm{E}+05 \\
1.42473 \mathrm{E}+07 \\
1.20408 \mathrm{E}+07 \\
20585 \\
2.16761 \mathrm{E}+05 \\
2.05394 \mathrm{E}+05 \\
1.90695 \mathrm{E}+05 \\
.00000 \mathrm{E}+00 \\
5.19529 \mathrm{E} \cdot 08 \\
3.48580 \mathrm{E} \\
7.09 \\
7.49267 \mathrm{E}+05 \\
7.49541 \mathrm{E}+05\end{array}$ & $\begin{array}{l}\text { Reynolds } \\
\text { vapor } \\
7.45651 \mathrm{E}-09 \\
4.50230 \mathrm{E}-10 \\
4.65804 \mathrm{E}-10 \\
4.81921 \mathrm{E} \cdot 10 \\
8.22815 \mathrm{E}-09 \\
.00000 \mathrm{E}+00 \\
.00000 \mathrm{E}+00 \\
.00000 \mathrm{E}+00 \\
.00000 \mathrm{E}+00 \\
.00000 \mathrm{E}+00 \\
.00000 \mathrm{E}+00 \\
.00000 \mathrm{E}+00 \\
8.17748 \mathrm{E}-09 \\
8.19538 \mathrm{E}-09 \\
3.96296 \mathrm{E}-10 \\
3.81015 \mathrm{E}-10 \\
3.69547 \mathrm{E}-10 \\
7.37523 \mathrm{E} \cdot 09 \\
6.23503 \mathrm{E}-09 \\
2.48835 \mathrm{E}-12 \\
35202\end{array}$ & $\begin{array}{l}\text { flow } \\
\text { regi } \\
\text { bby } \\
\text { bby } \\
\text { bby } \\
\text { bby } \\
\text { bby } \\
\text { bby } \\
\text { bby } \\
\text { bby } \\
\text { bby } \\
\text { mpr } \\
\text { mpr } \\
\text { mpr } \\
\text { bby } \\
\text { bby } \\
\text { bby } \\
\text { bby } \\
\text { bby } \\
\text { bby } \\
\text { ctb } \\
\text { bby } \\
\text { slg } \\
\text { slg } \\
\text { slg } \\
\text { vst } \\
\text { mpr } \\
\text { mpr } \\
\text { bby } \\
\text { bby }\end{array}$ \\
\hline
\end{tabular}


Table 9.20 (Cont'd)

\begin{tabular}{|c|c|c|c|c|c|c|c|c|c|c|}
\hline $\begin{array}{l}260 \cdot 010000 \\
270-010000 \\
280-00000 \\
290 \cdot 010000\end{array}$ & $\begin{array}{l}.00000 \mathrm{E}+00 \\
.00000 \mathrm{E}+00 \\
.00000 \mathrm{E}+00 \\
.00000 \mathrm{E}+00\end{array}$ & $\begin{array}{l}.00000 E+00 \\
.00000 E+00 \\
.00000 E+00 \\
.00000 E+00\end{array}$ & $\begin{array}{l}.33616 \\
-2.71622 E-02 \\
.00000 E+00 \\
.3 .6394\end{array}$ & $\begin{array}{l}.00000 E+00 \\
.00000 E+00 \\
.00000 E+00 \\
.00000 E+00\end{array}$ & $\begin{array}{l}1.55131 \mathrm{E}+0 \\
4.26349 \mathrm{E}+0 . \\
1.00000 \mathrm{E}+1 \\
1.05031 \mathrm{E}+0\end{array}$ & $\begin{array}{lr}7 & 4.23098 \mathrm{E}+05 \\
5 & 8.77290 \mathrm{E}+05 \\
2 & .00000 \mathrm{E}+00 \\
18 & 5.23783 \mathrm{E}+06\end{array}$ & $\begin{array}{l}88.167 \\
411.83 \\
.00000 E+00 \\
.00000 E+00\end{array}$ & $\begin{array}{lr} & 1155.9 \\
& 6.24272 E+05 \\
00 & .00000 E+00 \\
00 & .00000 E+00\end{array}$ & $\begin{array}{c}3.28968 E+06 \\
1693.5 \\
.00000 \mathrm{E}+00 \\
.00000 \mathrm{E}+00\end{array}$ & $\begin{array}{l}\text { anm } \\
\text { bby } \\
\mathrm{mpr} \\
\mathrm{mpr}\end{array}$ \\
\hline \multicolumn{11}{|c|}{ System 1 *none* } \\
\hline Jun.no. & from vol. & to vol. & $\begin{array}{l}\operatorname{lig} . j . v e 1 . \\
(\mathrm{m} / \mathrm{sec})\end{array}$ & $\begin{array}{l}\text { vap. J.vel. } \\
(\mathrm{m} / \mathrm{sec})\end{array}$ & $\begin{array}{l}\text { mass flow } \\
(\mathrm{kg} / \mathrm{sec})\end{array}$ & $\operatorname{jun}_{(\mathrm{m} 2)}$ area & $\begin{array}{l}\text { throat } \\
\text { ratio }\end{array}$ & \multicolumn{3}{|c|}{$\begin{array}{c}\ldots . . \text { Convergence } \\
\mathrm{fsm} / \mathrm{p} \quad \mathrm{fdf} / \mathrm{vg}\end{array}$} \\
\hline $\begin{array}{l}\text { corein sns } \\
101-000000\end{array}$ & 100-010002 & $110-010001$ & 7.2377 & 7.2377 & 275.00 & $5.00000 E \cdot 02$ & 1.0000 & $2.87463 E \cdot 08$ & $.00000 E+00$ & \\
\hline $\begin{array}{l}\text { core pip } \\
110.010000 \\
110-020000\end{array}$ & $\begin{array}{l}\text { ee } \\
110.010002 \\
110.020002\end{array}$ & $\begin{array}{l}110-020001 \\
110 \cdot 030001\end{array}$ & $\begin{array}{l}2.1846 \\
2.2697\end{array}$ & $\begin{array}{l}2.1846 \\
2.2697\end{array}$ & $\begin{array}{l}275.00 \\
275.00\end{array}$ & $\begin{array}{l}.17000 \\
.17000\end{array}$ & $\begin{array}{l}1.0000 \\
1.0000\end{array}$ & $\begin{array}{l}1.45735 \mathrm{E}-12 \\
8.28735 \mathrm{E}-13\end{array}$ & $\begin{array}{l}.00000 \mathrm{E}+00 \\
.00000 \mathrm{E}+00\end{array}$ & \\
\hline $\begin{array}{l}\text { coreout br } \\
120.010000 \\
120.020000 \\
120.030000\end{array}$ & $\begin{array}{l}\text { anch } \\
110-030002 \\
120-010002 \\
120-010002\end{array}$ & $\begin{array}{l}120 \cdot 010001 \\
140 \cdot 010001 \\
130 \cdot 010001\end{array}$ & $\begin{array}{l}7.9646 \\
7.9673 \\
.00000 \mathrm{E}+00\end{array}$ & $\begin{array}{l}7.9646 \\
7.9673 \\
.00000 E+00\end{array}$ & $\begin{array}{l}275.00 \\
275.00 \\
.00000 \mathrm{E}+00\end{array}$ & $\begin{array}{l}5.00000 \mathrm{E}-02 \\
5.00000 \mathrm{E}-02 \\
1.45000 \mathrm{E}-03\end{array}$ & $\begin{array}{l}1.0000 \\
1.0000 \\
1.0000\end{array}$ & $\begin{array}{l}1.72719 \mathrm{E} \cdot 13 \\
3.79900 \mathrm{E} \cdot 12 \\
6.25052 \mathrm{E} \cdot 12\end{array}$ & $\begin{array}{l}.00000 E+00 \\
.00000 E+00 \\
.00000 E+00\end{array}$ & \\
\hline $\begin{array}{l}\text { prsszr pip } \\
130-010000 \\
130-020000 \\
130-030000\end{array}$ & $\begin{array}{l}130-010002 \\
130-020002 \\
130-030002\end{array}$ & $\begin{array}{l}130 \cdot 020001 \\
130 \cdot 030001 \\
130 \cdot 040001\end{array}$ & $\begin{array}{l}.00000 E+00 \\
.00000 E+00 \\
.00000 E+00\end{array}$ & $\begin{array}{l}.00000 E+00 \\
.00000 E+00 \\
.00000 E+00\end{array}$ & $\begin{array}{l}.00000 E+00 \\
.00000 E+00 \\
.00000 E+00\end{array}$ & $\begin{array}{l}1.45000 \mathrm{E} \cdot 03 \\
.60000 \\
.60000\end{array}$ & $\begin{array}{l}1.0000 \\
1.0000 \\
1.0000\end{array}$ & $\begin{array}{r}-4.71592 \mathrm{E}-17 \\
2.17623 \mathrm{E}-17 \\
-2.49854 \mathrm{E}-17\end{array}$ & $\begin{array}{l}.00000 E+00 \\
.00000 E+00 \\
.00000 E+00\end{array}$ & \\
\hline $\begin{array}{l}\text { prz- } \\
131 .\end{array}$ & $\begin{array}{l}\text { jun } \\
130-040002\end{array}$ & 132.010001 & $.00000 E+00$ & $.00000 E+00$ & $.00000 E+00$ & .60000 & 1.0000 & $-2.34244 \mathrm{E} \cdot 17$ & $.00000 E+00$ & \\
\hline $\begin{array}{l}\text { prssz } \\
132-0\end{array}$ & 132.010002 & $132 \cdot 020001$ & $.00000 E+00$ & $.00000 E+00$ & $.00000 E+00$ & .60000 & 1.0000 & $4.57432 \mathrm{E} \cdot 17$ & $.00000 E+00$ & \\
\hline $\begin{array}{l}\operatorname{prz} \cdot r \\
133-0\end{array}$ & $\begin{array}{l}\text { ve } \\
132.020002\end{array}$ & $134 \cdot 010000$ & $.00000 \mathrm{E}+00$ & $.00000 E+00$ & $.00000 E+00$ & .60000 & $.00000 E+00$ & $.00000 E+00$ & $.00000 E+00$ & \\
\hline $140-010000$ & $140 \cdot 010002$ & $140-020001$ & 7.9663 & 7.9663 & 275.00 & $5.00000 E-02$ & 1.0000 & $3.85238 \mathrm{E}-12$ & $.00000 E+00$ & \\
\hline $\begin{array}{l}\text { Stgen } \\
141 \cdot 0 \\
\text { staen }\end{array}$ & $140-020002$ & $150-010001$ & 9.7151 & 9.7151 & 275.00 & $4.10000 \mathrm{E} \cdot 02$ & 1.0000 & $1.10010 \mathrm{E} \cdot 08$ & $.00000 E+00$ & \\
\hline $\begin{array}{l}\text { stgen pif } \\
150-010000 \\
150.020000\end{array}$ & $\begin{array}{l}150-010002 \\
150.020002\end{array}$ & $\begin{array}{l}150 \cdot 020001 \\
150 \cdot 030001\end{array}$ & $\begin{array}{l}9.3257 \\
9.0453\end{array}$ & $\begin{array}{l}9.3257 \\
9.0453\end{array}$ & $\begin{array}{l}275.00 \\
275.00\end{array}$ & $\begin{array}{l}4.10000 \mathrm{E}-02 \\
4.10000 \mathrm{E}-02\end{array}$ & $\begin{array}{l}1.0000 \\
1.0000\end{array}$ & $\begin{array}{l}4.69334 \mathrm{E} \cdot 08 \\
8.44536 \mathrm{E} \cdot 08\end{array}$ & $\begin{array}{l}.00000 E+00 \\
.00000 E+00\end{array}$ & \\
\hline $\begin{array}{l}\text { stgenout sns } \\
151 \cdot 000000\end{array}$ & $150-030002$ & $160 \cdot 010001$ & 8.8278 & 8.8278 & 275.00 & $4.10000 \mathrm{E}-02$ & 1.0000 & $1.02436 \mathrm{E} \cdot 07$ & $.00000 E+00$ & \\
\hline $\begin{array}{l}\text { pump pun } \\
170 \cdot 010000 \\
170-020000\end{array}$ & $\begin{array}{l}160-010002 \\
170-010002\end{array}$ & $\begin{array}{l}170-010001 \\
100 \cdot 010001\end{array}$ & $\begin{array}{l}7.2388 \\
7.2383\end{array}$ & $\begin{array}{l}7.2388 \\
7.2383\end{array}$ & $\begin{array}{l}275.00 \\
275.00\end{array}$ & $\begin{array}{l}5.00000 \mathrm{E}-02 \\
5.00000 \mathrm{E}-02\end{array}$ & $\begin{array}{l}1.0000 \\
1.0000\end{array}$ & $\begin{array}{l}1.71503 \mathrm{E} \cdot 07 \\
1.37347 \mathrm{E} \cdot 11\end{array}$ & $\begin{array}{l}.00000 E+00 \\
.00000 E+00\end{array}$ & \\
\hline $\begin{array}{l}\text { System 2 } \\
\text { aufwva tmo } \\
201-000000 \\
\text { stgen-2 pip }\end{array}$ & $\begin{array}{l}\text { *none* } \\
\text { tpjun } \\
200 \cdot 010000 \\
\text { ee }\end{array}$ & $250-010001$ & .61277 & .61277 & 26.450 & $5.00000 E-02$ & 1.0000 & $.00000 E+00$ & $.00000 E+00$ & \\
\hline $\begin{array}{l}210-010000 \\
210-020000\end{array}$ & $\begin{array}{l}210 \cdot 010002 \\
210-020002\end{array}$ & $\begin{array}{l}210-020001 \\
210-030001\end{array}$ & $\begin{array}{l}.48259 \\
.61470\end{array}$ & $\begin{array}{l}2.1140 \\
3.5736\end{array}$ & $\begin{array}{l}150.00 \\
150.00\end{array}$ & $\begin{array}{l}.60000 \\
.60000\end{array}$ & $\begin{array}{l}1.0000 \\
1.0000\end{array}$ & $\begin{array}{l}1.65545 \mathrm{E}-04 \\
1.28303 \mathrm{E} \cdot 04\end{array}$ & $\begin{array}{l}3.54702 \mathrm{E}-03 \\
8.51856 \mathrm{E}-03\end{array}$ & $\begin{array}{l}\text { no } \\
\text { no }\end{array}$ \\
\hline
\end{tabular}


Table 9.20 (Cont'd)

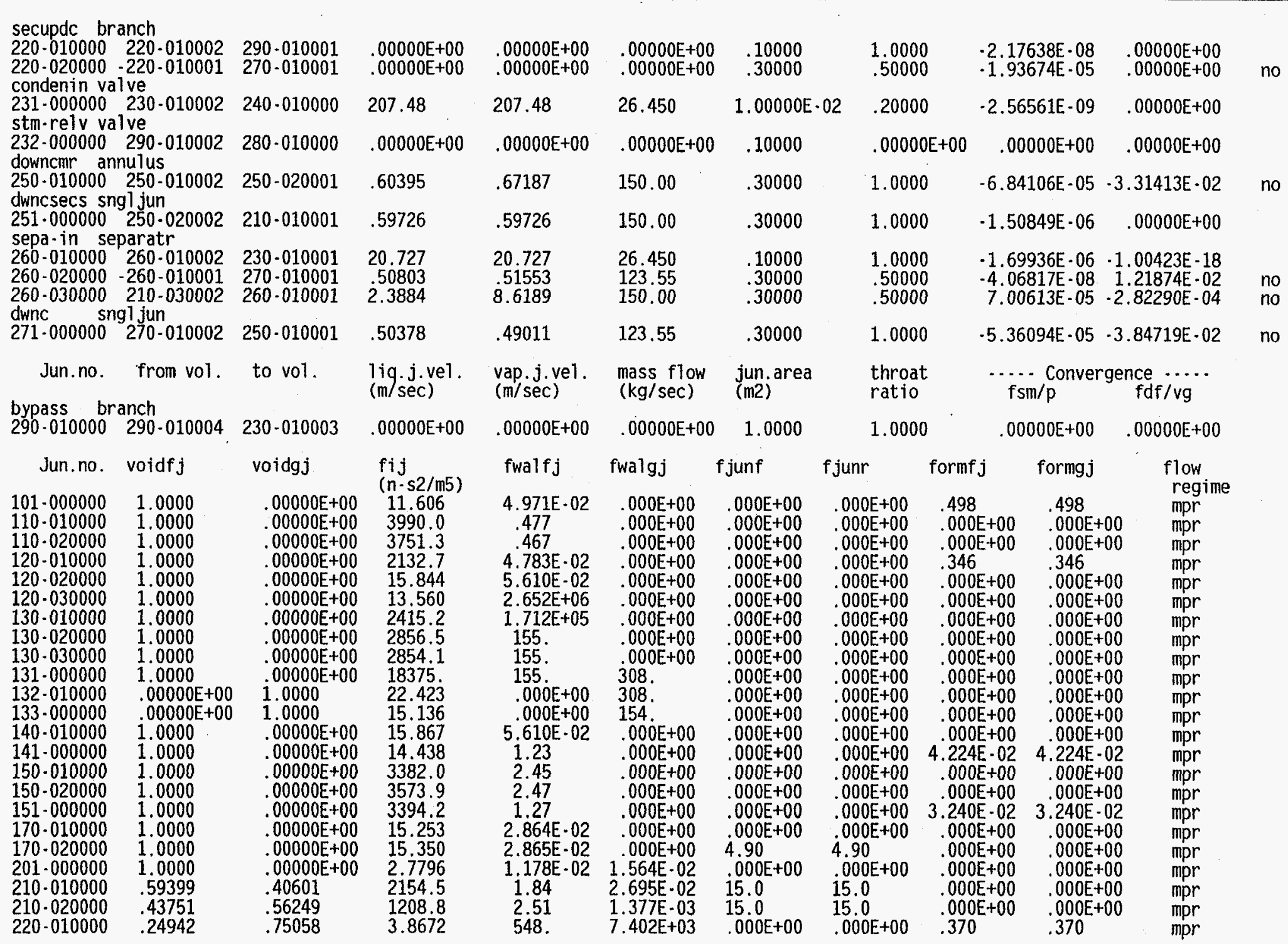


Table 9.20 (Cont'd)

\begin{tabular}{|c|c|c|c|c|c|c|c|c|c|c|}
\hline $\begin{array}{l}220-020000 \\
231-000000 \\
232-000000 \\
250-010000 \\
251 \cdot 000000 \\
260-010000 \\
260-020000 \\
260 \cdot 030000 \\
271-000000 \\
290-010000\end{array}$ & $\begin{array}{l}.98013 \\
.00000 \mathrm{E}+00 \\
.00000 \mathrm{E}+00 \\
.98864 \\
1.0000 \\
.00000 \mathrm{E}+00 \\
.97170 \\
.20704 \\
.98013 \\
.00000 \mathrm{E}+00\end{array}$ & $\begin{array}{c}1.98719 \mathrm{E}-02 \\
1.0000 \\
1.0000 \\
1.13555 \mathrm{E}-02 \\
.00000 \mathrm{E}+00 \\
1.0000 \\
2.83033 \mathrm{E}-02 \\
.79296 \\
1.98719 \mathrm{E}-02 \\
1.0000\end{array}$ & $\begin{array}{c}2348.6 \\
.27292 \\
2.4068 \\
2206.6 \\
1543.4 \\
93.680 \\
1.00000 \mathrm{E}+30 \\
169.13 \\
3131.4 \\
2.7348\end{array}$ & $\begin{array}{l}5.993 E+05 \\
.000 E+00 \\
.000 E+00 \\
.141 \\
.296 \\
.000 E+00 \\
.108 \\
.170 \\
.161 \\
.000 E+00\end{array}$ & $\begin{array}{l}2.630 \mathrm{E}+04 \\
2.372 \mathrm{E}-04 \\
6.482 \mathrm{E}+03 \\
.171 \\
.100 \\
2.928 \mathrm{E}-02 \\
6.148 \mathrm{E}-03 \\
7.661 \mathrm{E}-06 \\
.218 \\
.000 \mathrm{E}+00\end{array}$ & $\begin{array}{l}.000 E+00 \\
8.90 \\
.000 E+00 \\
.000 E+00 \\
56.9 \\
.000 E+00 \\
1.82 \\
.000 E+00 \\
.000 E+00 \\
.000 E+00\end{array}$ & $\begin{array}{l}.000 E+00 \\
8.90 \\
.000 E+00 \\
.000 E+00 \\
56.9 \\
.000 E+00 \\
1.82 \\
.000 E+00 \\
.000 E+00 \\
.000 E+00\end{array}$ & $\begin{array}{l}4.82 \\
6.689 \mathrm{E} \cdot 03 \\
.000 \mathrm{E}+00 \\
.000 \mathrm{E}+00 \\
.250 \\
.333 \\
3.99 \\
28.6 \\
.000 \mathrm{E}+00 \\
.000 \mathrm{E}+00\end{array}$ & $\begin{array}{l}4.82 \\
6.689 \mathrm{E} \cdot 03 \\
.000 \mathrm{E}+00 \\
.000 \mathrm{E}+00 \\
.250 \\
.333 \\
3.95 \\
3.56 \\
.000 \mathrm{E}+00 \\
.000 \mathrm{E}+00\end{array}$ & $\begin{array}{l}\mathrm{mpr} \\
\mathrm{mpr} \\
\mathrm{mpr} \\
\mathrm{mpr} \\
\mathrm{mpr} \\
\mathrm{mpr} \\
\mathrm{mpr} \\
\mathrm{mpr} \\
\mathrm{mpr} \\
\mathrm{mpr}\end{array}$ \\
\hline
\end{tabular}

RELAP5/3.1

Reactor Loss of Coolant Analysis Program

RELAP5 Direct Steady-State Initialization - Ver. 1.0 - 30/06/95 - Copyright 1995 by Computer Simulation \& Analysis. Inc.

PWR DSSI Test Case (based on workshop sample problem no. 2) $30 / 06 / 95$

$02: 28: 32$

HEAT STRUCTURE OUTPUT H+

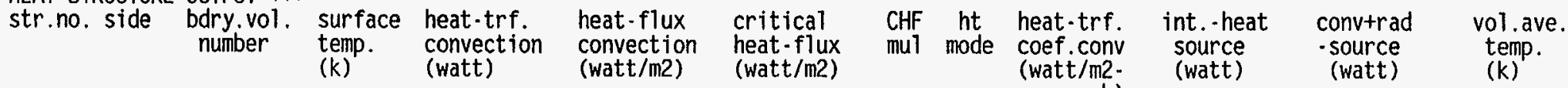
(watt/m2

k) $00 \quad 1.50000 E+07 \quad 2.04891 E-08 \quad 947.57$

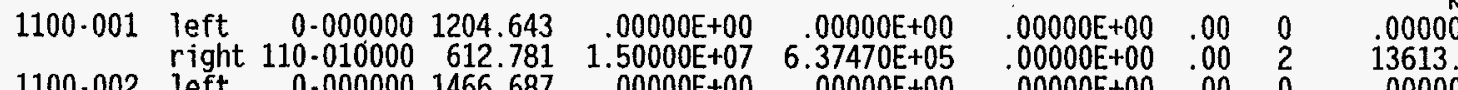
13613 . $0000 \mathrm{E}+07-5.21541 \mathrm{E} \cdot 081080.89$

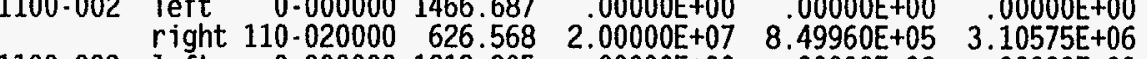

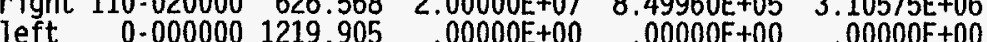
$\begin{array}{llllll}\text { right } 110.030000 & 624 & 510 & 1.50000 \mathrm{E}+07 & 6.37470 \mathrm{E}+05 & 2.95707 \mathrm{E}+06\end{array}$ left $150-010000 \quad 565.824 \cdot 1.97308 \mathrm{E}+07 \cdot 6.15134 \mathrm{E}+05 \quad .00000 \mathrm{E}+00$ $\begin{array}{llllll}1500-001 & \text { right } 210.030000 & 526.257 & 1.97308 \mathrm{E}+07 & 4.94607 \mathrm{E}+05 & 5.40353 \mathrm{E}+06\end{array}$ 1500.002 left $150.020000 \quad 556.498 \cdot 1.63716 \mathrm{E}+07 \quad .5 .10405 \mathrm{E}+05 \quad .00000 \mathrm{E}+00$

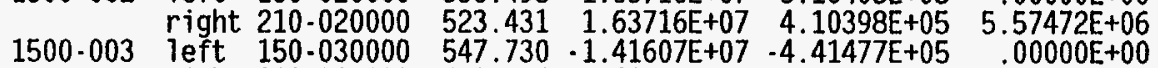
right $210-010000 \quad 518.904 \quad 1.41607 \mathrm{E}+07 \quad 3.54975 \mathrm{E}+05 \quad 5.54517 \mathrm{E}+06$

$00000 E+00 \quad 1.50000 E+07-9.31323 E-09959.91$ 28717

59540

17869

58580 .

16610

57943

SUM of int.-heat-source

$00000 E+00 \quad 7.45058 E-08 \quad 544.76$

$00000 E+00-1.63913 E-07538.88$

$00000 E+00-9.59262 E-07 \quad 532.36$ $.50000 \mathrm{E}+08$ (watt)

\begin{tabular}{|c|c|c|c|c|c|c|c|c|c|c|}
\hline $\begin{array}{l}\text { str. no. } \\
1100-001\end{array}$ & $\begin{array}{l}\text { mesh } \\
1204.6\end{array}$ & $\begin{array}{c}\text { int tempe } \\
1181.9\end{array}$ & $\begin{array}{l}\text { res } \\
1115.1\end{array}$ & (k) 1010.1 & 878.80 & 731.17 & 643.13 & 632.68 & 622.57 & 612.78 \\
\hline $1100 \cdot 002$ & 1466.7 & 1432.0 & 1330.8 & 1173.5 & 975.04 & 763.62 & 666.49 & 652.77 & 639.47 & 626.57 \\
\hline $100 \cdot 003$ & 1219.9 & 1196.9 & 1129.6 & 1023.0 & 890.33 & 740.96 & 654.61 & 644.24 & 634.22 & 624.51 \\
\hline $\begin{array}{l}500-001 \\
500-002 \\
500-003\end{array}$ & $\begin{array}{l}565.82 \\
556.50 \\
547.73\end{array}$ & $\begin{array}{l}559.73 \\
551.39 \\
543.27\end{array}$ & $\begin{array}{l}553.81 \\
546.43 \\
538.94\end{array}$ & $\begin{array}{l}548.03 \\
541.60 \\
534.72\end{array}$ & $\begin{array}{l}542.39 \\
536.89 \\
530.62\end{array}$ & $\begin{array}{l}536.89 \\
532.29 \\
526.62\end{array}$ & $\begin{array}{l}531.51 \\
527.81 \\
522.71\end{array}$ & $\begin{array}{l}526.26 \\
523.43 \\
518.90\end{array}$ & & \\
\hline
\end{tabular}


Table 9.20 (Cont'd)

\begin{tabular}{ccclc}
\hline Str.no. & gas gap & clad radius & ruptured & pressure \\
$\mathrm{m}$ & $\mathrm{m}$ & (pa) \\
$1100-001$ & $6.37728 \mathrm{E}-05$ & $5.35437 \mathrm{E}-03$ & no & $2.46183 \mathrm{E}+06$ \\
$1100-002$ & $5.45147 \mathrm{E}-05$ & $5.35492 \mathrm{E}-03$ & no & \\
$1100 \cdot 003$ & $6.34090 \mathrm{E}-05$ & $5.35472 \mathrm{E}-03$ & no & \\
\hline
\end{tabular}


RELAP5/3.1

Reactor Loss of Coolant Analysis Program

RELAP5 Direct Steady-State Initialization - Ver. 1.0 - 30/06/95 - Copyright 1995 by Computer Simulation \& Analysis, Inc

PWR DSSI Test Case (based on workshop sample problem no. 2) 30/06/95 02:28:32

iteration $=78$

Trip number, trip time (sec)

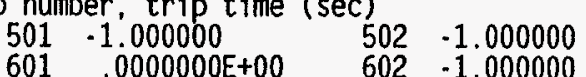

ystem 1 *none* mass $=3186.2 \quad \mathrm{~kg}$

Vol.no. pressure voidg tempf

pump-out snglvol

pump-out snglvol

$100-010000.1 .5$

core pipe $110-0100001.51163 \mathrm{E}+07$

$\begin{array}{ll}110-010000 & 1.51163 \mathrm{E}+07 \\ 110-020000 & 1.51010 \mathrm{E}+07\end{array}$

$110.030000 \quad 1.50861 \mathrm{E}+07$

coreout branch

$120-010000 \quad 1.49666 \mathrm{E}+07$

prsszr pipe 130.010000 1.50524E+07

$\overrightarrow{\vec{D}}$

$130-020000 \quad 1.50243 \mathrm{E}+07$

$130 \cdot 030000 \quad 1.50154 E+07$

$130.040000 \quad 1.50066 \mathrm{E}+07$

prssztop pipe

$132.0100001 .50014 \mathrm{E}+07$

$132.020000 \quad 1.50000 \mathrm{E}+07$

przbndry tmdpvol

$134.010000 \quad 1.00000 E+05$

stgen-in pipe

$140.0100001 .50091 \mathrm{E}+07$

$140.020000 \quad 1.50079 \mathrm{E}+07$

stgen pipe $150-0100001.49433 \mathrm{E}+07$

$150.020000 \quad 1.48865 \mathrm{E}+07$

$150.030000 \quad 1.48305 E+07$

tempf

(k)

(k)

$.0000 E+00 \quad 555.494 \quad 615.708$

$.0000 E+00 \quad 565.954 \quad 615.900$

$.0000 \mathrm{E}+00 \quad 579.273 \quad 615.818$

$.0000 E+00 \quad 588.634 \quad 615.739$

$.0000 \mathrm{E}+00 \quad 588.600$

615.102

$\begin{array}{lll}.0000 \mathrm{E}+00 \quad 615.324 & 615.560\end{array}$

$.0000 E+00 \quad 615.300 \quad 615.410$

$.0000 E+00 \quad 615.293 \quad 615.363$

$.0000 E+00 \quad 615.286 \quad 615.316$

1.000

1.000

1.000

615.288

615.316

$615.281 \quad 615.281$

$372.782 \quad 600.000$

$0000000 E+00$

$504-1.000000$

$604-1.000000$

$\begin{array}{ll}506 & -1.000000 \\ 605 & -1.000000\end{array}$

$.0000 E+00 \quad 588.612 \quad 615.330$

$.0000 \mathrm{E}+00 \quad 588.612 \quad 615.323$

$.0000 E+00 \quad 576.156 \quad 614.978$

DOOOE+00

$.0000 \mathrm{E}+00$

555.350

614.673

614.372

pump-in snglvol

$.0000 \mathrm{E}+00$

555.350

614.372

pump pump

$\mathrm{rpm}=369.00 \quad(\mathrm{rad} / \mathrm{sec}) \quad$ head $=2.56798 \mathrm{E}+05(\mathrm{pa})$

octant $=1$

$\begin{array}{lllll}170.010000 & 1.50335 \mathrm{E}+07 & .0000 \mathrm{E}+00 & 555.490 & 615.459\end{array}$

sat. temp.

(k)

fvc/voidg dug/ug duf/uf

615.708

$.00000 E+00 \quad .00000 E+00 \quad .00000 E+00$

615.900

615.818

615.739

$.00000 \mathrm{E}+00 \quad .00000 \mathrm{E}+00 \quad 6.37853 \mathrm{E}-11$

$-6.92764 \mathrm{E}-24 \quad 2.09081 \mathrm{E}-25 \quad 6.02983 \mathrm{E}-11$

$9.46088 \mathrm{E}-24 \cdot 3.52898 \mathrm{E}-25 \quad 5.78999 \mathrm{E}-11$

615.102

$.00000 \mathrm{E}+00 \quad .00000 \mathrm{E}+00 \quad 5.78968 \mathrm{E} \cdot 11$

615.560

615.410

615.363

615.316

$.00000 E+00 \quad .00000 E+00 \quad .00000 E+00$

$00000 E+00 \quad 00000 E+00 \quad 0000$ E +00

OOODE +00 .0ODE

.000

$.00000 \mathrm{E}+00 \quad .00000 \mathrm{E}+00$

$615.288 \quad .00000 \mathrm{E}+00 \quad .00000 \mathrm{E}+00 \quad .00000 \mathrm{E}+00$

$615.281 \quad .00000 \mathrm{E}+00 \quad .00000 \mathrm{E}+00 \quad .00000 \mathrm{E}+00$

$372.782 \quad .00000 E+00 \quad .00000 E+00 \quad .00000 E+00$

$615.330 \quad 1.60460 \mathrm{E} \cdot 23 \quad .00000 \mathrm{E}+00 \quad 5.78975 \mathrm{E}-11$

$\begin{array}{llll}615.323 & .00000 \mathrm{E}+00 \quad .00000 \mathrm{E}+00 \quad 5.78973 \mathrm{E}-11\end{array}$

$614.978 \quad .00000 \mathrm{E}+00 \quad .00000 \mathrm{E}+00-3.74235 \mathrm{E}-07$

$614.673 \quad 00000 \mathrm{E}+00 \quad .00000 \mathrm{E}+00-3.25821 \mathrm{E}-07$

$614.372 \quad 5.29396 \mathrm{E}-23 \quad .00000 \mathrm{E}+00-2.40369 \mathrm{E} \cdot 08$

614.372

$00000 E+00$

$.00000 \mathrm{E}+00 \cdot 2.40557 \mathrm{E} \cdot 08$

torque $=.724 .00 \quad(n-m)$

mtr torque $=724.00 \quad(n-m)$

$\begin{array}{llll}615.459 & -1.05744 \mathrm{E}-25 & .00000 \mathrm{E}+00 & -2.45885 \mathrm{E}-08\end{array}$ 
Table 9.21 (Cont'd)

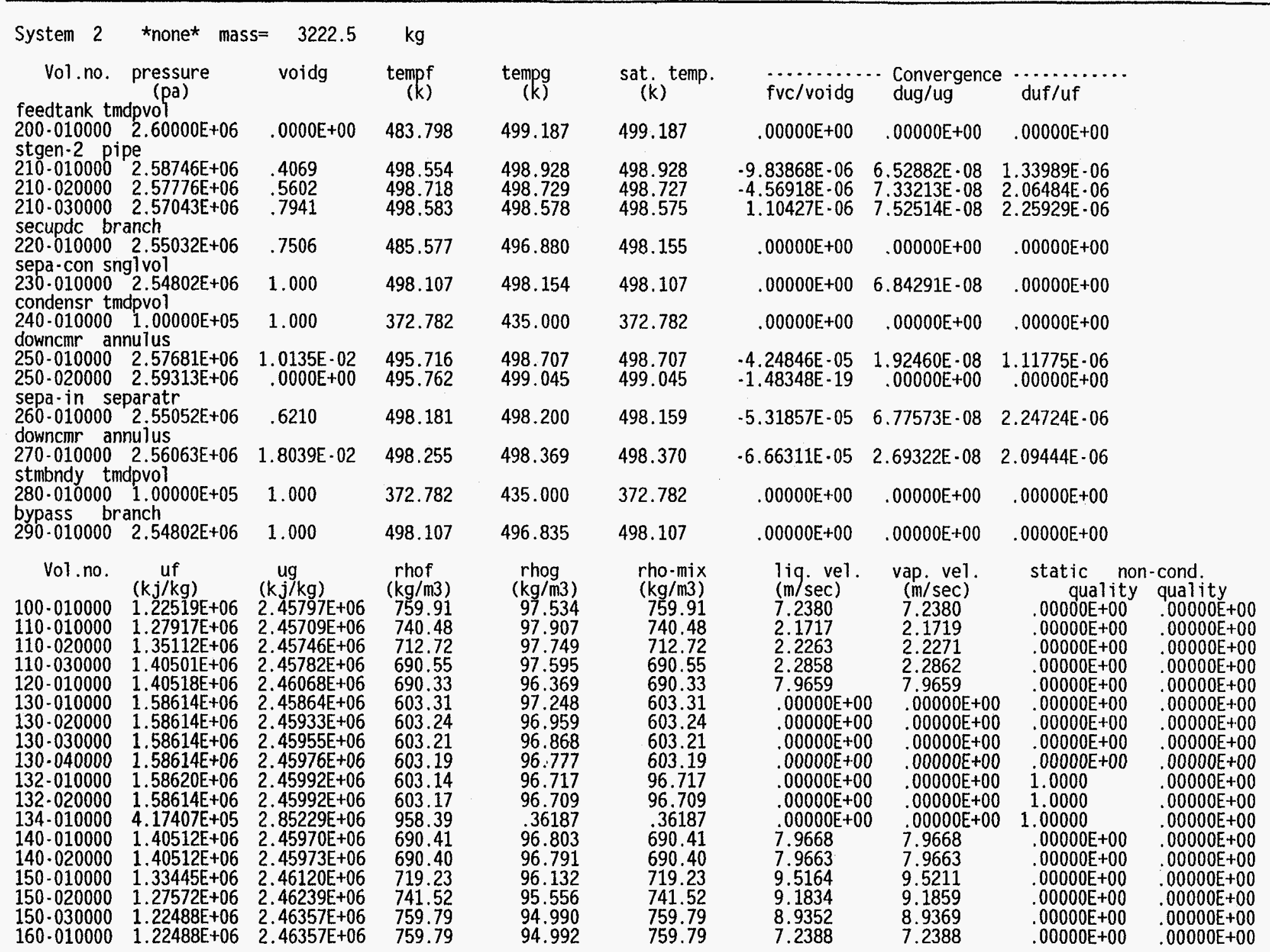


Table 9.21 (Cont'd)

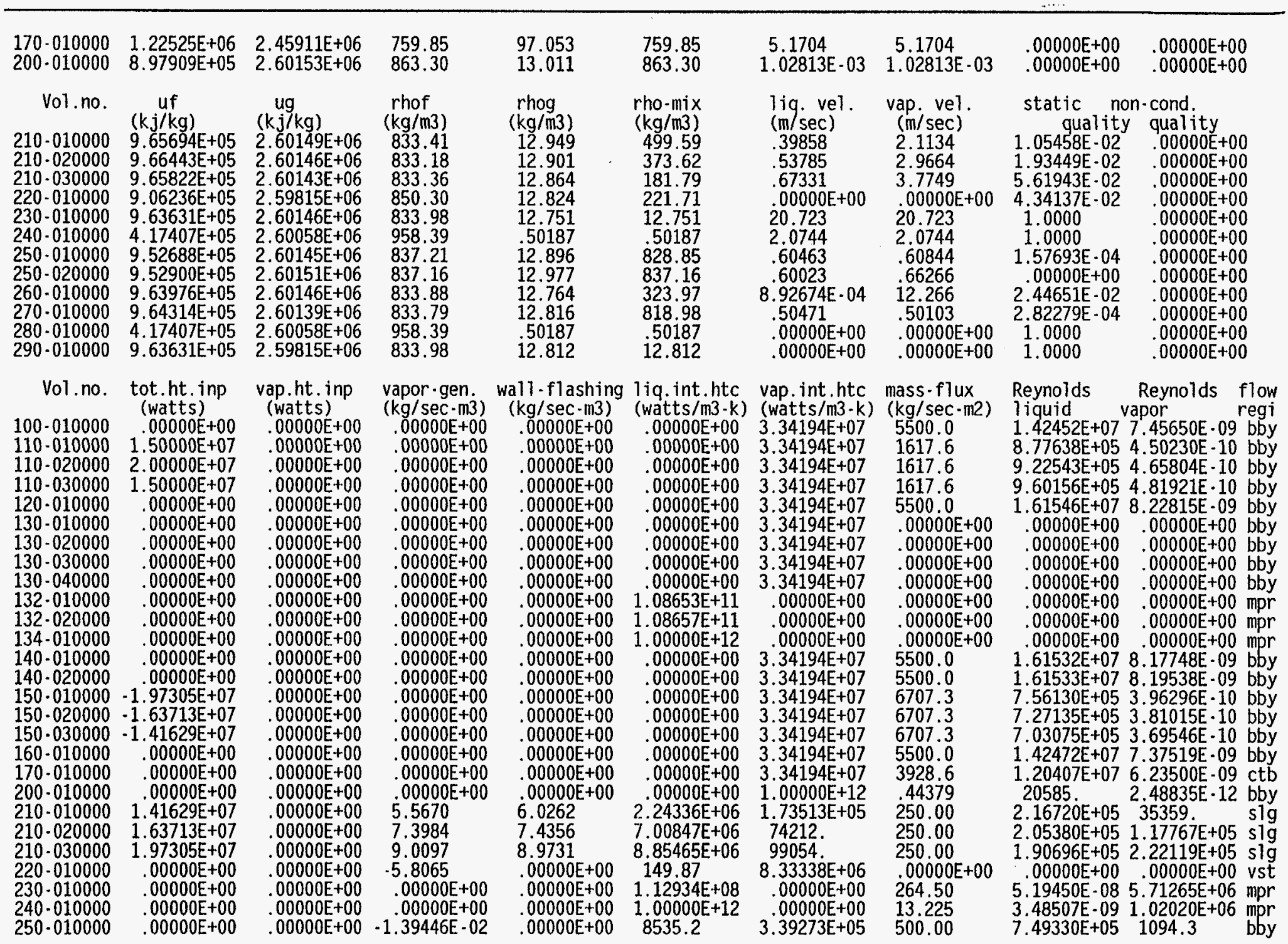


Table 9.21 (Cont'd)

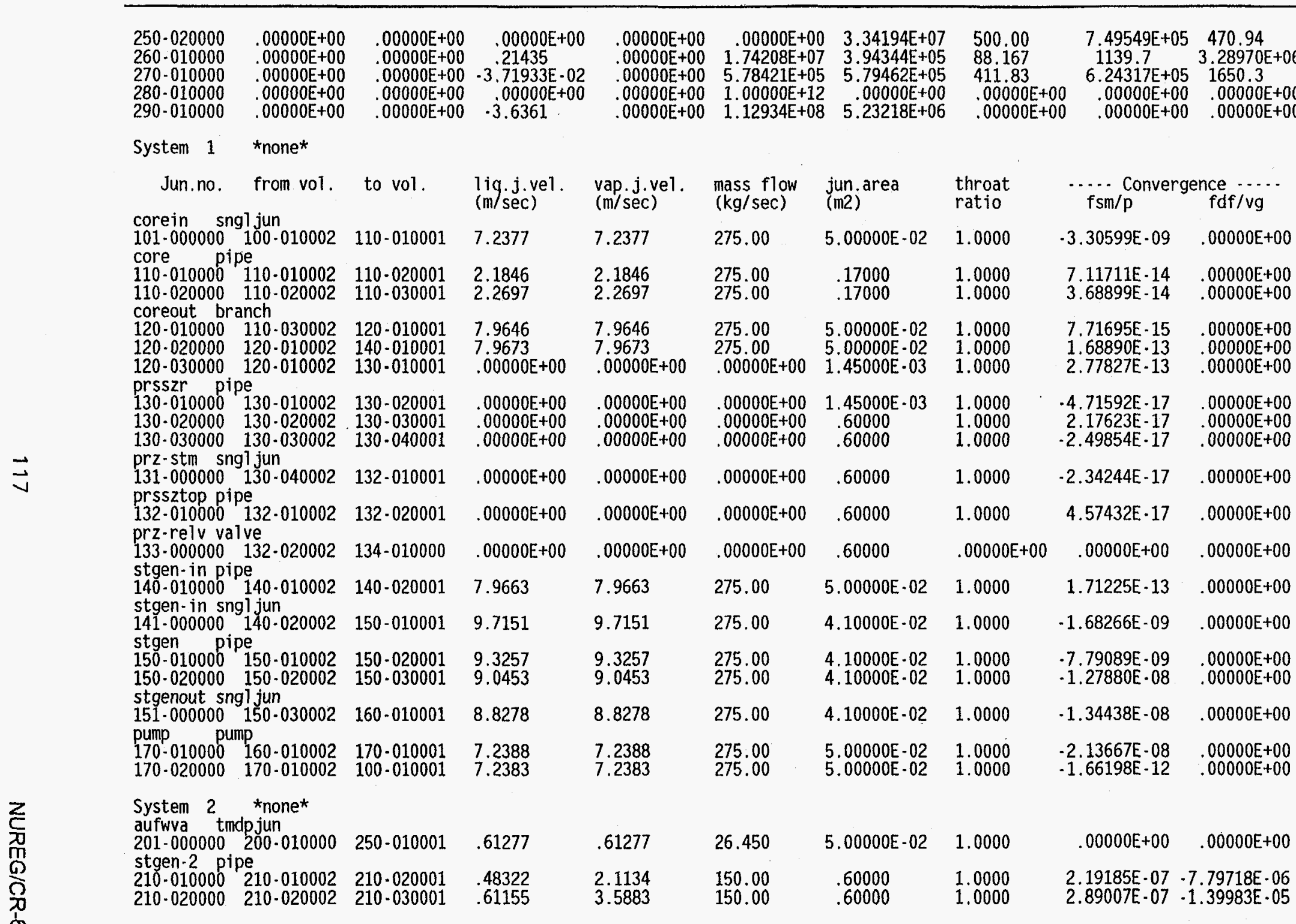


Table 9.21 (Cont'd)

secupdc branch

$220-010000 \quad 220.010002 \quad 290.010001$ $220 \cdot 020000 \cdot 220 \cdot 010001 \quad 270-010001$

condenin valve
$231-000000 \quad 230.010002 \quad 240.010000$ stm-relv valve

232-000000 290-010002 280-010000 downcmr annulus

$250.010000 \quad 250 \cdot 010002 \quad 250 \cdot 020001$ dwncsecs sngl jun

$251.000000 \quad 250.020002 \quad 210-010001$

sepa-in separatr
$260.010000 \quad 260.010002 \quad 230-010001$

$260-020000-260 \cdot 010001 \quad 270-010001$

$260-030000 \quad 210-030002 \quad 260-010001$

dwnc sngl jun

271-000000 270-010002 250-010001

Jun.no. from vol. to vol.

bypass branch

290-010000 290-010004 230-010003

$.00000 \mathrm{E}+00$

$.00000 \mathrm{E}+00$

207.44

$.00000 \mathrm{E}+00$

.60323

.59726

20.723

.50843

2.4017

.50286

1ig.j.vel. $(\mathrm{m} / \mathrm{sec})$

Jun.no. voidf $j$

$101-000000 \quad 1.0000$

$110-010000 \quad 1.0000$

$110-020000 \quad 1.0000$

$120.010000 \quad 1.0000$

$\begin{array}{ll}120.020000 & 1.0000 \\ 120.030000 & 1.0000\end{array}$

$130.010000 \quad 1.0000$

$130.020000 \quad 1.0000$

$130.030000 \quad 1.0000$

$131.000000 \quad 1.0000$

$132-010000 \quad .00000 E+00$

133.000000

140.010000

141.000000

150.010000

150.020000

151.000000

170.010000

$170-020000$

210.010000

210.020000

$220-010000$ voidgj fij

$00000 \mathrm{E}+00 \quad 3990.0$

$.00000 \mathrm{E}+00 \quad 3751.3$

$.00000 \mathrm{E}+00 \quad 2132.7$

$00000 \mathrm{E}+00 \quad 15.844$

$00000 \mathrm{E}+00 \quad 13.56$

$.00000 \mathrm{E}+00 \quad 2415.2$

.00000 +00 2856.5

$.00000 \mathrm{E}+00 \quad 2854.1$

$00000 \mathrm{E}+00$

1.0000

$00000 E+00$

1.0000

1.0000

1.0000

1.0000

1.0000

1.0000

1.0000

.59313

.53975

.24942

1202.9
3.8668
$.00000 E+00 \begin{gathered}(n-s 2 / m 5) \\ 11.606\end{gathered}$
$.00000 \mathrm{E}+00$

$.00000 \mathrm{E}+00$

207.44

$.00000 \mathrm{E}+00$

.10000

1.0000

$7.75236 \mathrm{E}-10$

$.00000 \mathrm{E}+00$

$\begin{array}{llll}.00000 \mathrm{E}+00 & .30000 \quad .50000\end{array}$

$2.78141 \mathrm{E} \cdot 07 \quad .00000 \mathrm{E}+00$

$.00000 \mathrm{E}+00$

$1.00000 E \cdot 02 \quad .20000$

$3.19555 E-11 \quad .00000 E+00$

.66266

.59726

$.00000 E+00$

$.00000 E+00 \quad .00000 E+00$

20.723

.50822

8.6061

.49525

$150.00 \quad .30000$

1.0000

$1.17284 \mathrm{E}-06 \quad 3.97036 \mathrm{E} \cdot 04$

$150.00 \quad .30000$

1.0000

$6.38115 E \cdot 09 \quad .00000 E+00$

$\begin{array}{ll}26.450 & .10000 \\ 123.55 & .30000\end{array}$

150.00

30000

123.55

.30000

1.0000

.50000

$5.07050 \mathrm{E} \cdot 08 \cdot 3.59856 \mathrm{E} \cdot 24$

$6.91694 \mathrm{E}-10-2.47498 \mathrm{E}-04$

3. $20998 \mathrm{E}-07-1.49156 \mathrm{E}-05$

$1.0000 \quad 8.65139 \mathrm{E}-07 \quad 5.68236 \mathrm{E}-04$

vap.j.vel. mass flow jun.area $(\mathrm{kg} / \mathrm{sec}) \quad(\mathrm{m} 2)$

throat

ratio

.... Convergence .....

1.0000

$.00000 \mathrm{E}+00$

1.0000

fwalfj

fwalgj fjunf

fjunr

formf $j$

formgj

flow.

$\begin{array}{lll}.977 & .000 E+00 & .000 E+00 \\ .000 E+00 & .000 E+00\end{array}$

$.000 \mathrm{E}+00 \quad .000 \mathrm{E}+00$
$.000+00$

$4.783 \mathrm{E}-02 \quad .000 \mathrm{E}+00 \quad .000 \mathrm{E}+00$

$5.610 \mathrm{E}-02 \quad .000 \mathrm{E}+00 \quad .000 \mathrm{E}+00$

$2.652 \mathrm{E}+06 \quad .000 \mathrm{E}+00 \quad .000 \mathrm{E}+00$

$\begin{array}{lll}1.712 \mathrm{E}+05 & .000 \mathrm{E}+00 \quad .000 \mathrm{E}+00\end{array}$

155 .

155

155.

$.000 \mathrm{E}+00$

308 .

$000 \mathrm{E}+00 \quad 154$

$5.610 \mathrm{E}-02$

1.23

2.45

2.47
1.27

$2.864 \mathrm{E}-02$

$2.865 \mathrm{E}-02$

$.000 \mathrm{E}+00$

$.000 \mathrm{E}+00$

$.000 \mathrm{E}+00$

$.000 \mathrm{E}+00$

$.000 E+00$

$.000 E+00 \quad .000 E+00$

$.000 \mathrm{E}+00$

$.000 \mathrm{E}+00$

$.000 E+00 \quad .000 E+00$

$.000 E+00 \quad .000 E+00$

$.000 E+00$

$.000 E+00$

1.84

$1.887 \mathrm{E}-02$

4.90

$.000 E+00$

$.000 \mathrm{E}+00$

$.000 \mathrm{E}+00$

$000 \mathrm{E}+00$

$000 \mathrm{E}+00$

$000 \mathrm{E}+00$

$000 \mathrm{E}+00$

$.000 E+00$

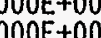

$000 \mathrm{E}+00$

$.000 \mathrm{E}+00$

$000 \mathrm{E}+00$

$.000 \mathrm{E}+00$

$000 \mathrm{E}+00$

$.000 E+00$

$.000 \mathrm{E}+00$

4.90

.498

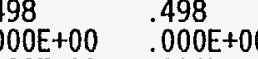

$.000 \mathrm{E}+00 \quad .000 \mathrm{E}+00$

346

$.000 E+00 \quad .000 E+00$

$.000 \mathrm{E}+00 \quad .000 \mathrm{E}+00$

$.000 E+00 \quad .000 E+00$

$.000 E+00 \quad .000 E+00$

$.000 E+00 \quad .000 E+00$

$000 E+00 \quad .000 E+00$

$000 E+00 \quad 000 E+00$

$.000 \mathrm{E}+00 \quad 000 \mathrm{E}+00$

$4.000 \mathrm{E}+00$

224E-02 4.224E.02

.000E

$.000 \mathrm{E}+00 \quad .000 \mathrm{E}+00$

$240 \mathrm{E}-02 \quad 3.240 \mathrm{E} \cdot 02$

$.000 \mathrm{E}+00 \quad .000 \mathrm{E}+00$

548 .

$1.308 E-03$
$7.401 E+03$

15.0

$.000 \mathrm{E}+00$

15.0

$.000 \mathrm{E}+00$ 
Table 9.21 (Cont'd)

\begin{tabular}{|c|c|c|c|c|c|c|c|c|c|c|}
\hline $\begin{array}{l}220 \cdot 020000 \\
231 \cdot 000000 \\
232 \cdot 000000 \\
250 \cdot 010000 \\
251 \cdot 000000 \\
260 \cdot 010000 \\
260 \cdot 020000 \\
260 \cdot 030000 \\
271 \cdot 000000 \\
290 \cdot 010000\end{array}$ & $\begin{array}{l}.98196 \\
.00000 \mathrm{E}+00 \\
.00000 \mathrm{E}+00 \\
.98986 \\
1.0000 \\
.00000 \mathrm{E}+00 \\
.97093 \\
.20589 \\
.98196 \\
.00000 \mathrm{E}+00\end{array}$ & $\begin{array}{c}1.80388 \mathrm{E}-02 \\
1.0000 \\
1.0000 \\
1.01351 \mathrm{E}-02 \\
.00000 \mathrm{E}+00 \\
1.0000 \\
2.90725 \mathrm{E}-02 \\
.79411 \\
1.80388 \mathrm{E}-02 \\
1.0000\end{array}$ & $\begin{array}{c}2706.3 \\
27289 \\
2.4065 \\
2094.7 \\
1543.4 \\
93.683 \\
1.00000 \mathrm{E}+30 \\
168.90 \\
3608.4 \\
2.7345\end{array}$ & $\begin{array}{l}5.989 E+05 \\
.000 E+00 \\
.000 E+00 \\
.141 \\
.297 \\
.000 E+00 \\
.108 \\
.168 \\
.161 \\
.000 E+00\end{array}$ & $\begin{array}{l}2.838 \mathrm{E}+04 \\
2.372 \mathrm{E}-04 \\
6.481 \mathrm{E}+03 \\
.209 \\
.101 \\
2.928 \mathrm{E}-02 \\
6.732 \mathrm{E}-03 \\
7.356 \mathrm{E}-06 \\
.257 \\
.000 \mathrm{E}+00\end{array}$ & $\begin{array}{l}.000 \mathrm{E}+00 \\
8.91 \\
.000 \mathrm{E}+00 \\
.000 \mathrm{E}+00 \\
58.2 \\
.000 \mathrm{E}+00 \\
1.70 \\
.000 \mathrm{E}+00 \\
.000 \mathrm{E}+00 \\
.000 \mathrm{E}+00\end{array}$ & $\begin{array}{l}.000 E+00 \\
8.91 \\
.000 E+00 \\
.000 E+00 \\
58.2 \\
.000 E+00 \\
1.70 \\
.000 E+00 \\
.000 E+00 \\
.000 E+00\end{array}$ & $\begin{array}{l}4.82 \\
6.689 \mathrm{E}-03 \\
.000 \mathrm{E}+00 \\
.000 \mathrm{E}+00 \\
.250 \\
.333 \\
3.98 \\
28.1 \\
.000 \mathrm{E}+00 \\
.000 \mathrm{E}+00\end{array}$ & $\begin{array}{l}4.82 \\
6.689 \mathrm{E}-03 \\
.000 \mathrm{E}+00 \\
.000 \mathrm{E}+00 \\
.250 \\
.333 \\
3.99 \\
3.57 \\
.000 \mathrm{E}+00 \\
.000 \mathrm{E}+00\end{array}$ & $\begin{array}{l}\text { mpr } \\
\text { mpr } \\
\text { mpr } \\
\text { mpr } \\
\text { mpr } \\
\text { mpr } \\
\text { mpr } \\
\text { mpr } \\
\text { mpr } \\
\text { mpr }\end{array}$ \\
\hline
\end{tabular}

RELAP5/3.1 Reactor Loss of Coolant Analysis Program

RELAP5 Direct Steady-State Initialization - Ver. 1.0 - 30/06/95 - Copyright 1995 by Computer Simulation \& Analysis, Inc.

PWR DSSI Test Case (based on workshop sample problem no. 2)

30/06/95 02:28:32

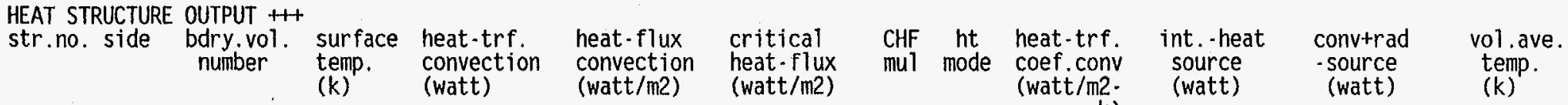
(k) (watt) (watt/m2) (watt/m2)

1100.001 left $0.0000001204 .643 \quad 00000 \mathrm{E}+00 \quad 00000 \mathrm{E}+00$

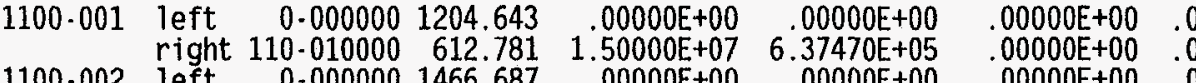
1100.002 left $0.0000001466 .687 \quad .00000 E+00 \quad .00000 E+00 \quad .00000 E+00 \quad .00$

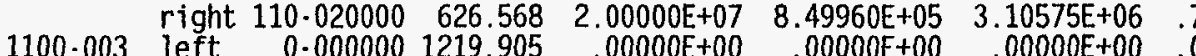
right $\begin{array}{rrrrr}0.000000 & 1219.905 & .00000 E+00 & .00000 E+00 & .00000 E+00\end{array}$ 1500.001 left $150.010000 \quad 565.825 .1 .97305 \mathrm{E}+07.6 .15124 \mathrm{E}+05 \quad .00000 \mathrm{E}+00$ right $210.030000 \quad 526.258 \quad 1.97305 \mathrm{E}+07 \quad 4.94599 \mathrm{E}+05 \quad 5.40359 \mathrm{E}+06$ 1500.002 left $150.020000 \quad 556.499 \cdot 1.63715 \mathrm{E}+07-5.10403 \mathrm{E}+05 \quad .00000 \mathrm{E}+00$ $\begin{array}{llllll} & \text { right } 210-020000 & 523.433 & 1.63715 \mathrm{E}+07 & 4.10397 \mathrm{E}+05 & 5.57481 \mathrm{E}+06 \\ 1500.003 & \text { left } 150 \cdot 030000 & 547.729 & -1.41631 \mathrm{E}+07 & -4.41553 \mathrm{E}+05 & .00000 \mathrm{E}+00\end{array}$ right $210.010000 \quad 518.897 \quad 1.41631 \mathrm{E}+07 \quad 3.55037 \mathrm{E}+05 \quad 5.54507 \mathrm{E}+06$

$\begin{array}{llllll}.00 & 0 & 00000 \mathrm{E}+00 & 1.50000 \mathrm{E}+07 & 3.16650 \mathrm{E}-08 & 947.57 \\ .00 & 2 & 13613 . & & \\ .00 & 0 & .00000 \mathrm{E}+00 & 2.00000 \mathrm{E}+07 & 2.23517 \mathrm{E}-081080.89 \\ .79 & 3 & 31794 . & & & \\ .00 & 0 & .00000 \mathrm{E}+00 & 1.50000 \mathrm{E}+07 & -2.23517 \mathrm{E}-08 & 959.91 \\ .79 & 3 & 28717 . & & & \\ .00 & 2 & 59540 . & .00000 \mathrm{E}+00 & 7.59959 \mathrm{E}-07 & 544.76 \\ .84 & 4 & 17868 . & & & \\ .00 & 2 & 58580 . & .00000 \mathrm{E}+00 & -3.83705 \mathrm{E}-07 & 538.88 \\ .84 & 3 & 16610 . & & & \\ .00 & 2 & 57942 . & .00000 \mathrm{E}+00 & 5.38304 \mathrm{E}-07 & 532.35 \\ .82 & 3 & 17722 . & & & \end{array}$

\begin{tabular}{|c|c|c|c|c|c|c|c|c|c|c|}
\hline $\begin{array}{l}\text { str. no. } \\
1100 \cdot 001\end{array}$ & $\begin{array}{r}\text { mesh } \\
1204.6\end{array}$ & $\begin{array}{l}\text { int tempe } \\
1181.9\end{array}$ & $\begin{array}{l}\text { res } \\
1115.1\end{array}$ & 1010.1 & 878.80 & 731.17 & 643.13 & 632.68 & 622.57 & 612.78 \\
\hline $100-002$ & 1466.7 & 1432.0 & 1330.8 & 1173.5 & 975.04 & 763.62 & 666.49 & 652.77 & 639.47 & 626.57 \\
\hline $100 \cdot 003$ & 1219.9 & 1196.9 & 1129.6 & 1023.0 & 890.33 & 740.96 & 654.61 & 644.24 & 634.22 & 624.51 \\
\hline
\end{tabular}


Table 9.21 (Cont'd)

\begin{tabular}{|c|c|c|c|c|c|c|c|c|}
\hline $\begin{array}{l}1500-001 \\
1500-002 \\
1500-003\end{array}$ & $\begin{array}{l}565.82 \\
556.50 \\
547.73\end{array}$ & $\begin{array}{l}559.74 \\
551.39 \\
543.27\end{array}$ & $\begin{array}{l}553.81 \\
546.43 \\
538.94\end{array}$ & $\begin{array}{l}548.03 \\
541.60 \\
534.72\end{array}$ & $\begin{array}{l}542.39 \\
536.89 \\
530.61\end{array}$ & $\begin{array}{l}536.89 \\
532.29 \\
526.61\end{array}$ & $\begin{array}{l}531.51 \\
527.81 \\
522.71\end{array}$ & $\begin{array}{l}526.26 \\
523.43 \\
518.90\end{array}$ \\
\hline $\begin{array}{l}\text { Str.no. } \\
1100-001 \\
1100.002 \\
1100-003\end{array}$ & 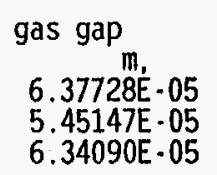 & $\begin{array}{l}\text { clad } \\
5.35 \\
5.35 \\
5.35\end{array}$ & 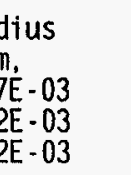 & $\begin{array}{l}\text { ruptured } \\
\text { no } \\
\text { no } \\
\text { no }\end{array}$ & $\begin{array}{c}\text { pressi } \\
(\mathrm{pa}) \\
2.461\end{array}$ & & & \\
\hline
\end{tabular}


Table 9.22 Comparison of the "stdy-st" and DSSI methods

\begin{tabular}{lcc}
\hline \multicolumn{1}{c}{ Parameter } & "stdy-st" & DSSI \\
\hline Core Power (mW) & 49.991 & 50.0 \\
Pump and Viscous Dissipation (kw) & 265.0 & 265.0 \\
Steam Generator Downcomer Level $(\mathrm{m})$ & 6.465 & 6.5 \\
Feedwater Flow (kg/s) & 26.233 & 26.5 \\
Steamline Flow (kg/s) & 26.334 & 26.5 \\
Steam Generator Primary Heat Removal Rate (Mw) & 50.291 & 50.265 \\
Steam Generator Secondary Heat Removal Rate & 50.214 & 50.265 \\
Steam Generator Bundle flows (kg/s) & & \\
Jun 251-01 & 149.74 & 150.0 \\
Jun 210-01 & 147.75 & 150.0 \\
Jun 210-02 & 149.08 & 150.0 \\
Jun 260-03 & 158.90 & 150.0 \\
\hline
\end{tabular}




\section{REFERENCES}

1. K. E. Carlson, et al., "RELAP5/MOD3 Code Manual - Volume 1: Code Structure, System Models, and Solution Methods (Draft)", NUREG/CR-5535, June 1990.

2. M. P. Paulsen, et al., "Feasibility Study for Improved Steady-State Initialization Algorithms for the RELAP5 Computer Code", NUREG/CR-6035, April 1993.

3. J. H. McFadden, et al., "RETRAN-O2 - A Program for Transient Thermal-Hydraulic Analysis of Complex Fluid Flow Systems: Volume 1 - Equations and Numerics", Electric Power Research Institute, EPRI CCM-1850, April 1981, revised June 1987.

4. J. H. McFadden, et al., "RETRAN-03 - A Program for Transient Thermal-Hydraulic Analysis of Complex Fluid Flow Systems: Volume 1 - Computer Code Manual", Electric Power Research Institute, EPRI CCM-7450, May 1992.

5. C. E. Peterson and M. P. Paulsen, "A RETRAN-03 Steady-State Initialization Method for Systems at Low Power", Proceedings of the Fifth International Topical Meeting on Reactor Thermal Hydraulics (NURETH-5), Salt Lake City, September 1992.

6. A. R. Curtis and J. K. Reid, "FORTRAN Subroutines for the Solution of Sparse Sets of Linear Equations", United Kingdom Atomic Energy Authority Research Group, AERE-R-6844, 1971.

7. O. Nylund, et al., "Hydrodynamic and Heat Transfer Measurements on a Full-Scale Simulated 36-Rod Marviken Fuel Element with Non-Uniform Radial Heat Flux Distribution", AB Atomenergi/ASEA-ATOM, FRIGG-3, 1969.

8. K. E. Carlson, et al., "RELAP5/MOD3 Code Manual - Volume III: Developmental Assessment Problems (Draft)", NUREG/CR-5535, June 1990. 


\section{APPENDIX A DIRECT STEADY-STATE INITIALIZATION INPUT REQUIREMENTS}

A new option is available on the Problem Type and Option Data Card 100. It is used to specify the DSSI solution option. The initial condition cards are used to specify initial conditions for volume state and junction flow conditions. These cards should be supplied only when the DSSI solution option is used.

The starting values for the volume thermodynamic state in volumes where initial conditions are not specified via the 150-169 cards, are obtained from the component data. All thermodynamic conditions must be supplied as required on the component cards, but they are overridden by the DSSI initial conditions and solution. By requiring the state specification on the component cards, starting (or zeroth iterate) estimates of the volume states are available. Additionally, no changes are required for existing input decks, except for the new steady-state cards described below.

\section{A.1 Card 100, Problem Type and Option}

This card is always required.

W1(A) Problem type. Enter one of the following: "new", "restart", "plot", "reedit", "strip", or "cmpcoms".

W2(A) Problem option. This word is needed if W1 is "new" or "restart" and is optional if W1 is STRIP.

If "new" is entered, enter either "stdy-st", "transnt", or "sstate" to specify the type of problem.

The "sstate" flag is used to request the DSSI option which may require use of Cards 148 and 150199. When the steady-state option is used, the "transnt" option is automatically executed after the "sstate" option is complete. Problems are terminated after the steady-state initialization process by supplying a time $=0.0$ end of problem trip signal.

\section{A.2 Card 148, Steady-State Convergence Criteria Data}

This card is optional. If this card is not supplied, default values are employed if the DSSI option is active. Any zero value supplied by a user is considered to be a flag specifying the default value is to be used. This card should not be supplied when DSSI solution method is not being used.

W1(R)

MAXIMUM ITERATIONS, MAXITR. The maximum number of steady-state iterations (default $=35$ ). 
MAXIMUM MASS CHANGE, EPSM. The maximum mass imbalance allowed (default $=5 . e-7)$. The sum continuity equations are converged if

$$
\left|\frac{\sum_{j \in i 0} w_{j}}{W_{L}}\right| \leq E P S M
$$

MAXIMUM PRESSURE CHANGE, EPSP. The maximum pressure change allowed (default $=5 . e-8)$. The sum momentum equations are converged if

$$
\left|\frac{P^{k+1}-P^{k}}{P^{k+1}}\right| \leq E P S P
$$

When loss coefficients are computed rather than pressures, changes in the loss coefficient from one iteration to the next are converted to effective pressure changes and the above convergence criteria is used.

W4(R)

MAXIMUM VELOCITY CHANGE, EPSV. The maximum velocity change (default $=5 . e-5)$. The difference momentum equations are converged if

$$
\left|\frac{v^{k+1}-v^{k}}{v^{k+1}}\right| \leq \text { EPSV }
$$

W5(R)

MAXIMUM VOID FRACTION CHANGE, EPSA. The maximum void fraction change (default $=5 . e-5$ ). The vapor continuity equations are converged if

$$
\left|\alpha_{g}^{k+1}-\alpha_{g}^{k}\right| \leq E P S A
$$

W6(R)

MAXIMUM INTERNAL ENERGY CHANGE, EPSU. The maximum phasic internal energy change (default $=5 . e-7$ ). The phasic liquid and vapor energy equations are respectively converged if

$$
\left|\frac{u_{g}^{k+1}-u_{g}^{k}}{u_{g}^{k+1}}\right| \leq \text { EPSU }
$$

and

$$
\left|\frac{u_{f}^{k+1}-u_{f}^{k}}{u_{f}^{k+1}}\right| \leq \text { EPSU }
$$




\section{A.3 Card 150 Through 169, Volume Initial Conditions}

These cards are required to specify control volume initial conditions. A minimum of two words is required and no more than nine words can be supplied. All words must be entered on a single card. Continuation cards can be used. Words entered as zero are ignored as initial conditions when the zero is part of a legitimate input combination. Words omitted from the end of the card default to zero. The cards need not start at 150 and need not be consecutive.

W1(1)

W2(R)

W3(R)

W4(R)

W5(R)

W6(R)

W7(R)

W8(R)

W9(R)
VOLUME NUMBER

PRESSURE $\left(\mathrm{Pa}, \mathrm{Ib}_{\mathrm{f}} / \mathrm{in}^{2}\right)$. This is the absolute pressure, not gauge pressure.

TEMPERATURE $\left(K,{ }^{\circ} \mathrm{F}\right)$

QUALITY

NONCONDENSABLE QUALITY (Currently not used.)

LIQUID SPECIFIC INTERNAL ENERGY (J/kg, Btu/lb)

VAPOR SPECIFIC INTERNAL ENERGY (J/kg, Btu/lb)

Several combinations of the above parameters can be used to specify the state of the system. The allowable combinations are the same as those presently used in volume components, plus two additional combinations. These new combinations, are the pressure only and/or the phasic-specific internal energies and vapor void fraction $\left(u_{f}, u_{g}, \alpha\right)$.

The five allowed input combinations follow. Words not listed are entered as zero.

\section{Pressure only}

$P>0$

Thermal nonequilibrium

$P \geq 0$

$\left.\begin{array}{l}u_{f}>0 \\ u_{g}>0\end{array}\right\}$ if $0<\alpha_{g}<1$ 


$$
\begin{aligned}
& \left.\begin{array}{l}
u_{f}>0 \\
u_{g}=0
\end{array}\right\} \quad \text { if } \alpha_{g}=0 \\
& \left.\begin{array}{l}
u_{f}=0 \\
u_{g}=0
\end{array}\right\} \quad \text { if } \alpha_{g}=1
\end{aligned}
$$

Two-Phase Thermal Equilibrium: T-x

$\mathrm{T}>0$

$0 \leq x \geq 1$

Two-Phase Thermal Equilibrium: P-x

$P>0$

$0 \leq x \geq 1$

Single Phase

$P>0$

$\mathrm{T}>0$

where

$\mathrm{P} \quad=\quad$ absolute pressure

$\mathrm{T}=$ temperature,

$x=$ quality or mass fraction,

$u_{1}=$ liquid-specific internal energy,

$\mathrm{u}_{\mathrm{g}}=$ vapor-specific internal energy, and

$\alpha_{g} \quad=\quad$ vapor void fraction.

\section{A.4 Card 170 Through 189, Junction Initial Condition}

These cards are used to specify junction mass flow rate initial conditions and the location where form loss coefficients are to be calculated. A minimum of two words must be entered on the card and a maximum of three words is allowed. The card numbers need not be consecutive.

W1(I)

JUNCTION NUMBER. 
$\neq 0$, initial mass flow rate

$=0$, ignore mass flow rate specification

W3(A)

CALCULATE LOSS COEFFICIENT . Used to specify that the junction loss coefficient is to be calculated by the steady-state initialization option.

= calck - calculate the loss coefficient

$\neq$ calck - do not calculate the loss coefficient

\section{A.5 Card 190 Through 199, Steam Generator and Feedwater System Description}

These cards are used to describe steam generators for PWR system models and feedwater systems for BWRs. A minimum of five words is required and a maximum of 205 can be supplied (continuation cards can be used). The card numbers need not be consecutive.

\section{A.5.1 Steam Generator Option}

W1.(I) STEAM-GENERATOR NUMBER. This is a unique number used to identify a steam generator. Steam generator numbers start with 1 and must be consecutive.

W2(I) BIAS JUNCTION. The junction number for which the feedwater enthalpy may be biased to obtain an overall energy balance. This junction must be a positive time dependent junction.

W3(I) POWER REMOVAL JUNCTION. Outlet junction number for the power removal system (typically in the steam line).

W4(I)

SECONDARY-SIDE REFERENCE TEMPERATURE. Options are:

$=0$, eliminate overall energy balance equation,

$>0$, use the saturation pressure method

$<0$, use the inlet enthalpy method

W5(R) POWER FRACTION. Fraction of the net system thermal power removed by this steam generator. The sum of all power fractions on Cards 190-199 must be equal to 1.0 .

W6(1)

CONDUCTOR NUMBER. The first conductor number associated with this steam generator. 
W7(1) CONDUCTOR NUMBER. Repeat until all conductors associated with this steam generator are listed. The maximum number of conductors per steam generator is 200.

\section{A.5.2 Feedwater Option}

W1(1) FEEDWATER SYSTEM. This is a unique number used to identify a feedwater system.

W2(I) BIAS JUNCTION. The junction number for which the feedwater enthalpy may be biased to obtain an overall energy balance. This junction must be a positive timedependent junction.

W3(1)

POWER REMOVAL JUNCTION. Outlet junction number for the power removal system (typically in the steam line).

W4(I) Not used

$=0$

W5(R)

POWER FRACTION. Fraction of the net system thermal power removed by this steam generator. The sum of all power fractions on Cards $190-199$ must be equal to 1.0 . 


\begin{tabular}{|c|c|}
\hline $\begin{array}{l}\text { NRC FORM } 335 \\
\text { (2-89) } \\
\text { NRCM } 1102, \\
3201,3202, \\
\text { BIBLIOG. NUCLEAR REGULATORY COMMISSION } \\
\text { (See instructions on the reverse) }\end{array}$ & NUREG/CR-6325 \\
\hline \multicolumn{2}{|l|}{ 2. TITLE AND SUBTITLE } \\
\hline \multirow{3}{*}{$\begin{array}{l}\text { An Implicit Steady-State Initialization Package } \\
\text { for the RELAP5 Computer code }\end{array}$} & DATE REPORT PUBLISHED \\
\hline & \begin{tabular}{c|r|} 
MONTH & YEAR \\
August & 1995 \\
\end{tabular} \\
\hline & $\begin{array}{l}\text { 4. FIN OR GRANT NUMBER } \\
\text { W6128 }\end{array}$ \\
\hline 5. AUTHOR $(S)$ & $\begin{array}{l}\text { 6. TYPE OF REPORT } \\
\text { TEChnical }\end{array}$ \\
\hline M. P. Paulsen, C. E. Peterson & 7. PERIOD COVERED /InC/Usive Dares! \\
\hline \multicolumn{2}{|c|}{$\begin{array}{l}\text { 8. PERFORMING ORGANIZATION - NAME AND ADDRESS i/t NRC, provide Division, Office or Region, U.S. Nuclear Regulatory Commission, and mailing address; if cantractor, provid } \\
\text { name and mailing address) }\end{array}$} \\
\hline \multicolumn{2}{|l|}{$\begin{array}{l}\text { Computer Simulation \& Analysis, Inc. } \\
\text { P. O. Box } 51596 \\
\text { Idaho Falls, ID } 83405\end{array}$} \\
\hline \multicolumn{2}{|c|}{$\begin{array}{l}\text { 9. SPONSORING ORGANIZATION - NAME AND ADDRESS (If NRC, type "Same as above"; if contractor, provide NRC Division, Office or Region, U.S. Nuclear Regulatory COmmission, } \\
\text { and mailing address.) }\end{array}$} \\
\hline \multicolumn{2}{|c|}{$\begin{array}{l}\text { Division of Systems Research } \\
\text { Office of Nuclear Regulatory Research } \\
\text { U. S. Nuclear Regulatory Commission } \\
\text { Washington, DC } 20555-0001\end{array}$} \\
\hline \multicolumn{2}{|l|}{ 10. SUPPLEMENTARY NOTES } \\
\hline \multicolumn{2}{|c|}{$\begin{array}{l}\text { 11. ABSTRACT } 200 \text { wordorless } \\
\text { A direct steady-state initialization (DSSI) method has been developed and } \\
\text { implemented in the RELAP5 hydrodynamic analysis program. It provides a means for } \\
\text { users to specify a small set of initial conditions which are then propagated } \\
\text { through the remainder of the system. The DSSI scheme utilizes the steady-state } \\
\text { form of the REIAP5 balance equations for nonequilibrium two-phase flow. It also } \\
\text { employs the RELAP5 component models and constitutive model packages for wall-to- } \\
\text { phase and interphase momentum and heat exchange. A fully implicit solution of the } \\
\text { linearized hydrodynamic equations is implemented. An implicit coupling scheme is } \\
\text { used to augment the standard steady-state heat conduction solution for steam } \\
\text { generator use. It solves the primary-side tube region energy equations, heat } \\
\text { conduction equations, wall heat flux boundary conditions, and overall energy } \\
\text { balance equations as a coupled system of equations and improves convergence. The } \\
\text { DsSI methods for initializing RELAP5 problems to steady-state conditions has been } \\
\text { compared with the transient solution scheme using a suite of test problems including; } \\
\text { adiabatic single-phase liquid and vapor flow through channels with and without } \\
\text { heating and area changes; a heated two-phase test bundle representative of BwR core } \\
\text { conditionsi anda single-locp pwR model. }\end{array}$} \\
\hline \multirow[t]{6}{*}{ 12. KEYWORDSiDESCR!PTOAS (List words or ohrases that will assist researchers in locating the report.) } & $\begin{array}{c}\text { 13. AVAILABILITY STATEMENT } \\
\text { Unlimited }\end{array}$ \\
\hline & 14. SECURITY CLASSIFICATION \\
\hline & Unclassified \\
\hline & $\begin{array}{l}\text { This Report } \\
\text { Unclassified }\end{array}$ \\
\hline & 15. NUMBER OF PAGES \\
\hline & \\
\hline
\end{tabular}




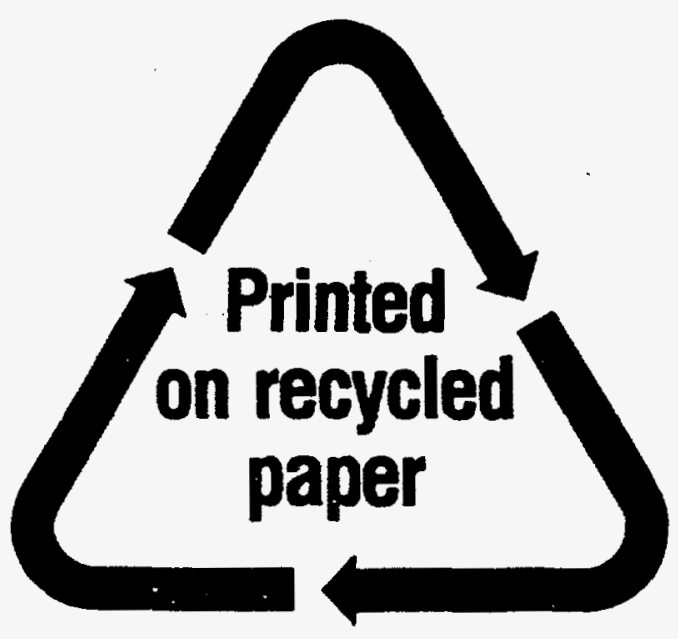

Federal Recycling Program 